\title{
Meltwater temperature in streams draining from Alpine glaciers
}

by

\author{
Robert James Williamson
}

A thesis submitted for the degree of

Doctor of Philosophy

School of Environment and Life Sciences

University of Salford

UK

September 2016 


\begin{abstract}
Thermal conditions in river water are of importance as they influence water quality, chemical processes, ecology, and biological conditions in rivers. In meltwater streams draining from Alpine glaciers, temperatures measured close to glacier termini show strong diurnal variation and paradoxical seasonal variation, being cool when energy availability is greatest. This thesis aims to describe temporal variations of water temperatures in five glacier-fed streams, which drain catchments of varying percentage glacierisation, in the Swiss Alps. Contrasting patterns of ablation season meltwater temperatures, and influences of basin characteristics and river channel morphology on water temperature are assessed. Relationships between solar radiation, air temperature, and water temperature were also investigated. A model was developed in order to estimate the impact of glacier recession on meltwater temperature. Observed temperatures in the Findelenbach during one ablation season were used to calibrate the model, which was subsequently validated on other years. Paucity of data in mountainous regions necessitated a model that required few measured variables to be developed. Distinctive seasonal water temperature regime was identified for larger rivers which drain relatively steep catchments, with substantial basin ice coverage. Such a regime is not replicated in streams draining smaller glaciers with lower gradients. Patterns in diurnal ranges of temperature in rivers draining large glaciers have been identified, temperature ranges reducing during days with high radiation and rising riverflows. Stream surface area was found to be the main catchment characteristic influencing temperature in glacier-fed rivers. Measured stream albedo values suggest that surface reflectivity is unlikely to be a major control on water temperature. Stream temperatures simulated by the model demonstrate high fidelity to those measured in the field. The temperature of glacier-fed streams will increase as climate warms as the distance over which heating can occur will lengthen as glaciers retreat, despite volume of flow being augmented by the deglaciation discharge dividend.
\end{abstract}




\section{Contents}

$\begin{array}{ll}\text { Abstract } & \text { i }\end{array}$

Contents

List of figures $\quad$ vii

List of tables $\quad$ xix

Acronyms $\quad$ xxii

Nomenclature $\quad$ xxiv

Dedication $\quad$ xxvi

Acknowledgements $\quad$ xxvii

Declaration $\quad$ xxix

I Introduction \& background 1

1 Introduction $\quad 2$

1.1 Context ....................... 2

1.2 Research motivations . . . . . . . . . . . . . . 8

1.2.1 Stream temperature and lotic habitats . . . . . . . . 10

1.3 Aims and objectives . . . . . . . . . . . . . . 12

1.4 Study area . . . . . . . . . . . . . . . . . . . . 13 
1.4.1 Allenbach .................... . 14

1.4 .2 Lonza . . . . . . . . . . . . . . . . . . . . 16

1.4 .3 Massa . . . . . . . . . . . . . . . . 16

1.4 .4 Findelen . . . . . . . . . . . . . . . . . . 17

1.4.5 Gorner . . . . . . . . . . . . . . . 17

1.5 Thesis outline . . . . . . . . . . . . . . . . . 18

2 Background $\quad 20$

2.1 Glaciers \& climate change . . . . . . . . . . . . . . 20

2.2 Glacier hydrology in the Swiss Alps . . . . . . . . . . . . 22

2.2.1 The deglaciation discharge dividend \& its effects on stream temperature regime . . . . . . . . . . . . 24

2.3 Thermal characteristics of streams . . . . . . . . . . . . . 26

2.3.1 Atmospheric . . . . . . . . . . . 27

2.3.2 Topographic . . . . . . . . . . . . . . 30

2.3.3 Hydrological . . . . . . . . . . . . . . . . . . 31

2.4 Stream temperature modelling . . . . . . . . . . . . . 32

2.4.1 Previous water temperature modelling studies . . . . . 38

2.5 Overview and research gaps . . . . . . . . . . . . . . . . 40

II Water temperature variations 46

3 Meltwater temperature in rivers draining $\begin{array}{ll}\text { from Alpine glaciers } & 47\end{array}$

3.1 Introduction . . . . . . . . . . . . . . . . 47

3.2 Data acquisition . . . . . . . . . . . . . . . 49

3.3 Results . . . . . . . . . . . . . . . . . . . 51

3.3.1 Seasonal variations of stream temperature and hydrometeorological factors . . . . . . . . . . . . . 51

3.3.2 Classification of seasonal water temperature time series 76

3.3.3 Diurnal measurements . . . . . . . . . . . . . 87

3.3.4 Year to year variations of stream temperature . . . . 110

3.4 Discussion . . . . . . . . . . . . . . . . . . . . . . 113 
3.4.1 Variations of water temperature and hydro meteorological variables . . . . . . . . . . . . . . . . . . . 114

3.4.2 Relationships between air temperature, global radiation, discharge and water temperature . . . . . . . 117

3.4.3 Basin characteristics impacts on patterns of stream temperature . . . . . . . . . . . . . . . . . 128

3.5 Conclusion . . . . . . . . . . . . . . . . . 130

4 Stream surface albedo in highly glacierised

$\begin{array}{ll}\text { Alpine catchments } & 134\end{array}$

4.1 Introduction . . . . . . . . . . . . . . . . . . . . . 134

4.2 Method ....................... 135

4.3 Results . . . . . . . . . . . . . . . . . . . . 139

4.3 .1 Findelenbach . . . . . . . . . . . . . . 139

4.3 .2 Gornera . . . . . . . . . . . . . . . . 143

4.4 Discussion . . . . . . . . . . . . . . . . . . . . . . . . 145

4.4.1 Comparison with albedo values used in previous studies . . . . . . . . . . . . . . . . 146

4.5 Conclusion . . . . . . . . . . . . . . . . . . 147

\section{Modelling meltwater temperature $\quad 150$}

5 Stream water temperature model $\quad 151$

5.1 Introduction . . . . . . . . . . . . . . . . . . . . . . 151

5.2 Method ..................... 153

5.2 .1 Scope of model . . . . . . . . . . . . . . 153

5.2 .2 Study Area . . . . . . . . . . . . . . . . . 153

5.2 .3 Model design . . . . . . . . . . . . . . . . . 154

5.3 Alpine Stream Water Temperature Model . . . . . . . . . . 157

5.3.1 River heat budget components and assumptions . . . . 158

5.3 .2 Model concept . . . . . . . . . . . . . . . . 158

5.3 .3 Model programming . . . . . . . . . . . . 160

5.3.4 Water temperature model ............ 161 
5.3.5 River dynamics models . . . . . . . . . . . . . . . 162

5.4 Model application and performance . . . . . . . . . . . . . 164

5.4.1 Model calibration . . . . . . . . . . . . . . . . . . 164

5.4 .2 Model validation . . . . . . . . . . . . . . 172

5.5 Model Application . . . . . . . . . . . . . . . . 177

5.5.1 Model application on other glacier-fed rivers . . . . . . 181

5.6 Conclusion . . . . . . . . . . . . . . . . . . . . . . . . . . 184

6 Modelling water temperature in a changing climate 187

6.1 Introduction . . . . . . . . . . . . . . . . . 187

6.2 Method . . . . . . . . . . . . . . . . 190

6.2.1 Study Area . . . . . . . . . . . . . . . . . . . 191

6.2.2 Data Collection . . . . . . . . . . . . . 193

6.2.3 Stream temperature model . . . . . . . . . . . . . 195

6.3 Results . . . . . . . . . . . . . . . . . . . . 195

6.3.1 Reference Period A (14 - 17 July 2006) . . . . . . . 196

6.3.2 Reference Period B (28 September - 1 October 2009) . 202

6.4 Discussion . . . . . . . . . . . . . . . . . 207

6.4.1 Future water temperature of a glacier-fed river . . . . 207

6.4.2 Channel shape influences . . . . . . . . . . . . . . 208

6.4.3 Credibility of results . . . . . . . . . . . . . . 211

6.5 Conclusion . . . . . . . . . . . . . . . . . . 212

IV Summary 214

7 Conclusion $\quad 215$

7.1 Introduction . . . . . . . . . . . . . . . . . 215

7.2 Summary of main findings . . . . . . . . . . . . . . 216

7.2.1 Meeting the aims and objectives . . . . . . . . . 217

7.3 Drawbacks and possible improvements . . . . . . . . . . . . 219

7.3.1 Understanding of water temperature patterns in the European Alps . . . . . . . . . . . . . . . . . . . . 219

7.3.2 Data availability and model inputs . . . . . . . . 220 
7.3.3 Application of the meltwater temperature model . . . . 221

7.4 Future research directions . . . . . . . . . . . . . . . . . 221

7.5 Impact of study . . . . . . . . . . . . . . . . . . . . 223

7.6 Summary . . . . . . . . . . . . . . . . . . . . . . 224

$\begin{array}{ll}\text { References } & 226\end{array}$

Appendix A Alpine Stream Temperature Model 237

Appendix B Conference presentations associated with this study 


\section{List of figures}

1.1 Schematic diagram of the paradoxical effect experienced by water temperature in a glacierised Alpine catchment. . . . . . . 5

1.2 Plot of paradoxical effect experienced by water temperature in a glacier-fed stream. . . . . . . . . . . . . . . . 6

1.3 Representative diagram illustrating how warm and cool summers effect distance downstream of the cold water "tongue".

1.4 Map of the study basins in the larger upper Rhône and contiguous upper Aare catchments, Switzerland. . . . . . . . 15

1.5 A thesis outline highlighting which Chapters address the aims and objectives of this study. Chapters are split into four Parts, the first Part includes an Introduction to the following two Parts, Part 2 assesses the water temperature variations and Part 3 addresses the modelling aims of this study. Part 4 provides an overall conclusion. . . . . . . . . . . . . .

2.1 Schematic plot demonstrating how vertical movements in the transient snowline impacts upon areas of the basin which are snow covered and snow free, and thus albedo, with respect to basin hypsometry (bold black line). . . . . . . . . . . 25

2.2 Diagram of factors impacting stream temperatures. . . . . . . 27

3.1 Year-to-year variation of mean summer $2 \mathrm{~m}$ (a.g.l) air temperature $\left(T_{5-9}\right)$ at Sion, Switzerland for the period 1864-2015. . . 
3.2 Year-to-year variation of mean summer $2 \mathrm{~m}$ (a.g.l) air temperature $\left(T_{5-9}\right)$ at Sion, Switzerland for the period 2003-2015. . .

3.3 Seasonal variations of 7 -day average water temperature (blue) and total discharge (green) of the Massa, together with 7-day total radiation (red) at Zermatt. For the years: (a) 2003 - (l) 2014, dotted line indicates week of summer solstice. (Continued ... . . . . . . . . . . . . . . .

3.3 Seasonal variations of 7 -day average water temperature (blue) and total discharge (green) of the Massa, together with 7-day total radiation (red) at Zermatt. For the years: (a) 2003 - (l) 2014, dotted line indicates week of summer solstice. (Continued ... . . . . . . . . . . . . . . . . 56

3.3 Seasonal variations of 7-day average water temperature (blue) and total discharge (green) of the Massa, together with 7-day total radiation (red) at Zermatt. For the years: (a) $2003-$ (l) 2014, dotted line indicates week of summer solstice. (Concluded.) . . . . . . . . . . . . . . .

3.4 Seasonal variations of 7-day average water temperature (blue) and total discharge (green) of the Lonza, together with 7-day total radiation (red) at Zermatt. For the years: (a) 2003 - (1) 2014, dotted line indicates week of summer solstice. (Continued ...) . . . . . . . . . . . . . .

3.4 Seasonal variations of 7-day average water temperature (blue) and total discharge (green) of the Lonza, together with 7-day total radiation (red) at Zermatt. For the years: (a) 2003 - (1) 2014, dotted line indicates week of summer solstice. (Continued ...) . . . . . . . . . . . . . . . . .

3.4 Seasonal variations of 7-day average water temperature (blue) and total discharge (green) of the Lonza, together with 7-day total radiation (red) at Zermatt. For the years: (a) 2003 (l) 2014, dotted line indicates week of summer solstice. (Concluded.) 
3.5 Seasonal variations of 7-day average water temperature (blue) and total discharge (green) of the Allenbach, together with 7day total radiation (red) at Zermatt. For the years: (a) $2003-$ (l) 2014, dotted line indicates week of summer solstice. (Continued ...) . . . . . . . . . . . . . . . . 65

3.5 Seasonal variations of 7-day average water temperature (blue) and total discharge (green) of the Allenbach, together with 7day total radiation (red) at Zermatt. For the years: (a) $2003-$ (l) 2014, dotted line indicates week of summer solstice. (Con-

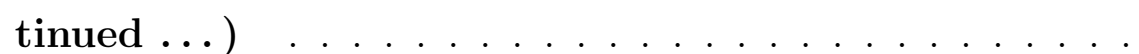

3.5 Seasonal variations of 7-day average water temperature (blue) and total discharge (green) of the Allenbach, together with 7day total radiation (red) at Zermatt. For the years: (a) $2003-$ (l) 2014, dotted line indicates week of summer solstice. (Concluded.)

3.6 Seasonal variations of daily average water temperature (blue) and total discharge (green), upper graphs, of the: (a) Findelen 2006, (b) Gornera 2006, (c) Findelen 2008, (d) Gornera 2008, (e) Findelen 2009, (f) Gornera 2009. lower plots are magnified to illustrate extent of the temperature data. (Continued ...)

3.6 Seasonal variations of daily average water temperature (blue) and total discharge (green), upper graphs, of the: (a) Findelen 2006, (b) Gornera 2006, (c) Findelen 2008, (d) Gornera 2008, (e) Findelen 2009, (f) Gornera 2009. lower plots are magnified to illustrate extent of the temperature data. (Concluded.) .

3.7 Seasonal variations of 1 week (7-day) total precipitation, measured at Zermatt, (a) 2003 - (l) 2014. (Continued ... ) . . . 74

3.7 Seasonal variations of 1 week (7-day) total precipitation, measured at Zermatt, (a) 2003 - (l) 2014. (Concluded.) . . . . . 75 
3.8 Box plots of average daily water temperature of the Allenbach (2003, 2009 and 2014) showing the median (horizontal line through box), mean $(+)$ and the first and third quartiles (box boundaries). Whiskers show $\pm 1.5 \times$ inter-quartile range and points signify outliers. . . . . . . . . . . . . 77

3.9 Box plots of average daily water temperature of the Lonza (2003, 2009 and 2014) showing the median (horizontal line through box), mean $(+)$ and the first and third quartiles (box boundaries). Whiskers show $\pm 1.5 \times$ inter-quartile range and points signify outliers. . . . . . . . . . . . . 78

3.10 Box plots of average daily water temperature of the Massa (2003, 2009 and 2014) showing the median (horizontal line through box), mean $(+)$ and the first and third quartiles (box boundaries). Whiskers show $\pm 1.5 \times$ inter-quartile range and points signify outliers.

3.11 Diurnal variations of Radiation (red), water temperature (blue) and discharge (green) of the Massa for the days: (a) 14-16 April, (b) 17-19 May, (c) 17-19 June, (d) 14-16 July, (e) 1316 Aug, (d) 17-19 September, 2004. Vertical lines indicate 06:00, 12:00 and 18:00 hours of each day. (Continued...) .

3.11 Diurnal variations of Radiation (red), water temperature (blue) and discharge (green) of the Massa for the days: (a) 14-16 April, (b) 17-19 May, (c) 17-19 June, (d) 14-16 July, (e) 1316 Aug, (d) 17-19 September, 2004. Vertical lines indicate 06:00, 12:00 and 18:00 hours of each day. (Continued...) .

3.11 Diurnal variations of Radiation (red), water temperature (blue) and discharge (green) of the Massa for the days: (a) 14-16 April, (b) 17-19 May, (c) 17-19 June, (d) 14-16 July, (e) 1316 Aug, (d) 17-19 September, 2004. Vertical lines indicate 06:00, 12:00 and 18:00 hours of each day. (Concluded.) . . . 90 
3.12 Diurnal variations of Radiation (red), water temperature (blue) and discharge (green) of the Lonza for the days: (a) 14-16 April, (b) 17-19 May, (c) 17-19 June, (d) 14-16 July, (e) 1316 Aug, (d) 17-19 September, 2004. Vertical lines indicate 06:00, 12:00 and 18:00 hours of each day. (Continued...) . 93

3.12 Diurnal variations of Radiation (red), water temperature (blue) and discharge (green) of the Lonza for the days: (a) 14-16 April, (b) 17-19 May, (c) 17-19 June, (d) 14-16 July, (e) 1316 Aug, (d) 17-19 September, 2004. Vertical lines indicate 06:00, 12:00 and 18:00 hours of each day. (Continued...) .

3.12 Diurnal variations of Radiation (red), water temperature (blue) and discharge (green) of the Lonza for the days: (a) 14-16 April, (b) 17-19 May, (c) 17-19 June, (d) 14-16 July, (e) 1316 Aug, (d) 17-19 September, 2004. Vertical lines indicate 06:00, 12:00 and 18:00 hours of each day. (Concluded.) . . .

3.13 Diurnal variations of Radiation (red), water temperature (blue) and discharge (green) of the Allenbach for the days: (a) 14-16 April, (b) 17-19 May, (c) 17-19 June, (d) 14-16 July, (e) 13-16 Aug, (d) 17-19 September, 2004. Vertical lines indicate 06:00, 12:00 and 18:00 hours of each day. (Continued...) . . . . .

3.13 Diurnal variations of Radiation (red), water temperature (blue) and discharge (green) of the Allenbach for the days: (a) 14-16 April, (b) 17-19 May, (c) 17-19 June, (d) 14-16 July, (e) 13-16 Aug, (d) 17-19 September, 2004. Vertical lines indicate 06:00, 12:00 and 18:00 hours of each day. (Continued...) . . . . .

3.13 Diurnal variations of Radiation (red), water temperature (blue) and discharge (green) of the Allenbach for the days: (a) 14-16 April, (b) 17-19 May, (c) 17-19 June, (d) 14-16 July, (e) 13-16 Aug, (d) 17-19 September, 2004. Vertical lines indicate 06:00, 12:00 and 18:00 hours of each day. (Concluded.) . . . . . . 99 
3.14 Diurnal variations of Radiation (red), water temperature (blue) and discharge (green) of the Gornera (a) and Findelenbach (b) for the days 24-27 Aug 2006. Vertical lines indicate 06:00, 12:00 and 18:00 hours of each day.

3.15 Diel cycles illustrating hysteresis of specific discharge ( $\mathrm{x}$ axis) and water temperature (y axis), the average of each hour within the calendar months April (a) - September (f) 2004, for the Massa. Open circle indicates the start of the loop, closed circle designates the loop end. . . . . . . . . . . . . . . . . 103

3.16 Diel cycles illustrating hysteresis of specific discharge (x axis) and water temperature (y axis), the average of each hour within the calendar months April (a) - September (f) 2006, for the Massa. Open circle indicates the start of the loop, closed circle designates the loop end.

3.17 Diel cycles illustrating hysteresis of specific discharge (x axis) and water temperature (y axis), the average of each hour within the calendar months June (a) - September (d) 2006, for the Findelenbach. Open circle indicates the start of the loop, closed circle designates the loop end. . . . . . . . . . . . . . . . . 105

3.18 Diel cycles illustrating hysteresis of specific discharge (x axis) and water temperature (y axis), the average of each hour within the calendar months April (a) - September (f) 2004, for the Lonza. Open circle indicates the start of the loop, closed circle designates the loop end. . . . . . . . . . . . . . . . 107

3.19 Diel cycles illustrating hysteresis of specific discharge ( $\mathrm{x}$ axis) and water temperature (y axis), the average of each hour within the calendar months May (a) - September (f) 2004, for the Allenbach. Open circle indicates the start of the loop, closed circle designates the loop end. 
3.20 Diel cycles illustrating hysteresis of solar radiation, measured at Zermatt, (x axis) and water temperature of the Massa (y axis), the average of each hour within the calendar months April (a) - September (f) 2004. Open circle indicates the start of the loop, closed circle designates the loop end. . . . . . . . 109

3.21 Year-to-year variations of total incoming shortwave radiation for the period 2003-2014 . . . . . . . . . . . . 112

3.22 Year-to-year variations of total incoming shortwave radiation between Jan 1 and June 13, for the period 2003-2014. . . . . . 113

3.23 Comparisons of seasonal stream temperature patterns (7 day averages) in the Massa for the years (a) 2003 and 2007 and (b) 2004 and 2009.

3.24 Comparisons of seasonal riverflow variations (7 day totals) of the Massa for the years (a) 2003 and 2007 and (b) 2004 and 2009.

3.25 Diurnal variations of water temperature and discharge of the Massa between March 21 (Julian day 80) and June 13 (Julian day 164) for the years; (a) 2003, (b) 2004, (c) 2007, and (d) 2009. Inset: Seasonal patterns of 7 day average, water temperature and discharge, grey box outlining Julian days 80 - 164 .

3.26 Diurnal patterns of water temperatures in the Massa, Gornera, Findelenbach,Lonza and Allenbach; for the period $21-25 \mathrm{Au}-$ gust 2006.

3.27 Diurnal variations of Radiation, measured at Zermatt, (red) water temperature (blue) and discharge (green) of the Massa for the period 14-16 July 2004. Black lines indicate fall/rise of maximum and minimum temperature. . . . . . . . . .

3.28 Diurnal variations of Radiation, measured at Zermatt, (red) water temperature (blue) and discharge (green) of the Gornera for the period 01-03 July 2006. Black lines indicate fall/rise of maximum and minimum temperature. 
3.29 Diurnal variations of Radiation, measured at Zermatt, (red) water temperature (blue) and discharge (green) of the Lonza for the period 14-16 July 2004. Black lines indicate fall/rise of maximum and minimum temperature.

3.30 Diurnal variations of Radiation, measured at Zermatt, (red) water temperature (blue) and discharge (green) of the Findelenbach for the period 07-09 July 2006. Black lines indicate fall/rise of maximum and minimum temperature. . . . . . . . 125

3.31 Demonstration of the change in hysteresis profiles during each month of the melt season (April-September) . . . . . . . . 128

4.1 Kipp and Zonen CMA6 Albedometer in position $1.5 \mathrm{~m}$ above the surface of the Findelenbach study site, close to the Findelenbach gauging station $\left(46.00^{\circ}, 7.81^{\circ}\right)$

4.2 Kipp and Zonen Albedometer showing the upward, downward facing pair of CMP6 pyranometers (Source: Kipp\&Zonen, (2015)).137

4.3 Kipp and Zonen CMA6 Albedometer wired to multimeter taking voltage readings. . . . . . . . . . . . . . 138

4.4 Incoming solar radiation measured over Findelenbach on the 6,7 and 8 September 2015. . . . . . . . . . . . . . 140

4.5 Reflected solar radiation measured over Findelenbach on the 6,7 and 8 September 2015. . . . . . . . . . . . . . . . 140

4.6 Stream surface albedo measured over Findelenbach on the 6,7 and 8 September 2015. . . . . . . . . . . . . . . . 141

4.7 Water temperature of the Findelenbach recorded at 10-minute intervals using TinyTag data-loggers between 12:30(CEST) 07 September 2015 and 12:40(CEST) 9 September 2015. . . . . . 141

4.8 Water temperature of the Findelenbach recorded at 10-minute intervals using TinyTag data-loggers between 09:00(CEST) and 18:00(CEST) 8 September 2015 . . . . . . . . . . . . . . . 142

4.9 Incoming solar radiation measured over the Gornera between the times 15:00 and 16:30 during 08-09-2015 . . . . . . . . 144 
4.10 Reflected solar radiation measured over the Gornera between the times 15:00 and 16:30 during 08-09-2015 . . . . . . . . . 144

4.11 Stream surface albedo measured over the Gornera between the times 15:00 and 16:30 during 08-09-2015 . . . . . . . . . 145

5.1 Map of Findelen study catchment in the upper Rhône basin, Kanton Wallis, Switzerland. . . . . . . . . . . . . . 154

5.2 Results of field experiment: (a) heating of still water under cloud cover, (b) heating of still water under cloud cover with black sheet covering bowl and (c) warming of still water uncovered under clear sky conditions, increased direction solar radiation and sides of bowl insulated. Each for separate 1 hour periods with readings taken every 5 minutes on 11 July 2014 . 156

5.3 Schematic of the Alpine Stream Temperature Model program, illustrating processes (grey boxes), input data (red boxes) and stored output data (blue boxes). . . . . . . . . . . . . . 159

5.4 Schematic of model creation, calibration and validation routines. 165

5.5 Sensitivity analysis result: altering coefficient $a$ and exponent $b$ to define a width which changes significantly with riverflow. $a=0.9$ and $b=1.5$, Figure (a), to 2.2, Figure (h), increasing by 0.1 each iteration. (Continued ...) . . . . . . . . . 168

5.5 Sensitivity analysis result: altering coefficient $a$ and exponent $b$ to define a width which changes significantly with riverflow. $a=0.9$ and $b=1.5$, Figure (a), to 2.2, Figure (h), increasing by 0.1 each iteration. (Concluded.) . . . . . . . . . . . . . 169

5.6 Sensitivity analysis result: altering coefficient $a$ and exponent $b$ to define a width which changes little with riverflow. $a=40$, Figure (a), to 75 , Figure (h), increasing by 5 each iteration. and $b=0.0006$. (Continued ...) . . . . . . . . . . 170

5.6 Sensitivity analysis result: altering coefficient $a$ and exponent $b$ to define a width which changes little with riverflow. $a=40$, Figure (a), to 75 , Figure (h), increasing by 5 each iteration. and $b=0.0006$. (Concluded.) . . . . . . . . . . 171 
5.7 Simulated water temperature (modelled with width changing substantially with discharge) during the period Julian day 180 (June 28) to Julian day 253 (September 8) 2006 (top plot), here shown together with: Hourly riverflow levels of the Findelenbach (middle plot) and daily precipitation totals at Zermatt (lower plot). . . . . . . . . . . . . . . . . . 174

5.8 Simulated water temperature (modelled with width changing little with discharge) during the period Julian day 180 (June 28) to Julian day 253 (September 8) 2006 (top plot), here shown together with: Hourly riverflow levels of the Findelenbach (middle plot) and daily precipitation totals at Zermatt (lower plot). . . . . . . . . . . . . . . . . . 175

5.924 hour average of simulated water temperature and average daily measured water temperature of the Findelenbach for the period Julian day 180 (June 28) to Julian day 253 (September

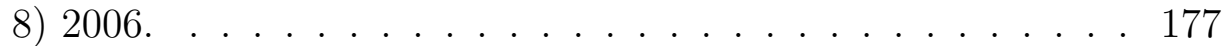

5.10 Simulated water temperature during the period Julian day 264 (September 21) to Julian day 280 (October 7) 2009 (top plot), shown together with: Observed up-stream temperature, at the glacier portal (middle plot), and Hourly riverflow levels of the Findelenbach (lower plot). . . . . . . . . . . . . . 178

5.11 Representation of the warming aliquots of water (black line on Time axis) as they pass downstream from the glacier portal for the period September 21 to September 24, 2009. . . . . . . . 179

5.12 Simulated water temperature and observed hourly water temperature of the Gornera at the Gorner gauging station, for the period Julian day 179 (June 27) to Julian day 190 (July 8) 2006.181

6.1 Schematic diagram showing the response of stream water temperature of a glacier-fed river to deglaciation (D. N. Collins, Personal Communication, May 2016) . . . . . . . . . . . . . 189 
6.2 Schematic diagram showing the response of stream water temperature of a glacier-fed river to increasing discharge augmented by deglaciation (D. N. Collins, Personal Communication, May 2016).

6.3 Aerial view of Findelenbach, captured with Dji Drone flown at $30 \mathrm{~m}$ a.g.l. Orthophoto mosaic from 348 individual images. Glacier portal to gauging station is from right to left. Courtesy of Dr Neil Entwistle, University of Salford. . . . . . . . . . . . 192

6.4 Findelengletscher positive (green bars) and negative (blue bars) length change together with cumulative length change (red line) for the period 1881-2015. Data: Glaciological-Reports, (2016). 194

6.5 Daily water temperature simulations, under current levels of shortwave radiation, with reach length $1000 \mathrm{~m}$ and varying levels of riverflow $(+10 \&+20 \%)$, during Reference Period A (14 17 July 2006)

6.6 Daily water temperature simulations, under current levels of shortwave radiation, with reach length $2000 \mathrm{~m}$ and varying levels of riverflow $(+10 \&+20 \%)$, during Reference Period A (1417 July 2006)

6.7 Daily water temperature simulations, under current levels of shortwave radiation, with reach length $3000 \mathrm{~m}$ and varying levels of riverflow $(+10 \&+20 \%)$, during Reference Period A (1417 July 2006) . . . . . . . . . . . . . . . . . . . 201

6.8 Daily water temperature simulations, under current levels of shortwave radiation, with reach length $1000 \mathrm{~m}$, each with varying levels of riverflow $(+10 \&+20 \%)$, during Reference Period B (28 September - 1 October 2009). . . . . . . . . . . . . . 204

6.9 Daily water temperature simulations, under current levels of shortwave radiation, with reach length $2000 \mathrm{~m}$, each with varying levels of riverflow $(+10 \&+20 \%)$, during Reference Period B (28 September - 1 October 2009). . . . . . . . . . . 205 
6.10 Daily water temperature simulations, under current levels of shortwave radiation, with reach length $3000 \mathrm{~m}$, each with varying levels of riverflow $(+10 \&+20 \%)$, during Reference Period B (28 September - 1 October 2009). . . . . . . . . . . 206

6.11 Daily water temperature simulations (blue line), under current levels of shortwave radiation, with riverflows at: (a) current levels, and (b) current levels $+10 \%$, with channel morphology resulting in width increasing significantly with discharge. Both compared to reference simulation (black line) under current hydro-climatic conditions for Reference Period A (14 - 17 July 2006). . . . . . . . . . . . . . . . . 209 


\section{List of tables}

1.1 Characteristics of study basins . . . . . . . . . . . . . . 14

2.1 Summary of reach- and basin- scale water temperature models. 39

2.2 Overview of research into stream water temperature and the thermal budget of rivers, both glacier and non-glacier fed. . . . 41

3.1 Summary of the hydrometeorological data available for this study. 50

3.2 Descriptive statistics of radiation $\left(\mathrm{W} \mathrm{m}^{-2}\right)$ measured at Zermatt. 53

3.3 Descriptive statistics of discharge $\left(10^{6} \mathrm{~m}^{3}\right)$ of the Massa measured at the Blatten-bei-Naters gauging station, for the calendar year. . . . . . . . . . . . . . . 5 58

3.4 Descriptive statistics of discharge $\left(10^{6} \mathrm{~m}^{3}\right)$ of the Lonza measured at the Blatten gauging station, for the calendar year. . . 58

3.5 Descriptive statistics of discharge $\left(10^{6} \mathrm{~m}^{3}\right)$ of the Allenbach measured at the Adelboden gauging station, for the calendar year. . . . . . . . . . . . . . . . .

3.6 Descriptive statistics of water temperature $\left({ }^{\circ} \mathrm{C}\right)$ of the Massa measured at the Blatten-bei-Naters gauging station, for the calendar year. . . . . . . . . . . . . . . 68

3.7 Descriptive statistics of water temperature $\left({ }^{\circ} \mathrm{C}\right)$ of the Lonza measured at the Blatten gauging station, for the calendar year. 68

3.8 Descriptive statistics of water temperature $\left({ }^{\circ} \mathrm{C}\right)$ of the Allenbach measured at the Adelboden gauging station, for the cal- 
3.9 Descriptive statistics of weekly precipitation totals $(\mathrm{mm})$ measured at Zermatt for the calendar year, 2003-2014. . . . . . . . 73

3.10 Correlation matrix of seasonal datasets, $\mathrm{Q}=$ Discharge and $\mathrm{T}=$ Water temperature and $\mathrm{R}=$ radiation for the year 2003 . .

3.11 Correlation matrices of seasonal datasets, $\mathrm{Q}=$ Discharge and $\mathrm{T}=$ Water temperature and $\mathrm{R}=$ radiation for the years (a) 2008 \& (b) $2014 \ldots \ldots \ldots \ldots$. . . . . . . . . . . . .

3.12 Summary statistics for multiple linear regression models of 7 day average river temperature, 7 day total discharge (Q) of the Massa and 7 day total shortwave radiation (R) and 7 day total precipitation (P), measured at Zermatt, 2003-2014. . . . . . .

3.13 Summary statistics for multiple linear regression models of 7 day average river temperature, 7 day total discharge (Q) of the Lonza and 7 day total shortwave radiation $(\mathrm{R})$ and 7 day total precipitation (P), measured at Zermatt, 2003-2014. . . . . . .

3.14 Summary statistics for multiple linear regression models of 7 day average river temperature, 7 day total discharge $(\mathrm{Q})$ of the Allenbach and 7 day total shortwave radiation (R) and 7 day total precipitation (P), measured at Zermatt, 2003-2014. . . . 85

3.15 Summary statistics for multiple linear regression models of monthly average temperature, stream area, gauging station elevation and percentage glacierisation, August 2006. . . . . . . . 85

3.16 Summary statistics for multiple linear regression models of monthly average temperature, stream area and percentage glacierisation for the four glacier-fed streams, August 2006. . . . . . . . . . 86

3.17 Total winter precipitation $\left(P_{11-5}\right)$ measured at Zermatt, for the period 2003-2014. . . . . . . . . . . . . . . . . . 110

3.18 MWAT statistics for the Massa (M), Lonza (L) and Allenbach (A) for the period $2003-2014 \ldots \ldots \ldots 111$

4.1 Values for measured stream surface albedo with comparison of other studies. . . . . . . . . . . . . . . . . . . 147 
5.1 Goodness of fit statistics for simulated to observed water temperature of the Gornera (27 June - 8 July 2006). . . . . . . . 182

6.1 Summary statistics of input data used for the modelling scenarios using Reference Period A (14 - 17 July 2006) and Reference Period B (28 September - 1 October 2009). . . . . . . . . 194

6.2 Goodness of fit statistics for simulated to observed water temperature during Reference Period A (14 - 17 July 2006). . . . 196

6.3 Simulated daily water temperature maxima of the Findelenbach $\left({ }^{\circ} \mathrm{C}\right)$, under current levels of shortwave radiation, during Reference Period A (14 - 17 July 2006). . . . . . . . . . . . 198

6.4 Goodness of fit statistics for simulated to observed water temperature during Reference Period Reference Period B (28 September - 1 October 2009). . . . . . . . . . . . . . 202

6.5 Simulated daily water temperature maxima of the Findelenbach $\left({ }^{\circ} \mathrm{C}\right)$, under current levels of shortwave radiation, during Reference Period B (28 September - 1 October 2009). . . . . . 203 


\section{List of acronyms}

A.S.L.:

AGP:

ASTER:

ASTER GDEM:

ASTM:

BAFU:

BST:

CC:

CET:

CEST:

$\mathrm{CO}_{2}$ :

DDF:

DEM:

EU:

FOEN:
Above Sea Level

Alpine Glacier Project (University of Salford)

Advanced Spacebourne Thermal Emission and Reflection Radiometer

ASTER Global Digital Elevation Map Alpine Stream Temperature Model Bundesamt für Umwelt (Switzerland's Federal Office for the Enivronment)

British Summer Time Creative Commons Central European Time Central European Summer Time Carbon Dioxide Degree Day Factor Digital Elevation Model European Union Federal Office of the Environment 
GMT:

GCMs:

IPCC:

LIA:

m A.S.L.:

MWAT:

NSE:

ODE:

OSM:

PDE:

QUAL2E:

RMSE:

SNTEMP:

SSTEMP:

UAV:

UN:
Greenwich Mean Time

General Circulation Models

Intergovernmental Panel on Climate Change

Little Ice Age

Meters Above Sea Level

Maximum Weekly Average Temperature Nash-Sutcliffe Efficiency Ordinary Differential Equation Open Street Map Partial Differential Equation Enhanced Stream Water Quality Model Root Mean Square Error Stream Network Temperature model (USGS) Stream Segment Temperature model (USGS) Unmanned Aerial Vehicle United Nations 


\section{List of nomenclature}

C:

DDF:

$\varepsilon_{w}:$

$\varepsilon_{a}:$

K:

$\Phi:$

$\rho:$

P:

$P_{11-10}$ :

Q:

$\sigma:$

$\mathrm{T}:$

$\mathrm{T}_{\mathrm{a}}$ :

$\mathrm{T}_{\mathrm{e}}$ :

t:

$\mathrm{T}_{2 \mathrm{~m}}$ :
Density of water $\left(\mathrm{kg} \mathrm{m}^{-1}\right)$

Degree Day Factor $\left(\mathrm{mm} \mathrm{d}^{-1}{ }^{\circ} \mathrm{C}^{-1}\right)$

Emissivity of water (Dimensionless)

Emissivity of air (Dimensionless)

Thermal Exchange Coefficient $\left(\mathrm{W} \mathrm{m}^{-2}{ }^{\circ} \mathrm{C}^{-1}\right)$

Total heat input $\left(\mathrm{W} \mathrm{m}^{-2}{ }^{\circ} \mathrm{C}^{-1}\right)$

Heat capacity of water $\left(\mathrm{J} \mathrm{kg}^{-1} \mathrm{~K}^{-1}\right)$

Precipitation (mm)

Precipitation November through October (mm)

Discharge/Riverflow $\left(\mathrm{m}^{3} \mathrm{~s}^{-1}\right)$

Standard deviaton (Units same as data)

Air temperature $\left({ }^{\circ} \mathrm{C}\right)$

Air temperature $\left({ }^{\circ} \mathrm{C}\right)$

Equilibrium temperature $\left({ }^{\circ} \mathrm{C}\right)$

Time (s)

$2 \mathrm{~m}$ Air temperature $\left({ }^{\circ} \mathrm{C}\right)$

xxiv 
$\mathrm{T}_{5-9}$ :

Air Temperature May through September $\left({ }^{\circ} \mathrm{C}\right)$

$\mathrm{T}_{\mathrm{w}}$ :

Water temperature $\left({ }^{\circ} \mathrm{C}\right)$ 
This thesis is dedicated to my parents, Linda and Keith, without whose encouragement and support I would not have come this far...

... I am forever grateful 


\section{Acknowledgements}

I am immensely grateful to my supervisor Professor David N. Collins, whose dedication to the study of glaciers and high mountain environments first attracted me to the University of Salford, and then inspired me to continue my studies at the university as a $\mathrm{PhD}$ student. For his guidance throughout the whole project - from encouragement when first applying to become a $\mathrm{PhD}$ student, through to the final completion of this thesis - I will be forever indebted. David is both professional and approachable and I have enjoyed every minute of my time at Salford, with some amazing field trips. I must also thank David for giving me the opportunity to visit the American Geophysical Union Fall Conference in San Francisco, which really opened my eyes to the world of science and allowed me to meet, and chat, to many of the experts in this field - receiving much needed guidance and ideas.

I would also like the thank Dr. Neil Entwistle for his input throughout my research, assistance on field trips in the Swiss Alps and giving me opportunities in teaching and fieldwork to enhance my career prospects. Additionally, his assistance proof-reading and his suggestions of some much needed changes is greatly appreciated. I am forever grateful for his friendship and support throughout, especially during the stressful final few months of this $\mathrm{PhD}$.

Thanks must also be given to fellow grad-students, past and present, including (but not limited to) Dominic Eaton, Josh Saunders, Joshua Davenport, Luke Bolton, Marc Matterson, George Brophy, Ricky Peters, Kirk Larsen, and George Pea all of whom helped me remain sane through a tough four years in Peel 313. Thanks are also given to the many undergrad students who assisted 
me on fieldwork in Switzerland. Furthermore, I am grateful to the academic staff at the University of Salford for assistance and kind words throughout my studies.

In addition, the programming language $\mathrm{R}$ was used throughout for data analysis, creating graphics and coding the models; the document preparation system $\mathrm{HT}_{\mathrm{E}} \mathrm{X}$ was used to generate the final thesis. I am grateful therefore, to the many $\mathrm{R}$ and $\mathrm{HT}_{\mathrm{E}} \mathrm{X}$ users, developers and posters on online forums for help and advice in getting to grips with, and using both languages.

My thanks go to the administration staff, especially Catriona Nardone, at the University of Salford for their help and understanding at all stages of this PhD.

Finally, I would like to express gratitude to my friends and family, most notably my parents, for their support both emotionally and financially. Without their encouragement I would never have been able to complete this thesis. 


\section{Declaration}

This is to certify that the copy of my thesis, which is presented for the degree of Doctor of Philosophy: embodies the results of my own course of research, has been completed by myself and has been viewed by my supervisor before presentation.

Date:

xxix 
All models are wrong but some are useful.

George E. P. Box, (1979) 


\section{Part I}

\section{Introduction \& background}




\section{Chapter 1}

\section{Introduction}

\subsection{Context}

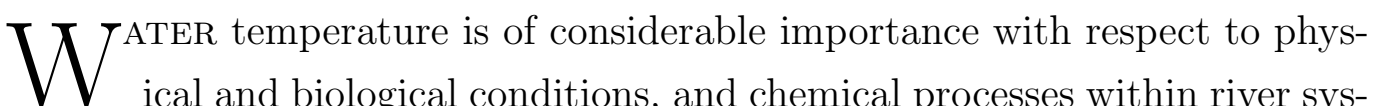
tems (Blaen et al., 2012; Dickson et al., 2012; Fellman et al., 2014; Woltemade and Hawkins, 2016; Yang et al., 2014). As a result of this the impact stream temperatures will have on downstream fisheries, specifically Salmonids has been thoroughly researched (Brittain and Milner, 2001; Brown et al., 2004; 2006a; Hannah et al., 2004). In spite of this, water temperature studies for streams draining large glaciers in high mountain environments has been relatively understudied (Hood and Berner, 2009; MacDonald et al., 2014).

Glacierised Alpine catchments have characteristic runoff regimes; minimum discharge occurs during the winter months with a distinct pulse in the summer, May through to September, as the river is fed by snow and ice melt (Smith et al., 2001). Rivers which discharge ice-free Alpine basins, have a distinctly different discharge regime; low winter flows, peaking earlier in the spring, as the seasonal snowpack melts. In streams which drain ice-free catchments, runoff follows, but is always less than, total annual precipitation. However, rivers which discharge mountain glaciers can be greater than, equal to or 
less than levels of precipitation (Collins, 2009). Annual runoff from glacial basins is dependent on two sources. One constituent of flow descends from the portion of the basin which is ice-free, whilst a second component is added to flow by the glaciated region (Brown et al., 2006b; Cadbury et al., 2008; Collins, 2009; Milner et al., 2010; Smith et al., 2001).

Snowmelt generates runoff from most of a glacial basin throughout spring, depleting as the snowpack migrates up valley throughout the summer (Milner et al., 2010). The extent of the winter snowpack is demonstrated by the altitude of the transient snow line and is dependant upon the amount of winter precipitation. Ice-melt will then increase as the transient snow line rises and glacier ice is uncovered. Surface albedo within the basin changes from high to low, as the percentage of surface snow and ice changes. This alteration in surface albedo leads to maximum discharge being delayed, behind peak radiation. In addition to this, meltwaters will move through the system at a faster rate, as the percentage of snow and ice changes. Moulins and development of the subglacial drainage network, also increase transit time of meltwaters through the glacial system (Collins, 1989; Milner et al., 2010). The relationship between the transient snow line and icemelt leads to higher discharge levels in years where dry winters precede warm summers (Collins, 2009).

Temperature is indicative of the kinetic energy of molecules within physical bodies; the more kinetic energy the warmer the substance will be (Ji, 2008). Stream water temperature is recognised as one of the most important physical, chemical and biological variables within river systems (Brown et al., 2006b; Cadbury et al., 2008; Caissie et al., 2001; Collins, 2009; Dickson et al., 2012; Fellman et al., 2014; Gu et al., 1998; Meier et al., 2003). Other important stream factors, for example, $\mathrm{pH}$ and dissolved oxygen are influenced by stream water temperature (Meier et al., 2003). This leads to water temperature being a key determiner in the health of biotic communities within lotic environments (Brown and Hannah, 2007; Brown et al., 2004; 2006a,b; Dickson et al., 2012; Hari et al., 2006). Changes in the thermal properties of streams can have widespread effects for biota (Webb et al., 2008), not just upstream but also for 
a distance downstream. For Alpine streams, it is considered that stream water temperature is the most important physical and chemical variable affecting the distribution and diversity of organisms (Dickson et al., 2012).

Combination of factors including: radiation, air temperature and hydrological conditions impact upon stream water temperature (Caissie, 2006; Collins, 2009; Fellman et al., 2014; Kurylyk et al., 2015; Webb et al., 2008). River water temperature, immediately after emerging from the glacier portal will be close to $0{ }^{\circ} \mathrm{C}$, and will only vary seasonally, by 1 or $2{ }^{\circ} \mathrm{C}$ (Fellman et al., 2014; Uehlinger et al., 2003). As the river flows downstream it will be heated by the direct incoming solar radiation. Radiation is the most important component determining stream water temperature (Caissie, 2006; Webb et al., 2003). Longwave radiation from the atmosphere and emitted from the river surface, together with the incoming solar radiation make up this component of the heat budget. Other factors which determine stream temperature include: gains and losses through bed conduction; warming through friction with the stream channel; heat exchange with the air; and condensation and evaporation (Caissie, 2006; Chikita et al., 2010; Webb et al., 2003).

Therefore, it could be expected that Alpine rivers will display distinct water temperature patterns, on both the diurnal and seasonal scale, when compared with both non-ice-fed and non-Alpine streams (Collins, 2009; Moore, 2006). High sensitivity to changes in the climate results in stream water temperature being greatly impacted by ongoing climate change (Brown et al., 2006a). Increasing energy availability within an Alpine catchment will have a direct positive impact upon stream temperature. However, large energy inputs increase the glacier melt, leading to a rise in river discharge. The amount of water within the river channel rises as a result, increasing the heat capacity of the stream water. River water temperature will therefore decrease. Despite more energy being available for heating, it is not sufficient to offset the increase in stream volume (Figure 1.1). This results in a paradox. Stream water temperature in a highly glaciated basin will be suppressed in the summer months despite high radiation (Figure 1.2) 


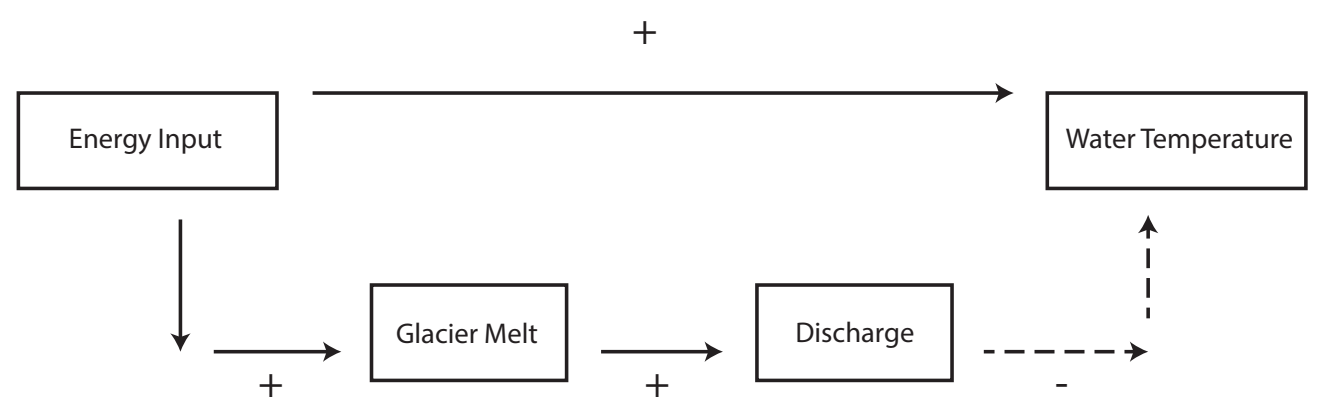

Figure 1.1: Schematic diagram of the paradoxical effect experienced by water temperature in a glacierised Alpine catchment.

There is widespread disagreement, however, as to why the pulse in summer discharge influences stream water temperature. Select observers of the aforementioned water temperature paradox have concluded the increase in volumetric flow and altering heat capacity of the stream, withholds water temperature during the summer months (Collins, 2009). Collins, (2009) also suggests the increase in stream velocity subdues the warming effect of the water, as residence time is reduced, leading to less exposure time to incoming radiation. Other studies conclude the increase in meltwater with a temperature of around $0{ }^{\circ} \mathrm{C}$ presents a cooling effect on water downstream (Fellman et al., 2014; Uehlinger et al., 2003).

Downstream of a glacier portal, stream water temperature would be expected to increase. The rate and distance of such longitudinal increase has been thoroughly studied in a wide range of study areas (Blaen et al., 2012; Brown and Hannah, 2008; Cadbury et al., 2008; Uehlinger et al., 2003; Webb and Nobilis, 1995). Widespread agreement in the results attained demonstrate increasing water temperature with distance downstream. In spite of this, the magnitude of warming has been found to differ (Blaen et al., 2012). There is little understanding as to how this longitudinal temperature change may alter, when comparing warm and cool summers. It is theorised that in cool summers the water temperature will increase to a higher extent, closer to the glacier terminus. Respectively, during a warm summer the cooler water will extend further downstream (Figure 1.3). How far, and at what temperature, 

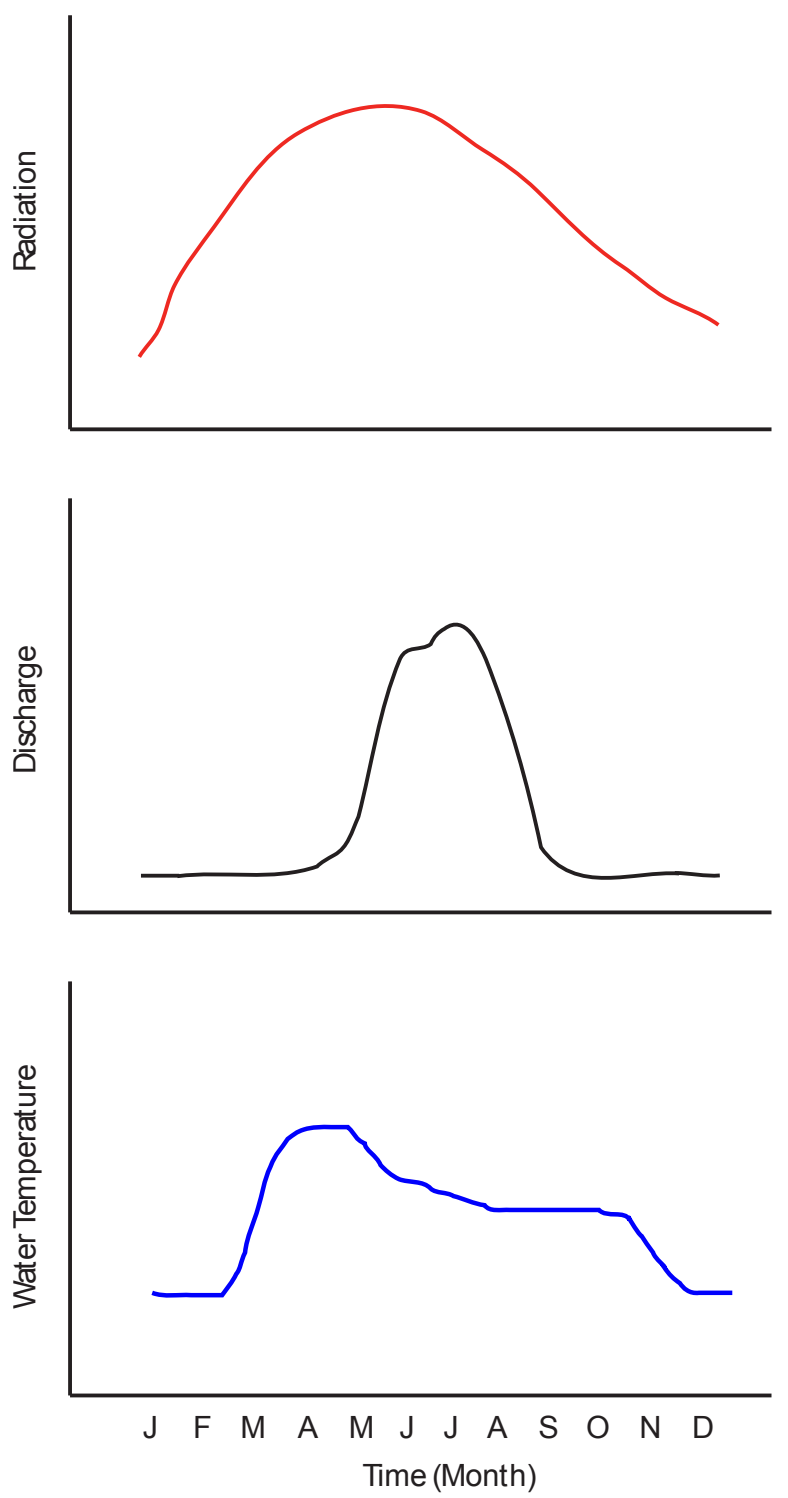

Figure 1.2: Plot of paradoxical effect experienced by water temperature in a glacier-fed stream.

this "tongue" of cool water extends downstream is understudied. Therefore, indicating a need for further research in this area.

Further understanding of how water temperature in Alpine streams will react to a changing climate is ever more important, with high mountain glaciers retreating in numerous areas of the planet (Hood and Berner, 2009). Alpine 


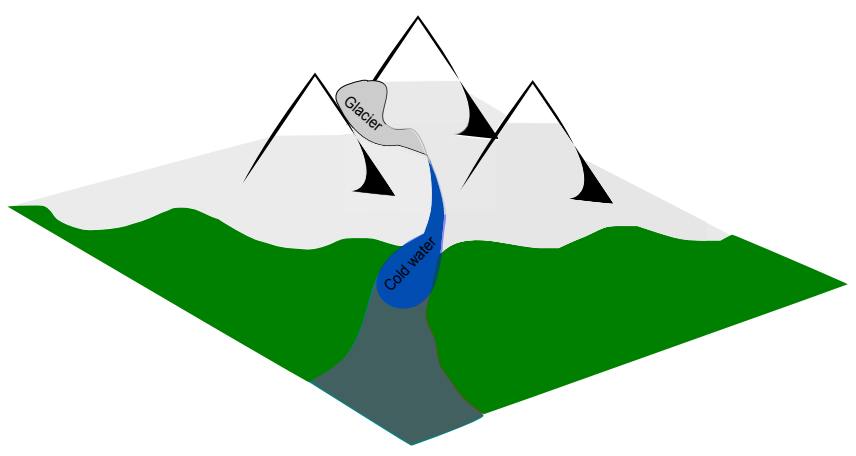

Cool Summer

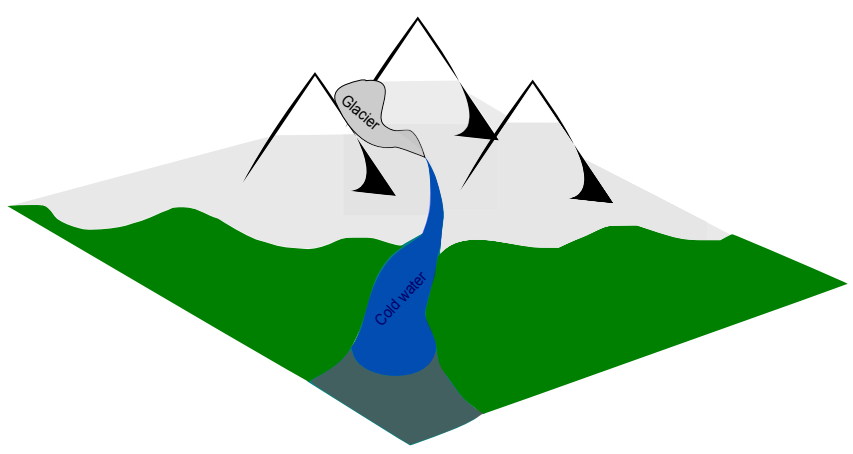

Warm Summer

Figure 1.3: Representative diagram illustrating how warm and cool summers effect distance downstream of the cold water "tongue".

streams fed by large glaciers are influenced most by incoming solar radiation and less so by air temperature (Fellman et al., 2014; Uehlinger et al., 2003). Studies indicate that with falling percentage glacierisation, the influence of discharge on water temperature declines (Fellman et al., 2014; Uehlinger et al., 2003). The importance of the controlling factors of water temperature is less understood. With declining percentage glacierisation, the influence of incoming solar radiation would be expected to decline; whilst the influence of air temperature driving stream water temperature would be greater.

Stream water temperature models have been thoroughly applied to water temperature studies, often those based in non-glacial non-Alpine regions (Caissie 
et al., 2001; Mohseni and Stefan, 1999; Webb et al., 2003; 2008), with relatively few being utilised in high Alpine catchments. Air temperature is often used as a surrogate for radiation in statistical based models (Caissie, 2006), and deterministic models are frequently over complicated, as most contain many input parameters (Chikita et al., 2010; Ouellet et al., 2014; Yearsley, 2009). A simple deterministic model which utilises discharge and incoming solar radiation would, therefore, be ideal for water temperature studies in highly-glacierised high mountain river basins.

The findings of this thesis suggest that the temperature of certain glacier-fed rivers are impacted more from heat gain due to loss in elevation, than solar radiation or friction with the stream bed; a theory previously outlined, in less steep Alaskan rivers, by Chikita et al., (2010). With regard to modelling water temperature, the temperature in streams for which heat gain due to loss of elevation is the major contributing factor (i.e. Massa and Gornera), can not be accurately simulated using the present model; changes in stream temperature would likely increase as a result of the increasing drop in altitude as the glacier retreats.

Despite the water temperature model used in this study producing some promising results, it must be stressed that, although the model could be modified to be applied to other river systems, in its present form it will only provide useful results in systems which are similar to the Findelenbach. The results attained in Chapter 6 are novel and useful in demonstrating potential changes to meltwater temperatures in a changing climate. However, they should be used as reference only and not for any mitigation and applications with respect to other basins and rivers.

\subsection{Research motivations}

Understanding the hydrology of proglacial streams in high mountain environments is important for the study of water temperature. Fast flowing streams will be exposed to less heating during the transit from the glacier portal down 
stream. Similarly, deep rivers will warm at a slower rate than shallow streams. Knowledge of patterns of discharge for streams emanating from glaciers will enable a greater understanding of the effects riverflows will have on water temperature.

The last two decades have been witness to a substantial increase in water temperature research (Webb et al., 2008). Many of these studies have assessed heat budgets of non-glacial streams. However, recently there has been an rise in studies investigating stream temperature in glacierised basins (Brown and Hannah, 2007; Brown et al., 2006a,b; Cadbury et al., 2008; Chikita et al., 2010; Collins, 2009; Fellman et al., 2014; Hood and Berner, 2009; Uehlinger et al., 2003). Many of these studies assess streams draining either basins with low percentage glacierisation, such as the Tailion-Gabiétous catchment in the French Pyrénées, which is only 5\% glacierised (Brown et al., 2006a), and the study by Cadbury et al., (2008) where the Rob Roy Glacier covers only $4.8 \mathrm{~km}^{2}$ of a $16 \mathrm{~km}^{2}$ basin. In addition to this, glaciers draining basins in the Alpine region of New Zealand are influenced by precipitation more than those of the European Alps, due to a differing climate (Cadbury et al., 2008). Thermal characteristics of proglacial streams in New Zealand will be impacted upon by the thermal properties of the precipitation. Recent studies have been conducted on glacier-fed streams in Alaska (Chikita et al., 2010; Fellman et al., 2014; Hood and Berner, 2009) and the Arctic (Blaen et al., 2012).

Stream temperature modelling has advanced greatly over the previous 20 years, and researchers have moved from statistical models, which determine water temperature from air temperature relationships (Mohseni et al., 1999), to more physically based, deterministic models (Caissie, 2006). Despite this increase, there has only been one major use of a heat budget approach to modelling water temperature of glacial streams (Chikita et al., 2010). Differing regional climates and percentage glacier cover of the watersheds, together with the simplicity of the model used in this study will give indications as to how the results in other regions are replicated in the European Alps.. 
How stream temperature will change due to anthropogenic causes, such as deforestation, flow diversion and climate change has been studied (Garner et al., 2014; Mellina et al., 2002; Mohseni et al., 1999). However, with regard to the response of water temperature in glacial streams due to climatic change there is a lack of research. This is surprising considering the importance of water temperature, and the knowledge behind retreating glaciers and the effects such retreats will have upon basin hydrology. The stream temperature model created for this research should alleviate this gap within the field, by demonstrating how water temperature will respond under different climate scenarios.

How climate change will impact water temperature of glacier-fed rivers, and therefore the downstream fisheries (Mohseni et al., 2003), has not been researched in depth, despite the importance of this subject. This gap in knowledge is highlighted as a major challenge and the direction of travel needed in this field of research. The large amount of data, collected over many years at hourly resolution, in the European Alps will help this present study fill gaps in the literature. Furthermore, the creation of a reduced parameter water temperature model, based solely on net radiation and discharge; will enable this study to determine future implications of climate change upon Alpine stream water temperature.

\subsubsection{Stream temperature and lotic habitats}

Thermal conditions within river systems are of vital importance in influencing biology and chemistry of rivers. In spite of this, knowledge of year round in-stream temperatures is limited (Brown et al., 2006b). These limits are accentuated when considering temperature change in streams fed by high mountain glaciers (Cadbury et al., 2008). Glacier-fed rivers are unique in that climatic changes will greatly affect discharge. Thermal patterns of all streams will be impacted on by changes in runoff. Greater understanding of stream temperature and the processes which drive it is important. This is due to the importance of water temperature of the ecology of lotic environments 
(Brown et al., 2004).

The impact water temperature has on aquatic life has been the basis of substantial research undertaken in recent years. Steam temperature is an essential factor influencing lotic communities (Brittain and Milner, 2001; Brown et al., 2006a; Cadbury et al., 2008; Trimmel et al., 2015; Yang et al., 2014). Water temperature impacts on dissolved oxygen, directly influencing the metabolism of lotic organisms, make temperature a major concern (Dickson et al., 2012). Biologists have examined how changes in stream temperatures, both glacial and non-glacial, have impacted on the organisms which inhabit them (Brown and Hannah, 2007; Brown et al., 2004; 2006a; Dickson et al., 2012; Hari et al., 2006). There is concern as to how warming stream temperature will negatively affect these natural habitats. Water temperature is the major physical and chemical factor which affects the diversity of a population of organisms, together with the distribution of habitats (Brown et al., 2004; Dickson et al., 2012; Gu et al., 1998; Meier et al., 2003). Benthic communities cannot migrate down river courses due to physical barriers - which leads to a population decrease (Hari et al., 2006). Shallower streams are more influenced by heat inputs than larger rivers, as the heat capacity of small streams will be lower. Therefore Alpine streams will experience greater changes as the climate warms (Meier et al., 2003).

Studies have been undertaken assessing the consequences for Salmonid populations in rivers, resulting from climate change (Hannah et al., 2004; Hari et al., 2006). Hari et al., (2006) indicate how warming in rivers draining the European Alps has increased within the last 25 years. This is linked to a large decline in brown trout in European rivers. Similarly Hannah et al., (2004) examine the energy budget of a Cairngorm Salmon spawning river, UK. Hannah et al., (2004) explain that development of Salmon eggs is greatly impacted by water temperature. Such research examines the biota affected within rivers emanating from ground water sources (krenal streams). Other stream types include, snowmelt fed streams named rhithral rivers and glacier-fed streams, referred to as kryal (Ward, 1994). 
In terms of river temperature, glacier-fed streams are said to be the most harsh environments for biota (Uehlinger et al., 2003). Biotic communities in glacier-fed streams are largely present in the form of immobile algae, mosses, lichens (Rott et al., 2006) and macro-invertebrates (Milner et al., 2010; Milner and Petts, 1994). Bare rock faces within Alpine streams are usually colonised by bacteria, fungi and viruses (micro-organisms). Close to glacier termini, micro-organisms in the form of bacteria are still common (Rott et al., 2006). During periods of enhanced melt in the summer months communities of algae and macro-invertebrates decline (Milner et al., 2010). Additionally, at times when discharge regimes alter and become more groundwater and snowmelt driven, conditions for biotic life improve leading to healthier populations. Rott et al., (2006) suggest wider reaching impacts to the greater food chain could be expected, due to the changes brought to the diversity of organisms, in glacier-fed Alpine streams. It is thought that in high mountain catchments the development of algae, something which may seem insignificant, is a critical source of energy to the greater food-web (Rott et al., 2006; Ward, 1994).

\subsection{Aims and objectives}

The aims of this research were to: Develop greater understanding of the water temperature regimes of Alpine meltwater streams, and develop a simplified water temperature model, said to be parsimonious in both resources and necessary predictor variables. The overriding principal aim was to utilise the stream temperature model to quantify the potential effect climate change will have on the temperature of the upper-reaches of rivers which drain Alpine glaciers. The specific objectives were to:

1. Examine how percentage glacierisation and basin properties affect the seasonal and diurnal patterns of stream temperature for rivers draining Alpine basins;

2. Create a simplified stream water temperature model with few parameters; a parsimonious model; 
3. Use the deterministic water temperature to quantify how water temperature will be affected under different climate scenarios;

This study will be unique in quantifying stream water temperature under different hydro-climatic scenarios, for rivers draining highly glacierised catchments in the Swiss Alps. Furthermore, this research will help to develop further understanding of water temperature in Alpine rivers; a need which has been expressed frequently (Cadbury et al., 2008; Collins, 2009; Moore et al., 2009; Uehlinger et al., 2003). This differentiates itself from other studies i.e. percentage glacierisation (Brown and Hannah, 2007; Brown et al., 2006a,b; Cadbury et al., 2008) and also geographical location (Blaen et al., 2012; Chikita et al., 2010; Fellman et al., 2014; Hood and Berner, 2009; Moore et al., 2009). The stream temperature model will be unique in using fewer parameters than those which are used in current literature; which often account for the entire energy budget of the stream (Caissie et al., 2005; Chikita et al., 2010; Edinger et al., 1968; Evans et al., 1998; Ouellet et al., 2014; Yearsley, 2009).

\section{$1.4 \quad$ Study area}

The study basins are located in the Upper Rhône and Upper Aare catchments, Switzerland. This region of the European Alps has a warm dry summer climate with many sunshine hours year round. This climate is ideal for studying water temperature of high altitude streams, due to the high incoming solar radiation. Selection of the study basins was based on the following factors:

1. Streams draining Massa, Lonza and Allenbach are gauged year round with easily obtainable data.

2. Findelenbach and the Gornera are gauged during field trips in the summer months with long term data available.

3. A wide range of percentage glacier cover. 
The locations of the individual basins are shown in Figure 1.4, and the basin characteristics are presented in Table 1.1.

Table 1.1: Characteristics of study basins

\begin{tabular}{lcccc}
\hline Basin & Principal glacier & $\begin{array}{c}\text { Reach } \\
\text { length } \\
(\mathrm{m})\end{array}$ & $\begin{array}{c}\text { Basin Area } \\
\text { area } \\
\left(\mathrm{km}^{2}\right)\end{array}$ & $\begin{array}{c}\text { Basin } \\
\text { glacierisation } \\
(\%)\end{array}$ \\
\hline Allenbach & Langgletscher & 8990 & 77.8 & 36.5 \\
Lonza & Grosser Aletschgletscher & 2440 & 195.0 & 65.9 \\
Massa & Findelengletscher & 1000 & 24.9 & 73.0 \\
Findelen & Gornergletscher & 1500 & 82.0 & 83.7 \\
Gorner & Gorlo & & & \\
\hline
\end{tabular}

\subsubsection{Allenbach}

The Allenbach catchment is ice-free. It is the only basin in this study located in the Upper Aare catchment. Basin area amounts to $28.8 \mathrm{~km}^{2}$. The Rossbach at $1507 \mathrm{~m}$ a.s.l., Stigelbach at $1414 \mathrm{~m}$ a.s.l. and Gilsback at $1371 \mathrm{~m}$ a.s.l. are tributaries to the Allenbach. The Allenbach drains through a gauging station in the town of Adelboden, at an elevation of $1297 \mathrm{~m}$ a.s.l. The highest point within the basin is Albristhorn, at $2762 \mathrm{~m}$ a.s.l. with an average elevation of 1856 m a.s.l. (Aktuelle Situation Gewässer 2014). Maximum outflow from the basin occurs during early spring (April - June). Measurements of discharge and water temperature are available at hourly resolution, recorded by the Swiss Department of the Environment, Transport, Energy and Communication's Bundesamt für Umvelt (BAFU), at their Adelboden gauging station. 


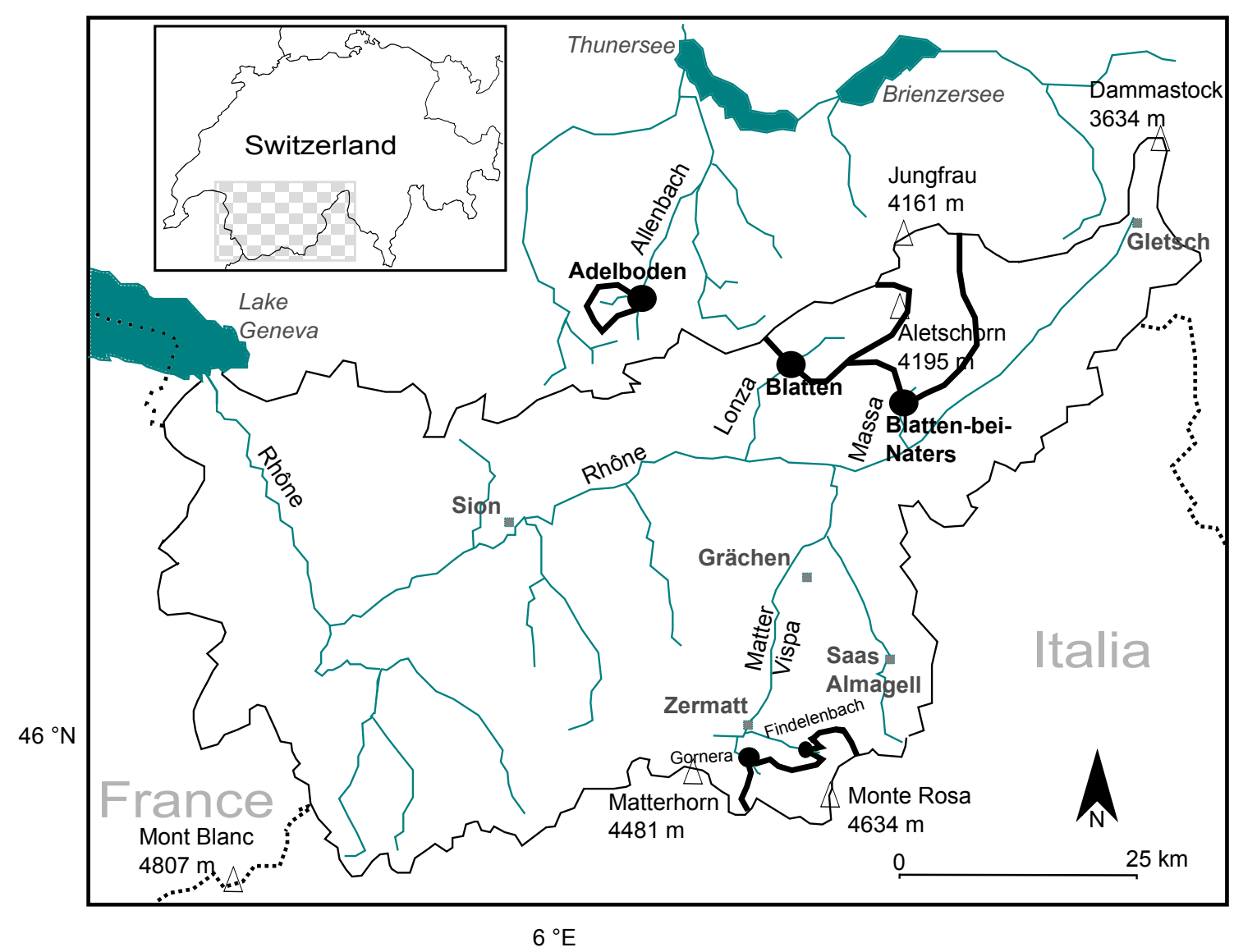

Figure 1.4: Map of the study basins in the larger upper Rhône and contiguous upper Aare catchments, Switzerland. 


\subsubsection{Lonza}

The Lonza is the least glacierised catchment (36.5\%) whilst being relatively large in size $\left(77.8 \mathrm{~km}^{2}\right)$. The principal glacier feeding the River Lonza is Langgletscher along with several other smaller glaciers, elevation of the glacier ranges from 2450-3005 $\mathrm{m}$ a.s.l. (Collins, 2006). The highest point of the basin being Mittaghorn (3897 m a.s.l.) with Grosshorn and Sattlehorn concluding the upper boundary of the basin. Discharge and water temperature are gauged in the town of Blatten, at $1520 \mathrm{~m}$ a.s.l., with a mean elevation of $2630 \mathrm{~m}$ a.s.l. (Aktuelle Situation Gewässer 2014). For the period 1956-2005, average discharge from the basin was calculated at $1.095 \mathrm{~m}$ (Collins, 2005). Stream length from glacier portal to gauging station is $8.9 \mathrm{~km}$, making this the largest stream reach in the study. Many small tributaries join the Lonza prior to the gauging station.

\subsubsection{Massa}

Ranging from the gauging station (1458 $\mathrm{m}$ a.s.l.) to its highest point $4195 \mathrm{~m}$ a.s.l. (Aletschhorn), the Massa basin has a basin area measuring $195 \mathrm{~km}^{2}$. The basin is $65.9 \%$ glacierised with the largest glacier in the basin being Grosser Aletschgletscher. The glaciers occupy the elevation ranges $1760-4193 \mathrm{~m}$ a.s.l. (Collins, 2006). Other major peaks in this basin are Jungfrau (4161 m a.s.l.) Trugberg (3933 m a.s.l.) to the east of the basin, and Mittaghorn $(3987 \mathrm{~m}$ a.s.l.) to the west of the catchment. Average annual runoff from the basin for the period 1957-2005 equated to $2.112 \mathrm{~m}$ (Collins, 2008). Glacier portal to gauging station has been measured as $2.4 \mathrm{~km}$. Data has been collected at hourly resolutions, both water temperature and discharge, for 1 January - 31 December since 2003. 


\subsubsection{Findelen}

Findelenbach is the stream discharging the Findelengletscher. The catchment measures $24.9 \mathrm{~km}^{2}$ and is currently $73 \%$ glacierised (Uhlmann et al., 2013). The catchment ranges in elevation from 2500-4190 $\mathrm{m}$ a.s.l. (Collins and Taylor, 1990). The gauge is located about $1 \mathrm{~km}$ from the glacier portal. As a contributory basin to the greater Grande Dixence watershed, albeit accounting for only $5 \%$ (Uhlmann et al., 2013), measurements of discharge have been recorded by the hydroelectric company, Grande Dixence, S.A. throughout the year. Other hydrological variables such as water temperature, have been collected through the Alpine Glacier Project, led by Professor David Collins, dating back 40 years. Data loggers are inserted into the stream close to the gauging station each summer. The Findelen basin is surrounded by the peaks of Rimpfischhorn (4190 m a.s.l.), Adlerhorn (3988 m a.s.l.), and Stralhorn (4190 m a.s.l.).

\subsubsection{Gorner}

The Gorner basin is the second largest in this study $\left(82 \mathrm{~km}^{2}\right)$, with a range of 2005-4634 $\mathrm{m}$ a.s.l. The major glacier in this basin is the Gornergletscher, Switzerland's second largest glacier (around $60 \mathrm{~km}^{2}$ ) (Huss et al., 2007). There are many smaller glacier tributaries to the Gornergletscher, the largest being Grentzgletscher. Together Grentzgletscher and Gornergletscher create an icedammed lake, Gornersee. A build up of water in the lake occurs during early spring and the lake usually drains between June and August over a 2-7 day period (Huss et al., 2007). The Gorner basin is $83.7 \%$ glacierised, the most highly glacierised basin in this study. The length of the Gorner stream equates to $1.5 \mathrm{~km}$, glacier portal to stream gauge. Discharge is gauged year round by Grande Dixence, S.A. at hourly resolution. Water temperature is measured during summer field visits using data loggers close to stream gauge. The highest point of the catchment is Dufourspitze (4643 m a.s.l.) with Stockhorn (3532 $\mathrm{m}$ a.s.l.) and Gornergrat (3135 $\mathrm{m}$ a.s.l.) bounding the basin round to 
the North, and Lyskamm (4527 m a.s.l.) and Theodulhorn (3468 m a.s.l.) to the South.

\subsection{Thesis outline}

This thesis comprises four parts and seven chapters, a general layout overview is illustrated in Figure 1.5. The thesis is structured as follows.

Part 1 encompasses the present introduction followed by Chapter 2 which introduces the background to the current understanding, delving deeper into the literature and recent research. Also demonstrated is the theory behind principles that have been referred to in this current chapter.

Part 2 contains the analysis of water temperature perturbations. Chapter 3 investigates the essential paradox of lower water temperatures at times of high energy inputs, ascertaining how percentage glacier cover in a basin can alter this effect on water temperature. This will be achieved by using daily, seasonal and year to year resolution data; including correlative analysis to demonstrate how changes in percentage glacierisation impact upon both driving forces and water temperature. Chapter 4 assesses the influence stream surface albedo of glacier meltwater streams on water temperatures.

Part 3 focuses on modelling of water temperature with Chapter 5, demonstrating the theory behind a new simplified stream water temperature model. The calibration of the model along with the illustration of data and analysis of results will be covered in detail. Chapter 6 will discuss the use of the deterministic temperature model used to simulate temperatures using different climate scenarios. This will quantify how a changing climate will impact upon the water temperature of Alpine glacial streams.

Finally, Part 4 and Chapter 7 will provide a conclusion; a final analysis of the main points presented in this thesis. 


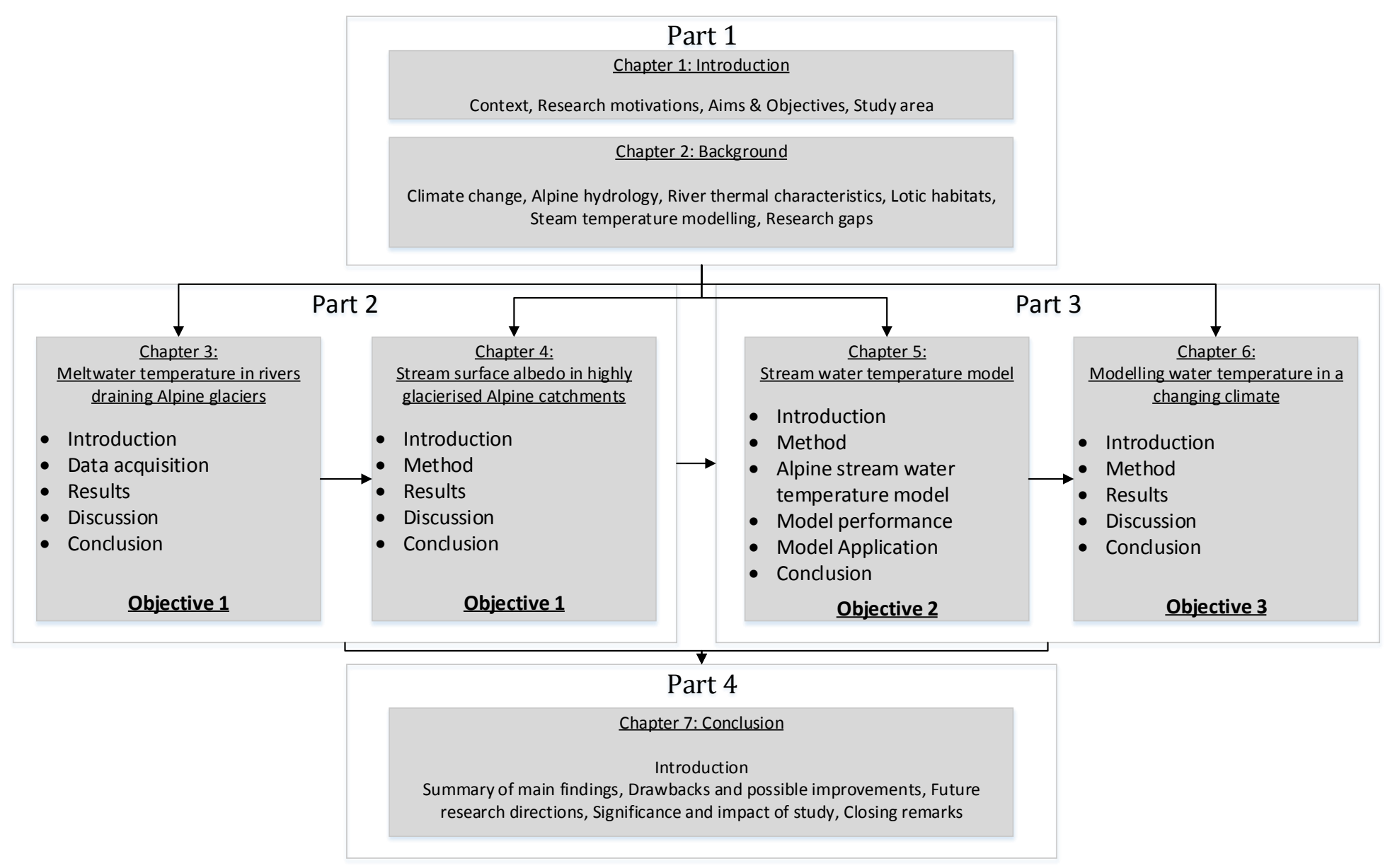

Figure 1.5: A thesis outline highlighting which Chapters address the aims and objectives of this study. Chapters are split into four Parts, the first Part includes an Introduction to the following two Parts, Part 2 assesses the water temperature variations and Part 3 addresses the modelling aims of this study. Part 4 provides an overall conclusion. 


\section{Chapter 2}

\section{Background}

\subsection{Glaciers \& climate change}

7 HE Cryosphere is a sensitive barometer of climate change. Fluctuations in 1 ice masses including, polar ice caps, sheets and mountain glaciers have followed cyclical changes in the climate throughout history. Consequently, during sustained cooling, glaciers and ice sheets would have been plentiful. These Ice Ages are believed to occur in the region of every 100,000 years (Hewitt, 1996). Contrastingly, during times of prolonged warming the Cryosphere will shrink. Within these interglacial periods there are brief cooling events. The most recent event is referred to as the Little Ice Age (LIA). This period of cooling occurred, globally, from the fourteenth to the nineteenth century (Matthews and Briffa, 2005). The LIA is thought to have occurred in Europe and regions surrounding the North Atlantic between the sixteenth and nineteenth centuries. Although global, the LIA was more pronounced and lasting in the North Atlantic region. In other regions, it is thought that brief warming spells occurred during the LIA (Mann, 2002).

A common feature of the current climatic shift is rising air temperatures (IPCC, 2013). The IPCC, (2013), indicates that atmospheric temperature during the last three decades has been warmer than any decade since 1850 . 
Furthermore, for the period 1880-2012 global land and sea surface temperature data indicates a warming of $0.85{ }^{\circ} \mathrm{C}$. Summer air temperatures strongly correlate with glacial discharge (Braithwaite and Zhang, 2000; Collins, 2008). Warming temperature therefore, must impact upon the streams in glaciated regions. During sustained global warming, glaciers and ice sheets will retreat.

Precipitation patterns also fluctuate over long time-scales and since 1901 has increased for the Northern Hemisphere (IPCC, 2013). The IPCC, (2013) report also suggests it is possible that heavy precipitation events have risen, in frequency, in more areas than they have fallen. Precipitation is an important aspect of the mass balance of glaciers. During periods of enhanced snowfall, glaciated areas will advance. Increases in precipitation, on smaller time-scales, can impact upon the albedo of glaciated basins and reduce the constituent of runoff produced by ice melt. In some high mountain regions of the globe, such as the central Himalayas and certain latitudes of the Andes, precipitation can be the major control in glacier mass balance (Barnett et al., 2005).

Radiation is another important aspect to consider when evaluating climate change, along with air temperature (Huss et al., 2009; Wild et al., 2004). As with air temperature, global radiation exhibits cyclical variation. This includes the Maunder Minimum, which was a period of extreme low solar activity, which occurred between the mid seventeenth and early eighteenth centuries to the high radiation of the present day (Lean et al., 1995). Changes in solar irradiance is known to impact upon air temperatures. Budyko, (1968) indicated how air temperature relates to solar radiation. More recently, air temperatures have been estimated to have increased by around $0.2{ }^{\circ} \mathrm{C}$, for the first fifty years of the $20^{\text {th }}$ Century, as a result of estimated changes in solar radiation (Karl and Trenberth, 2003). Despite this, Lean et al., (1995) demonstrate, through the use of reconstructing historic radiation, that since the 1970 s, less than a third of surface warming is attributable to solar irradiance changes. This figure is $50 \%$ for the period 1600 to the present. However, some studies have shown, despite recent air temperature warming trends, radiation has been decreasing (Wild et al., 2004). This is coupled with the fact snow and ice melt in the Swiss Alps was much greater in the 1940s - 8\% 
higher than the long term average - despite current day air temperatures being higher (Huss et al., 2009). Total irradiance from the sun displays a clear 11 year cycle, and satellite based measurements indicate an increase of $1.3 \mathrm{~W} \mathrm{~m}^{-2}$ between the cycle maximum during 1980 and 1990 compared to the minimum period, 1986 and 1996 respectively (Fröhlich and Lean, 1998). Recent research, IPCC, (2013), indicates dimming of solar radiation in the period 1950s to 1980s, followed by increases up to the present day.

Since the end of the LIA, circa 1850, glacial coverage has shrunk. Furthermore, it is now a highly accepted view that recent climate perturbation is not only triggered naturally, but is also influenced by anthropogenic causes (Braithwaite and Zhang, 2000; Braun et al., 2000; Hock et al., 2005; IPCC, 2013; Wild et al., 2004). Recent research indicates the possibility of small mountain glaciers being present in the UK during the LIA, despite the widespread belief that glaciers had fully retreated from Scotland much earlier. Harrison et al., (2014) used modelling techniques, based on local climate data, to show the possibility of such glaciers. Moreover, Davies and Glasser, (2012) indicate that temperatures in the UK were $1.5^{\circ} \mathrm{C}$ lower and precipitation $10 \%$ greater than present levels. Despite the suggestion that the LIA was more pronounced in the North Atlantic region, research shows how other regions of the planet were affected. Glaciers in the Andes have lost much of their coverage since the end of the LIA. A study of over 600 glaciers in the region has revealed over $15 \%$ reduction in glacial area. Additionally, it is suggested that the rate of shrinkage is faster since the 1980s (Davies and Glasser, 2012).

\subsection{Glacier hydrology in the Swiss Alps}

Knowledge of the components which contribute to discharge in high mountain rivers is important when assessing the impact on stream temperature. Each constituent of flow has a unique thermal characteristic (Collins, 2009). Therefore, large levels of cold water released in the summer months could impact upon the wider stream temperature. 
Glaciers essentially act as a store for precipitation (Jansson et al., 2003). Rainfall is stored in a variety of ways over varying time scales. As opposed to using the generalised term 'storage', Jansson et al., (2003) suggest talking in terms of short, intermediate and long term storage. Over the short time scale, water is stored in the glacier system, in the subglacial and englacial drainage routes. Short term storage of precipitation will last hours or days. Rainfall stored over weeks, months and years is referred to as intermediate storage. This is water that, collects in pools between the upper layer of permeable firn, and the lower saturated and impermeable layer. Water is delayed during the early stages of the melt season. Passages within the firn and ice during this time are underdeveloped, often leading to water refreezing as it comes into contact with cooler ice. Runoff stored in the seasonal snow cover can also be categorised as intermediate storage. Water stored in the glacier system over the long term is the glacial ice. This can be stored in the system for years and centuries.

Percentage glacierisation provides the areal percentage of a drainage basin which is occupied by glacial ice. A basin with any percentage glacierisation will have a lesser variability of annual discharge when compared with that of total yearly precipitation (Collins, 1987; 2005). Glaciers essentially moderate flow within a glaciated basin, due to the differing hydrological response to waters coming from the ice-free and glaciated regions of the basin.

There are two main types of Alpine rivers, glacial-fed and snow melt-fed (Nival). Both glacier-fed, and nival streams have regimes which differ from that of non-alpine streams. Peak discharge for non alpine streams will occur in the wetter months, as precipitation and groundwater inputs are the major contributors. Alpine streams will peak during the hotter months, when snow and ice melt is greatest(Collins, 2005).

Year round, Alpine streams are fed by precipitation, in the form of rain, and groundwater sources. In the summer months, ice and snow melt are the major contributors (Braun et al., 2000; Collins, 2006; 2009). As such, glacial rivers have vastly differing annual patterns. Research undertaken by 
Fleming, (2005) illustrates the differences between nival, which is snow-melt dominated, streams and glacial-fed rivers. Time series analysis demonstrates nival streams have a maximum discharge early in the summer, and by the time of maximum air temperatures discharge has dropped significantly. Furthermore, discharge after this peak reflects levels of summer precipitation. Comparatively, discharge from rivers which are glacier-fed is greatest in the mid-summer months. This occurrence illustrates how high mountain river regimes vary with the presence of glaciers. During the winter months, both regimes reflect levels of groundwater and, resultantly, discharge is vastly less. Why peak discharge occurs later in the summer months, despite levels of radiation being greatest in June, for rivers which drain glacial regions, is due to a combination of heat input and surface albedo. Incoming shortwave solar radiation is the principal heat source which melts both the seasonal snow cover and glacier ice. Throughout the winter, the seasonal snow cover blankets the glacier ice. As solar radiation rises throughout spring to its maximum on June 21, the snow cover will be vast. The basin therefore, will have a high albedo and as a result much of the solar radiation will be reflected. As the transient snowline regresses, the albedo of the area, which has been exposed as ice, will fall and in turn, the melt rate will increase. Further retreat of the seasonal snow cover will expose greater areas of ice, decreasing the albedo and increasing the melt rate, per area. This concept is demonstrated schematically in Figure 2.1. Eventually, the falling radiation is offset by the increased area of bare ice aided by the, still rising, air temperature (Collins, 1998).

\subsubsection{The deglaciation discharge dividend \& its effects on stream temperature regime}

Glacier ice volume is driven by its mass balance; the difference between the accumulation of snow over many years compacting into glacier ice, and the ablation. Mass balance is driven by the climate. During warm dry periods there will be negative mass balance and, in wet cool periods it would be positive. How discharge of high mountain rivers has reacted to a changing 


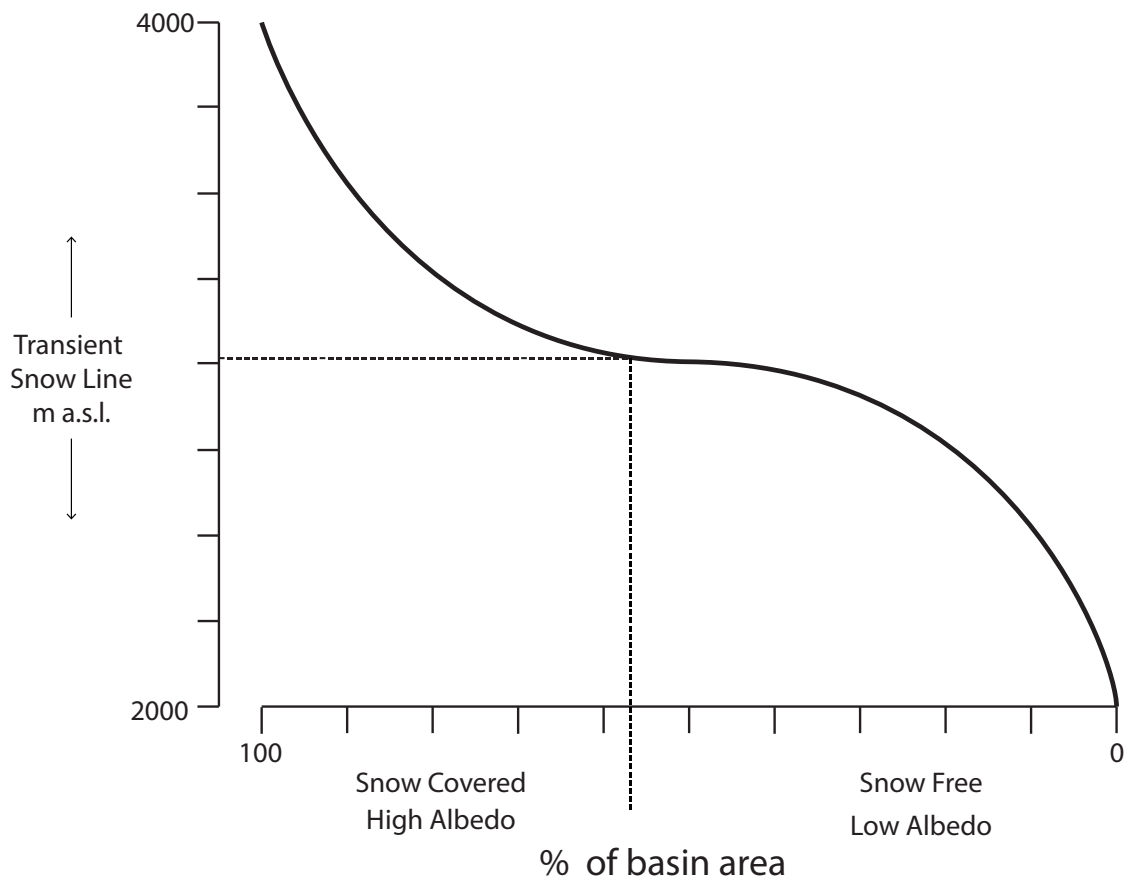

Figure 2.1: Schematic plot demonstrating how vertical movements in the transient snowline impacts upon areas of the basin which are snow covered and snow free, and thus albedo, with respect to basin hypsometry (bold black line).

climate has been thoroughly researched (Braun et al., 2000; Collins, 1987; $2005 ; 2006 ; 2008)$. The areal dimensions of a glacier within a drainage basin impacts upon discharge of that basin. Collins, (2006), provides the view that in basins with greater than $60 \%$ glacier cover, year to year variation in discharge reflects average summer temperature; that is the mean for the months May through to September. Rivers in basins which were less than $60 \%$ glacierised but greater than $35 \%$ followed similar discharge patterns up until the 1990s. Rivers draining glaciers which covered less than $2 \%$ of drainage basin followed the inverse of summer air temperatures. However such glacier-fed rivers did follow year to year changes in precipitation. Runoff from the ice- 
free portion of the basin will also follow trends in precipitation, although less than the levels of precipitation (Collins, 2006). During a warming climate, glaciers mass balance will be negative. This will lead to an increase in meltwater draining from the basin, as more energy becomes available for melting (Jansson et al., 2003). This rise in runoff has been termed the 'deglaciation discharge dividend' (Collins, 2008, p. 119). This increase would not continue endlessly but would, however, be greater than the element of runoff generated by precipitation. As the glacier further shrinks less area will be available for melting. Therefore, this constituent of flow will begin to decline and eventually terminate once the glacier has fully retreated. Future runoff from these basins will then be led by levels of precipitation (Collins, 2008). Furthermore, Collins, (2008) demonstrates changing percentage glacierisation over many decades impacts discharge levels. Runoff from Swiss glaciers peaked during the first warming period of the previous century (1912-1950); despite the second warming period (1980-present) seeing higher summer air temperatures. Melting of the glaciers, therefore, could not offset the reduced glacier area and declining levels of precipitation.

Coupling future climate scenarios with long term data of discharge, precipitation and air temperature, future runoff has been modelled (Braun et al., 2000). Results indicate basins with high percentage glacierisation will see increased discharge levels, and it is suggested that long term summer runoff will decline. Braun et al., (2000) consider, that when the glaciers disappear, runoff regime will follow that of nival streams; with melting of the seasonal snow pack leading high spring discharges.

\subsection{Thermal characteristics of streams}

Factors impacting upon stream temperature are said to be spatially segregated into three scales. Those on the micro scale include riparian shading and geometry of the channel. Meso scale factors consist of hydrology within the basin, and localised climate (Kurylyk et al., 2015). Finally, macro scale 
influences covers altitude and latitude (Cadbury et al., 2008). Water temperature of an Alpine stream is determined by many factors (Figure 2.2), energy inputs due to solar radiation, the air and water temperature difference and changes in discharge. It also involves: streambed friction, vegetation shading, topography including altitude, bedrock and orientation of streams, other ground water sources and precipitation (Caissie, 2006; Chikita et al., 2010; $\mathrm{Gu}$ and $\mathrm{Li}, 2002$ ). These are often categorised into different groups including, topographic, atmospheric and hydrological (Caissie, 2006).

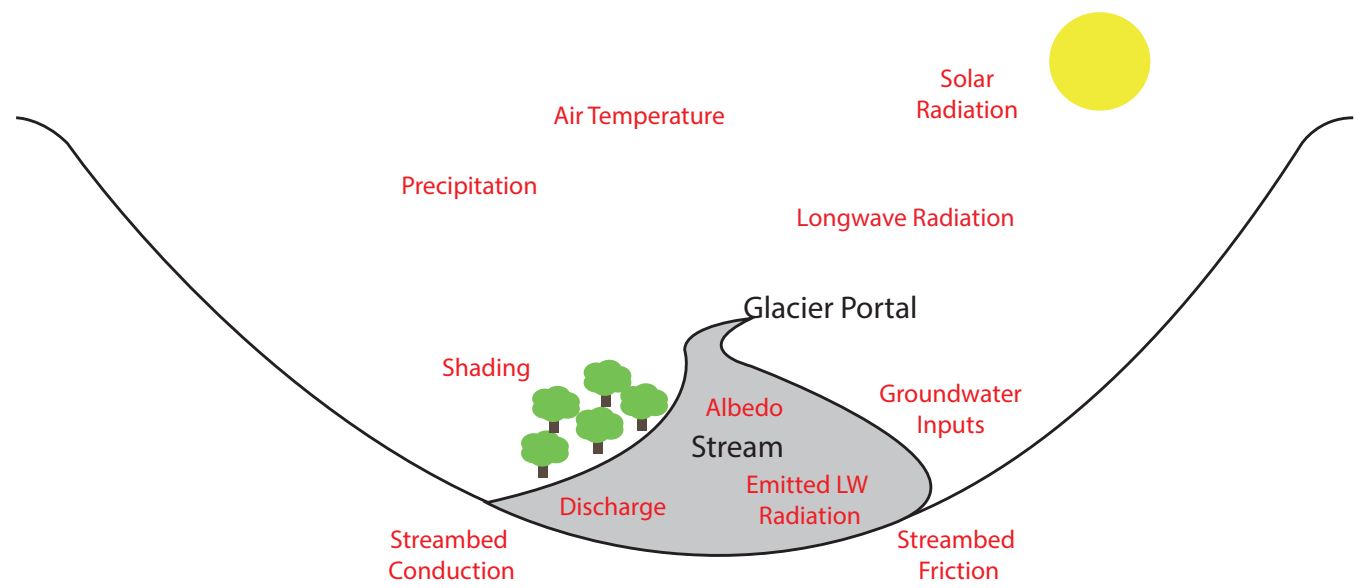

Figure 2.2: Diagram of factors impacting stream temperatures.

\subsubsection{Atmospheric}

It has been specifically indicated that atmospheric and climatic influences are the most important factors in determining the temperature of streams (Caissie, 2006). Much of the research in the field of water temperature investigates how as the climate warms, rising air temperatures will affect stream temperature. These studies are, however, in areas which are either little glacierised (Brown and Hannah, 2007; Brown et al., 2004; 2006b; Cadbury et al., 2008) or non-glacierised (Caissie et al., 2001; Gu et al., 1998; Webb et al., 2003; 2008; Webb and Zhang, 1999). Alpine stream temperatures are different from 
other streams as the majority are fed by glacial melt waters. Therefore, as the climate warms measured discharge in alpine streams will increase. As a result alpine streams are more responsive, with regard to changes in temperature (Chikita et al., 2010).

Research on rivers in the United Kingdom has analysed the air, water temperature relationship (Webb et al., 2003; 2008). Results reveal a strong relationship; indicating that warmer air temperatures lead to higher stream temperatures. Furthermore, studies in the French Pyrénées have found an increase in stream temperatures, as the climate warms (Brown and Hannah, 2007; Brown et al., 2004; 2006b). Research is undertaken at the TailionGabiétous basin, which is $5 \%$ glacierised from two cirque glaciers. The results here indicate that a warming climate increases the temperature of the water in the stream. Water temperature measurements taken in 2003, a warm year, are higher than those taken in cooler years. Water temperature is found to correlate positively with air temperature, in some instances recording a correlation coefficient of 0.70 (Brown et al., 2006b). Research findings indicate that discharge will increase as the climate warms, which will influence the thermal heterogeneity of the streams further. Water temperature has a positive correlation with air temperature (Brown et al., 2004; Caissie et al., 2001; Gu and Li, 2002; Gu et al., 1998; Hari et al., 2006), air temperature therefore is often used as a replacement for radiation and net heat exchange (Webb et al., 2008).

There are some studies which examine more highly glacierised basin streams (Chikita et al., 2010; Uehlinger et al., 2003) and find that water temperature in fact decreases with rising air temperatures (Cadbury et al., 2008; Uehlinger et $a l ., 2003)$. One alternative view is expressed by Chikita et al., (2010) who examine the temperature budget for a glacier-fed stream in Alaska. The Phelan Creek is fed, principally, by the Gulkana glacier, and the basin is $31.1 \mathrm{~km}^{2}$, with two glaciers; Gulkana Glacier $\left(19.8 \mathrm{~km}^{2}\right)$ and the Pegmatite Glacier (1.7 $\mathrm{km}^{2}$ ) (Chikita et al., 2010), making the basin $69 \%$ glacierised. Chikita et al. (2010) find that there are daily variations in water temperature between $0{ }^{\circ} \mathrm{C}$ and $3{ }^{\circ} \mathrm{C}$. This was in line with the diurnal changes in both radiation and air 
temperature. Water temperature is found to positively correlate with both air temperature $\left(r^{2}=0.76\right)$ and radiation $\left(r^{2}=0.59\right)$, implying that these factors are the most significant drivers of water temperature. Studies of streams in Antarctica have found significant relationships between radiation and stream temperature; radiation being responsible for $99 \%$ of warming (Webb et al., 2008). Webb et al., (2008) further suggest that the main determiners of heat inputs within river systems vary considerably, dependant on the location of streams in different climates.

It has been argued that at air temperature extremes, relationship between air and water temperature is less great (Webb et al., 2008). Air temperature is used in stream temperature research as it acts as a good replacement for the complete heat exchange (Webb et al., 2003). Furthermore, there has been evidence that variability of the North Atlantic Oscillation, a so called teleconnection where there are alterations in the atmospheric sea level pressure between subtropical and northern Atlantic (Hurrell, 1995), influences winter time water temperature in Austrian rivers (Webb and Nobilis, 2007).

Precipitation can affect water temperature in mountain streams (Brown and Hannah, 2007; Cadbury et al., 2008; Kobayashi et al., 1999). Brown and Hannah, (2007) highlight a negative relationship between precipitation time and water temperature change, despite no correlation between water temperature and rainfall intensity. Similarly, Kobayashi et al., (1999) found that measured water temperatures are cooler than that of the precipitation. Kobayashi et al., (1999) believe this is possibly due to the rain water forcing older cold water, stored in the ground, through the basin system, despite a reduction in air temperature during heavy rainfall events. Cadbury et al., (2008) researched a New Zealand glacier fed basin (Rob Roy Glacier) and recorded a rise in water temperature, as discharge began to increase. Cadbury et al., (2008) express how this contradicts studies of basins in the European Alps. The Rob Roy basin, is, however, much more glacierised (30\%) than the 5\% glacierised Tailion-Gabiétous basin (Brown and Hannah, 2007). Furthermore, during certain periods, Cadbury et al., (2008) find decreasing water temperatures during a heavy rainfall. The authors suggest this could be as a result 
of colder stored groundwater being forced through the basin system, therefore agreeing with the view of Kobayashi et al., (1999). Another possible reason behind these findings, could be increased snow and glacier melt, driven by warm rainfall.

\subsubsection{Topographic}

Alpine streams are dominated by steep gradients (Smith et al., 2001). Locational factors are known to hold significant control over solar radiation receipts above the stream; a major site factor is local topographic shading (Woltemade and Hawkins, 2016). As a parcel of water moves through the river system, it will be heated by the friction along the streambed. In an area with steeper gradients, the parcel of water will move more rapidly and friction will be greater which, in turn, will generate more heat.

Precipitation can also impact upon the temperature of water in Alpine streams, due to temperature differences between rainwater and meltwater, precipitation forcing cooler water through the glacier system (Kobayashi et al., 1999), as well as increasing rainfall adding to stream discharge (Cadbury et al., 2008). Finally, vegetation can hinder the amount of solar radiation which is available to warm glacial meltwaters, as it shades the stream; which could result in the rate of warming slowing or reduction in stream temperatures. Chikita et al., (2010) found that the main heat sources are sensible heat flux, shortwave radiation and friction with the streambed; in agreement with (Webb and Zhang, 1999) and Webb et al., (2008). Another control of water temperature is found to be vegetation in close proximity to streams (Brown and Hannah, 2007). Johnson, (2004) in trying to establish relationships between energy inputs and stream water temperature, shaded a $150 \mathrm{~m}$ reach of an Oregon stream with a dark plastic covering. That study revealed a decrease in water temperature maxima, as solar radiation decreased from 860 to $4 \mathrm{~W} \mathrm{~m}^{-2}$. Johnson, (2004) illustrated a net heat gain of $580 \mathrm{~W} \mathrm{~m}^{-2}$ without shading, compared to a loss of $149 \mathrm{~W} \mathrm{~m}^{-2}$ with shading (Johnson, 2004). Furthermore, cropping activities around stream courses have been proven to have an upward effect upon water 
temperatures (Caissie et al., 2001).

Natural energy sources are not the only heat contributor within a stream Many anthropogenic factors can have an effect on water temperature (Dickson et al., 2012; Meire et al., 2003) and its relationship to air temperature, such as waste water treatment plants (Webb et al., 2008).

\subsubsection{Hydrological}

Basin size, arbitrarily set by the location of a gauging station, has been found to affect the temperature regime of rivers (Brown et al., 2006a,b; Cadbury et al., 2008; Webb and Zhang, 1999); having a greater effect in glacial streams (Collins, 2009). As climate warms and glaciers retreat, the distance from the glacier tongue to the gauging station increases and in turn percentage glacierisation declines. This is thought to increase the sensitivity of glacierfed streams to changes in air temperature (Chikita et al., 2010).

Discharge is an important variable in water temperatures. With increasing discharge, the body of water within a stream reach will increase and more energy will be required to warm the stream. Furthermore, the water is moving faster as velocity increases - which, further offsets the increase in energy availability for warming (Collins, 2009). Water temperature was also correlated with a lagged discharge (3 hours); this returns an $r^{2}$ value of 0.115 . Chikita et al., (2010) explain that this is due to the runoff being derived from three different sources, one being rainfall. The $r^{2}$ was greatly improved when the 14 days which had the least rain and highest radiation were subset from the data.

Runoff in glacial basins is generated from a variety of water sources, including rainfall, ice and snow melt and groundwater. Every source has its own individual thermal trademark (Cadbury et al., 2008). Streams which are gauged further downstream, are greater influenced by these sources. Groundwater inputs and tributaries will have differing temperatures. 
The literature demonstrates that the main controls of water temperature are solar radiation (Chikita et al., 2010; Johnson, 2004; Webb et al., 2008), stream bed friction (Chikita et al., 2010; Webb and Zhang, 1999) and air temperature ( $\mathrm{Gu}$ and Li, 2002; Gu et al., 1998; Uehlinger et al., 2003). Lesser controls include shading (Johnson, 2004) and precipitation (Chikita et al., 2010)

The overwhelming opinion expressed in the literature is that the incoming shortwave radiation is the major contributor to thermal heating within streams. The importance of shortwave radiation is increasing, with respect to exposed, shallow upland streams (Webb et al., 2003; 2008). Shading from the local topographic and vegetation features are therefore significant controls over stream temperature (Johnson, 2004).

\subsection{Stream temperature modelling}

Stream temperature models can be categorised into two categories: Statistical and Deterministic (Benyahya et al., 2007; Caissie, 2006; Caissie et al., 2005). Being relatively simplistic, statistical models are used throughout the literature (Caissie et al., 2001). Deterministic models are more complex, often requiring more input variables. Dependant on the application both model variants have positives and negatives (Benyahya et al., 2007; Caissie, 2006). Caissie et al., (2001) suggest that deterministic models are useful at times where waters mix i.e. through different sources, and also when more input parameters are available. The opposite is true with statistical models, useful at times with fewer input variables.

\section{Statistical models}

Statistical or stochastic models utilise the relationship between water temperature and other variables to predict stream temperature. Such models will simulate temperature by use of regression type modelling, which will extrapolate the known relationship. Models of this nature are relatively 
simple to apply and data requirements are minimal. Benyahya et al., (2007) suggest stochastic models can be further grouped into parametric and nonparametric statistical models. Parametric stochastic models, utilise the correlation between water temperature and one or more independent variables (Mohseni and Stefan, 1999). The most commonly used variable is air temperature, as a result of them both being driven by the same factors, i.e. solar radiation, and thus are highly correlated (Caissie et al., 2001). Equation (2.1) specifies how these models can be expressed.

$$
T_{w}(t)=a_{0}+a_{1} T_{a}(t)+\varepsilon(t)
$$

$T_{w}(t)$ gives the water temperature in a given time period and $T_{a}(t)$ is the corresponding air temperature during that time. $\varepsilon(t)$ is an error term, with $a_{0}$ and $a_{1}$ being regression coefficients. This linear regression model has been used throughout literature, in studies ranging from assessing streams in the north English Pennines and Lake District (Crisp and Howson, 1982) to streams in the U.S. (Stefan and Preud'Homme, 1993). Crisp and Howson, (1982) successfully simulate water temperatures for eight streams in northern England. Two were located around $50 \mathrm{~km}$ away from the meteorological stations used. The research found that the air and water temperature relationship was linear, except at times where air temperatures dropped below $0{ }^{\circ} \mathrm{C}$. Only a small improvement when utilising discharge and rainfall was found with the use of multiple regression. Similarly, Stefan and Preud'Homme, (1993) used weather stations at long distances from the streams, ranging from 0 to 231 $\mathrm{km}$, and derived water temperature at daily and weekly resolutions. Standard deviation between modelled results and measured values were $2.7{ }^{\circ} \mathrm{C}$ at the daily scale and $2.1{ }^{\circ} \mathrm{C}$ at the weekly time scale. River parameters changed the standard deviation, with shallower streams reducing the deviation.

The linearity of the air and water temperature relationship is questionable (Benyahya et al., 2007). Beginning with Mohseni et al., (1998), a logistic S-shaped function was selected to derive the air to water temperature relationship. 


$$
T_{w}=\frac{\alpha}{1+e^{\Upsilon\left(\beta-T_{a}\right)}}
$$

In which $T_{w}$ is the water temperature and $T_{a}$ is the air temperature. $\alpha, \beta$, and $\Upsilon$ are three logistic coefficients. $\alpha$ being the maximum water temperature which can be predicted, $\beta$ is the air temperature at the inflection point of the curve and $\Upsilon$ is the steepest gradient at the inflection point. This function is frequently used in stream temperature research (Caissie et al., 2001; Johnson et al., 2014; Mohseni et al., 1998; Webb et al., 2003). Caissie et al., (2001) developed a regression model using this air and water temperature relationship. The model was applied to the Catamaran Brook, New Brunswick, Canada. The modelled results concurred with the measured results; differences between the two being less than $0.9{ }^{\circ} \mathrm{C}$. Webb et al., (2003) used this function for research into the River Exe, UK. The research found that although significant non-linearity between the two for hourly time scales, this was not replicated on daily or weekly time scales. Findings also indicated that the multiple regression demonstrated there to be a negative correlation between water temperature and discharge.

This section provided a brief overview of methods which have been utilised for simulating stream temperatures, assessing models which use both simple linear and multiple regression.

\section{Deterministic models}

Statistical models are said to be zero dimensional (Caissie, 2006), meaning they can only be applied to single sites. Deterministic stream temperature models make use of the mathematics and physics which underpin the process of heat exchange between the surrounding atmosphere and stream. These models will often use the energy budget of the stream to calculate the river temperature. Many input variables, such as solar radiation, stream hydrology data, topography and reach characteristics, are often needed for successful modelling (Benyahya et al., 2007). Therefore, when more controls are avail- 
able it is best to use deterministic models (Caissie et al., 2001). However, such models can be quite complex as they account for the complete heat exchange between the water and its surroundings (Caissie et al., 2005). Due to the number of possible parameters, deterministic models are often viewed as difficult to develop. This deters possible users, who will look to use simpler model techniques (Caissie et al., 2001; 2005). Deterministic models have a major advantage in that they can be applied across many sites and are, said to be one dimensional with temperatures modelled longitudinally downstream (Caissie, 2006).

\section{Lagrangian water temperature modelling}

The majority of deterministic stream temperature models used in the literature operate under Lagrangian theory. Essentially the Lagrange method tracks a parcel of water within the stream as it passes through the system. In this framework temperature can be expressed as a function of distance $(\mathrm{x})$. The majority of the research undertaken uses the energy conservation equation expressed as:

$$
\frac{\delta T_{w}}{\delta x}=\frac{W \Phi}{\rho C Q}
$$

Where $T_{w}$ is water temperature $\left({ }^{\circ} \mathrm{C}\right), x$ is distance $(\mathrm{m}), \rho$ equals $4.21 \times 10^{3}$ $\mathrm{J} \mathrm{kg}^{-1} \mathrm{~K}^{-1}$ (at $0{ }^{\circ} \mathrm{C}$ ) - water's specific heat capacity, and $Q$ is riverflow with $W$ representing the stream width $(\mathrm{m}), C$ is density of water expressed in $\mathrm{kg} \mathrm{m}^{-3}$. $\Phi$ is the complete heat input $\left(\mathrm{W} \mathrm{m}^{-2}\right)$.

Alternatively, information of the parcel of water (or fluid) can be viewed once observed, i.e. at a point in time which the parcel passes the observer. As such the equation can be expressed as a function of time (t) (Equation 2.4). This equation is said to be the appropriate method when uniformity of rivers longitudinal temperature change has been reached, and such changes are small when compared to sub-daily temporal variations (Caissie et al., 2007). 


$$
\frac{\delta T_{w}}{\delta t}=\frac{\Phi}{\rho C \bar{d}}
$$

In equation $2.4, T_{w}$ is water temperature $\left({ }^{\circ} \mathrm{C}\right), t$ is time (s), $\rho$ equals 4.21 $\times 10^{3} \mathrm{~J} \mathrm{~kg}^{-1} \mathrm{~K}^{-1}$ (at $0{ }^{\circ} \mathrm{C}$ ) - water's specific heat capacity, and $\bar{d}$ is equal to the mean water depth of the stream, measured in metres, $C$ is density of water expressed in $\mathrm{kg} \mathrm{m}^{-3}$. $\Phi$ is the complete heat input $\left(\mathrm{W} \mathrm{m}^{-2}\right)$ and can be determined by calculating the total heat flux, incoming and outgoing, in a given time period. The heat flux equation has is expressed as:

$$
\Phi=R+K-R_{e}-R_{c}
$$

Where $\mathrm{R}$ equates to the total incoming shortwave radiation $\left(\mathrm{W} \mathrm{m}^{-2}\right)$, this is the difference between the incoming solar radiation and the reflected solar radiation. Equation 2.6 is a frequently used calculation of the net solar radiation (Caissie et al., 2005; Chikita et al., 2010). $\mathrm{K}$ is the net longwave radiation $\left(\mathrm{W} \mathrm{m}^{-2}\right), R_{e}$ is the heat transfer due to evaporation and $R_{c}$ is heat loss through convection.

$$
R=(1-\alpha) R_{s}(1-S F)
$$

In which $\alpha$ is the albedo of the stream, $S F$ is the shading factor, accounting for the topography and riparian vegetation, and $R_{s}$ represents the incoming solar radiation $\left(\mathrm{W} \mathrm{m}^{-2}\right)$. Net longwave radiation is calculated using the StefanBolzman law, which provides the longwave radiation emitted from a black body object.

$$
K=\varepsilon_{w} \sigma\left(\varepsilon_{a}\left(T_{a}+273\right)^{4}-\left(T_{w}+273\right)^{4}\right)
$$

Where $\varepsilon_{w}$ and $\varepsilon_{a}$ are the emissivity of water and air respectively, $T_{a}$ and $T_{w}$ are the air and water temperature in ${ }^{\circ} \mathrm{C}$ and $\sigma$ is the Stefan Bolzman constant 
$\left(5.6703 \times 10^{-8} \mathrm{~W} \mathrm{~m}^{-2} K^{-4}\right)$. For equation (2.5), further calculations are used to give $R_{e}$ and $R_{c}$, using meteorological data, see Caissie et al., (2005). These equations highlight the complexity of deterministic models, illustrating the data necessities as well as the computational difficulties.

Deterministic stream temperature models have been used on numerous occasions (Chikita et al., 2010; Cho and Lee, 2011; Garner et al., 2014; MacDonald et al., 2014; Piccolroaz et al., 2013). The modelled results fit well to the measured data, especially in days with little rainfall, returning a coefficient of determination of 0.80 . Much of the research uses this heat flux equation, when determining a water temperature model ( $\mathrm{Gu}$ and $\mathrm{Li}, 2002$; $\mathrm{Gu}$ et al., 1998).

To simplify the process of modelling water temperature, it has been suggested that total heat input can be expressed as a function of the equilibrium temperature and a approximated or known stream temperature (Bustillo et al., 2014; Deas and Lowney, 2000; Herb and Stefan, 2011), i.e.

$$
\Phi=K\left(T_{e}-T\right)
$$

where $T_{e}$ is the equilibrium temperature of the stream, $T$ is water temperature and $K$ equates to the thermal exchange coefficient $\left(\mathrm{W} \mathrm{m}^{-2}{ }^{\circ} \mathrm{C}^{-1}\right)$. Deas and Lowney, (2000) state that this simplification is most usable for studies which require modelling of low resolution data i.e. months, as the equilibrium temperature method is most appropriate for unvarying conditions. Assuming temperature is mixed, both vertically and horizontally, the partial differential equation becomes:

$$
\frac{\delta T_{w}}{\delta t}=K\left(T_{e}-T\right)
$$

More recently there has been a movement for the development of simple deterministic models which are capable of modelling stream temperature accurately, but with the advantages, mainly the need for fewer input variables, 
of statistic models (e.g. Piccolroaz et al., 2013; Toffolon et al., 2014). This movement has developed out of the lack of hydro-meteorological data, which is one of the major drawbacks of deterministic modelling. Such simulations often use air temperature as an input variable, as it is capable of being used to parametrise most of the other meteorological variables needed in sophisticated deterministic models. Piccolroaz et al., (2013) developed the Air2Water model, which has been used to simplify the interactions between the air and epilimnion layer of a lake. The model uses either four or eight parameters which attempt to account for the entire heat exchange processes e.g. incoming shortwave radiation, latent and sensible heat fluxes. The model has been applied to lake Superior (Piccolroaz et al., 2013) and subsequently 14 lakes worldwide (Toffolon et al., 2014). On each occasion the model performs well when reproducing known datasets. Due to the high correlation between global measured radiation and net heat flux it may be possible to parametrise heat flux from global radiation (Iziomon et al., 2000).

\subsubsection{Previous water temperature modelling studies}

There have been many modelling techniques applied to both glacier-fed and non-glacier-fed rivers. The earliest attempt at modelling the heat budget and subsequently water temperature appears to have been conducted by Theurer et al., (1985). The most comprehensive instructions for techniques modelling the heat budget and water temperature of rivers has been developed and published as result of the SNTEMP model, the Stream Network Temperature Model (USGS) (Theurer et al., 1985). The USA Environment Protection Agency developed the Enhanced Stream Water Quality Model (QUAL2E) capable of modelling water quality of lakes and rivers for example sub-daily variations in water temperature and dissolved oxygen. The model is said to be complex and requires over 100 inputs (Birgand, n.d.), although not all are used to model the water temperature. A scaled down SNTEMP model, named SSTEMP (Bartholow, 2002) was developed to model reach-scale water temperature, as opposed to basin-scale. This program is modelling a single 
stream reach for one time period only for example one day or one month. It is a very simple model but not capable of modelling an entire data series. It requires meteorological and hydrological inputs with optional shading inputs. An overview of some of the major available water temperature models is given in Table 2.1.

Table 2.1: Summary of reach- and basin- scale water temperature models.

\begin{tabular}{|c|c|c|c|}
\hline Model & Inputs & Time step & Reference \\
\hline QUAL2E & $\begin{array}{l}\text { Entire heat } \\
\text { budget }\end{array}$ & Hourly & $\begin{array}{l}\text { Brown and } \\
\text { Barnwell, } \\
(1987)\end{array}$ \\
\hline SNTEMP & $\begin{array}{l}\text { Entire heat } \\
\text { budget }\end{array}$ & $\begin{array}{l}\text { Daily- } \\
\text { Monthly }\end{array}$ & $\begin{array}{l}\text { Theurer } \\
\text { et al., (1985) }\end{array}$ \\
\hline SSTEMP & $\begin{array}{l}\text { Entire heat } \\
\text { budget }\end{array}$ & $\begin{array}{l}\text { Daily-- } \\
\text { Monthly }\end{array}$ & $\begin{array}{l}\text { Bartholow, } \\
(2002)\end{array}$ \\
\hline HeatSource & $\begin{array}{l}\text { Entire heat } \\
\text { budget }\end{array}$ & Hourly & $\begin{array}{l}\text { Boyd and } \\
\text { Kasper, } \\
(2003)\end{array}$ \\
\hline Air2water & $\begin{array}{l}\text { Air } \\
\text { Temperature \& } \\
4-8 \text { parameters }\end{array}$ & $\begin{array}{l}\text { Monthly- } \\
\text { Annually }\end{array}$ & $\begin{array}{l}\text { Piccolroaz } \\
\text { et al., (2013) }\end{array}$ \\
\hline
\end{tabular}

The Alpine Stream Water Temperature Model created for the purpose of this research will utilise much fewer inputs than those models listed, whilst retaining its usefulness as a water temperature model. The temperature model will also be much simpler to use, with only a little knowledge of the underlying programming language necessary. Although some of the models listed in Table 2.1 are capable of simulating temperatures of rivers on the diurnal scale, many are not and those that are e.g. SSTEMP will only simulate models for a single time-step, not a dataset of continuous information, the model created for this research will only simulate temperatures on the hourly time-step. 


\subsection{Overview and research gaps}

An overview of studies of river temperature, modelling and heat fluxes between streams and their surroundings along with studies into the longitudinal changes downstream of rivers is provided in Table 2.2. 
Table 2.2: Overview of research into stream water temperature and the thermal budget of rivers, both glacier and non-glacier fed.

\begin{tabular}{|c|c|c|c|c|}
\hline Study author(s) & Basin type & Brief summary & Principal findings & Research period \\
\hline $\begin{array}{l}\text { Benyahya } \\
\text { et al., (2007) }\end{array}$ & - & $\begin{array}{l}\text { Review of statistical } \\
\text { water temperature } \\
\text { models. }\end{array}$ & $\begin{array}{l}\text { Reiterates the } \\
\text { simplicity of } \\
\text { statistical models over } \\
\text { deterministic models. }\end{array}$ & - \\
\hline $\begin{array}{l}\text { Cadbury et al., } \\
(2008)\end{array}$ & $\begin{array}{l}\text { A } 30 \% \text { glacierised } \\
\text { catchment in New } \\
\text { Zealand }\end{array}$ & $\begin{array}{l}\text { Examining the } \\
\text { thermal dynamics } \\
\text { with a glacier-fed } \\
\text { river in New Zealand. }\end{array}$ & $\begin{array}{l}\text { Water sources were } \\
\text { significant drivers of } \\
\text { downstream } \\
\text { temperatures. }\end{array}$ & $\begin{array}{l}11 \text { December } 2003-19 \\
\text { February } 2004 \& 1 \\
\text { December } 2004-28 \\
\text { February } 2005 .\end{array}$ \\
\hline $\begin{array}{l}\text { Chikita et al., } \\
(2010)\end{array}$ & $\begin{array}{l}\text { Proglacial stream } \\
\text { draining the Gulkana } \\
\text { Glacier, Alaska. }\end{array}$ & $\begin{array}{l}\text { Predicting the heat } \\
\text { budget of a glacier-fed } \\
\text { stream during the } \\
\text { summer of } 2006 \text {. }\end{array}$ & $\begin{array}{l}\text { Largest constituent of } \\
\text { heat input was bed } \\
\text { friction }(38.2 \%) \\
\text { followed by shortwave } \\
\text { radiation }(32.1 \%) \text {. }\end{array}$ & $\begin{array}{l}\text { June-September } \\
2006 .\end{array}$ \\
\hline
\end{tabular}


Table 2.2 - continued from previous page.

\begin{tabular}{lllll}
\hline Study author(s) & Basin type & Brief summary & Principal findings & Research period \\
\hline Fellman et al., & Basins ranging & Determining how air & Percentage & May-October 2011 \\
(2014) & between 0 and 63\% & temperature and & glacierisation is a & \\
& glacier covered, & basin characteristics & significant driver of \\
& Juneau, Alaska & influence seasonal & cooler stream \\
& patterns in stream & temperature, as is \\
& temperature & basin lake coverage. \\
& & Also mean weekly \\
& & stream temperature is \\
& & strongly correlated \\
& & with MWAT \\
& & temperatures \\
\hline
\end{tabular}

Continued on next page ... 
Table 2.2 - continued from previous page.

\begin{tabular}{|c|c|c|c|c|}
\hline Study author(s) & Basin type & Brief summary & Principal findings & Research period \\
\hline $\begin{array}{l}\text { Garner et al., } \\
(2014)\end{array}$ & $\begin{array}{l}\text { Upland basin in north } \\
\text { east Scotland, } \\
\text { mixture of open } \\
\text { moorland and } \\
\text { semi-natural forest } \\
\left(24 \mathrm{~km}^{2}\right) \text {. }\end{array}$ & $\begin{array}{l}\text { Analysing the energy } \\
\text { exchange process } \\
\text { which drive decreases } \\
\text { in stream } \\
\text { temperature } \\
\text { downstream under } \\
\text { riparian vegetation } \\
\text { down river of open } \\
\text { moorland. }\end{array}$ & $\begin{array}{l}\text { No cooling occurs as } \\
\text { a stream flows } \\
\text { downstream under } \\
\text { forested canopies, bu } \\
\text { heat budget is } \\
\text { reduced significantly }\end{array}$ & 1-7 July 2007 \\
\hline $\begin{array}{l}\text { Ouellet et al., } \\
(2014)\end{array}$ & $\begin{array}{l}\text { Artificial pool erected } \\
\text { close to Québec City, } \\
\text { Canada }\end{array}$ & $\begin{array}{l}\text { Assessment of the } \\
\text { heat budget } \\
\text { processes, highlight } \\
\text { the importance of } \\
\text { radiative fluxes }\end{array}$ & $\begin{array}{l}\text { Net radiation is the } \\
\text { most important } \\
\text { energy input }\end{array}$ & $\begin{array}{l}10 \text { September }-29 \\
\text { October } 2008\end{array}$ \\
\hline
\end{tabular}


Table 2.2 - continued from previous page.

\begin{tabular}{lllll}
\hline Study author(s) & Basin type & Brief summary & Principal findings & Research period \\
\hline $\begin{array}{l}\text { Leach and } \\
\text { Moore, (2014) }\end{array}$ & Malcolm Knapp & Assessment of winter & Advective fluxes is & October 2011 - May \\
& Research Forest, 60 & stream temperatures & principal control over & 2013 \\
& by east of Vancouver & by advective fluxes & temperatures & \\
MacDonald & Mountain streams, & Simulating stream & Meteorological, & January - December \\
et al., (2014) & Alberta, Canada & temperatures of & hydrological and & 2010 \\
& & ground water & basin properties & \\
& & dominated mountain & significantly effect & \\
& & temperature model & \\
\hline
\end{tabular}

Continued on next page ... 
Table 2.2 - continued from previous page.

\begin{tabular}{|c|c|c|c|c|}
\hline Study author(s) & Basin type & Brief summary & Principal findings & Research period \\
\hline $\begin{array}{l}\text { Segura et al., } \\
(2015)\end{array}$ & $\begin{array}{l}\text { Rivers across the } \\
\text { continental USA }\end{array}$ & $\begin{array}{l}\text { Modelling stream } \\
\text { water temperature } \\
\text { across the continental } \\
\text { USA and assessing } \\
\text { the landcover charac- } \\
\text { teristics/climatic } \\
\text { controls upon stream } \\
\text { temperature }\end{array}$ & $\begin{array}{l}\text { Drainage area exerts } \\
\text { significant control on } \\
\text { thermal sensitivity } \\
\text { with groundwater } \\
\text { contributions } \\
\text { negatively related to } \\
\text { mean stream } \\
\text { temperature. Steep } \\
\text { basins are cooler as a } \\
\text { result of reduced } \\
\text { residence times }\end{array}$ & - \\
\hline
\end{tabular}




\section{Part II}

\section{Water temperature variations}




\section{Chapter 3}

\section{Meltwater temperature in rivers draining from Alpine glaciers}

\subsection{Introduction}

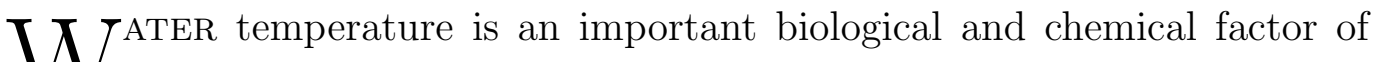

$\sqrt{\text { streams. As such, ecological impacts of temperature changes have }}$ been thoroughly studied (Brown et al., 2006b; Caissie et al., 2007; Webb et al., 2008). Furthermore, the study of thermal variability in river systems has received much attention recently (Cadbury et al., 2008; Chikita et al., 2010; Fellman et al., 2014; Hood and Berner, 2009; Kaushal et al., 2010). In spite of this, less focus has been placed on assessing thermal changes in streams draining large Alpine glacial basins; much of the research has investigated either small watersheds (Cadbury et al., 2008), or basins with low percentage glacierisation (Brown et al., 2006b).

Seasonal patterns in meteorological and hydrological conditions in the Swiss Alps are well understood. Rising radiation, from a minimum in December to a maximum in June, leads to more energy available for snow and ice melt. Enhanced melting leads to rapid, but delayed, increase in discharge for rivers which drain Alpine basins. Peak radiation occurs around the summer solstice, 
21 June. Highest discharge will lag behind as the surface albedo changes from high reflectivity in the spring to low reflectivity in the summer. Peak runoff time is dependent on percentage glacierisation of the basin. For ice free basins, maximum discharge occurs in May, predominately constituting melt from the winter snow pack. Peak runoff is delayed further, into July and August, with increasing percentage glacierisation. In snowmelt-fed streams, water temperature would be expected to follow seasonal patterns of radiation, as more energy becomes available for warming. The same could be expected for glacial streams. However, with increasing discharge the thermal capacity of water will change. More energy would be required, therefore, to warm the body of water within the reach. Consequently, it is reasonable to suggest that summer stream temperature will be suppressed by the increase in flow. Furthermore, the melt water leaving the glacier and entering the system will be at or around $0^{\circ} \mathrm{C}$, and this will also negatively impact upon the stream temperature.

High mountain environments often suffer a lack of water temperature data plus many other hydrometeorological data, close to glacier termini; even with respect to highly developed regions such as the Swiss Alps. In spite of this, discharge, air temperature, precipitation and solar radiation measurements have been recorded over a substantial time period in the Swiss Alps. Consequently, the lack of water temperature records illustrate the difficulties faced when assessing long term trends and highlights the lack of understanding surrounding water temperature of high mountain glacier-fed rivers.

This chapter outlines how data for this study has been collated (§3.2) followed by the initial investigatory analysis of how Alpine stream water temperature has responded to climatic change (§3.3). These results will be presented in the following way, first, assessment of the seasonal variations for: incoming solar radiation, discharge, water temperature and precipitation (§3.3.1). The next section will outline classification of seasonality in water temperatures of streams issuing from Alpine glaciers (§3.3.2). The subsequent section will investigate how patterns of seasonal water temperature records are reflected on an hourly timescale (§3.3.3). Finally there is a cursory analysis of the year 
to year trend in maximum 7 day average stream temperature (§3.3.4). The trends highlighted in the results will be critically analysed in (§3.4).

\subsection{Data acquisition}

The data used in this study was collated from numerous sources. The majority of hydrological data has been collected, at hourly resolution, from the Swiss Federal Office of the Environment (FOEN); who provide data free of charge for research purposes. Access to meteorological data has also been provided from the Swiss Federal Office of Meteorology and Climatology (MeteoSwiss), also at hourly resolution. Data from these sources are available for the period 2003-2014.

Further water temperature records have been acquired over a number of years through field visits to the Swiss Alps, led by Prof. David N. Collins at the Findelenbach and Gornera river. This data was collected using data-loggers inserted into the streams in the spring of each year, only available for periods in which the logger was running. One disadvantage to this set of data is that malfunctioning loggers and battery life, coupled with the frequency of field trip programmes led to patches within the data sets.

One significant issue that arose during the data collection process was the lack of shortwave radiation observations taken close to, or within, the individual study basins. For example, solar irradiance data, recorded in the Findelen basin, was available for only a limited number of seasons. It was decided that solar irradiance data measured at Zermatt, available for every season within the study period, would be appropriate to use for the purpose of this study, despite being a distance from some study catchments. Brief analysis of the data demonstrated Zermatt irradiance correlated well with more local solar radiation data, despite the distances involved.

A summary of the time series data available for this study is provided in Table 3.1. 
Table 3.1: Summary of the hydrometeorological data available for this study.

\begin{tabular}{|c|c|c|c|c|}
\hline & Station & Source & Temporal resolution & Record period \\
\hline \multirow{5}{*}{$\begin{array}{l}\text { Solar } \\
\text { radiation }\end{array}$} & Zermatt & MeteoSwiss & Hourly & 2003-2014 \\
\hline & Findelen & MeteoSwiss & Hourly & 2004-2008 \\
\hline & Massa & FOEN* & Hourly & 2003-2012 \\
\hline & & & Daily & 2013-2014 \\
\hline & Lonza & FOEN & Hourly & 2003-2012 \\
\hline \multirow{8}{*}{ Discharge } & & & Daily & 2013-2014 \\
\hline & Allenbach & FOEN & Hourly & 2003-2012 \\
\hline & & & Daily & 2013-2014 \\
\hline & Gornera & Grand Dixence S.A. & Hourly & 2003-2014 \\
\hline & Findelenbach & Grand Dixence S.A. & Hourly & $2003-2014$ \\
\hline & Massa & FOEN & Hourly & $2003-2012$ \\
\hline & & & Daily & $2013-2014$ \\
\hline & Lonza & FOEN & Hourly & 2003-2012 \\
\hline \multirow{6}{*}{$\begin{array}{l}\text { Water } \\
\text { temperature }\end{array}$} & & & Daily & $2013-2014$ \\
\hline & Allenbach & FOEN & Hourly & 2003-2012 \\
\hline & & & Daily & $2013-2014$ \\
\hline & Gornera & $\mathrm{APG}^{* *}$ & Hourly & $2004-2010$ \\
\hline & & & Half-hourly & 2008 \\
\hline & Findelenbach & $\mathrm{APG}$ & Hourly & 2006-2010 \\
\hline
\end{tabular}

${ }^{*}$ Federal Office of the Environment

**Alpine Glacier Project - University of Salford 


\subsection{Results}

The discharge, water temperature and incoming shortwave radiation data that were obtained for the present study are outlined in the following section. The data was analysed over the diurnal, seasonal as well as the annual timescale.

\subsubsection{Seasonal variations of stream temperature and hydrometeorological factors}

A key objective of this chapter was to assess and describe the seasonal variations of solar irradiance, basin hydrology and water temperature. The aim was to illustrate the paradoxical relationship between water temperature and energy input. A secondary aim was to assess how water temperature in glacierfed rivers may have changed over a long time period.

\section{Incoming solar irradiance}

Incoming shortwave radiation regimes exhibit the typical annual cycle that would be expected for a study site in the mid-latitude region. Incoming solar radiation peaks in late June, around the time of the summer solstice, with minima in late December in time with the winter solstice (Figure 3.3). Comparison with long-term summer (May-September) air temperature records at Sion, Switzerland (Figure 3.1 \& Figure 3.2) shows the study region experienced warm summers in the years $2003\left(19.9^{\circ} \mathrm{C}\right), 2009\left(18.7^{\circ} \mathrm{C}\right)$, $2012\left(18.7^{\circ} \mathrm{C}\right)$ and $2015\left(19.2^{\circ} \mathrm{C}\right)$. These years tend to have higher average shortwave radiation, despite maxima not necessarily being greatest during the warmer years (Table 3.2). 


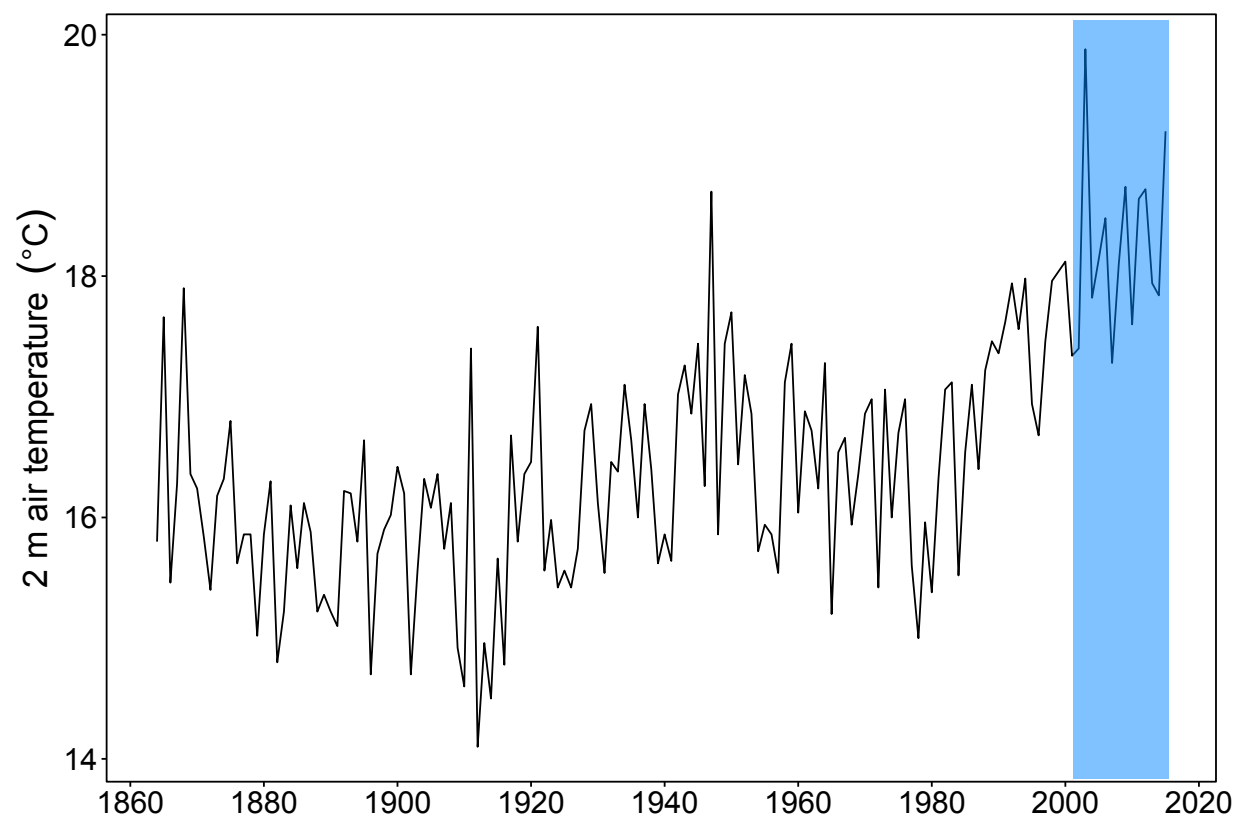

Figure 3.1: Year-to-year variation of mean summer $2 \mathrm{~m}$ (a.g.l) air temperature $\left(T_{5-9}\right)$ at Sion, Switzerland for the period 1864-2015.

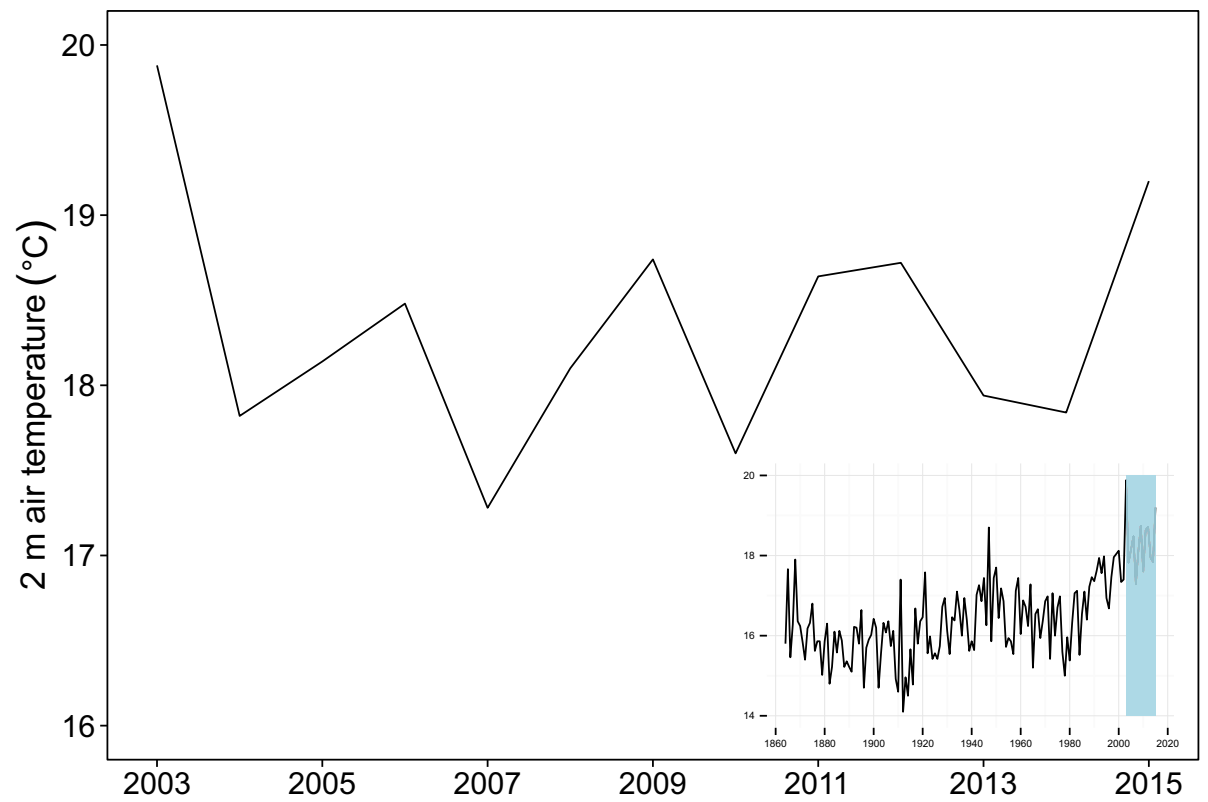

Figure 3.2: Year-to-year variation of mean summer $2 \mathrm{~m}$ (a.g.l) air temperature $\left(T_{5-9}\right)$ at Sion, Switzerland for the period 2003-2015. 
Table 3.2: Descriptive statistics of radiation $\left(\mathrm{W} \mathrm{m}^{-2}\right)$ measured at Zermatt.

\begin{tabular}{rccrc}
\hline & Mean & Std. Dev. & Min & Max \\
\hline 2003 & 96.66 & 46.83 & 3.66 & 172.71 \\
2004 & 92.00 & 44.83 & 12.54 & 176.64 \\
2005 & 93.86 & 44.27 & 3.93 & 176.22 \\
2006 & 93.67 & 45.94 & 5.58 & 182.53 \\
2007 & 94.43 & 45.66 & 5.97 & 171.58 \\
2008 & 93.21 & 45.41 & 8.35 & 177.41 \\
2009 & 97.70 & 48.55 & 2.97 & 182.01 \\
2010 & 95.23 & 48.09 & 6.16 & 174.39 \\
2011 & 96.26 & 49.37 & 1.05 & 180.30 \\
2012 & 98.12 & 49.08 & 12.18 & 173.79 \\
2013 & 97.24 & 47.71 & 6.06 & 192.80 \\
2014 & 94.90 & 46.94 & 5.98 & 176.85 \\
& & & & \\
\hline
\end{tabular}

\section{Basin hydrology}

Both Massa (Figure 3.3) and Lonza (Figure 3.4) basins demonstrate runoff regimes typical of an Alpine glacial catchments. Runoff levels in the winter months (October through April) account for less than 10\% of annual runoff (Collins, 1987). Discharge slowly rises through late April and early May, from minimum flows, as a result of increasing energy becoming available for melting of snow and ice. Melting of the winter snowpack (rise of the transient snowline) throughout the summer leads to decreasing surface albedo, ice being less reflective than snow. Increasing melt is produced throughout June and July despite falling energy inputs, as total ice-melt depends on both the rate of melt and the area of ice exposed, despite melt per unit area of ice following radiation. Runoff peaks in July or August, after the maximum of solar radiation levels in late June.

The ice-free Allenbach basin is indicative of a typical snowmelt dominated (Nival) basin (Figure 3.5). Discharge rises rapidly throughout April and consistently peaks during May. Runoff levels of the Allenbach rapidly decline through June and July, as the winter snowpack is exhausted, to lower levels 
where runoff solely reflects precipitation, less evaporation. This can be seen during late summer where discharge frequently rises, seemingly as a result of storm events bringing high levels of precipitation. For example, this was evident in late August 2005 (Figure 3.5c).

Descriptive statistics for discharge of the Massa (Table 3.3), Lonza (Table 3.4), and Allenbach (Table 3.5) have been assessed. Standard deviation (and coefficient of variation) decreases with falling levels of catchment percentage glaciation, for the three catchments in question. Maximum standard deviations, for example, occurred in riverflows of the most highly glacierised Massa, during the year with the warmest summer air temperature, $2003\left(16.7 \times 10^{6} \mathrm{~m}^{3}\right)$, although the high average riverflows results in coefficient of variation being lower than other years. This was reduced substantially, even for riverflows draining the somewhat (around $50 \%$ lower) glacierised Lonza catchment $\left(3.69 \times 10^{6} \mathrm{~m}^{3}\right)$, and is negligible in the ice-free Allenbach $\left(0.44 \times 10^{6} \mathrm{~m}^{3}\right)$. Additionally, coefficient of variation in riverflows of the Allenbach are greater during years with higher levels of precipitation and lower summer air temperatures. High spring air temperatures combined with substantial levels of winter precipitation, in the preceding year, will influence the total, average and thus standard deviation in riverflows. Therefore, coefficient of variation in riverflows of the Allenbach, are influenced as a result of higher spring melt production. 


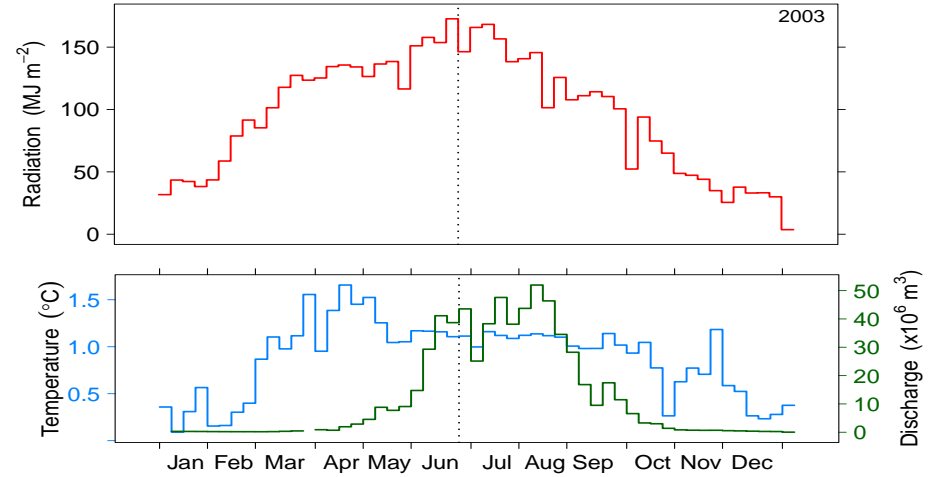

(a)
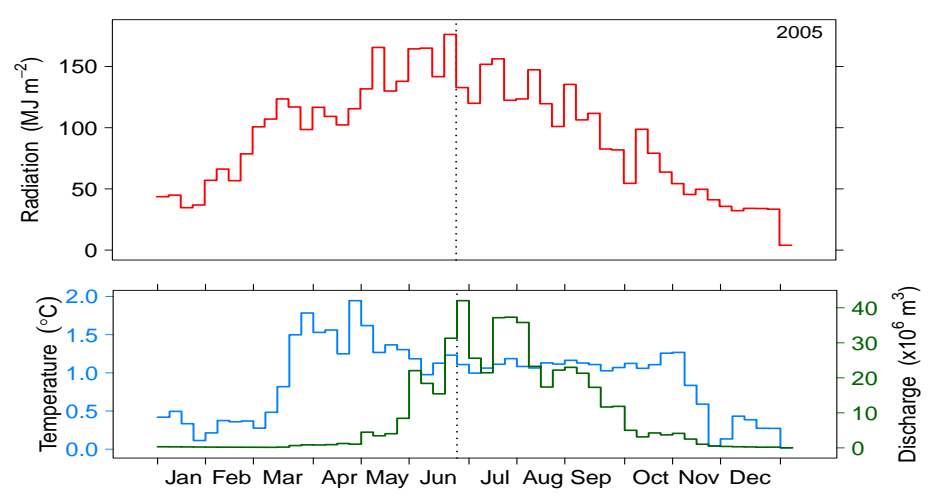

(c)
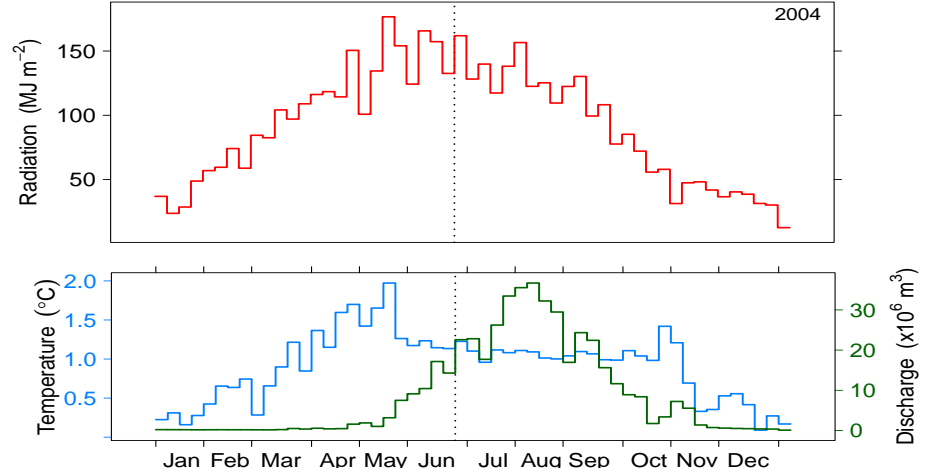

(b)
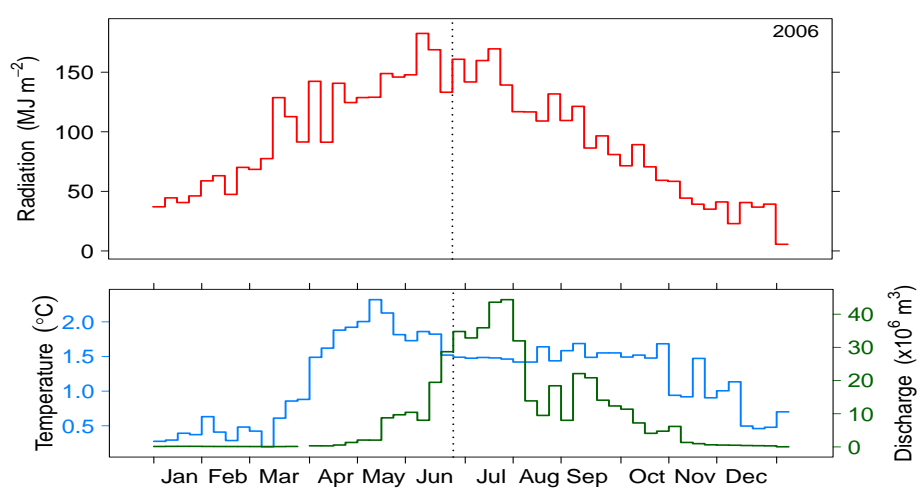

(d)

Figure 3.3: Seasonal variations of 7-day average water temperature (blue) and total discharge (green) of the Massa, together with 7-day total radiation (red) at Zermatt. For the years: (a) 2003 - (l) 2014, dotted line indicates week of summer solstice. (Continued ...) 

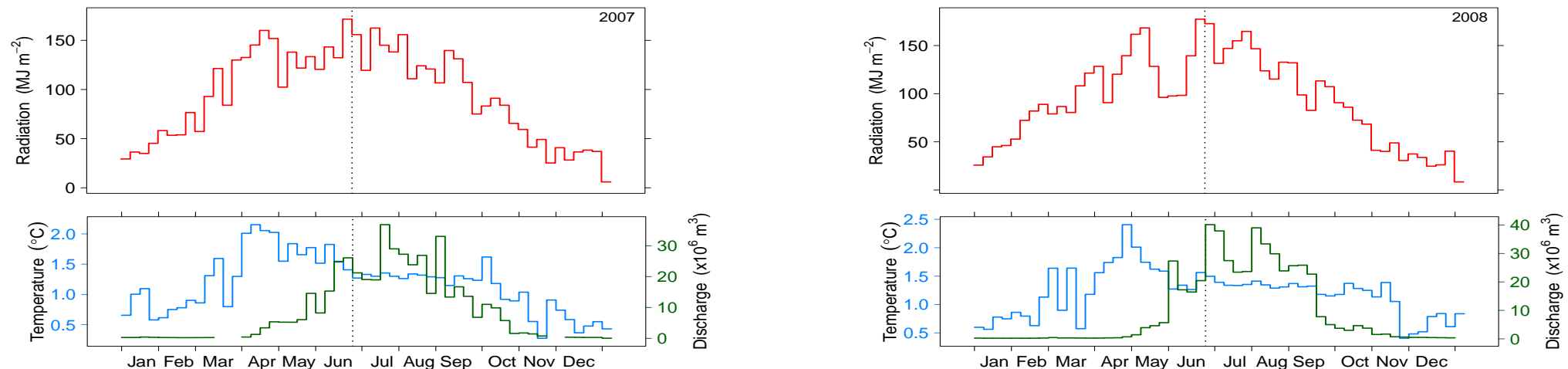

(e)
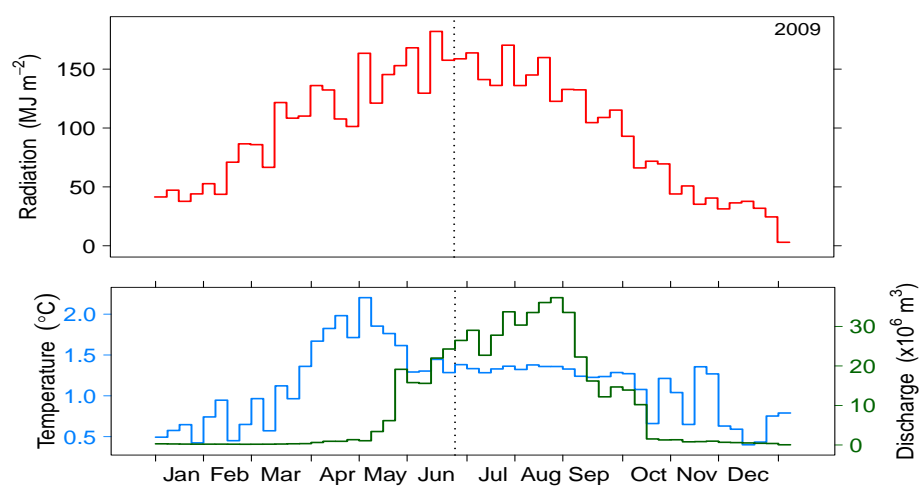

(g)

(f)
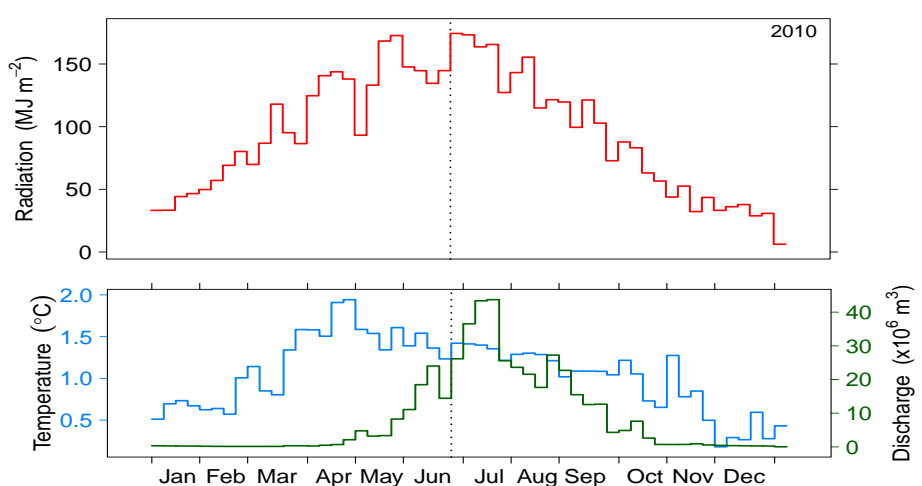

(h)

Figure 3.3: Seasonal variations of 7-day average water temperature (blue) and total discharge (green) of the Massa, together with 7-day total radiation (red) at Zermatt. For the years: (a) 2003 - (l) 2014, dotted line indicates week of summer solstice. (Continued ...) 

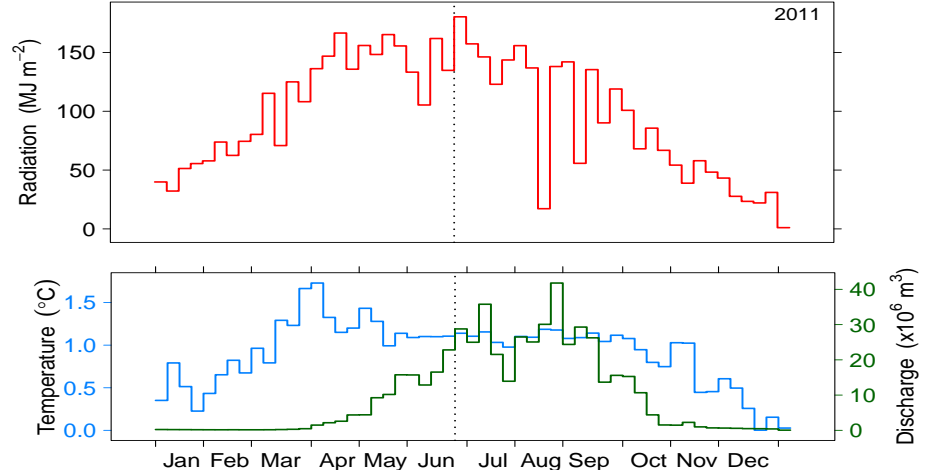

(i)
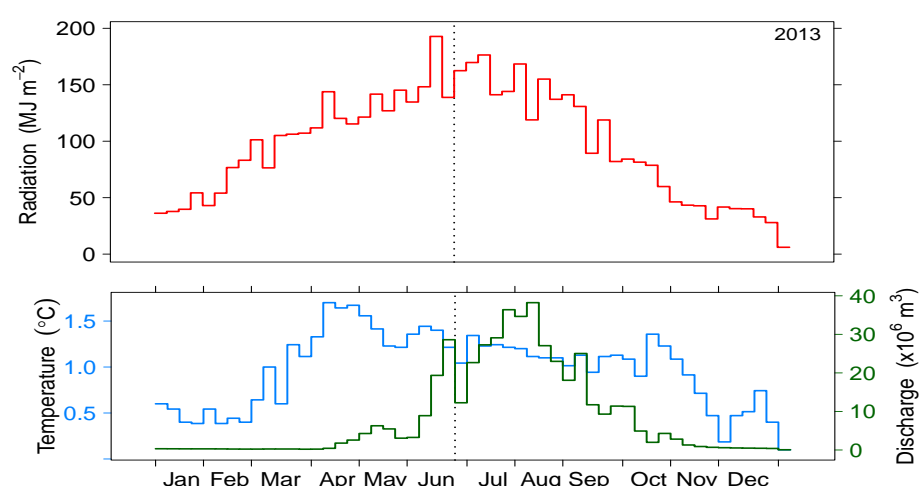

$(\mathrm{k})$
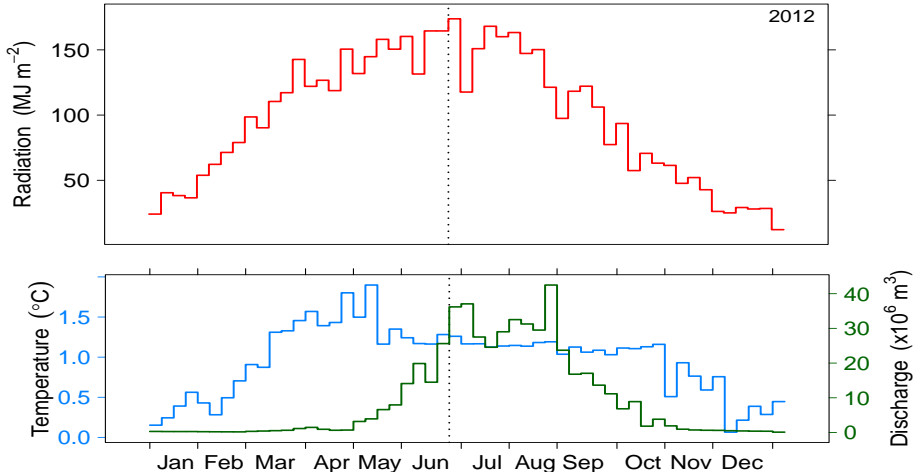

$(\mathbf{j})$
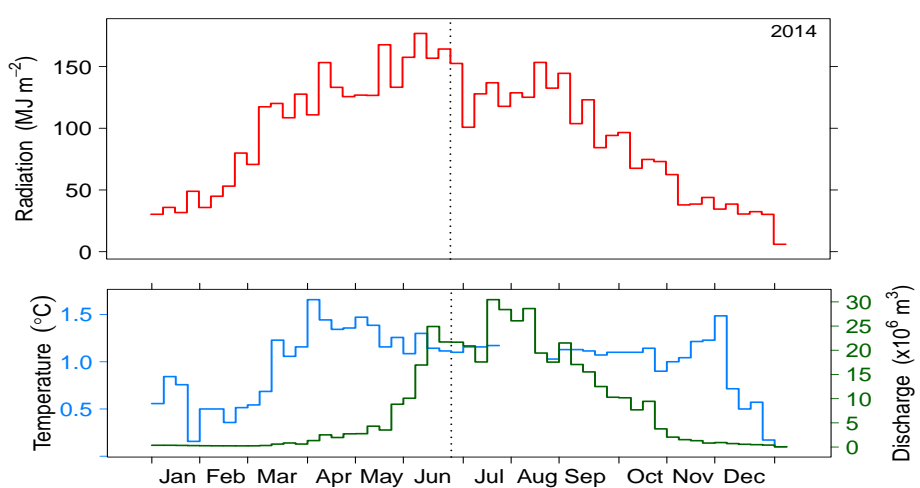

(1)

Figure 3.3: Seasonal variations of 7-day average water temperature (blue) and total discharge (green) of the Massa, together with 7-day total radiation (red) at Zermatt. For the years: (a) 2003 - (l) 2014, dotted line indicates week of summer solstice. (Concluded.) 
Table 3.3: Descriptive statistics of discharge $\left(10^{6} \mathrm{~m}^{3}\right)$ of the Massa measured at the Blatten-bei-Naters gauging station, for the calendar year.

\begin{tabular}{rrcccc}
\hline & Mean & Std. Dev. & CV & Min & Max \\
\hline 2003 & 12.46 & 16.70 & 1.34 & 0.03 & 51.97 \\
2004 & 8.65 & 11.17 & 1.30 & 0.10 & 36.68 \\
2005 & 9.22 & 12.08 & 1.31 & 0.03 & 42.04 \\
2006 & 9.13 & 12.46 & 1.36 & 0.04 & 44.39 \\
2007 & 9.45 & 10.64 & 1.13 & 0.04 & 36.83 \\
2008 & 9.42 & 12.68 & 1.34 & 0.21 & 40.11 \\
2009 & 9.88 & 12.46 & 1.26 & 0.05 & 37.28 \\
2010 & 8.45 & 11.86 & 1.40 & 0.04 & 43.71 \\
2011 & 9.78 & 11.56 & 1.18 & 0.06 & 41.79 \\
2012 & 9.52 & 12.39 & 1.30 & 0.09 & 42.49 \\
2013 & 8.39 & 11.32 & 1.35 & 0.05 & 38.22 \\
2014 & 8.19 & 9.54 & 1.16 & 0.06 & 30.46 \\
& & & & & \\
\hline
\end{tabular}

Table 3.4: Descriptive statistics of discharge $\left(10^{6} \mathrm{~m}^{3}\right)$ of the Lonza measured at the Blatten gauging station, for the calendar year.

\begin{tabular}{rrcccr}
\hline & Mean & Std. Dev. & CV & Min & Max \\
\hline 2003 & 3.30 & 3.69 & 1.12 & 0.34 & 11.91 \\
2004 & 2.66 & 2.80 & 1.05 & 0.12 & 9.44 \\
2005 & 2.49 & 2.70 & 1.08 & 0.05 & 9.75 \\
2006 & 2.79 & 3.19 & 1.14 & 0.05 & 11.28 \\
2007 & 2.96 & 3.01 & 1.02 & 0.05 & 10.73 \\
2008 & 2.95 & 3.29 & 1.12 & 0.30 & 11.49 \\
2009 & 2.91 & 3.02 & 1.04 & 0.06 & 8.48 \\
2010 & 2.51 & 2.90 & 1.16 & 0.05 & 9.99 \\
2011 & 2.66 & 2.62 & 0.98 & 0.07 & 9.48 \\
2012 & 3.03 & 3.28 & 1.08 & 0.12 & 11.57 \\
2013 & 2.73 & 3.13 & 1.15 & 0.06 & 12.16 \\
2014 & 2.30 & 2.26 & 0.98 & 0.06 & 8.68 \\
& & & & & \\
\hline
\end{tabular}


Table 3.5: Descriptive statistics of discharge $\left(10^{6} \mathrm{~m}^{3}\right)$ of the Allenbach measured at the Adelboden gauging station, for the calendar year.

\begin{tabular}{cccccc}
\hline & Mean & Std. Dev. & CV & Min & Max \\
\hline 2003 & 0.55 & 0.44 & 0.80 & 0.04 & 2.37 \\
2004 & 0.70 & 0.73 & 0.83 & 0.03 & 3.32 \\
2005 & 0.57 & 0.62 & 1.08 & 0.06 & 2.91 \\
2006 & 0.75 & 0.86 & 1.15 & 0.03 & 3.81 \\
2007 & 0.76 & 0.56 & 0.74 & 0.05 & 2.45 \\
2008 & 0.93 & 0.61 & 0.66 & 0.47 & 3.01 \\
2009 & 0.66 & 0.50 & 0.76 & 0.07 & 2.04 \\
2010 & 0.67 & 0.45 & 0.67 & 0.05 & 2.19 \\
2011 & 0.59 & 0.43 & 0.73 & 0.07 & 2.78 \\
2012 & 0.76 & 0.57 & 0.75 & 0.14 & 2.60 \\
2013 & 0.90 & 0.74 & 0.82 & 0.06 & 2.86 \\
2014 & 0.72 & 0.47 & 0.65 & 0.03 & 2.02 \\
& & & & & \\
\hline
\end{tabular}



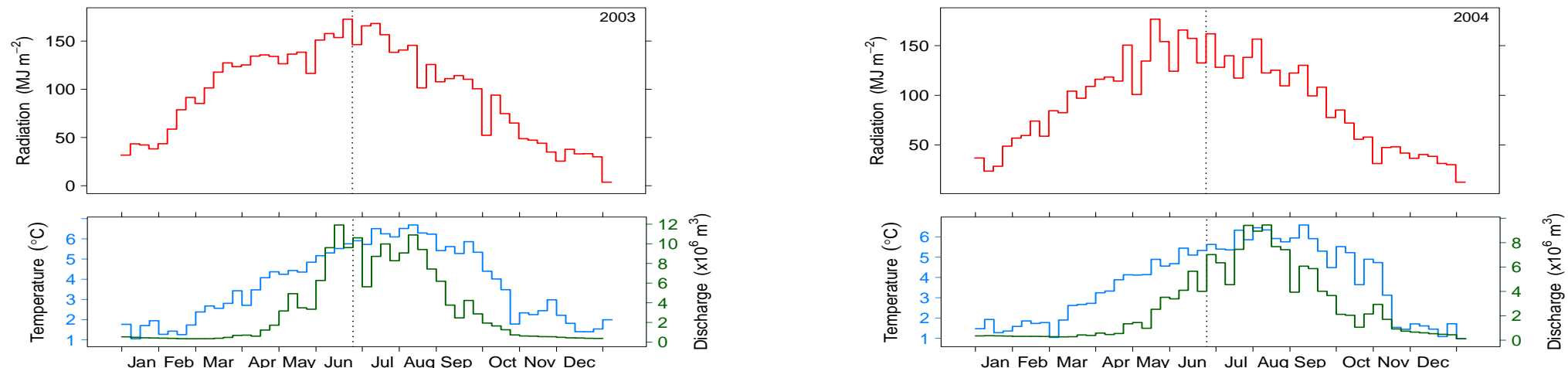

(a)

(b)
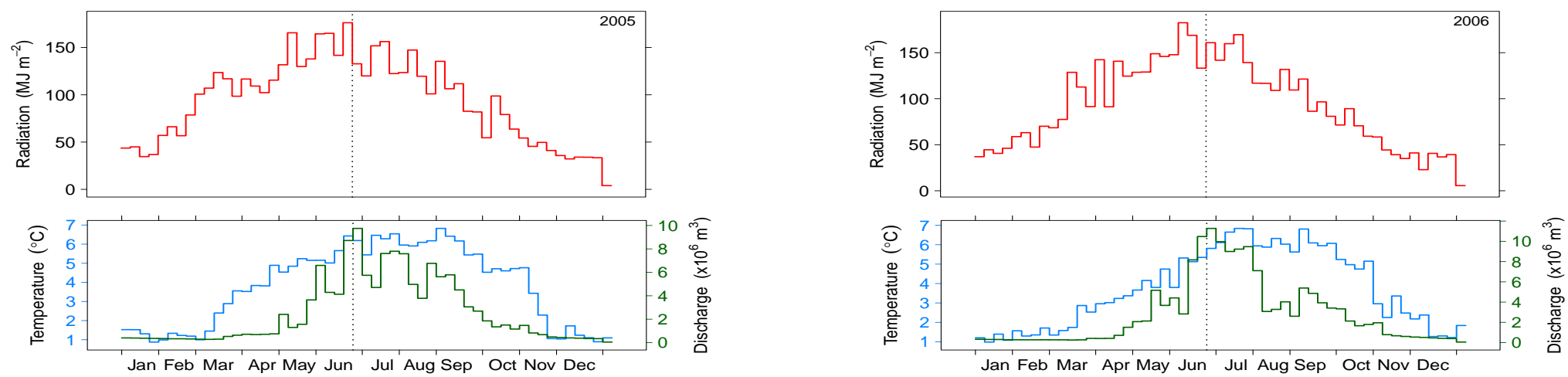

(c)

(d)

Figure 3.4: Seasonal variations of 7-day average water temperature (blue) and total discharge (green) of the Lonza, together with 7-day total radiation (red) at Zermatt. For the years: (a) 2003 - (l) 2014, dotted line indicates week of summer solstice. (Continued ...) 


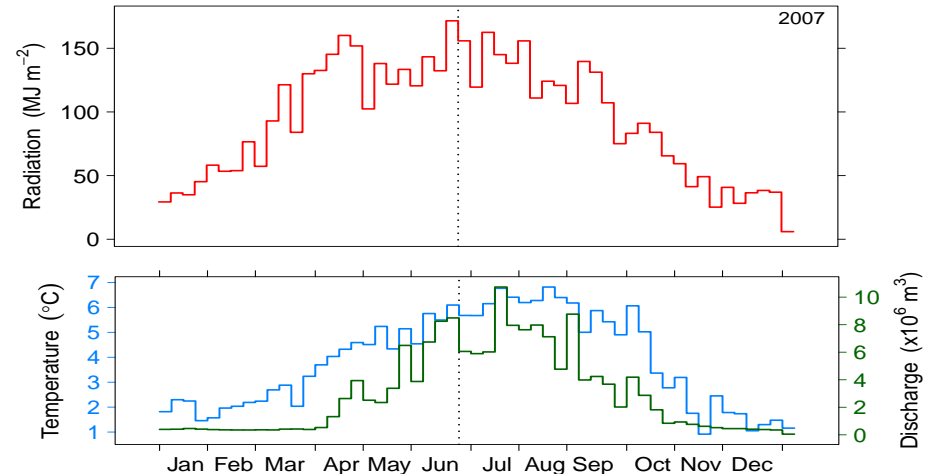

(e)
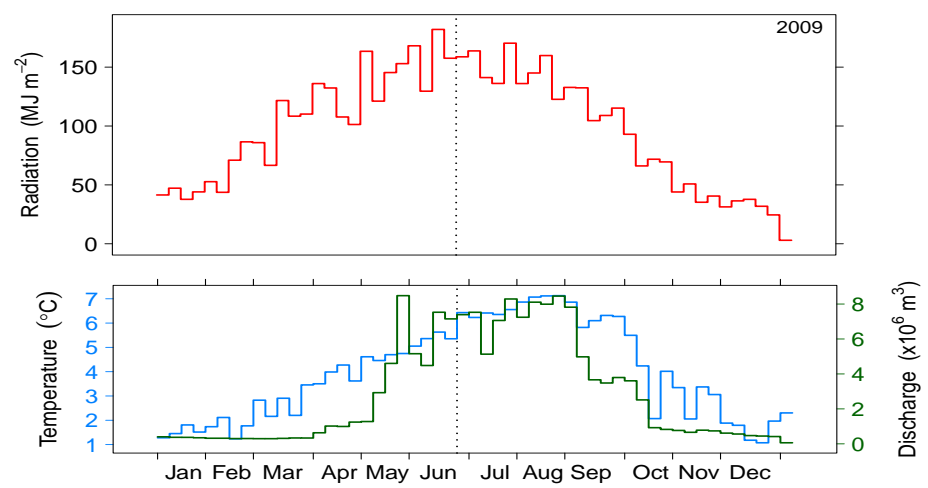

(g)
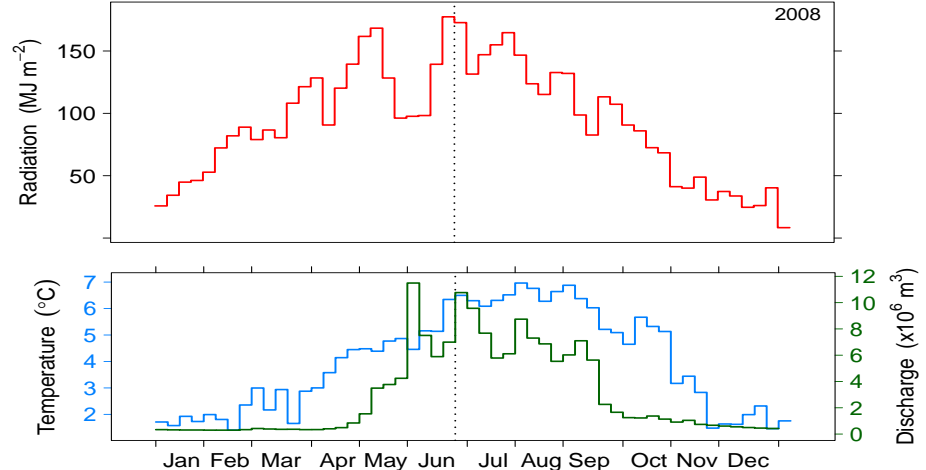

(f)
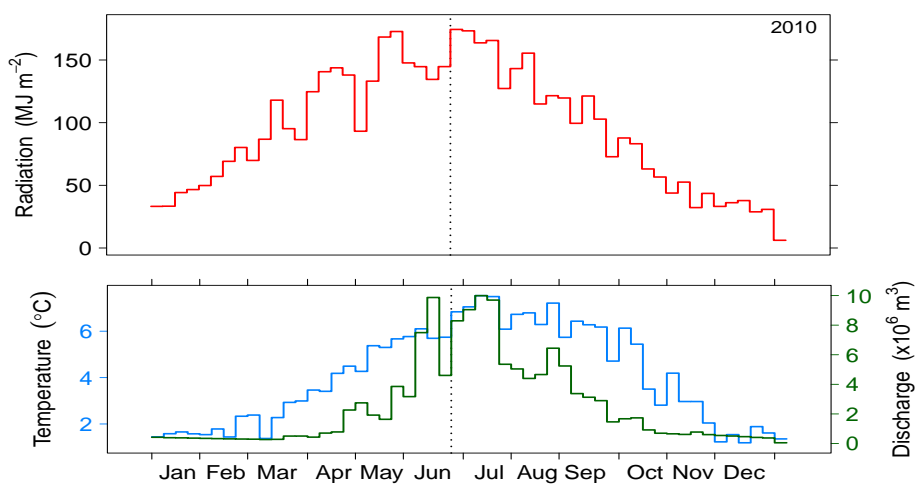

(h)

Figure 3.4: Seasonal variations of 7-day average water temperature (blue) and total discharge (green) of the Lonza, 

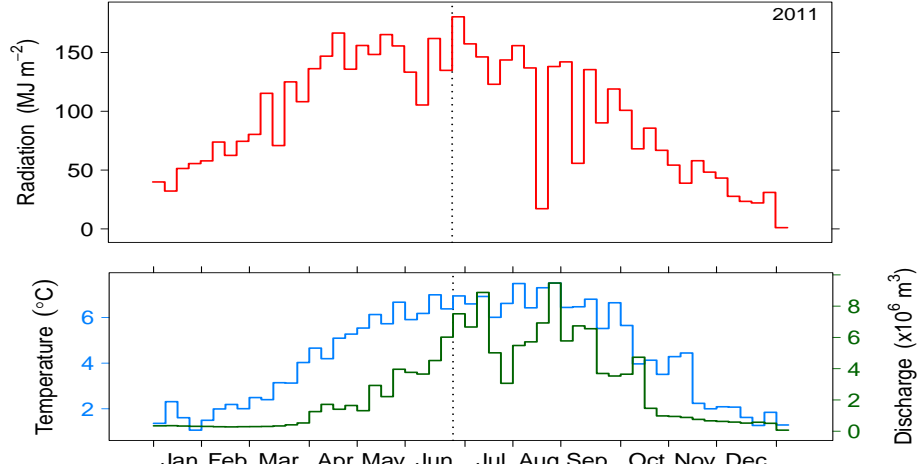

(i)
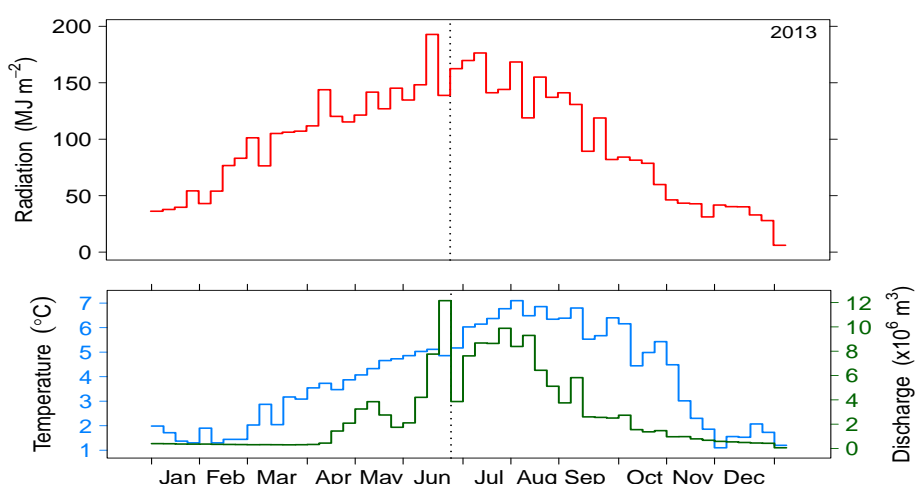

$(\mathrm{k})$
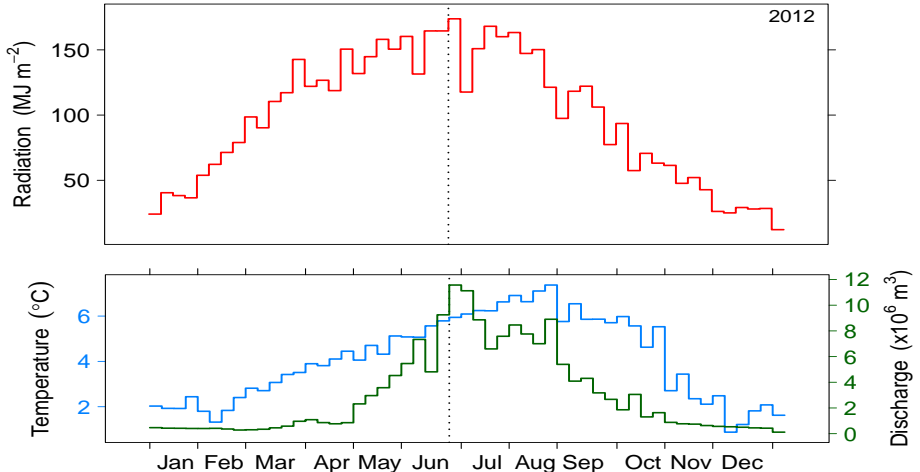

$(\mathbf{j})$
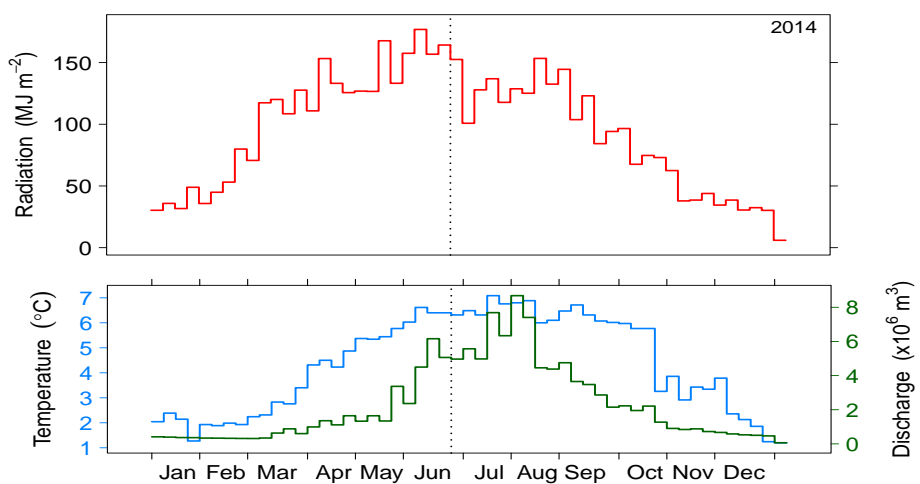

(1)

Figure 3.4: Seasonal variations of 7-day average water temperature (blue) and total discharge (green) of the Lonza, together with 7-day total radiation (red) at Zermatt. For the years: (a) 2003 - (l) 2014, dotted line indicates week of summer solstice. (Concluded.) 


\section{Water temperature}

Water temperatures in the Allenbach (Figure 3.5) typically reflect those of nival basins. In such basins, stream temperature increases in-line with incoming solar radiation between the months January and June. Temperature is suppressed slightly during May and June, dependant on the time of maximum discharge. Temperatures rise after the spring meltwaters have subsided due to the depletion of the winter snowpack and with runoff beginning to follow levels of precipitation. Water temperature continues to rise, consistently peaking around six weeks after maximum solar radiation. Temperatures of the Allenbach begin to decline in July and August, by which point solar radiation is substantially lower. The falling limb of the thermal regime in such basins follows the decline in solar radiation well.

The Lonza basin (Figure 3.4) shows similar seasonality of thermal regime to the Allenbach, despite being $36.5 \%$ glacierised. In spite of discharge being typical of a glacier-fed stream, volume of water flowing through the basin is relatively low, when compared to watersheds with greater ice cover. Temperatures, therefore, follow patterns similar to ice-free catchments. One succinct difference between basins with no ice cover and those with higher glacier cover, is the much lower maxima which temperatures will rise to. As with the icefree Allenbach, temperatures of the Lonza decline in line with falling levels of solar radiation.

Basins with greater than $50 \%$ glacier cover, such as the Massa (Figure 3.3) demonstrate a distinctive seasonal thermal regime. Patterns in water temperature of meltwaters draining highly glacierised catchments initially rise in-line with incoming solar radiation. However, such temperature regime is unusual in that it peaks during the early spring (April or May). This spring maxima occurs before the peak of solar radiation and is much lower than the levels attained in the same period in the Lonza and Allenbach. Between the months of May and October, meltwater temperatures decline with little variability and remain low throughout this period. After the summer, temperatures increase slightly before entering the falling limb and declining in line with decreasing 
levels of solar radiation.

Descriptive statistics for water temperature observations of the Massa (Table 3.6), Lonza (3.7), and Allenbach(3.8) were analysed. With respect to falling percentage basin glacierisation, average temperatures are substantially increased. For example, in 2014 average water temperature in the Massa (65.9\% glacier cover) was $0.98^{\circ} \mathrm{C}$, whereas temperatures in the Lonza $(36.5 \%$ glacier cover) were $346 \%$ higher $\left(4.37^{\circ} \mathrm{C}\right)$. Average temperature in the river draining the ice-free Allenbach basin, were only slightly greater than the Lonza, $5.67{ }^{\circ} \mathrm{C}$, this is likely resulting from the lower minimum values counteracting the higher maxima which are observed in the Allenbach. This further highlights the substantial effect that the reduction in summer water temperature has on the annual average water temperature. Furthermore, it shows the substantial difference between patterns in glacierised catchment river characteristics. 


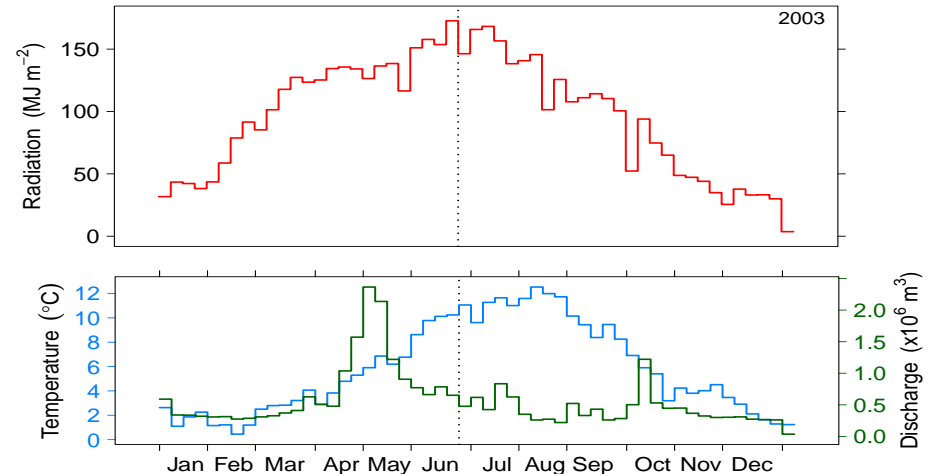

(a)
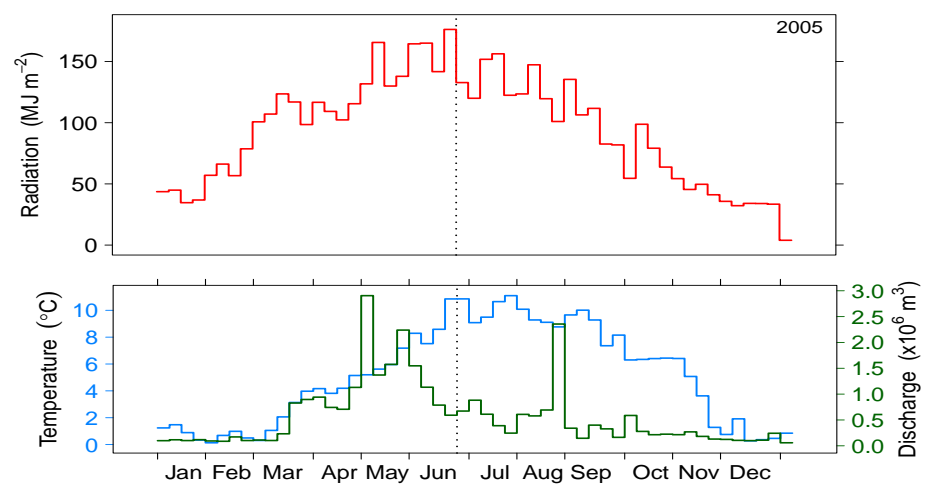

(c)
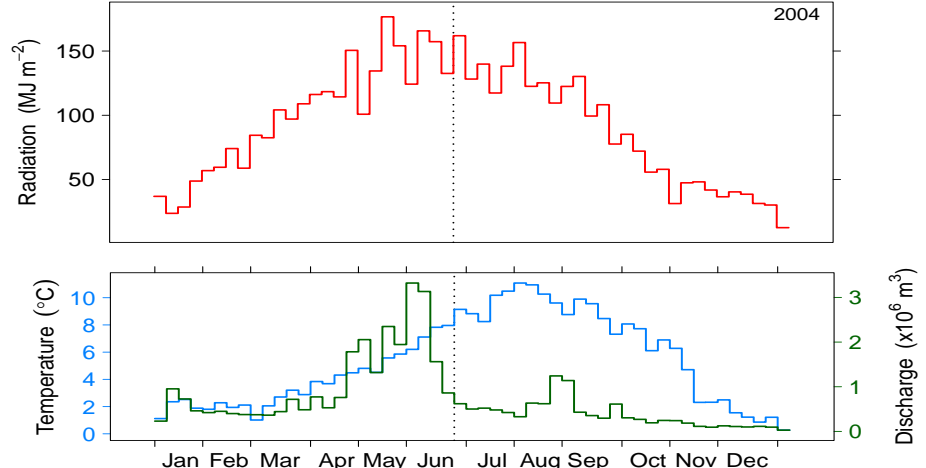

(b)
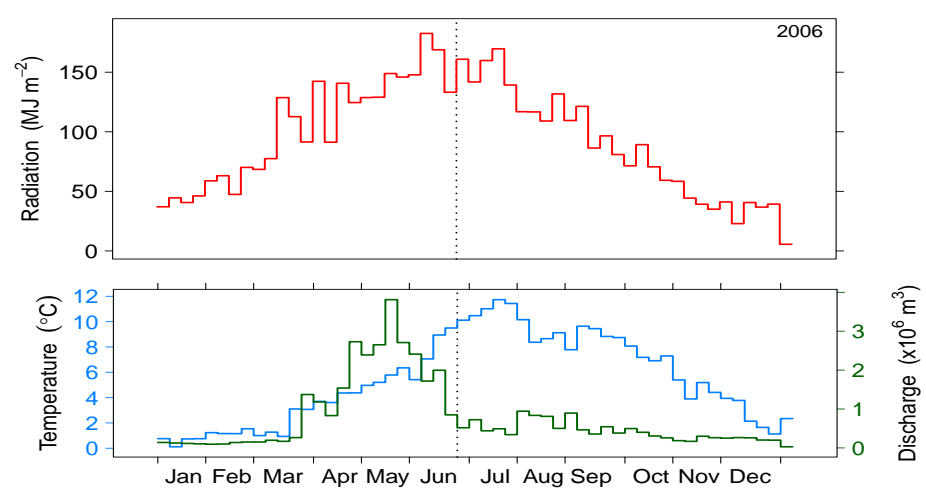

(d)

Figure 3.5: Seasonal variations of 7-day average water temperature (blue) and total discharge (green) of the

Allenbach, together with 7-day total radiation (red) at Zermatt. For the years: (a) 2003 - (l) 2014, dotted line indicates week of summer solstice. (Continued ...) 

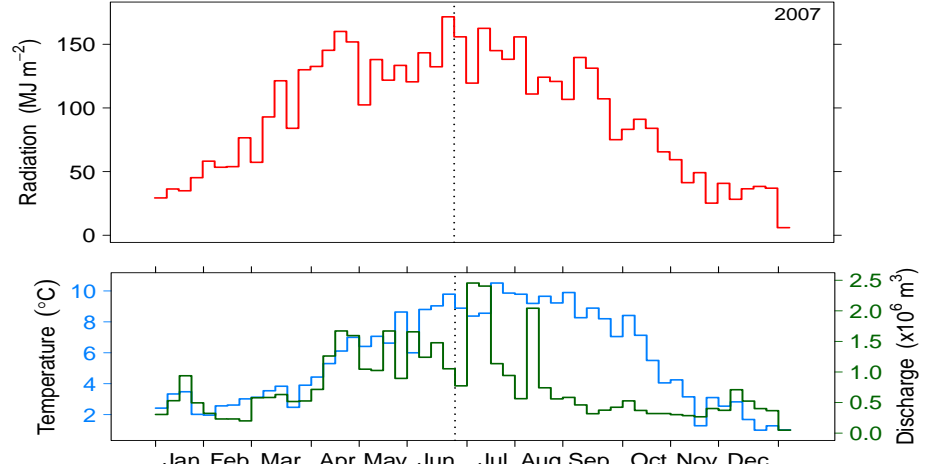

(e)
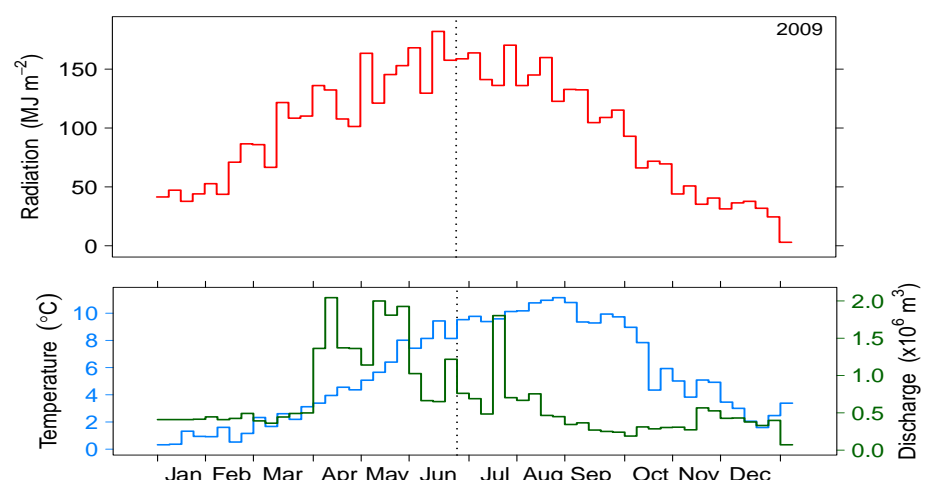

(g)
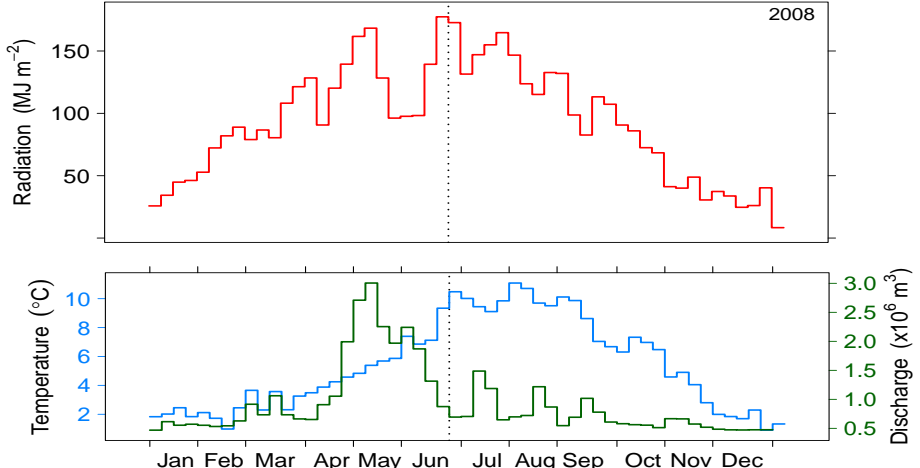

(f)
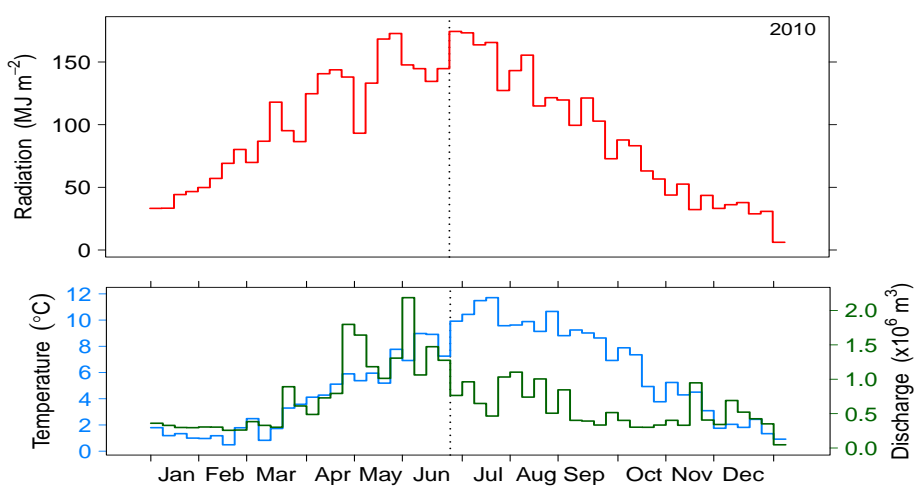

(h)

Figure 3.5: Seasonal variations of 7-day average water temperature (blue) and total discharge (green) of the

indicates week of summer solstice. (Continued ...) 


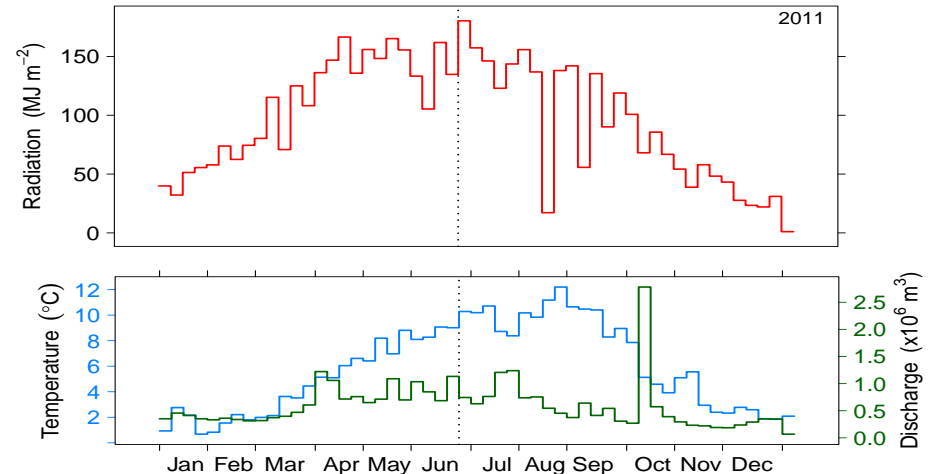

(i)
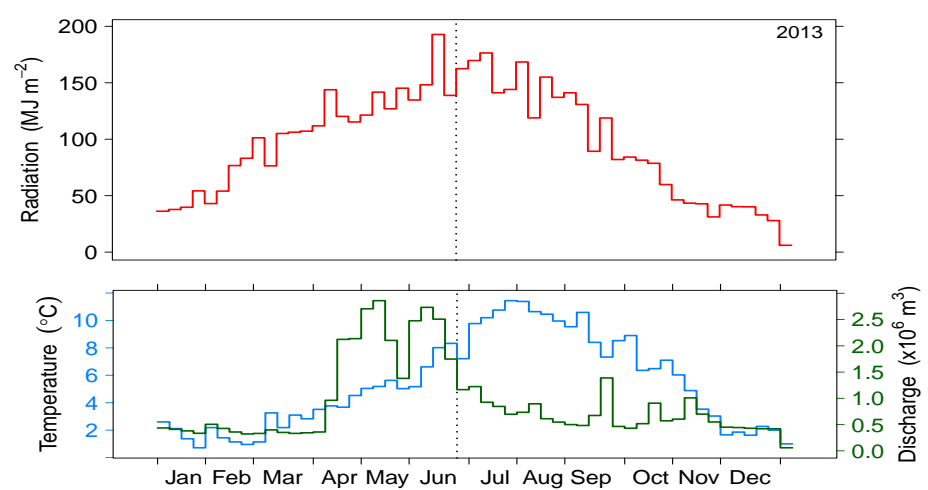

(k)
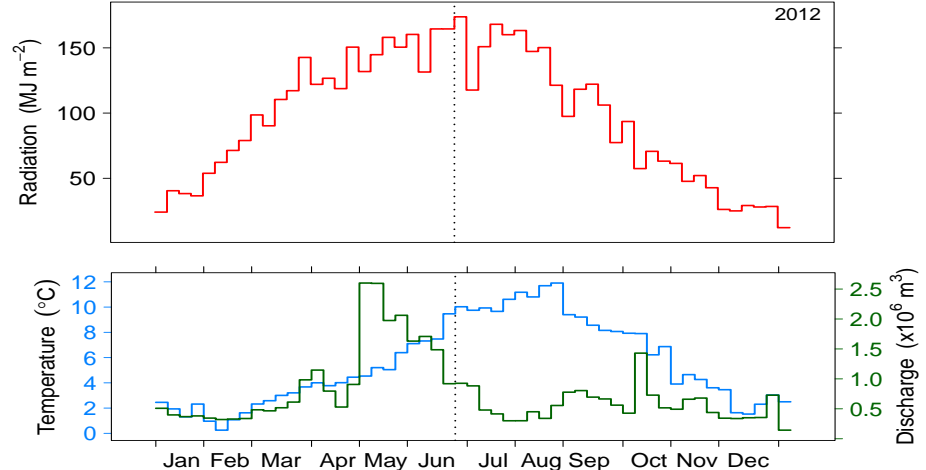

(j)
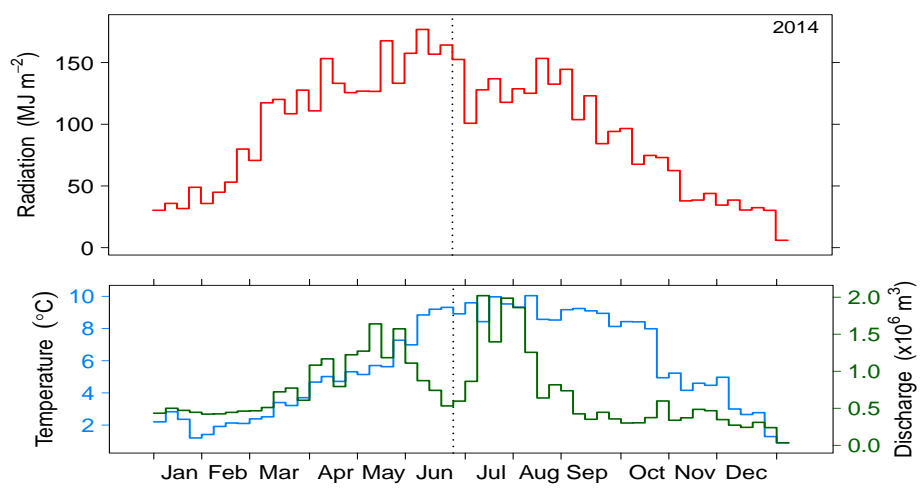

(1)

Figure 3.5: Seasonal variations of 7-day average water temperature (blue) and total discharge (green) of the Allenbach, together with 7-day total radiation (red) at Zermatt. For the years: (a) 2003 - (l) 2014, dotted line indicates week of summer solstice. (Concluded.) 
Table 3.6: Descriptive statistics of water temperature $\left({ }^{\circ} \mathrm{C}\right)$ of the Massa measured at the Blatten-bei-Naters gauging station, for the calendar year.

\begin{tabular}{ccccc}
\hline & Mean & Std. Dev. & Min & Max \\
\hline 2003 & 0.88 & 0.40 & 0.09 & 1.66 \\
2004 & 0.91 & 0.45 & 0.09 & 1.97 \\
2005 & 0.91 & 0.49 & 0.02 & 1.95 \\
2006 & 1.21 & 0.58 & 0.20 & 2.32 \\
2007 & 1.17 & 0.47 & 0.28 & 2.15 \\
2008 & 1.20 & 0.42 & 0.41 & 2.41 \\
2009 & 1.14 & 0.44 & 0.40 & 2.20 \\
2010 & 1.06 & 0.43 & 0.18 & 1.94 \\
2011 & 0.92 & 0.38 & 0.00 & 1.73 \\
2012 & 0.97 & 0.43 & 0.07 & 1.90 \\
2013 & 0.97 & 0.41 & 0.10 & 1.70 \\
2014 & 0.98 & 0.37 & 0.10 & 1.66 \\
& & & & \\
\hline
\end{tabular}

Table 3.7: Descriptive statistics of water temperature $\left({ }^{\circ} \mathrm{C}\right)$ of the Lonza measured at the Blatten gauging station, for the calendar year.

\begin{tabular}{rrccc}
\hline & Mean & Std. Dev. & Min & Max \\
\hline 2003 & 3.74 & 1.81 & 1.06 & 6.69 \\
2004 & 3.71 & 1.84 & 0.98 & 6.59 \\
2005 & 3.81 & 2.06 & 0.88 & 6.82 \\
2006 & 3.73 & 1.95 & 0.99 & 6.84 \\
2007 & 3.85 & 1.87 & 0.92 & 6.82 \\
2008 & 4.01 & 1.88 & 1.40 & 6.96 \\
2009 & 3.98 & 1.97 & 1.07 & 7.13 \\
2010 & 4.06 & 2.10 & 1.19 & 7.53 \\
2011 & 4.38 & 2.11 & 1.06 & 7.51 \\
2012 & 4.12 & 1.86 & 0.88 & 7.37 \\
2013 & 3.92 & 1.94 & 1.10 & 7.10 \\
2014 & 4.37 & 1.93 & 1.20 & 7.09 \\
& & & & \\
\hline
\end{tabular}


Table 3.8: Descriptive statistics of water temperature $\left({ }^{\circ} \mathrm{C}\right)$ of the Allenbach measured at the Adelboden gauging station, for the calendar year.

\begin{tabular}{rrccc}
\hline & Mean & Std. Dev. & Min & Max \\
\hline 2003 & 5.80 & 3.72 & 0.45 & 12.53 \\
2004 & 5.26 & 3.27 & 0.27 & 11.08 \\
2005 & 5.14 & 3.66 & 0.13 & 11.09 \\
2006 & 5.38 & 3.46 & 0.12 & 11.74 \\
2007 & 5.60 & 3.00 & 0.99 & 10.51 \\
2008 & 5.38 & 3.14 & 0.90 & 11.08 \\
2009 & 5.59 & 3.50 & 0.32 & 11.14 \\
2010 & 5.35 & 3.42 & 0.49 & 11.71 \\
2011 & 5.81 & 3.42 & 0.68 & 12.20 \\
2012 & 5.55 & 3.33 & 0.25 & 11.91 \\
2013 & 5.33 & 3.36 & 0.71 & 11.44 \\
2014 & 5.67 & 2.94 & 0.90 & 10.04 \\
& & & & \\
\hline
\end{tabular}


Water temperatures of the Findelenbach which drains a $73 \%$ glacierised basin, and the Gornera which drains a basin of $83.7 \%$ glacierisation, are collected during short field visits. Temperatures have been recorded at different stages of the melt season since 2003, with the introduction of Hach Minisonde loggers. For the purpose of this study a selection of years: 2006, 2008 and 2009 were selected to demonstrate the temperatures in each stream. The years were selected on the criteria: availability of data, periods which overlap between basins, and those that give a demonstration of temperatures at different times throughout the season. Figure 3.6 shows daily average water temperature alongside daily total discharge for the years: 2006, 2008 and 2009, throughout the calendar year (upper graphs). Lower graphs zoom in on the extent of the water temperature measurement period.

Temperatures in the Findelenbach and Gornera are low through the summer period, with low ranges similar to those of the Massa. Water temperature of both rivers is extremely responsive to climatic trends; periods of low discharges, thought to coincide with period of cloud cover and possible precipitation events are reflected with substantial rises in temperature. Such periods occurred around August 15 and September 012006 (Figures 3.6a \& 3.6b). Temperatures of both the Findelenbach and Gornera appear to be more responsive to precipitation, than those of the Massa, possibly due to the smaller riverflows. With assessment of the periods of overlapping data (e.g. Figures $3.6 \mathrm{a} \& 3.6 \mathrm{~b}$ and Figures $3.6 \mathrm{e} \& 3.6 \mathrm{f})$ it is apparent that, excluding period of substantially reduced discharge or rainfall events, temperatures of the Findelenbach are generally greater than those of the Gornera. In the period 17 to 29 August 2006, temperature in the Findelenbach range between $0.8^{\circ} \mathrm{C}$ and $1.8^{\circ} \mathrm{C}$, with a mean average of $1.1^{\circ} \mathrm{C}\left(\sigma=0.3{ }^{\circ} \mathrm{C}\right)$. Comparatively temperatures of the Gornera range between $0.5^{\circ} \mathrm{C}$ and $1.2^{\circ} \mathrm{C}$, with a mean average of $0.7^{\circ} \mathrm{C}\left(\sigma=0.2^{\circ} \mathrm{C}\right)$. 

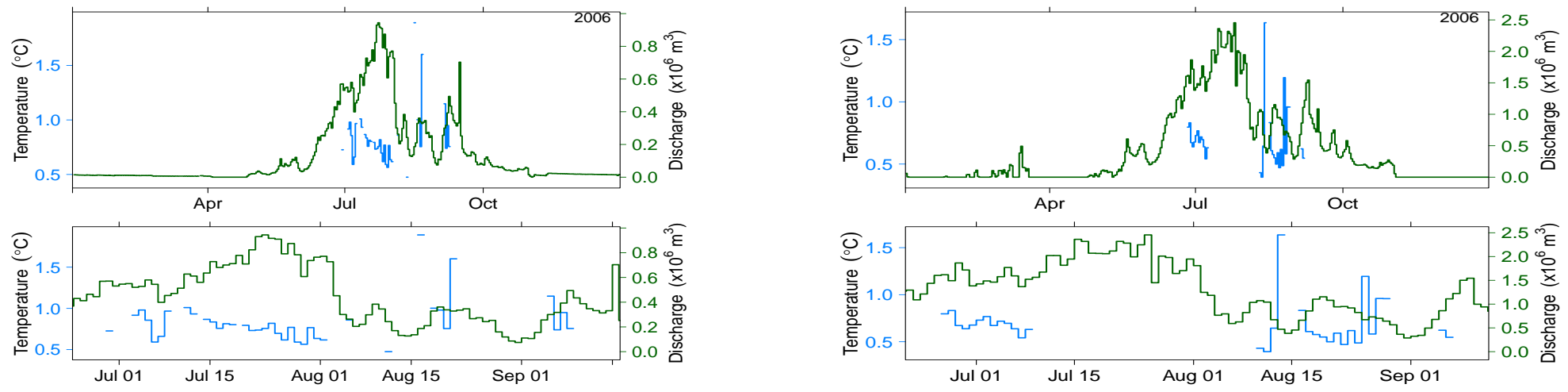

(a)

(b)
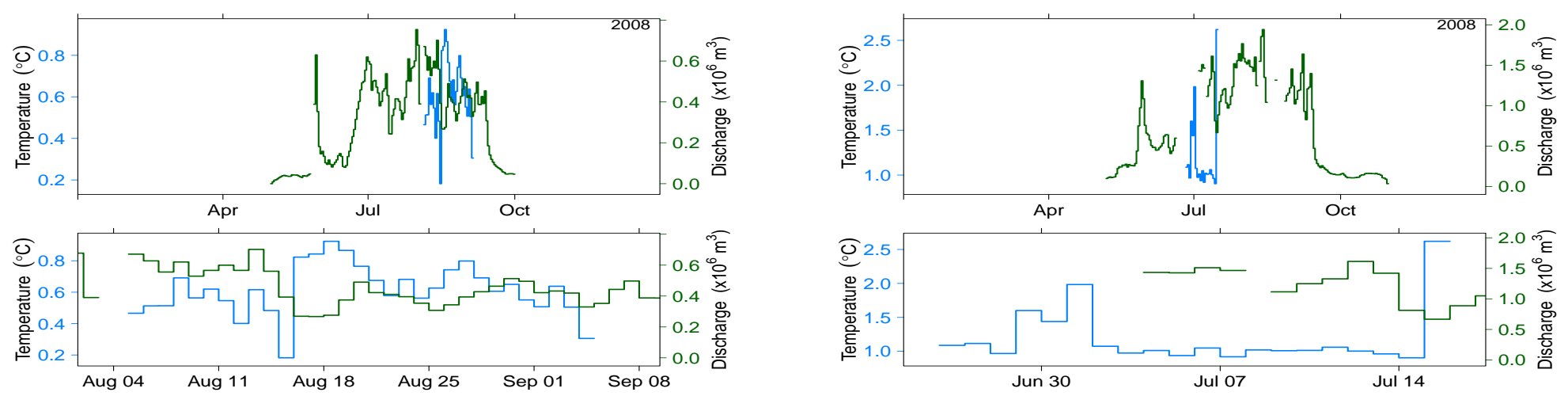

(c)

(d)

Figure 3.6: Seasonal variations of daily average water temperature (blue) and total discharge (green), upper graphs, of the: (a) Findelen 2006, (b) Gornera 2006, (c) Findelen 2008, (d) Gornera 2008, (e) Findelen 2009, (f) Gornera 2009. lower plots are magnified to illustrate extent of the temperature data. (Continued ...) 

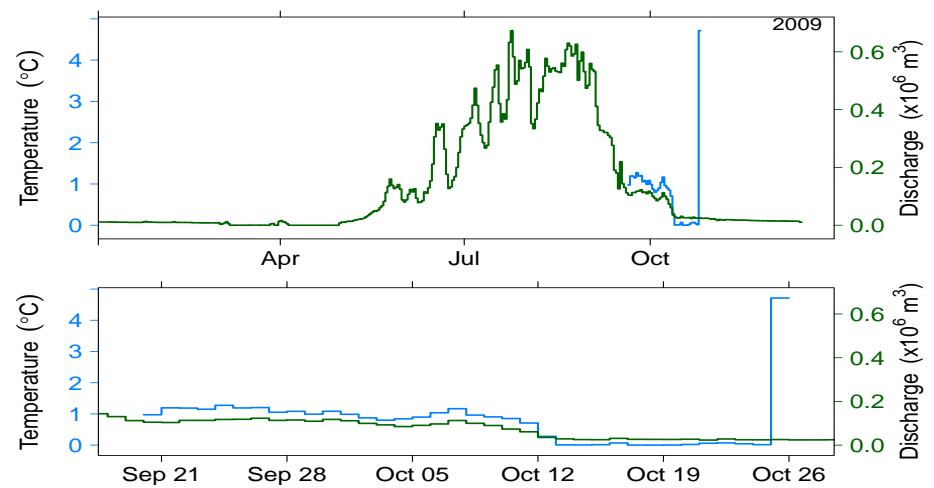

(e)
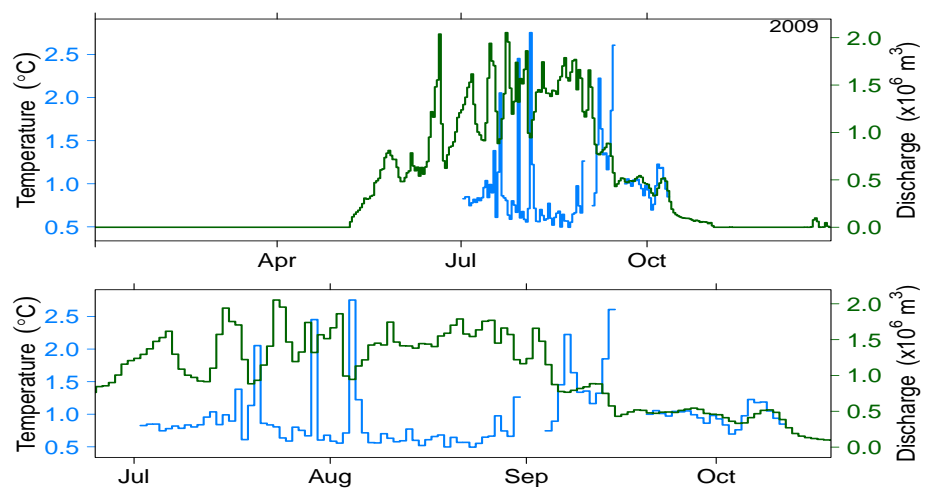

(f)

Figure 3.6: Seasonal variations of daily average water temperature (blue) and total discharge (green), upper graphs, of the: (a) Findelen 2006, (b) Gornera 2006, (c) Findelen 2008, (d) Gornera 2008, (e) Findelen 2009, (f) Gornera 2009. lower plots are magnified to illustrate extent of the temperature data. (Concluded.) 


\section{Precipitation}

Precipitation observations (Figure 3.7) are useful when analysing the seasonal variations in water temperature and discharge, as precipitation will impact seasonal stream temperatures in two ways. Firstly, snowfall in the preceding winter will alter the run-off regime of the following summer. As a result, discharge may be delayed or brought forward in the spring and the timing of high volumetric flow will influence early season water temperatures. Secondly, precipitation in the form of rain, in the summer months, will positivity drive water temperatures as rainfall is warmer than the glacier-fed streams. Precipitation varied least and was consistently low throughout 2003, with maximum precipitation occurring during week 44 (26 October - 1 November) measuring $25.9 \mathrm{~mm}$. Precipitation was greater during the years: 2004-06, 2008 and 2011-13. However, total weekly precipitation rarely exceeded $60 \mathrm{~mm}$. Noticeably, the years: 2007 and 2010 contained some significantly wet periods, with maxima close to, if not exceeding $100 \mathrm{~mm}$ (103.4 mm in 2007 week 22 (27 May - 2 June)). Table 3.9 gives descriptive statistics for total weekly precipitation recorded at Zermatt across the study period.

Table 3.9: Descriptive statistics of weekly precipitation totals ( $\mathrm{mm}$ ) measured at Zermatt for the calendar year, 2003-2014.

\begin{tabular}{rrcccc}
\hline & Mean & Std. Dev. & CV & Min & Max \\
\hline 2003 & 5.8 & 7.7 & 1.3 & 0.0 & 25.9 \\
2004 & 8.6 & 12.9 & 1.5 & 0.0 & 53.8 \\
2005 & 10.4 & 14.8 & 1.4 & 0.0 & 69.5 \\
2006 & 9.4 & 12.9 & 1.4 & 0.0 & 52.2 \\
2007 & 15.1 & 20.5 & 1.4 & 0.0 & 103.4 \\
2008 & 14.9 & 17.0 & 1.1 & 0.0 & 71.8 \\
2009 & 10.2 & 13.0 & 1.3 & 0.0 & 73.1 \\
2010 & 11.0 & 17.7 & 1.6 & 0.0 & 91.8 \\
2011 & 10.2 & 13.3 & 1.3 & 0.0 & 57.6 \\
2012 & 12.8 & 13.0 & 1.0 & 0.0 & 46.3 \\
2013 & 14.1 & 16.3 & 1.2 & 0.0 & 66.6 \\
2014 & 14.2 & 17.0 & 1.2 & 0.0 & 74.3 \\
& & & & & \\
\hline
\end{tabular}




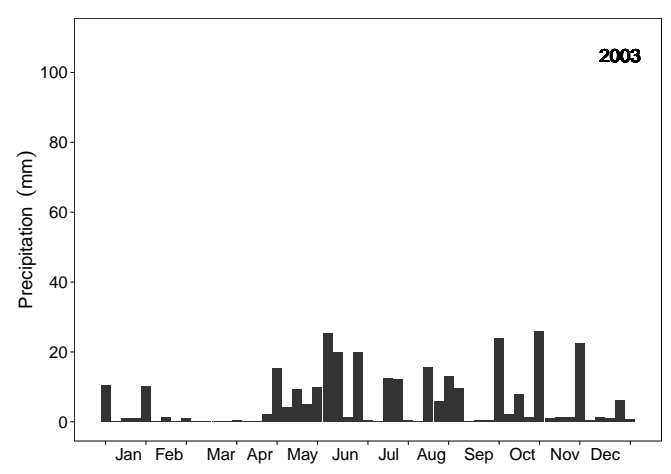

(a)

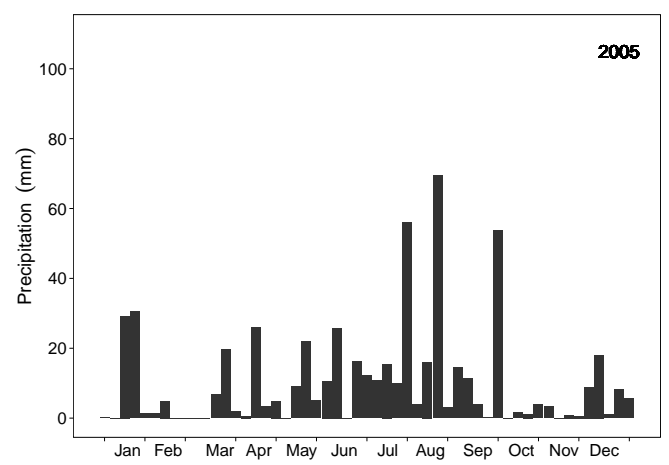

(c)

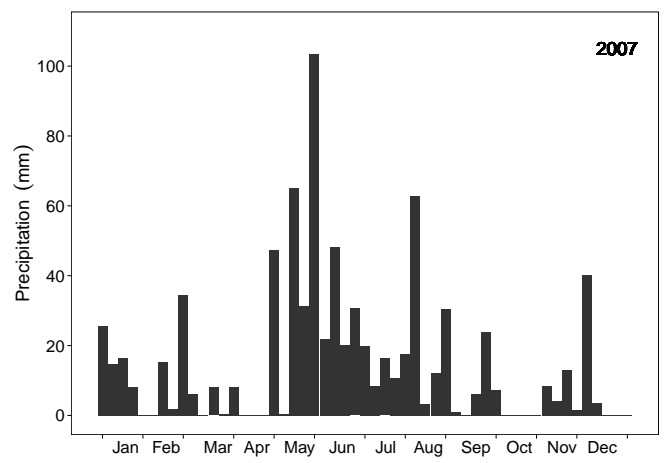

(e)

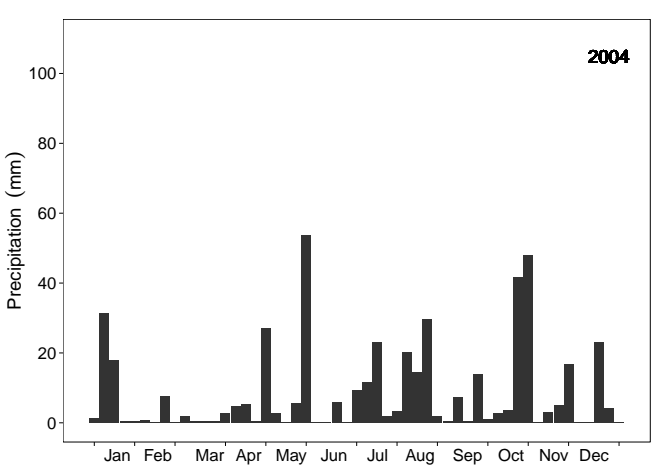

(b)

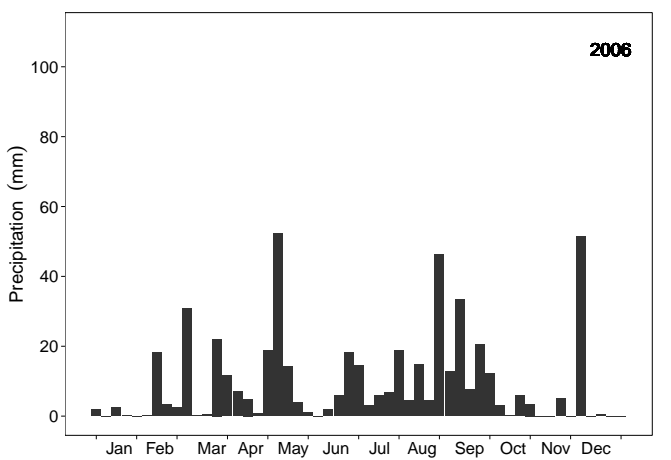

(d)

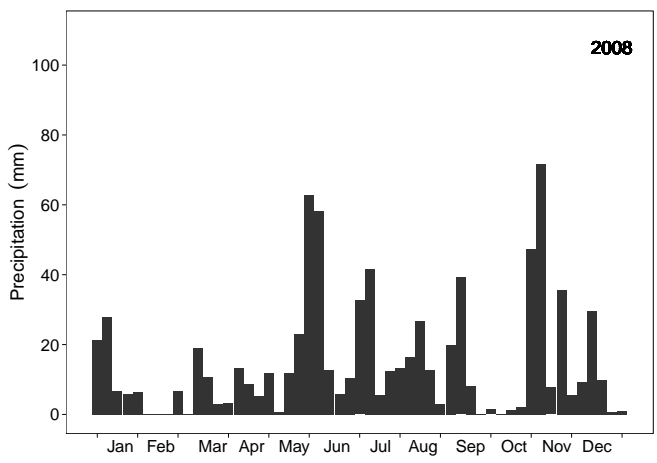

(f)

Figure 3.7: Seasonal variations of 1 week (7-day) total precipitation, measured at Zermatt, (a) 2003 - (l) 2014. (Continued ...) 


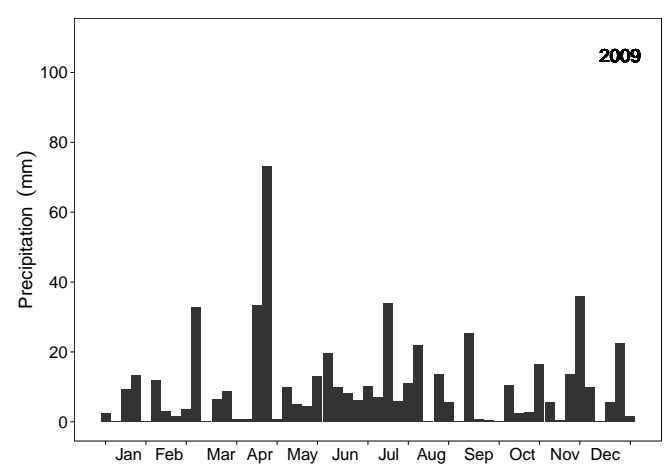

(g)

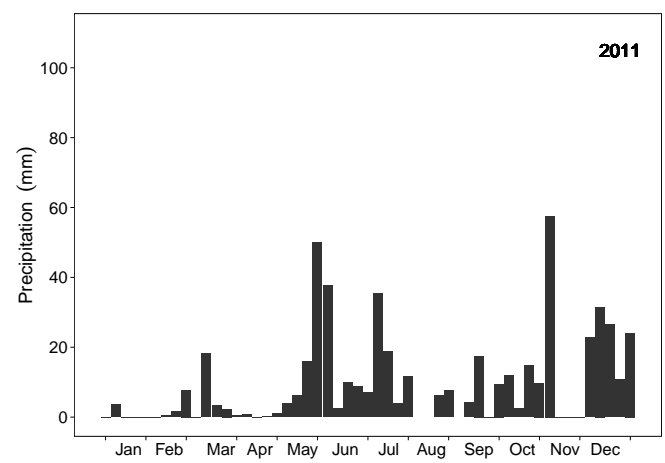

(i)

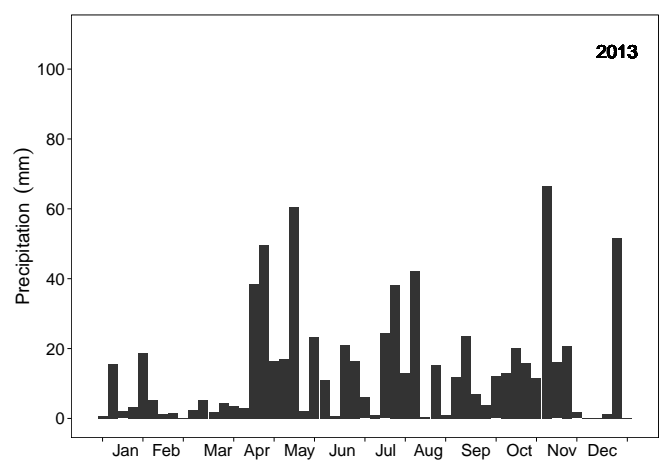

$(\mathrm{k})$

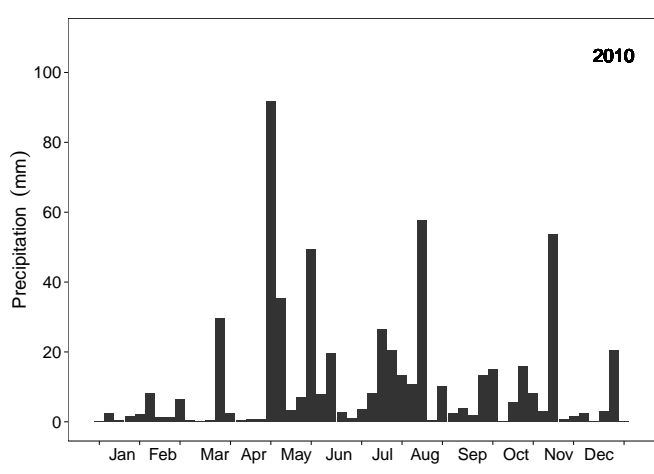

(h)

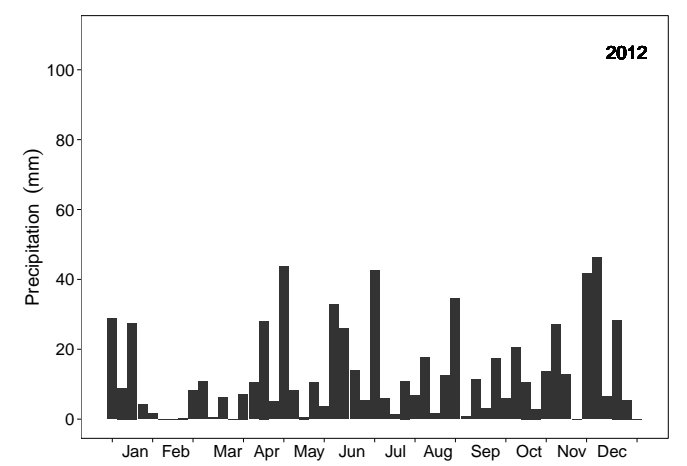

$(\mathbf{j})$

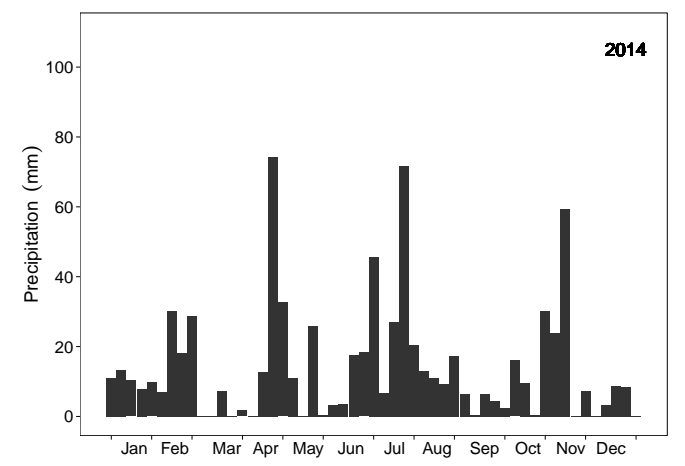

(1)

Figure 3.7: Seasonal variations of 1 week (7-day) total precipitation, measured at Zermatt, (a) 2003 - (l) 2014. (Concluded.) 


\subsubsection{Classification of seasonal water temperature time series}

To analyse seasonality in stream temperatures across different streams throughout the year, box plots illustrating the daily average water temperatures for each month were used. Boxplots used in such a way are useful for distinguishing between group patterns (Vega et al., 1998).

Seasonal patterns in average daily water temperatures vary with different basin percentage glacierisation. In the ice-free Allenbach, seasonality in water temperature is characterised by low variations during the first 3-4 months of the year, coinciding with the increased discharges resulting from snowmelt. This is followed by increasing variation around the mean, with greater ranges between May-July as discharge falls. Variations in daily temperatures reduce again in August, before increasing with falling energy receipts, October through to November, coinciding with warm precipitation driven discharge (Figure 3.8).

Increasing basin glacier cover reduces the maximum warming which occurs within streams; as a result of changing patterns in discharge and cold water inputs from glacier ice melt. The Lonza which drains a watershed with $36.5 \%$ glacier cover, is typified by greater variation, in the first 4 months, than that of the Allenbach. Variation in temperatures for the months May-September remain similar and as a result, close to those of the Allenbach. Similar to the Allenbach, late season temperature varies significantly. This is probably as a result of discharges being relatively low and precipitation constituting a greater percentage of riverflow (Figure 3.9).

The Massa, which drains a $65.9 \%$ glacier covered watershed, has a distinctly different seasonal pattern than those of both the glacier-fed Lonza and the ice-free Allenbach. Variations in water temperature in the months JanuaryMay, are significantly increased with respect to the less glacierised catchments. Temperatures from June to September are reflected by extremely low variation around the mean. During this period total riverflow accounts for up to $80 \%$ of 
annual levels. Variations in water temperature in the late summer and winter months, for the Massa, reflect those of all study basins (Figure 3.10).

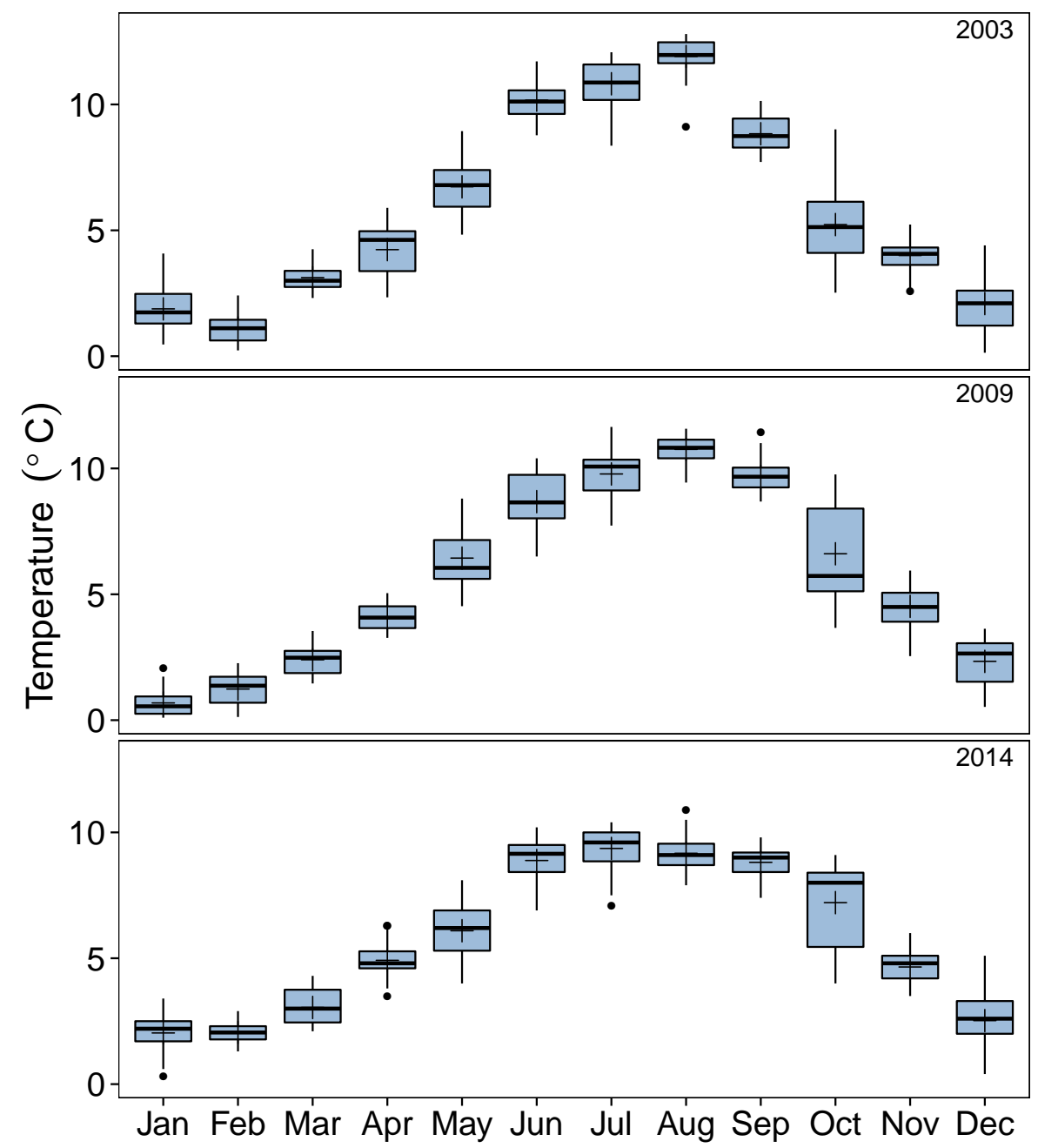

Figure 3.8: Box plots of average daily water temperature of the Allenbach (2003, 2009 and 2014) showing the median (horizontal line through box), mean $(+)$ and the first and third quartiles (box boundaries). Whiskers show $\pm 1.5 \times$ inter-quartile range and points signify outliers. 


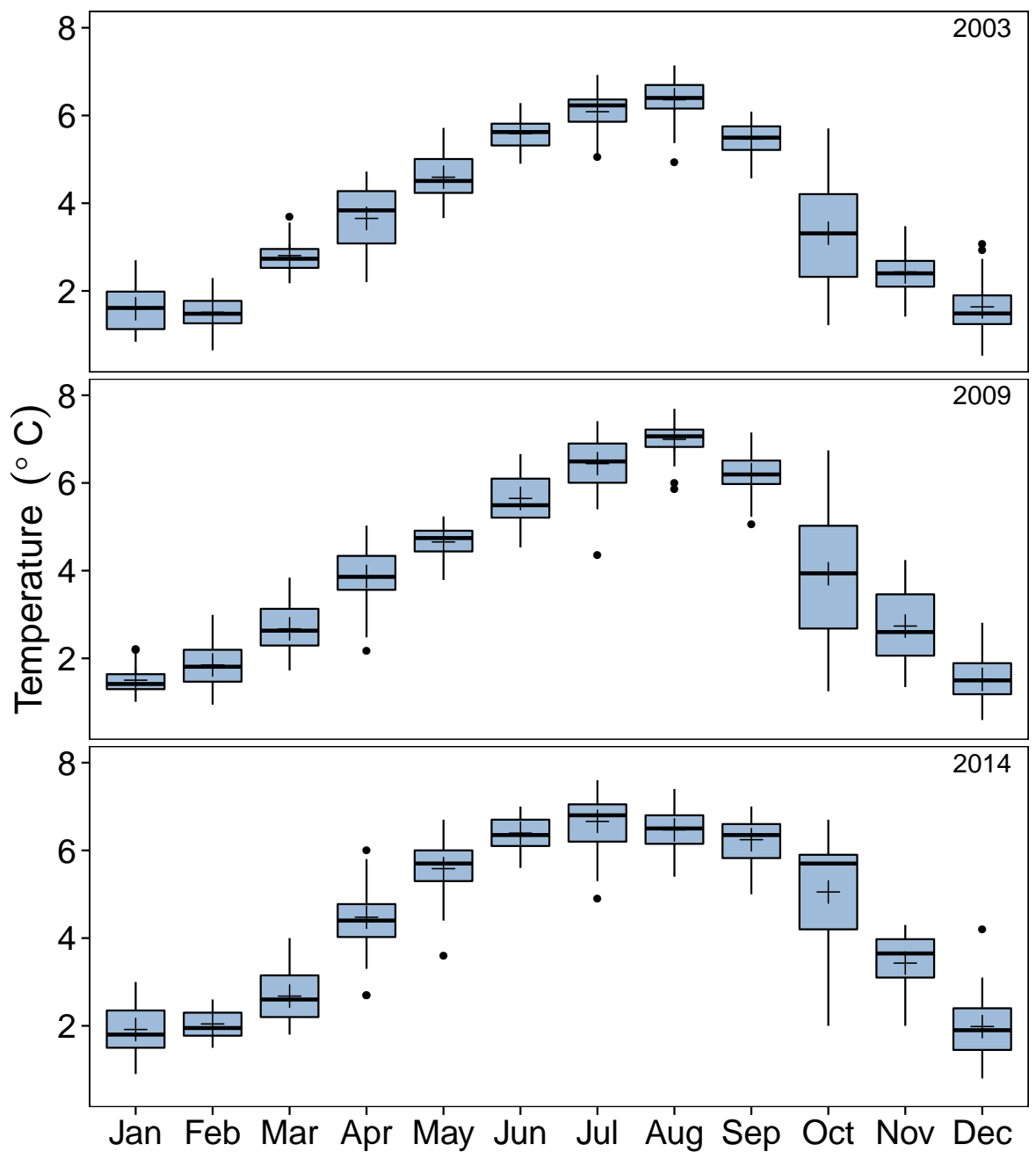

Figure 3.9: Box plots of average daily water temperature of the Lonza (2003, 2009 and 2014) showing the median (horizontal line through box), mean $(+)$ and the first and third quartiles (box boundaries). Whiskers show $\pm 1.5 \times$ inter-quartile range and points signify outliers. 


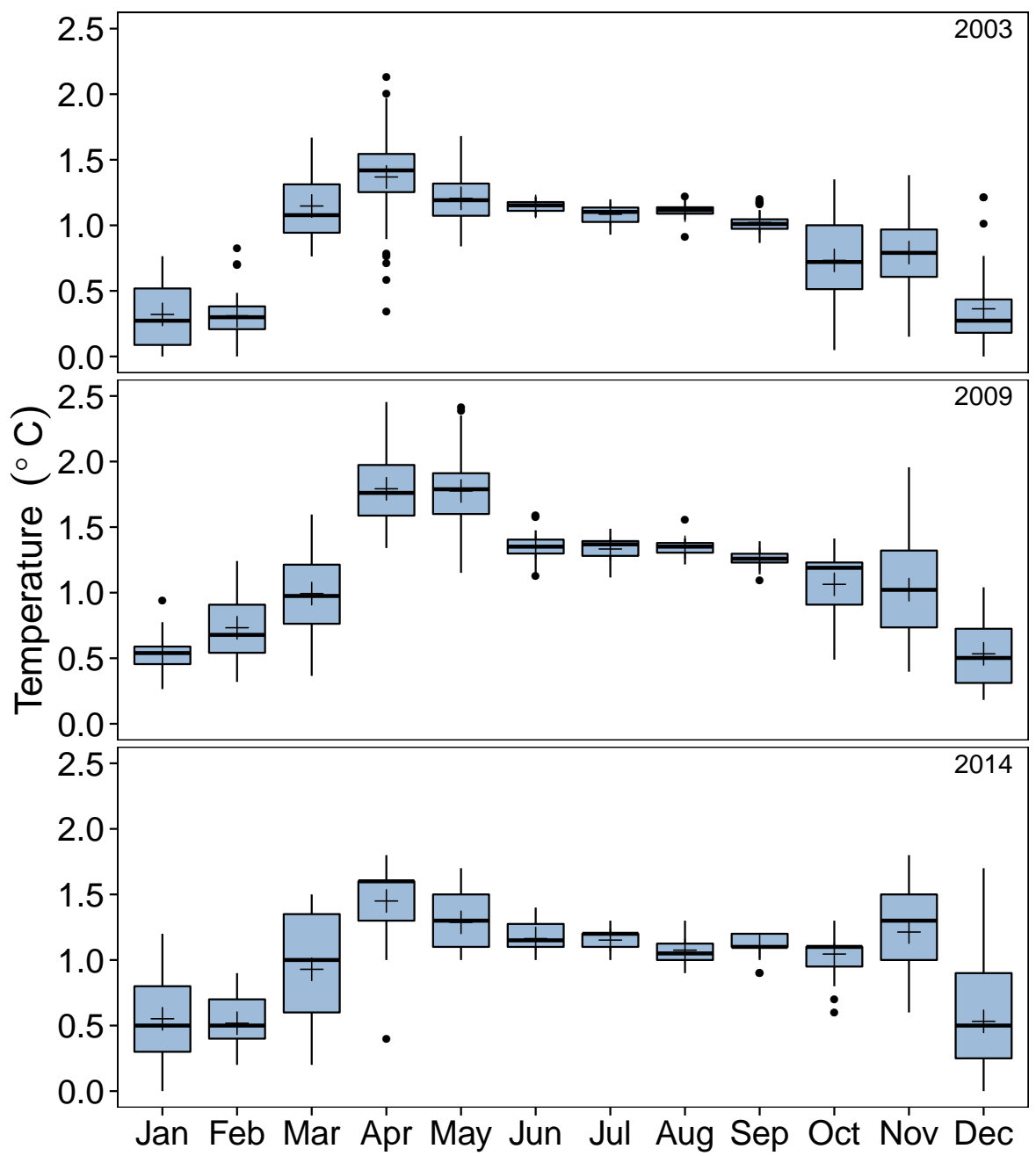

Figure 3.10: Box plots of average daily water temperature of the Massa (2003, 2009 and 2014) showing the median (horizontal line through box), mean $(+)$ and the first and third quartiles (box boundaries). Whiskers show $\pm 1.5 \times$ inter-quartile range and points signify outliers. 


\section{Correlation Analysis}

Correlation coefficients between 7 day shortwave radiation (measured at Zermatt), riverflow (Massa, Lonza and Allenbach), and stream temperatures (Massa, Lonza and Allenbach), are provided in Tables 3.10 \& 3.11, for the years 2003, 2008 and 2014. Incoming solar radiation correlated best with discharge of the Lonza, with coefficients of determination ranging from 0.61 0.72 , less with that of the Massa, and least with the Allenbach $(\mathrm{r}=0.42-0.61)$. Short-wave radiation also correlates highly with the Lonza water temperature, $\mathrm{r}=0.74-0.76$, and again less positively with the Massa and Allenbach. Seasonal patterns of water temperature of the Massa correlate better with incoming shortwave radiation in 2003. Water temperature of the Allenbach correlates more positively than the Massa in 2008 and 2014.

Correlation coefficients can also be used to give a comparison between time series of the same variables. Discharge of the Massa correlates most positively with the discharge of the Lonza (0.96-0.98), and extremely weak positive correlation occurs between the Massa discharge and Allenbach discharge as well as the Lonza discharge and Allenbach discharge. 
Table 3.10: Correlation matrix of seasonal datasets, $Q=$ Discharge and $\mathrm{T}=$ Water temperature and $\mathrm{R}=$ radiation for the year 2003 .

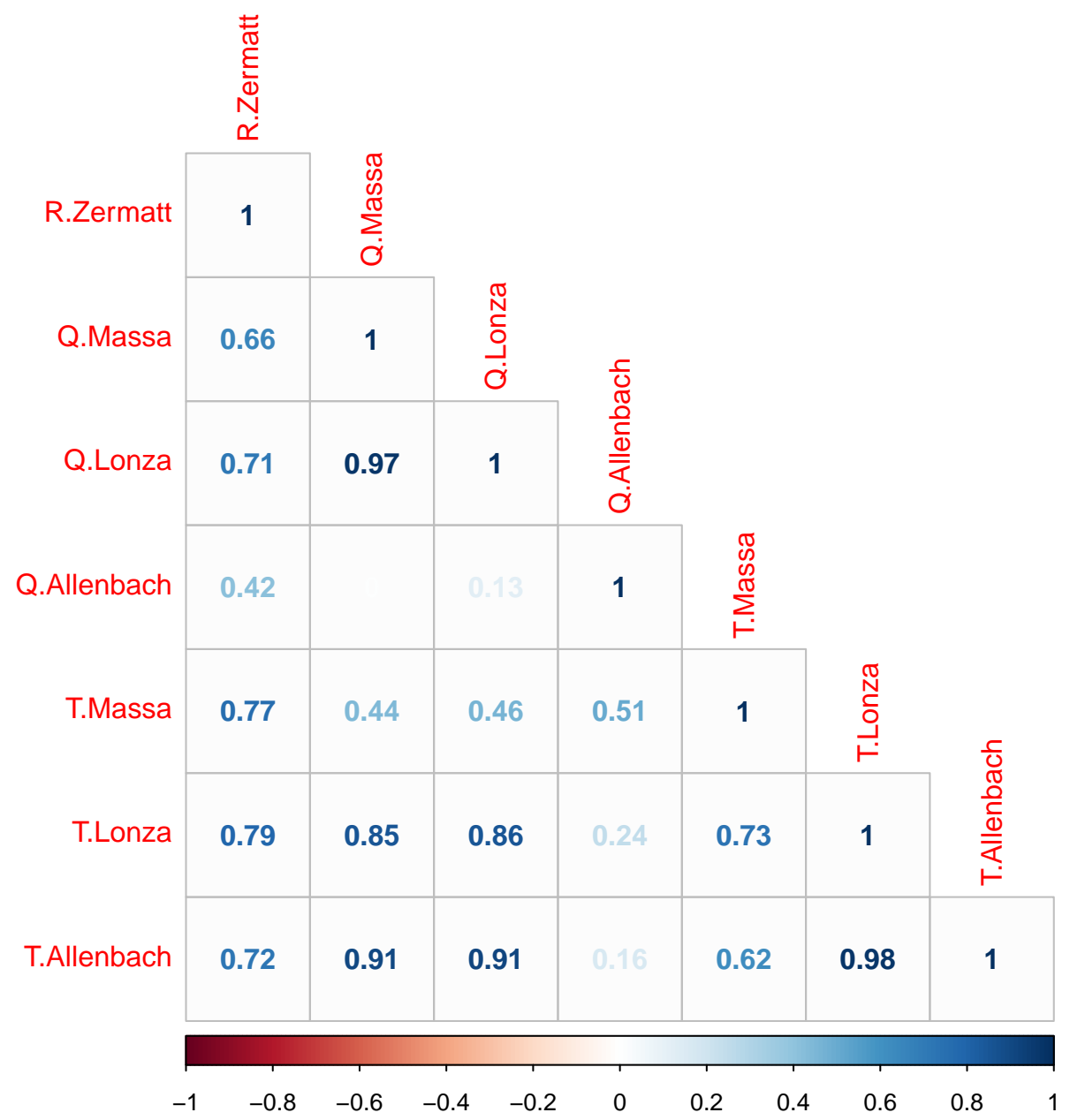


Table 3.11: Correlation matrices of seasonal datasets, $\mathrm{Q}=$ Discharge and $\mathrm{T}=$ Water temperature and $\mathrm{R}=$ radiation for the years (a) 2008 \& (b) 2014.

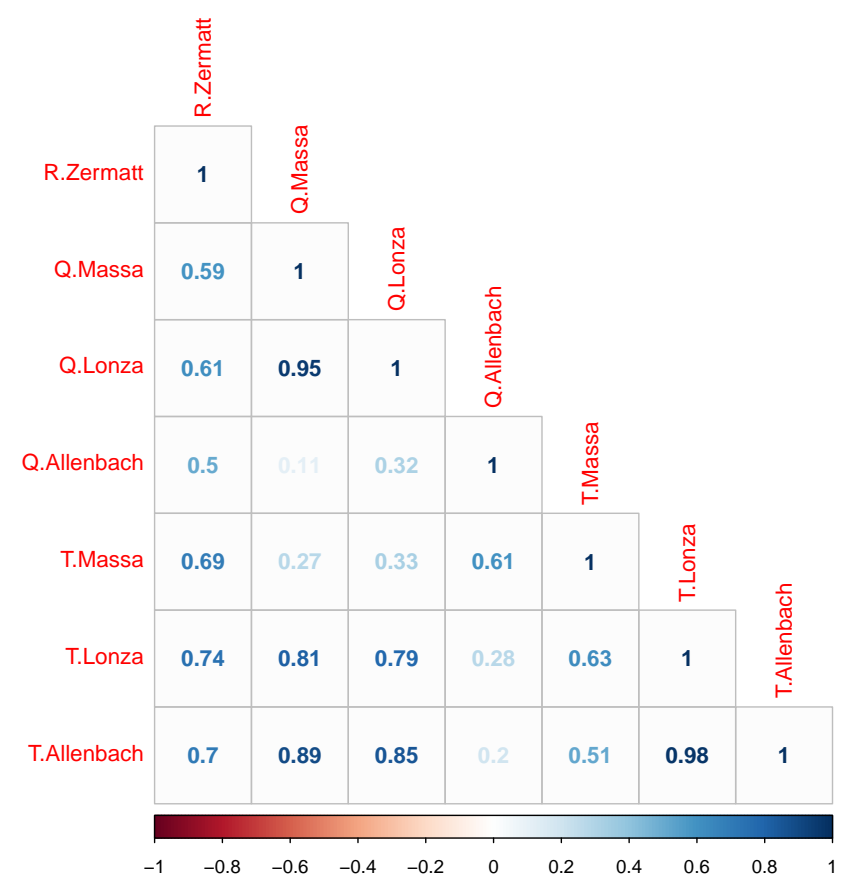

(a)

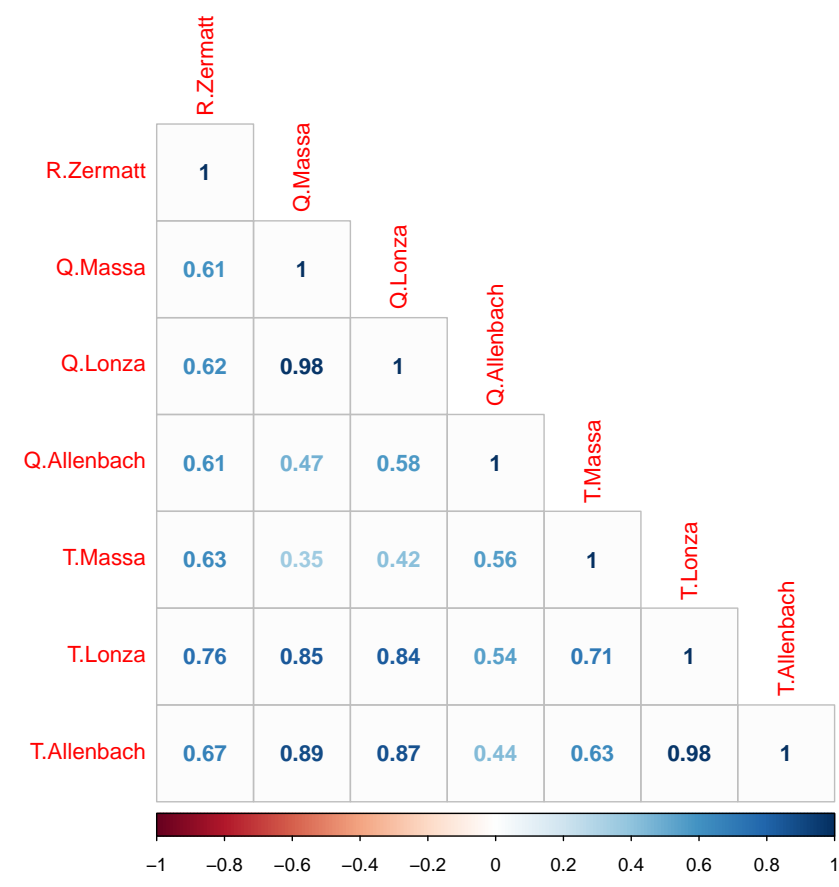

(b) 


\section{Regression Analysis}

Multiple linear regression analysis was used to assess the relationship between 7 day average water temperature and total shortwave radiation, total precipitation and riverflow. Analysis of the 7 day averages is thought best, as it is known to improve the fit with comparison to daily models, as this smooths out temperature data, thus moderating extremes (Fellman et al., 2014; Kelleher et al., 2012). Standardised $\beta$ coefficients $\left(\beta_{\text {std }}\right)$ were used in the present regression analyses as they are computed once the data (dependant and independent variables) have been standardised so the variance is equal to 1 . Therefore, the $\beta_{s t d}$ can be compared for each predictor variable, in that a change in 1 standard deviation of the predictor variable will result in a change of $n$ standard deviations of the dependant variable.

Multiple linear regression of water temperature against both incoming solar radiation, precipitation and riverflow was high in the three catchments (Massa (Table 3.13), Lonza (Table 3.12) and Allenbach (Table 3.14)), $\mathrm{R}^{2}$ values regularly greater than 0.5 and often as high at 0.7 for the Massa, being statistically significant at the 0.05 scale in most years for incoming radiation; temperature against discharge was only significant $(p=0.05)$ for 7 of the 11 year period. Regressions of Lonza water temperature against shortwave radiation, precipitation and streamflow were significant $(p=0.05)$ for both discharge and shortwave radiation predictors. $\mathrm{R}^{2}$ values were greatest in the Lonza, ranging from 0.65-0.86, whilst those of the ice-free Allenbach range from 0.48 to 0.72 only raising above 0.72 once in the study period. Regression coefficients (slope) were positive for both incoming shortwave radiation and precipitation, whilst being negative for riverflow. Regression slopes for incoming solar radiation demonstrated a small increase with increasing percentage glacierisation. This general trend is repeated for regression slopes, when assessing precipitation as a predictor. 
Table 3.12: Summary statistics for multiple linear regression models of 7 day average river temperature, 7 day total discharge (Q) of the Massa and 7 day total shortwave radiation $(\mathrm{R})$ and 7 day total precipitation $(\mathrm{P})$, measured at Zermatt, 2003-2014.

\begin{tabular}{ccccccc}
\hline Year & $\mathrm{R}_{A d j}^{2}$ & $p$ value & Slope $(\mathrm{R})$ & Slope $(\mathrm{Q})$ & Slope $(\mathrm{P})$ & $\mathrm{SE}$ \\
\hline 2003 & 0.58 & $<0.01$ & $0.85^{*}$ & -0.17 & 0.13 & 0.62 \\
2004 & 0.70 & $<0.01$ & $0.96^{*}$ & $-0.25^{*}$ & $0.28^{*}$ & 0.57 \\
2005 & 0.47 & $<0.01$ & $0.81^{*}$ & -0.22 & 0.17 & 0.72 \\
2006 & 0.50 & $<0.01$ & $0.70^{*}$ & -0.04 & $0.23^{*}$ & 0.70 \\
2007 & 0.73 & $<0.01$ & $1.07^{*}$ & $-0.38^{*}$ & 0.13 & 0.53 \\
2008 & 0.53 & $<0.01$ & $0.99^{*}$ & $-0.38^{*}$ & $0.29^{*}$ & 0.68 \\
2009 & 0.56 & $<0.01$ & $0.93^{*}$ & $-0.29^{*}$ & 0.16 & 0.66 \\
2010 & 0.72 & $<0.01$ & $0.99^{*}$ & $-0.29^{*}$ & $0.21^{*}$ & 0.52 \\
2011 & 0.59 & $<0.01$ & $0.96^{*}$ & -0.23 & 0.14 & 0.65 \\
2012 & 0.68 & $<0.01$ & $1.00^{*}$ & $-0.28^{*}$ & 0.11 & 0.57 \\
2013 & 0.63 & $<0.01$ & $0.91^{*}$ & $-0.25 *$ & $0.28^{*}$ & 0.60 \\
2014 & 0.38 & $<0.01$ & $0.67^{*}$ & -0.07 & 0.17 & 0.79 \\
& & & & & & \\
\hline
\end{tabular}

* Indicates significance at $p=<0.05$ for individual predictors

Table 3.13: Summary statistics for multiple linear regression models of 7 day average river temperature, 7 day total discharge (Q) of the Lonza and 7 day total shortwave radiation $(\mathrm{R})$ and 7 day total precipitation $(\mathrm{P})$, measured at Zermatt, 2003-2014.

\begin{tabular}{ccccccc}
\hline Year & $\mathrm{R}_{\text {Adj }}^{2}$ & $p$ value & Slope $(\mathrm{R})$ & Slope $(\mathrm{Q})$ & Slope $(\mathrm{P})$ & $\mathrm{SE}$ \\
\hline 2003 & 0.79 & $<0.01$ & $0.39^{*}$ & $0.58^{*}$ & 0.15 & 0.46 \\
2004 & 0.80 & $<0.01$ & $0.43^{*}$ & $0.56^{*}$ & $0.16^{*}$ & 0.44 \\
2005 & 0.71 & $<0.01$ & $0.41^{*}$ & $0.51^{*}$ & 0.07 & 0.53 \\
2006 & 0.64 & $<0.01$ & $0.25^{*}$ & $0.60^{*}$ & 0.15 & 0.65 \\
2007 & 0.85 & $<0.01$ & $0.39^{*}$ & $0.61^{*}$ & -0.01 & 0.39 \\
2008 & 0.70 & $<0.01$ & $0.38^{*}$ & $0.57^{*}$ & -0.05 & 0.54 \\
2009 & 0.79 & $<0.01$ & $0.30^{*}$ & $0.64^{*}$ & 0.05 & 0.45 \\
2010 & 0.77 & $<0.01$ & $0.47^{*}$ & $0.46^{*}$ & 0.10 & 0.8 \\
2011 & 0.87 & $<0.01$ & $0.61^{*}$ & $0.42^{*}$ & $0.16^{*}$ & 0.4 \\
2012 & 0.71 & $<0.01$ & $0.37^{*}$ & $0.53^{*}$ & -0.02 & 0.5 \\
2013 & 0.64 & $<0.01$ & $0.45^{*}$ & $0.42^{*}$ & 0.91 & 0.6 \\
2014 & 0.77 & $<0.01$ & $0.40^{*}$ & $0.58^{*}$ & 0.32 & 0.5 \\
\hline \multicolumn{7}{c}{} \\
\hline
\end{tabular}


Table 3.14: Summary statistics for multiple linear regression models of 7 day average river temperature, 7 day total discharge (Q) of the Allenbach and 7 day total shortwave radiation $(R)$ and 7 day total precipitation $(P)$, measured at Zermatt, 2003-2014.

\begin{tabular}{ccccccc}
\hline Year & $\mathrm{R}_{\text {Adj }}^{2}$ & $p$ value & Slope $(\mathrm{R})$ & Slope $(\mathrm{Q})$ & Slope $(\mathrm{P})$ & $\mathrm{SE}$ \\
\hline 2003 & 0.62 & $<0.01$ & $0.79^{*}$ & $-0.23^{*}$ & $0.32^{*}$ & 0.61 \\
2004 & 0.64 & $<0.01$ & $1.04^{*}$ & $-0.52^{*}$ & $0.47^{*}$ & 0.59 \\
2005 & 0.56 & $<0.01$ & $0.81^{*}$ & -0.19 & $0.30^{*}$ & 0.66 \\
2006 & 0.45 & $<0.01$ & $0.82^{*}$ & $-0.34^{*}$ & 0.19 & 0.73 \\
2007 & 0.66 & $<0.01$ & $0.83^{*}$ & -0.78 & 0.18 & 0.58 \\
2008 & 0.64 & $<0.01$ & $0.97^{*}$ & $-0.37^{*}$ & $0.43^{*}$ & 0.59 \\
2009 & 0.55 & $<0.01$ & $0.88^{*}$ & $-0.24^{*}$ & 0.14 & 0.67 \\
2010 & 0.58 & $<0.01$ & $0.85^{*}$ & -0.19 & 0.23 & 0.65 \\
2011 & 0.69 & $<0.01$ & $0.82^{*}$ & -0.02 & $0.32^{*}$ & 0.53 \\
2012 & 0.48 & $<0.01$ & $0.82^{*}$ & $-0.27^{*}$ & $0.22^{*}$ & 0.72 \\
2013 & 0.55 & $<0.01$ & $0.87^{*}$ & $-0.35 *$ & $0.31^{*}$ & 0.67 \\
2014 & 0.44 & $<0.01$ & $0.69^{*}$ & -0.40 & 0.16 & 0.74 \\
& & & & \\
\hline \multicolumn{7}{c}{ Indicates significance at $p=<0.05$ for individual predictors }
\end{tabular}

Table 3.15: Summary statistics for multiple linear regression models of monthly average temperature, stream area, gauging station elevation and percentage glacierisation, August 2006.

\begin{tabular}{clc}
\hline Variable & $p$ value & Slope \\
\hline Glacierisation & $<0.05$ & $-1.11^{*}$ \\
Gauge Elevation & $<0.2$ & 0.92 \\
Stream Area & $<0.2$ & 0.12 \\
\hline
\end{tabular}

* Indicates significance at $p=<0.05$ for individual predictors Overall $R_{A d j}^{2}=0.99$ 
Three basin properties (on all five study basins) were selected to understand which predictor had the strongest control on average monthly water temperature. Percentage glacierisation (\%), gauge elevation (m a.s.l.) and stream area $\left(\mathrm{m}^{2}\right)$ accounted for $99 \%$ of the variability in stream temperatures (Table 3.15). Radiation slope was greatest and statistically significant for the percentage glacieriation predictor, whilst $p$ values were as high as 0.2 for both gauge elevation and stream area.

Table 3.16 shows the predictors: percentage glacierisation and stream area for the four glaciated catchments (removing the ice-free basin), August 2006. In this instance the multiple regression model accounted for $91 \%$ of variability in monthly stream temperature. With respect to the glacier-fed rivers river temperature regression slope was greatest for the stream area predictor. Percentage glacier cover had a negative warming effect on stream temperature $\left(-0.35{ }^{\circ} \mathrm{C}\right.$ standard deviations with every standard deviation increase in glacier cover), comparatively increasing channel area in the magnitude of 1 standard deviation has a warming effect of $0.46^{\circ} \mathrm{C}$ standard deviations.

Table 3.16: Summary statistics for multiple linear regression models of monthly average temperature, stream area and percentage glacierisation for the four glacier-fed streams, August 2006.

\begin{tabular}{ccr}
\hline Variable & $p$ value & Slope \\
\hline Glacierisation & 0.4 & -0.35 \\
Stream Area & 0.7 & 0.46 \\
\hline
\end{tabular}




\subsubsection{Diurnal measurements}

Hourly measurements of global radiation, recorded at Zermatt, specific discharge and water temperature of the Massa, Lonza and Allenbach, were used to identify relationships between the three variables. This should give indication of how the aforementioned seasonal thermal regime is reflected on the sub-daily level.

\section{Solar radiation}

Solar irradiance, i.e. the rate of energy landing on a given surface in a set time $\left(\mathrm{W} \mathrm{m}^{-2}\right)$, has been measured at Zermatt. Irradiance data is illustrated in the upper plots of Figures 3.11 - 3.13, between May and August 2004. Incoming shortwave radiation consistently peaks around $1000 \mathrm{~W} \mathrm{~m}^{-2}$, averaging across each three day period, 578.51 $\mathrm{W} \mathrm{m}^{-2}$ (17-19 May 2004), 408.9 $\mathrm{W} \mathrm{m}^{-2}(17-119$ June 2004), 435.7 $\mathrm{W} \mathrm{m}^{-2}$ (14-16 July 2004) and 419.5 $\mathrm{W} \mathrm{m}^{-2}$ (13-15 August 2004). Average irradiance is significantly lower in the 14-16 April and 17-19 September 2004 periods at $300.7 \mathrm{~W} \mathrm{~m}^{-2}$ and $388.6 \mathrm{~W} \mathrm{~m}^{-2}$, respectively. Data of three days with clear-sky condition were subset from the wider dataset to demonstrate the impact incoming shortwave radiation has on both stream discharge and water temperature. Figures $3.11 \mathrm{c}$ and $3.11 \mathrm{~d}$ show collection of three clear days was not always possible during 2004, 19 June and 16 July are both demonstrative of days of significant cloud cover, mean averages during these days reading $343.3 \mathrm{~W} \mathrm{~m}^{-2}$ (19 June 2004) and $347.2 \mathrm{~W} \mathrm{~m}^{-2}$ (16 July 2004). Under clear-sky conditions peak irradiance occurs between 13:00-14:00 CEST with a sinusoidal pattern. Incoming shortwave radiation is 0 during the hours of 22:00 to 06:00, dependant on the hours of sunrise and sunset. 

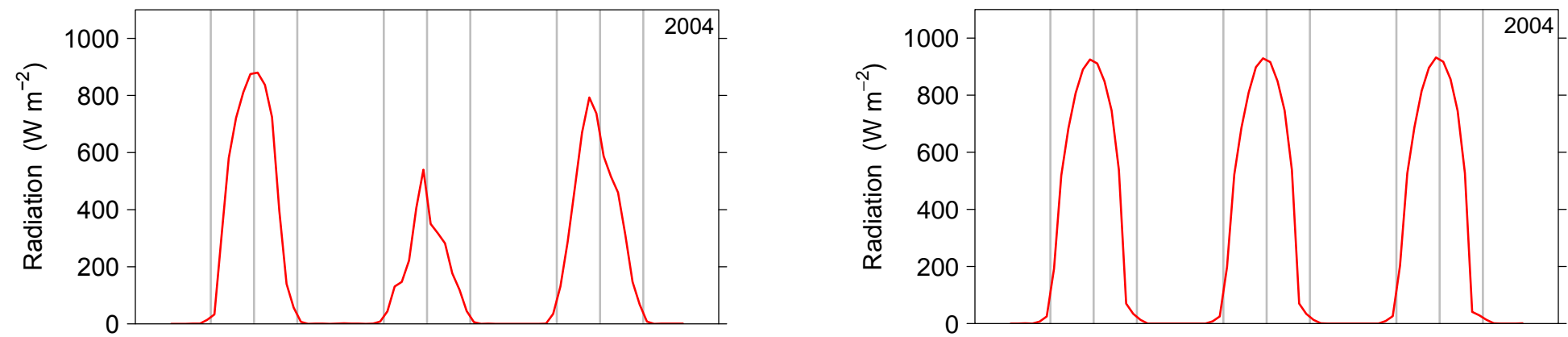

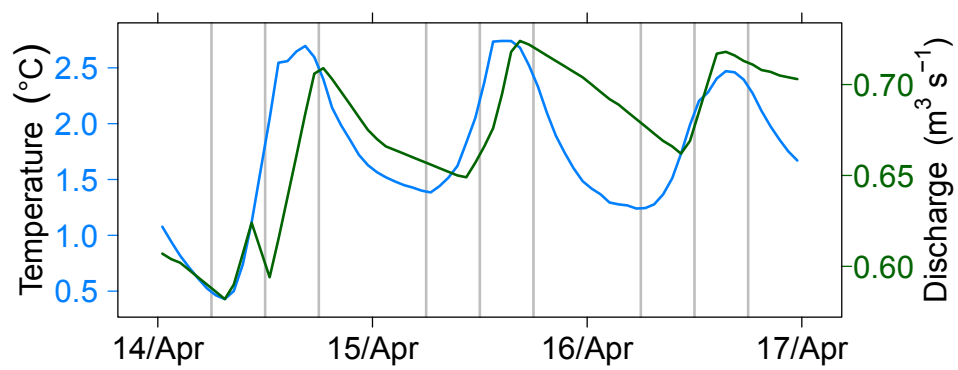

(a)

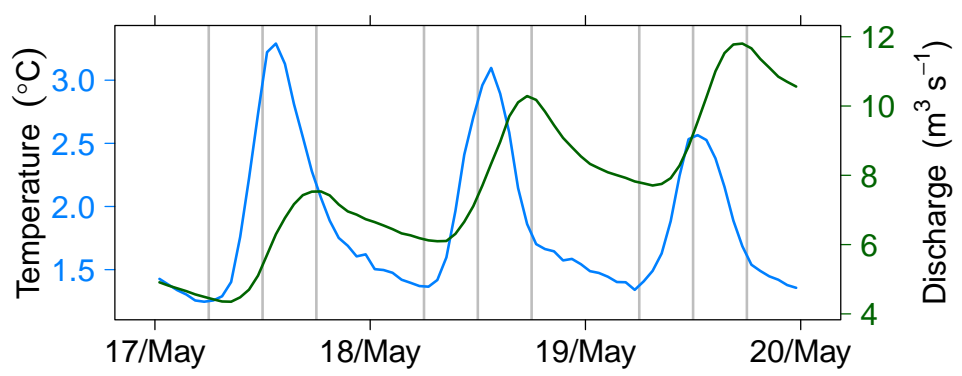

(b)

Figure 3.11: Diurnal variations of Radiation (red), water temperature (blue) and discharge (green) of the Massa for the days: (a) 14-16 April, (b) 17-19 May, (c) 17-19 June, (d) 14-16 July, (e) 13-16 Aug, (d) 17-19 September, 2004. Vertical lines indicate 06:00, 12:00 and 18:00 hours of each day. (Continued...) 

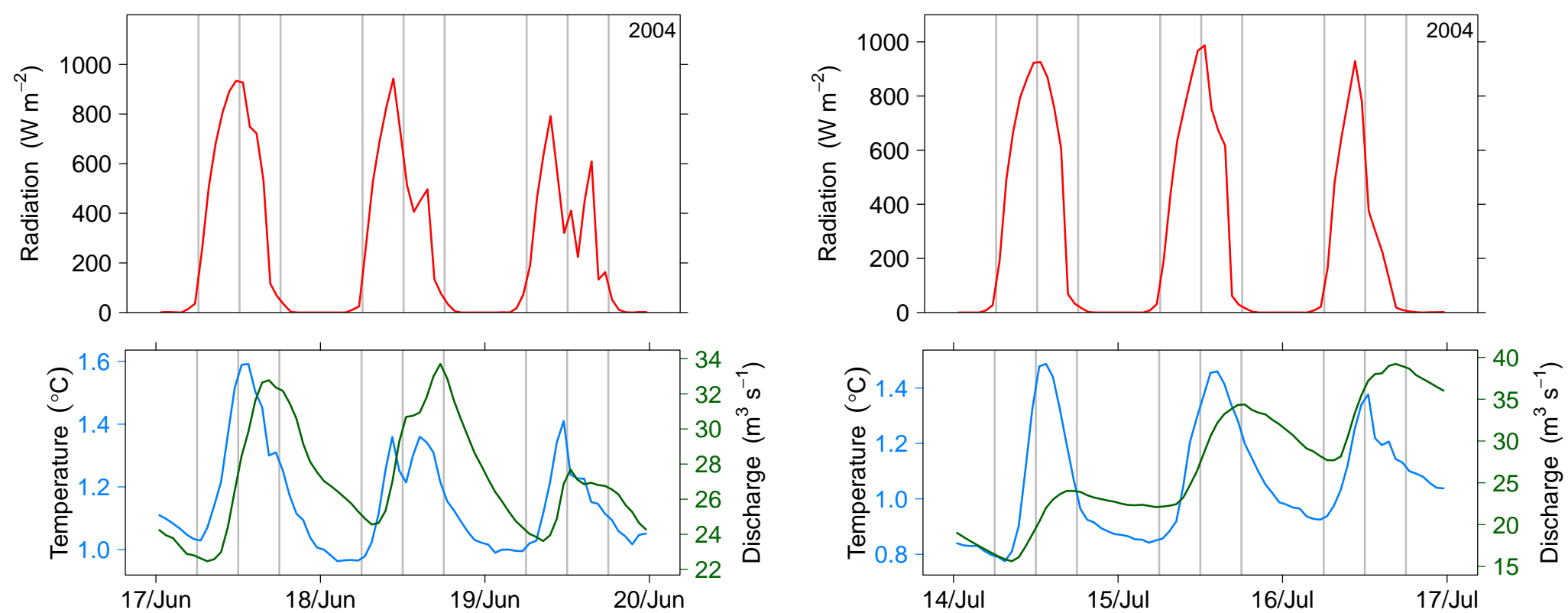

(c)

(d)

Figure 3.11: Diurnal variations of Radiation (red), water temperature (blue) and discharge (green) of the Massa for the days: (a) 14-16 April, (b) 17-19 May, (c) 17-19 June, (d) 14-16 July, (e) 13-16 Aug, (d) 17-19 September, 2004. Vertical lines indicate 06:00, 12:00 and 18:00 hours of each day. (Continued... ) 

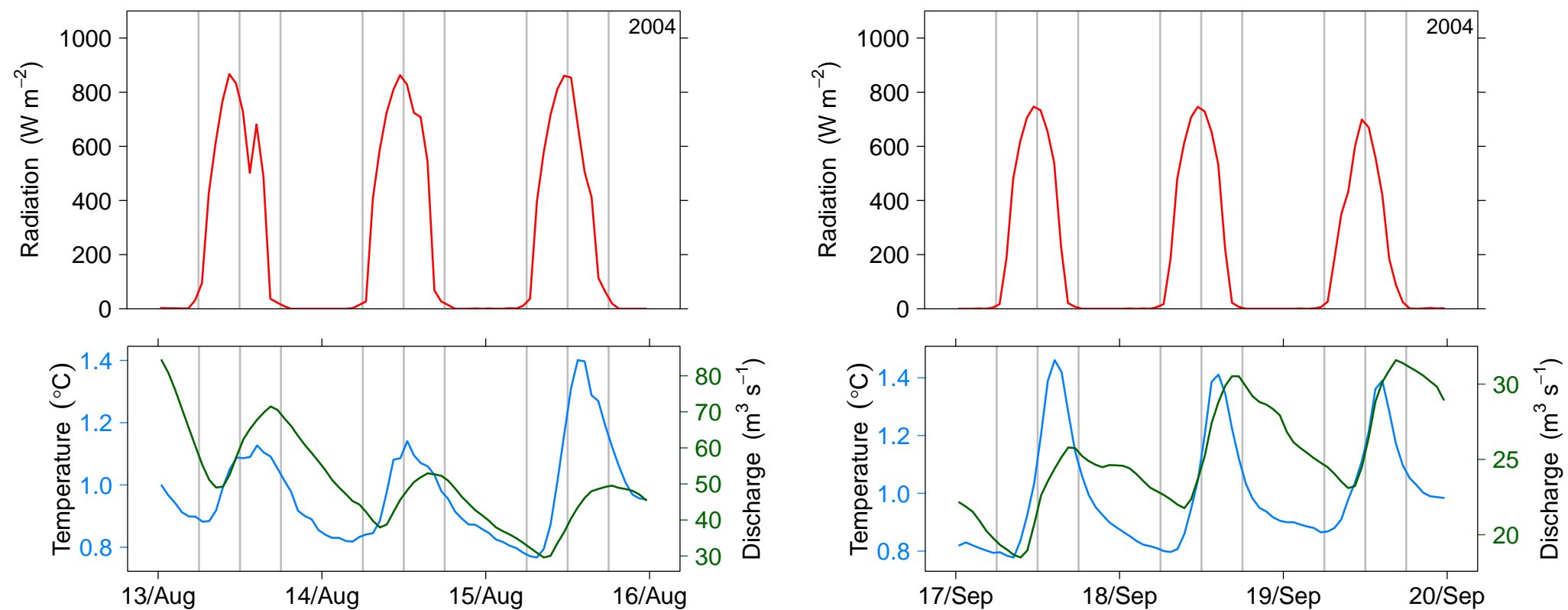

(e)

(f)

Figure 3.11: Diurnal variations of Radiation (red), water temperature (blue) and discharge (green) of the Massa for the days: (a) 14-16 April, (b) 17-19 May, (c) 17-19 June, (d) 14-16 July, (e) 13-16 Aug, (d) 17-19 September, 2004. Vertical lines indicate 06:00, 12:00 and 18:00 hours of each day. (Concluded.) 


\section{Discharge}

Discharge of the Massa demonstrates usual diurnal patterns through the summer months; typically the rising phase (Figure 3.11b) in early summer, a consistently high phase (Figure 3.11c) in the height of summer, and a falling phase (Figure 3.11e) during late summer. Specific discharge of the Massa is negligible throughout April (minimum of $0.58 \mathrm{~m}^{3} \mathrm{~s}^{-1}$, maximum of $0.72 \mathrm{~m}^{3} \mathrm{~s}^{-1}$ ). Runoff then rises rapidly during May, with night time minimum measuring $4.35 \mathrm{~m}^{3} \mathrm{~s}^{-1}$, peaking at $11.80 \mathrm{~m}^{3} \mathrm{~s}^{-1}$ during the three days $17-9$ May 2004 . The arrival of June - the theoretical solar radiation maximum - characterises steadily high discharge, mean average of $27.09 \mathrm{~m}^{3} \mathrm{~s}^{-1}$ during 17-19 June 2004. Runoff of the Massa rises further during July and August, measuring 39.22 $\mathrm{m}^{3} \mathrm{~s}^{-1}$ (16 July 2004) and $84.35 \mathrm{~m}^{3} \mathrm{~s}^{-1}$ (13 August 2004). Discharge then falls over the three day August period, back to lower levels around $40 \mathrm{~m}^{3} \mathrm{~s}^{-1}$, remaining moderate into the September period (17-19 September 2004) with an average of $25.25 \mathrm{~m}^{3} \mathrm{~s}^{-1}$. Peak discharge of the Massa systematically occurs between hours 16:00 and 18:00. However, on days with afternoon cloud cover maximum discharge can occur closer to midday.

Runoff of the Lonza in the month of April is more haphazard than that of the Massa (Figure 3.12a). Despite this, riverflow of the Lonza in the 14-16 April period is greater than that of the Massa (minimum of $0.73 \mathrm{~m}^{3} \mathrm{~s}^{-1}$, maximum of $0.85 \mathrm{~m}^{3} \mathrm{~s}^{-1}$ ). Runoff of the Lonza begins to reflect that of the Massa in May, with a distinctive rising pattern common in glacier-fed streams. Levels of riverflow during May are much greater than those in April (maximum of $8.70 \mathrm{~m}^{3} \mathrm{~s}^{-1}$ ) as ice-melt begins to dominate discharge. However, levels are lower in the Lonza than the Massa. In a period of falling radiation (Figure 3.12c), riverflow in the Lonza falls much more as a percentage over the three day period falling by $35.8 \%$. Alternatively, riverflow in the Massa declines by only $14.1 \%$. Despite this, patterns of discharge in the Lonza reflect changes in incoming radiation, less than those of Massa (comparing Figure 3.11c and Figure 3.12c). As with the Massa, levels of riverflow in the Lonza rise substantially in the three days of July, Figure 3.12d, with maximum levels in 
August $\left(19.20 \mathrm{~m}^{3} \mathrm{~s}^{-1}\right)$.

Discharge in the Allenbach initially reflects the levels of incoming shortwave radiation (Figure 3.13a). Riverflow is principally being driven by snowmelt and hence maximum levels are approached in the May period (range $=2.20 \mathrm{~m}^{3} \mathrm{~s}^{-1}$ $\left.8.45 \mathrm{~m}^{3} \mathrm{~s}^{-1}\right)$. Discharges are on par with those in the Lonza and slightly lower than those of the Massa during this period. Unlike the flows of the glacier-fed streams, the Allenbach reduces in June (maximum $=2.50 \mathrm{~m}^{3} \mathrm{~s}^{-1}$ ), as winter snow is depleted and cannot sustain the relatively high discharges. The selected periods of July, August and September demonstrate the typical summer variation in riverflow from ice-free Alpine catchments. Flows in this period are insignificant, with any major increases reflecting large rainfall events (e.g. Figure 3.13e).

\section{Water temperature}

Sub-daily, maximum water temperature of the Massa occurs prior to the discharge maxima throughout summer months, April - September (Figure 3.11). Temperatures of the Massa appear to be most influenced by meteorological conditions (solar radiation). Maximum temperatures were recorded during May (Figure 3.11b), before reducing in June and remaining consistently low between July and September (peaking around $1.4^{\circ} \mathrm{C}$ ). An interesting pattern in diurnal variation in water temperature is the reduction in range, over a period of high solar radiation (Figure 3.11d) i.e. higher minima and lower maxima. 

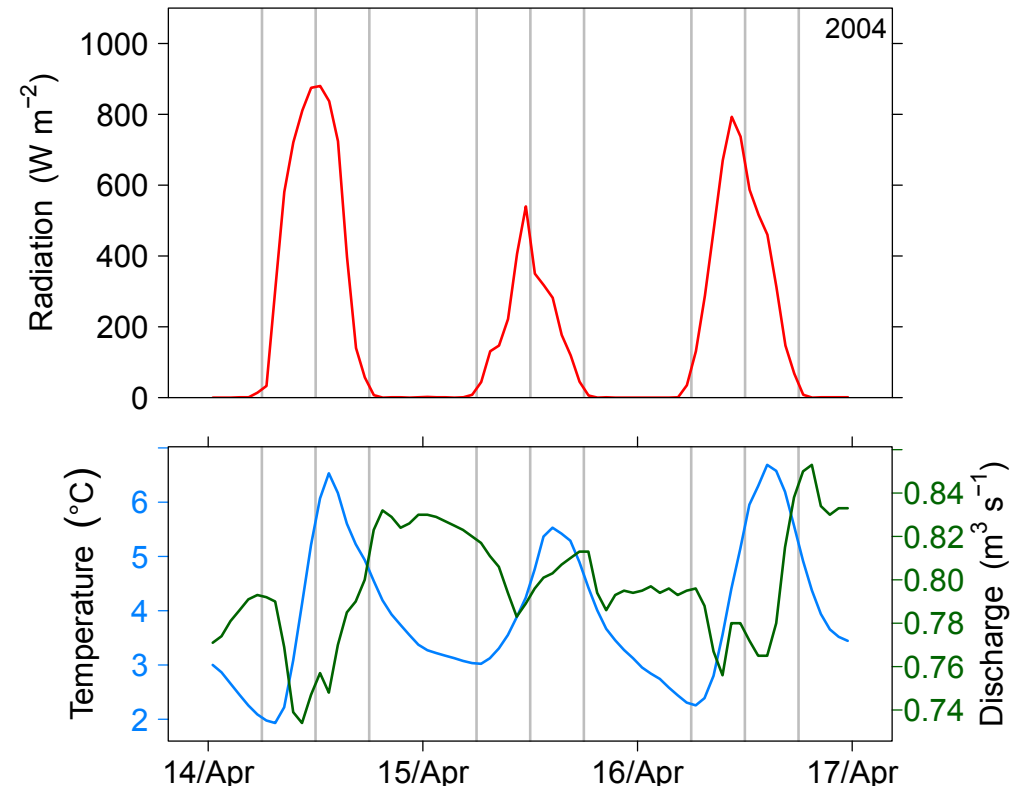

(a)
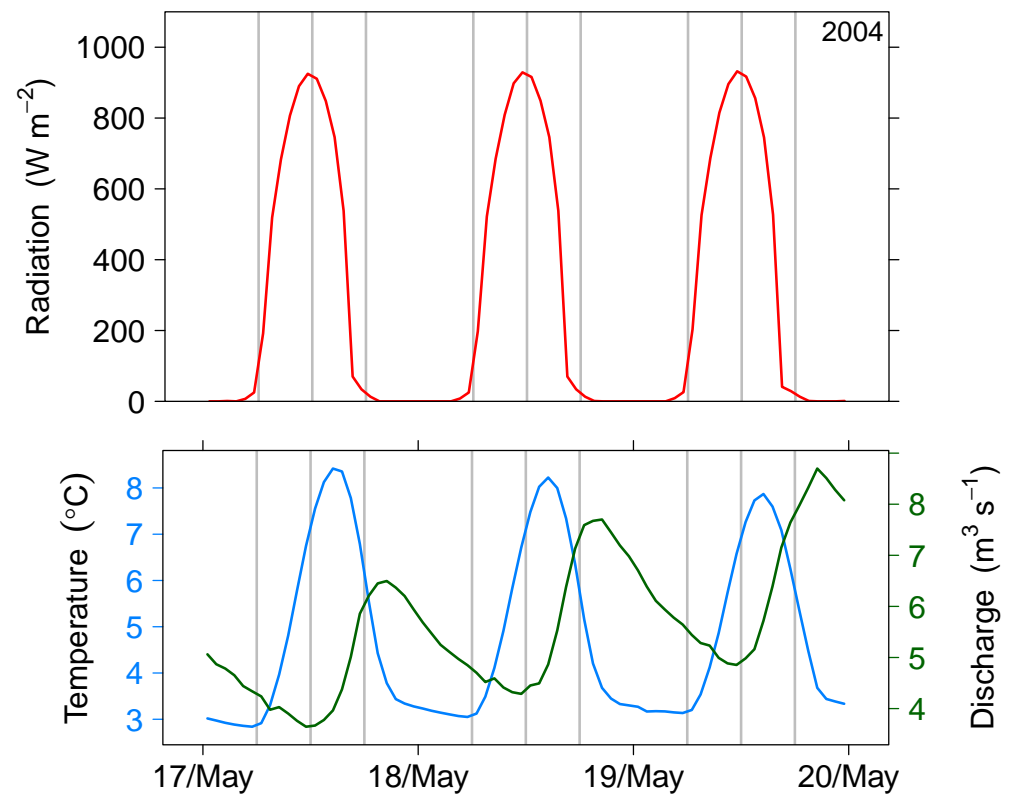

(b)

Figure 3.12: Diurnal variations of Radiation (red), water temperature (blue) and discharge (green) of the Lonza for the days: (a) 14-16 April, (b) 17-19 May, (c) 17-19 June, (d) 14-16 July, (e) 13-16 Aug, (d) 17-19 September, 2004. Vertical lines indicate 06:00, 12:00 and 18:00 hours of each day. (Continued...) 

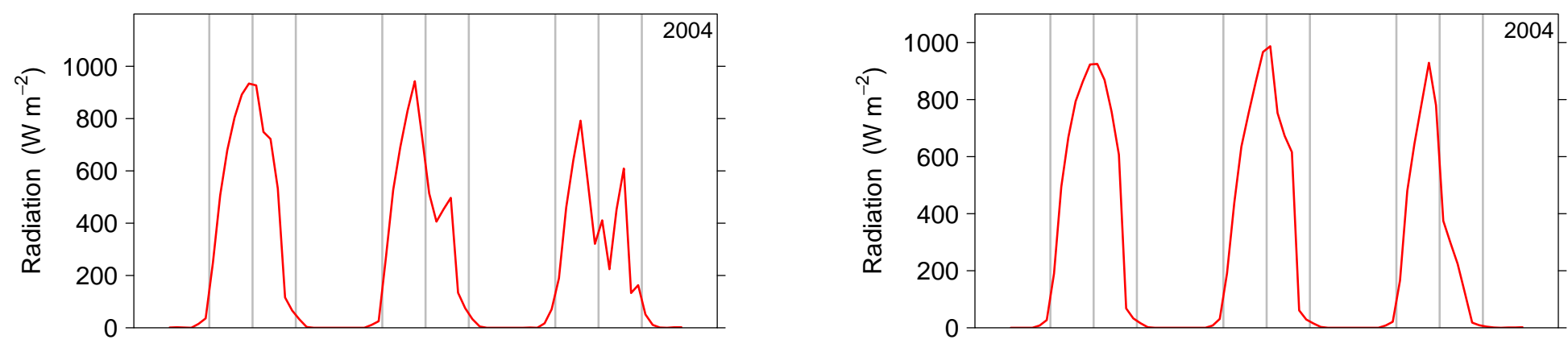

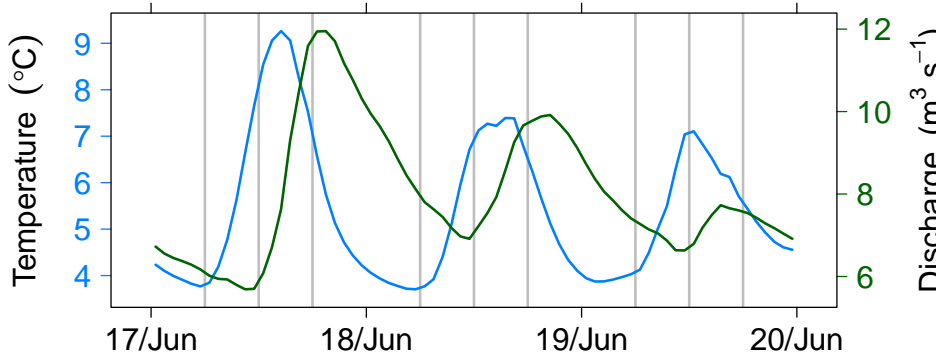

(c)

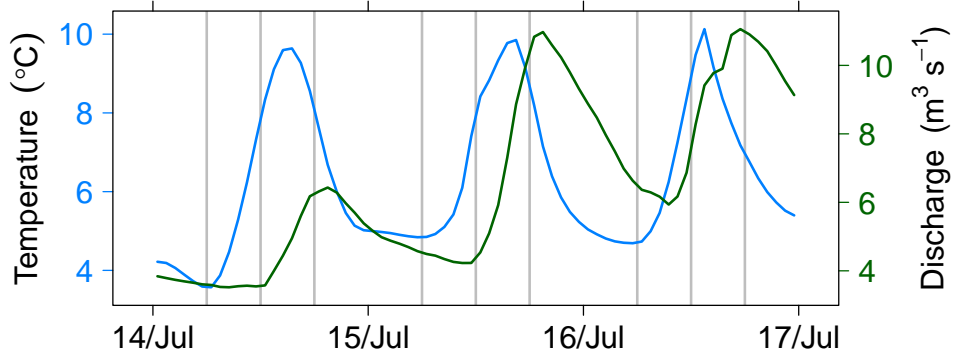

(d)

Figure 3.12: Diurnal variations of Radiation (red), water temperature (blue) and discharge (green) of the Lonza for the days: (a) 14-16 April, (b) 17-19 May, (c) 17-19 June, (d) 14-16 July, (e) 13-16 Aug, (d) 17-19 September, 2004. Vertical lines indicate 06:00, 12:00 and 18:00 hours of each day. (Continued... ) 

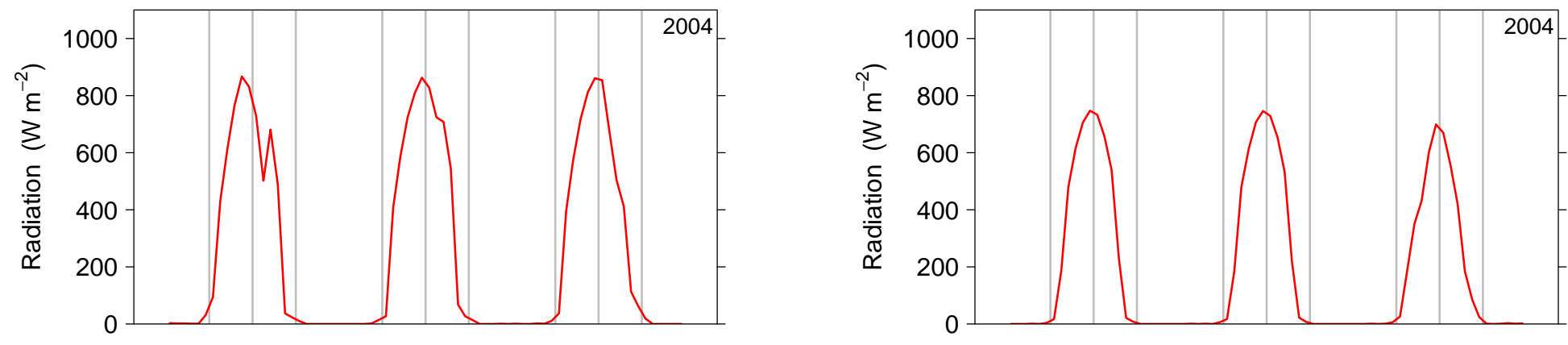

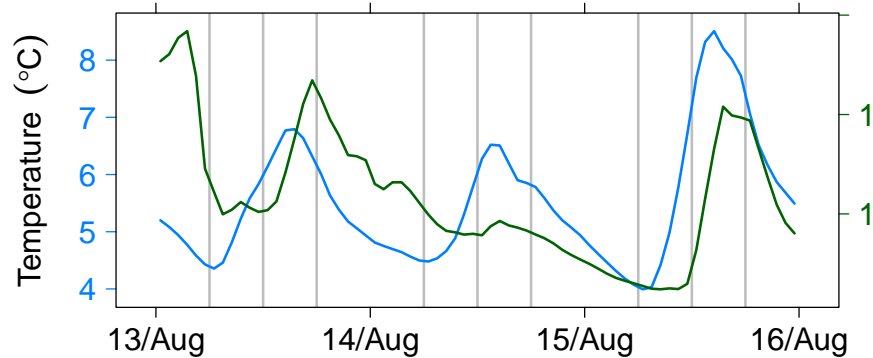

(e)
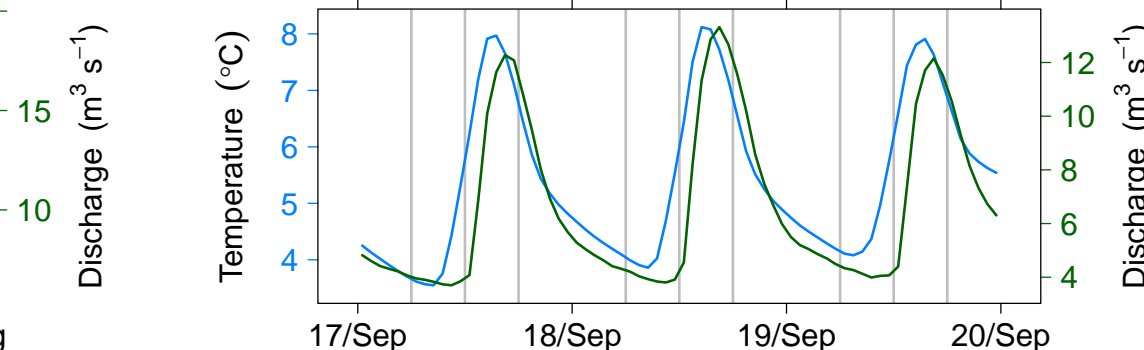

(f)

Figure 3.12: Diurnal variations of Radiation (red), water temperature (blue) and discharge (green) of the Lonza for the days: (a) 14-16 April, (b) 17-19 May, (c) 17-19 June, (d) 14-16 July, (e) 13-16 Aug, (d) 17-19 September, 2004. Vertical lines indicate 06:00, 12:00 and 18:00 hours of each day. (Concluded.) 
Stream temperature of the Lonza demonstrated a clear diurnal fluctuation throughout the study periods of each month. Daily maximum water temperature rises from the months April $\left(6.7^{\circ} \mathrm{C}\right)$ to July $\left(10.1^{\circ} \mathrm{C}\right)$. Temperature of the Lonza then drops, with falling levels of radiation and high riverflows. Influence of meteorological factors appears to be less in the Lonza than in the Massa. This is notable most in Figure 3.12c (18 June 2004) when compared to the same day for the Massa (Figure 3.11c). Unlike in the Massa the diurnal range in temperature does not appear to reduce day on day through sustained high incoming solar radiation (e.g. Figure $3.12 b$ ).

On the diurnal scale, water temperature of the Allenbach reflects levels of radiation consistently well throughout the year. Daily maximum temperatures of the Allenbach rise month on month between April and July $\left(7.6^{\circ} \mathrm{C}\right.$ in April to $13.0^{\circ} \mathrm{C}$ in July). Stream temperature then falls in-line with falling levels of incoming radiation. Figure 3.13d and Figure 3.13e, illustrate how precipitation events (indicated by substantial increases in riverflow) have a warming effect on stream temperature (17 July and 14 August). Water temperature of the Allenbach is consistently warmer than the temperature of the glacierfed rivers during every month. However, daily maximum temperatures are reached in the same month for both the Lonza and Allenbach. 

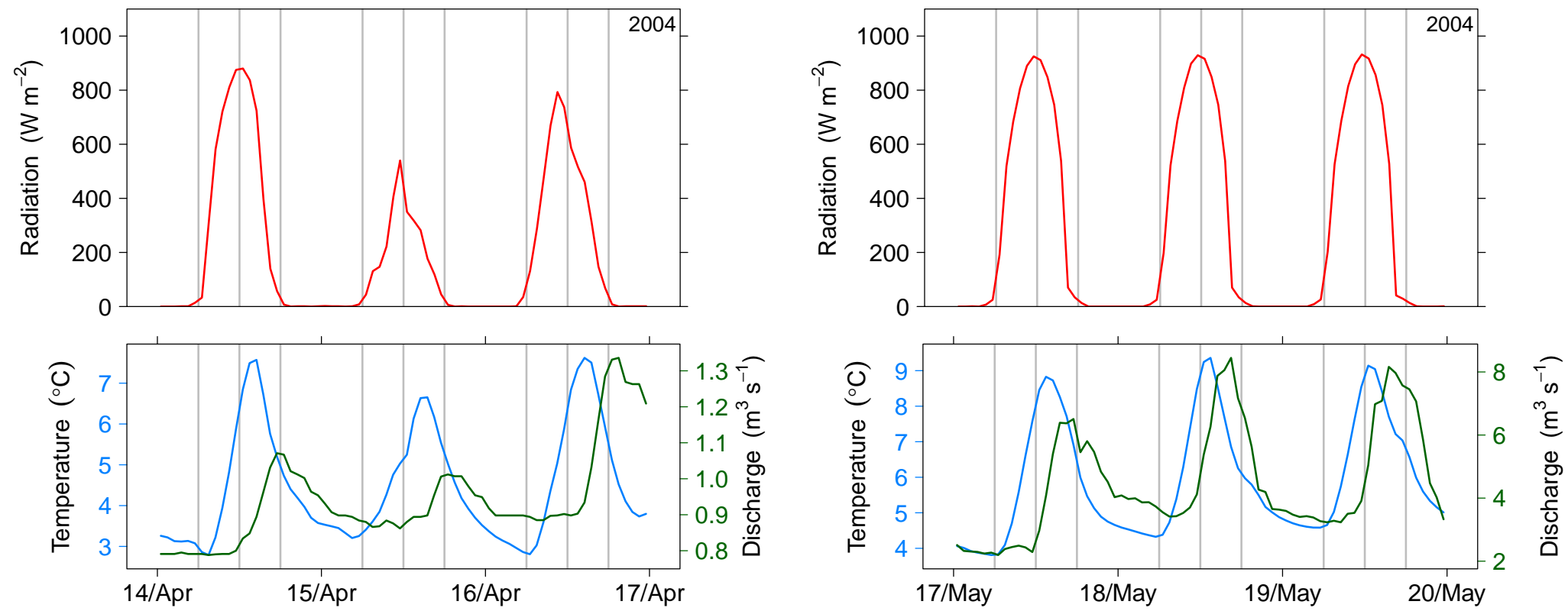

(a)

(b)

Figure 3.13: Diurnal variations of Radiation (red), water temperature (blue) and discharge (green) of the Allenbach for the days: (a) 14-16 April, (b) 17-19 May, (c) 17-19 June, (d) 14-16 July, (e) 13-16 Aug, (d) 17-19 September, 2004. Vertical lines indicate 06:00, 12:00 and 18:00 hours of each day. (Continued...) 

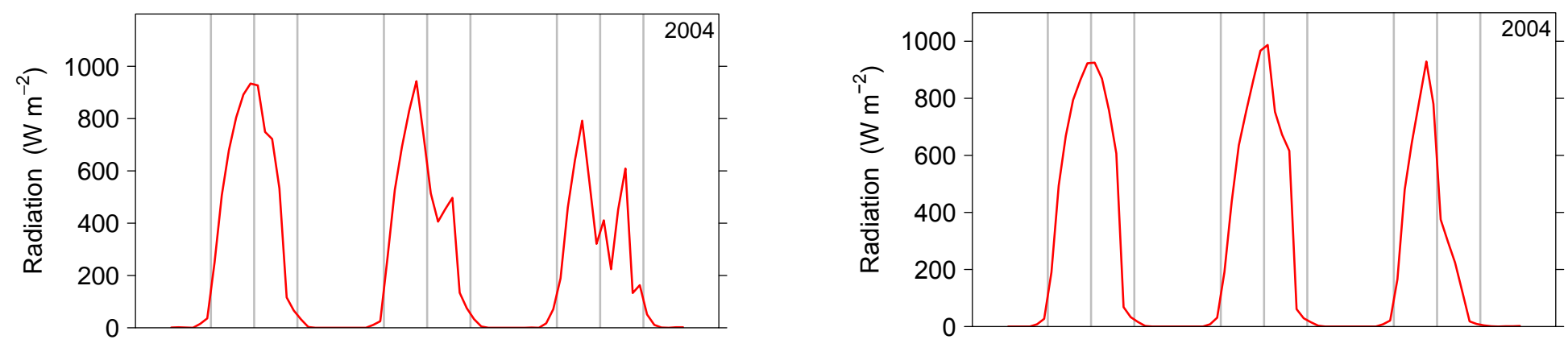

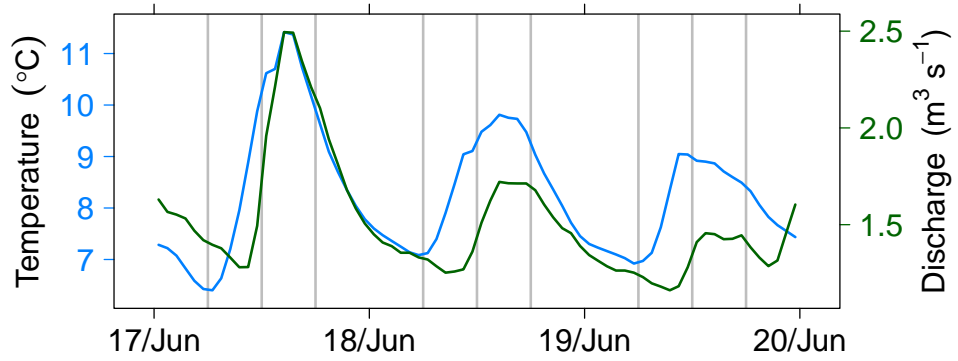

(c)

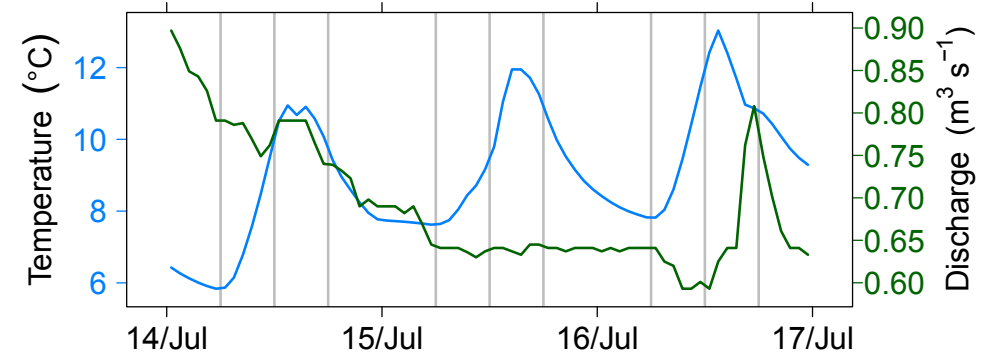

(d)

Figure 3.13: Diurnal variations of Radiation (red), water temperature (blue) and discharge (green) of the Allenbach for the days: (a) 14-16 April, (b) 17-19 May, (c) 17-19 June, (d) 14-16 July, (e) 13-16 Aug, (d) 17-19 September, 2004. Vertical lines indicate 06:00, 12:00 and 18:00 hours of each day. (Continued... ) 

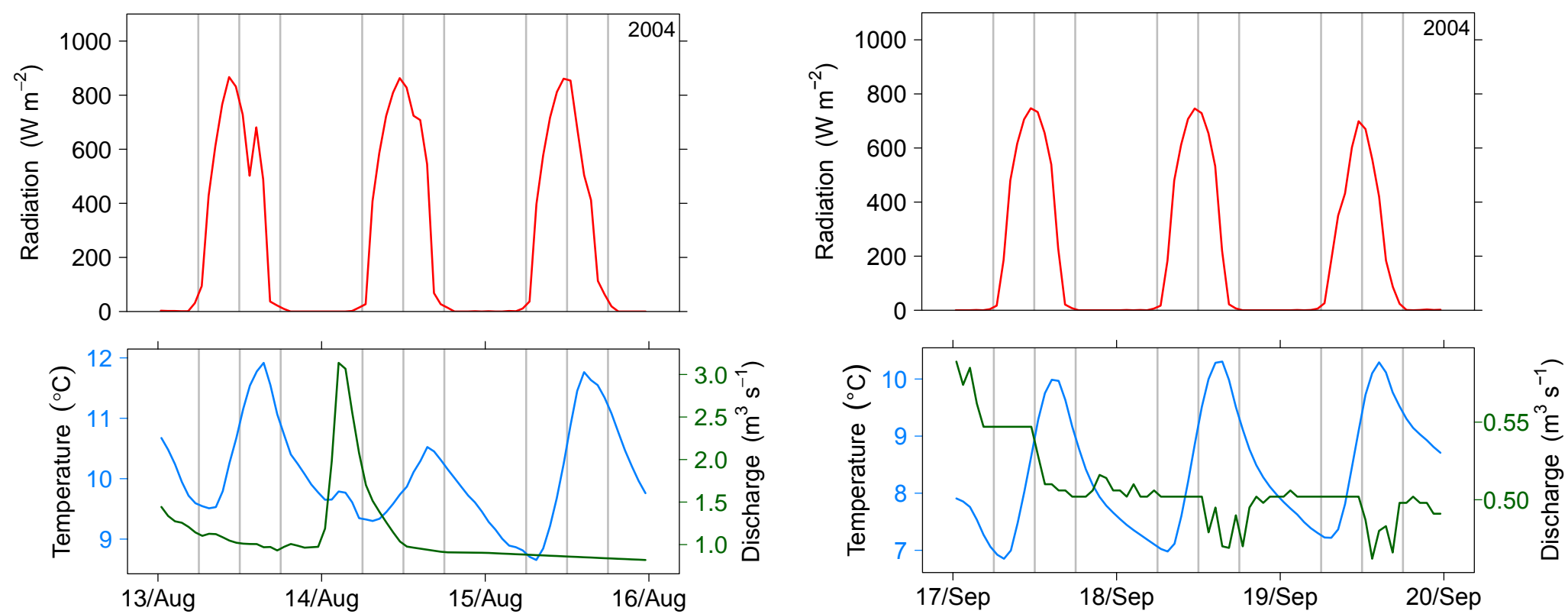

(e)

(f)

Figure 3.13: Diurnal variations of Radiation (red), water temperature (blue) and discharge (green) of the Allenbach for the days: (a) 14-16 April, (b) 17-19 May, (c) 17-19 June, (d) 14-16 July, (e) 13-16 Aug, (d) 17-19 September, 2004. Vertical lines indicate 06:00, 12:00 and 18:00 hours of each day. (Concluded.) 

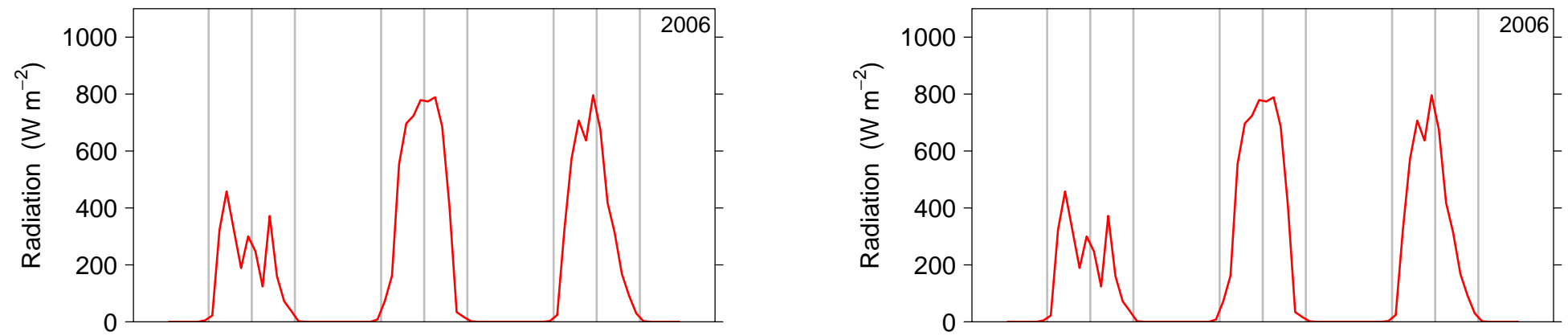

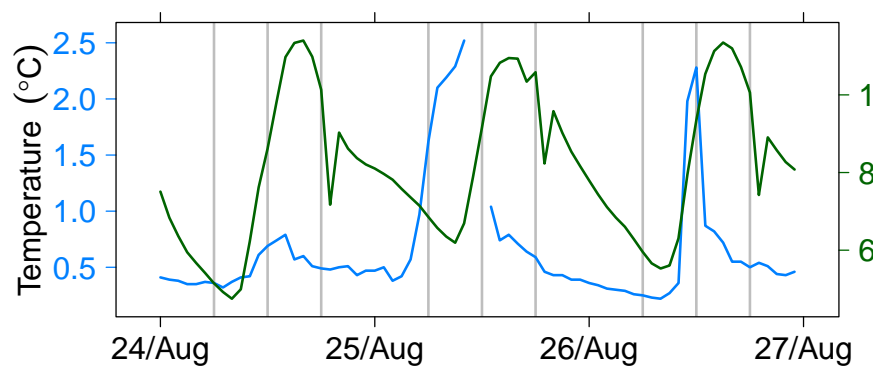

(a)

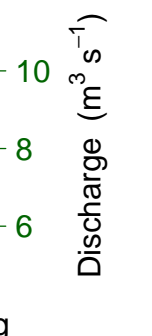

Figure 3.14: Diurnal variations of Radiation (red), water temperature (blue) and discharge (green) of the Gornera (a) and Findelenbach (b) for the days 24-27 Aug 2006. Vertical lines indicate 06:00, 12:00 and 18:00 hours of each day.

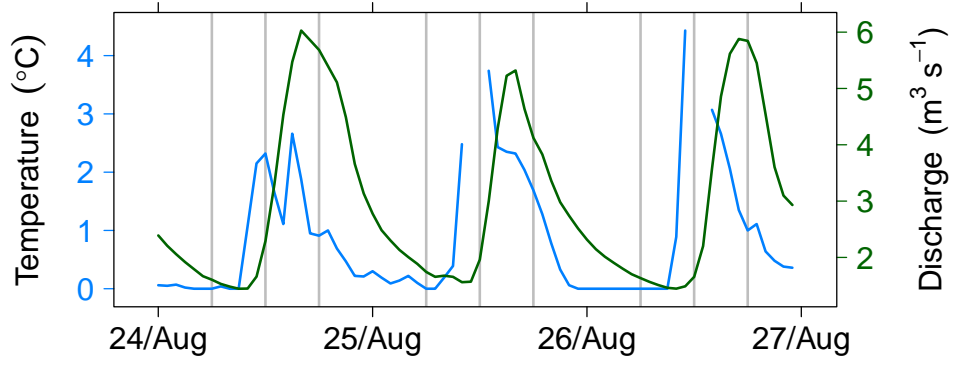

(b) 


\section{Radiation, discharge \& temperature relationships}

Total daily solar insolation $\left(\mathrm{MJ} \mathrm{m}^{-2}\right)$, actual discharge $\left(\mathrm{m}^{3}\right)$ and water temperature maxima $\left({ }^{\circ} \mathrm{C}\right)$ were used to illustrate the relationships between each variable. Analysis over three day periods is useful to demonstrate how stream temperature of glacier-fed rivers is not solely dependant upon the total incoming solar radiation of the same day. There is not always an inverse relationship between incoming solar radiation and the temperature, as total discharge does not immediately reflect radiation levels. A relatively cool day, 19 September $2004\left(168.23 \mathrm{MJ} \mathrm{m}^{-2}\right)$, is not reflected in the total discharge $\left(23.68 \times 10^{6} \mathrm{~m}^{3}\right)$, which is higher than the previous two days $\left(22.41 \times 10^{6} \mathrm{~m}^{3}\right.$ and $19.35 \times 10^{6} \mathrm{~m}^{3}$ ), despite lower levels of total shortwave radiation, 200.04 $\mathrm{MJ} \mathrm{m}^{-2}$ and $204.33 \mathrm{MJ} \mathrm{m}^{-2}$, respectively. As a result, maximum stream temperature on 19 September 2004, is lower than 17 September, following the decline in radiation. Similarly 17-19 May witnessed total insolation vary little (311.01-313.23 $\mathrm{MJ} \mathrm{m}^{-2}$ ); however, day-on-day total discharge of the Massa increases as the high radiation levels keep discharge high into the evening and early hours of the following morning. A similar decline in water temperature occurs between 17-19 May, despite radiation levels rising, albeit only slightly. This indicates that the radiation levels of a single given day can not be used as an predictor to water temperature, with the simplistic view that high radiation leads to high discharge and low water temperature. The shortwave energy levels of multiple days prior must also be considered, because of the lag time between days of high radiation and rising discharge.

Figures 3.15, 3.16, and 3.17 illustrate the clockwise hysteresis which occurs, on the diurnal scale, between specific discharge and meltwater temperature in the highly glacierised Massa and Findelenbach. Similar to lag times, hysteresis evolves throughout the ablation season. During April, water temperature varies most, rising from less than $1^{\circ} \mathrm{C}$ to greater than $2{ }^{\circ} \mathrm{C}$. Discharge, however has much less variation, hence the hysteresis is distinguished as flatter and taller. Increasing discharge in May is signified with a widening hysteresis loop, whilst temperature maxima of the meltwater remains high. Hysteresis 
in June significantly widens, as glacial meltwaters take hold. Temperatures of the basin, begin to reflect the typically low summer temperature with little variance, thus the hysteresis loop shortens. Further shortening and widening leads to a differently shaped hysteresis in July and August. Average runoff levels in September reduce rapidly, flattening the hysteresis in width, temperatures remain low and vary little which is reflected in the loop's shape returning to one similar to that which would be expected in May and June. 

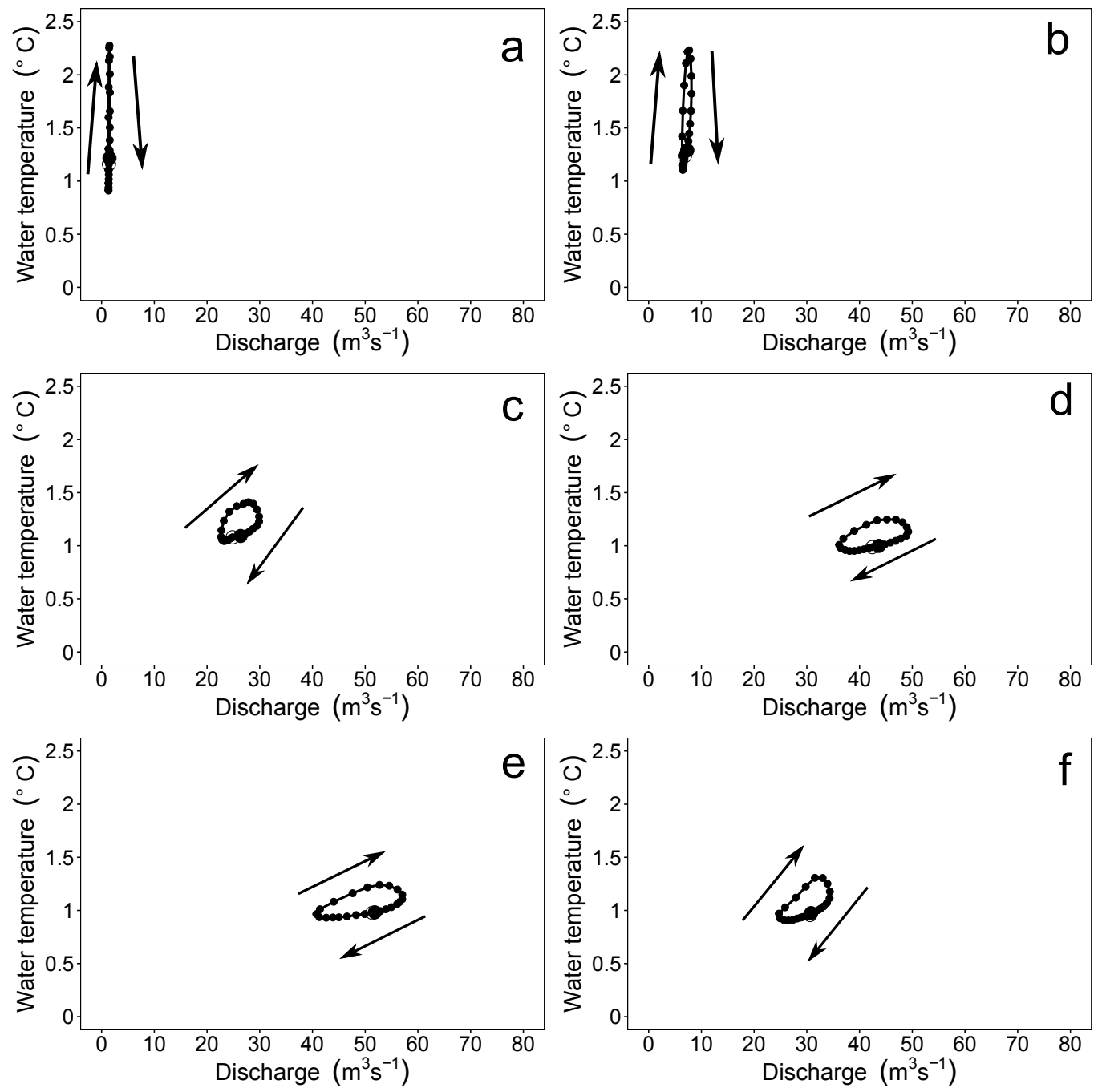

Figure 3.15: Diel cycles illustrating hysteresis of specific discharge (x axis) and water temperature (y axis), the average of each hour within the calendar months April (a) - September (f) 2004, for the Massa. Open circle indicates the start of the loop, closed circle designates the loop end. 

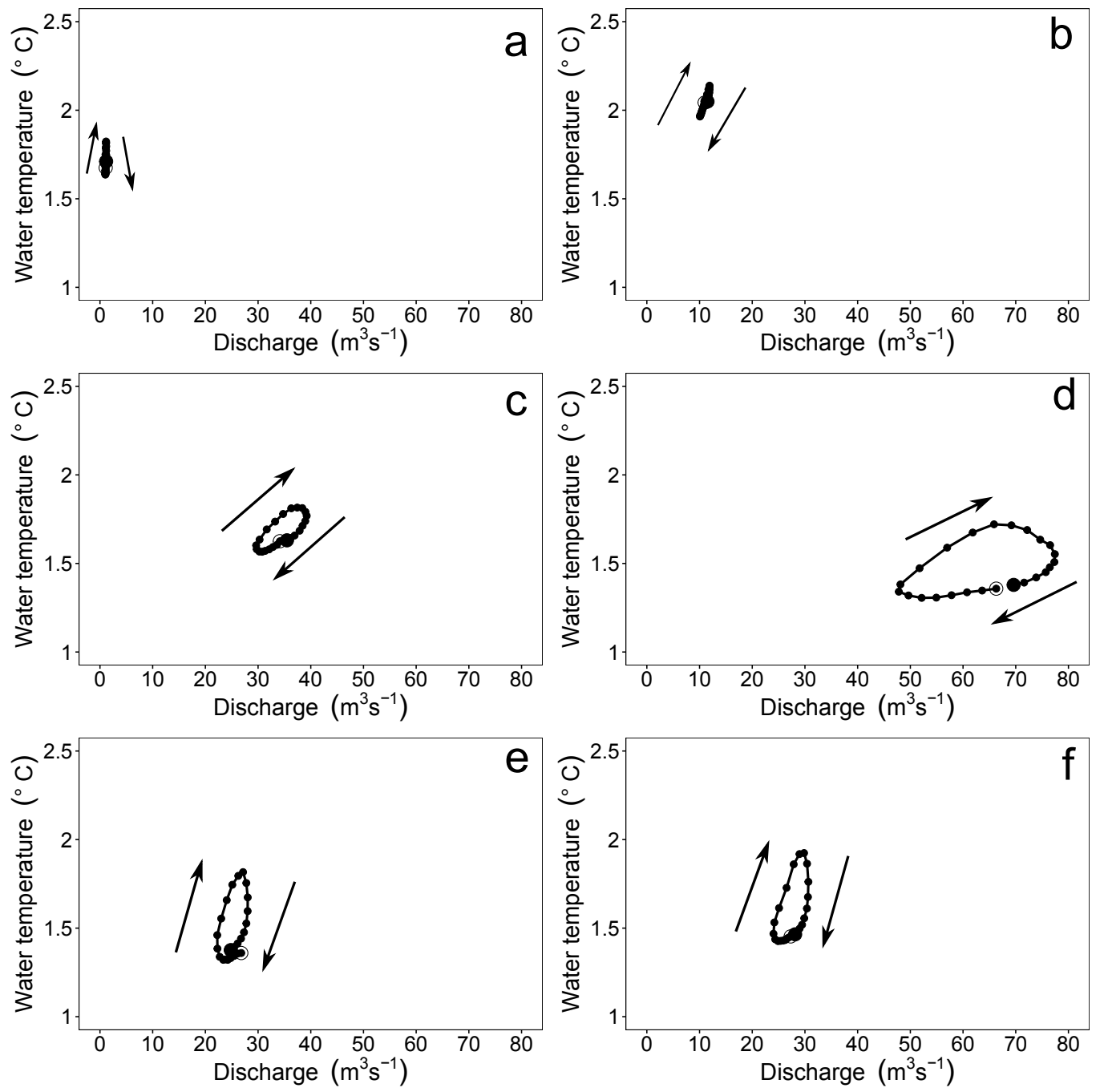

Figure 3.16: Diel cycles illustrating hysteresis of specific discharge (x axis) and water temperature (y axis), the average of each hour within the calendar months April (a) - September (f) 2006, for the Massa. Open circle indicates the start of the loop, closed circle designates the loop end. 

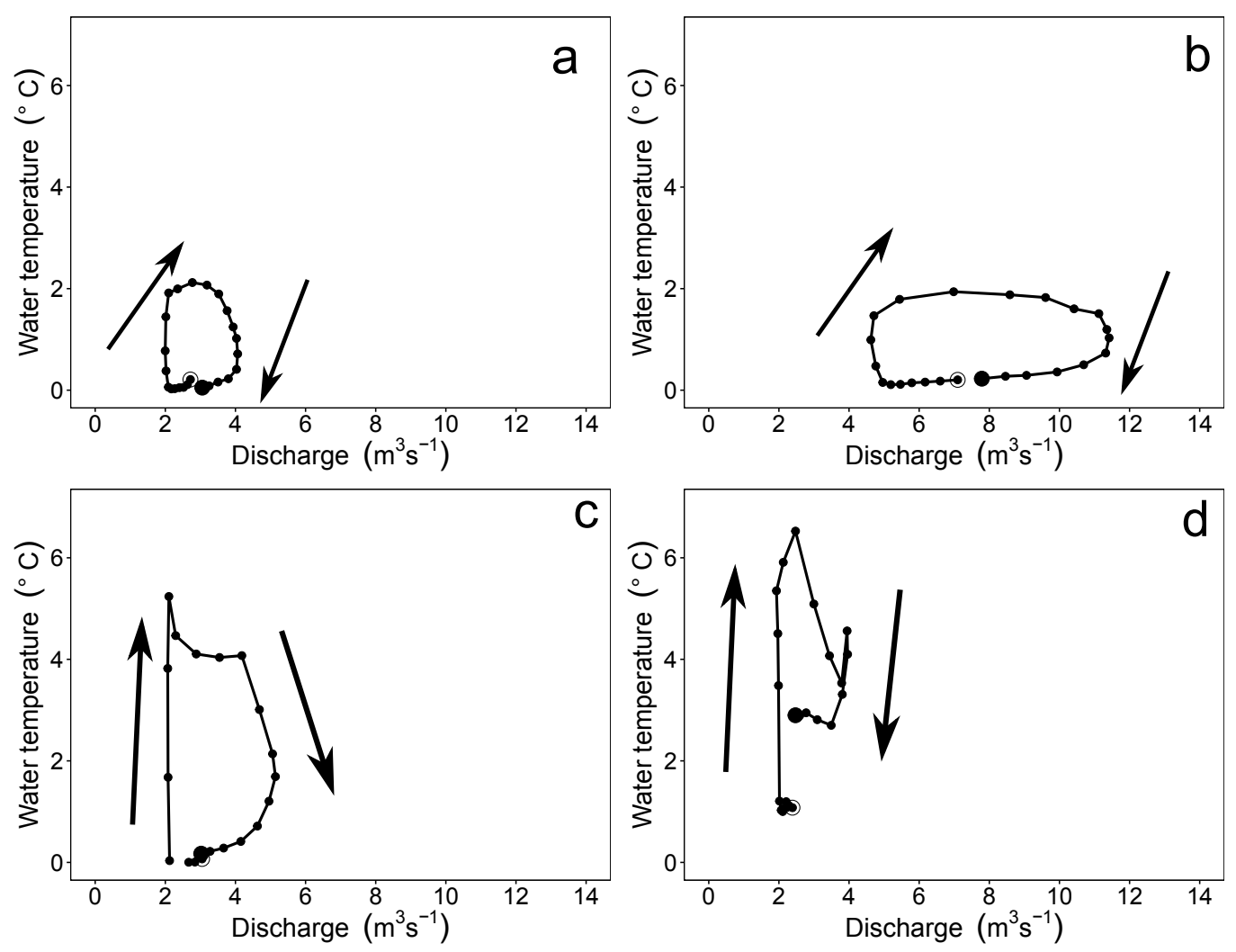

Figure 3.17: Diel cycles illustrating hysteresis of specific discharge (x axis) and water temperature (y axis), the average of each hour within the calendar months June (a) - September (d) 2006, for the Findelenbach. Open circle indicates the start of the loop, closed circle designates the loop end. 
Similar hysteresis is illustrated in the Lonza (Figure 3.18). However, discharge levels increase whilst water temperature ranges remain similar throughout the months April--July. Ranges in stream temperature narrow in the months of August and September.

Scatterplots of mean hourly discharge and water temperatures of the snowmeltfed Allenbach (Figure 3.19) shows water temperatures rise synchronously with discharge. This rise continues as runoff levels begin to decline. In the late afternoon, temperatures and discharge fall in line with one another. Figure 3.20 demonstrates cycles of water temperature with respect to levels of solar radiation. This shows a clear anti-clockwise hysteresis. Shrinking ranges in water temperatures, together with rising levels of radiation in the months April to June, lead to gradually thinner and longer loops. Loops shorten and fatten as radiation declines and temperatures become more varied from July to September. 

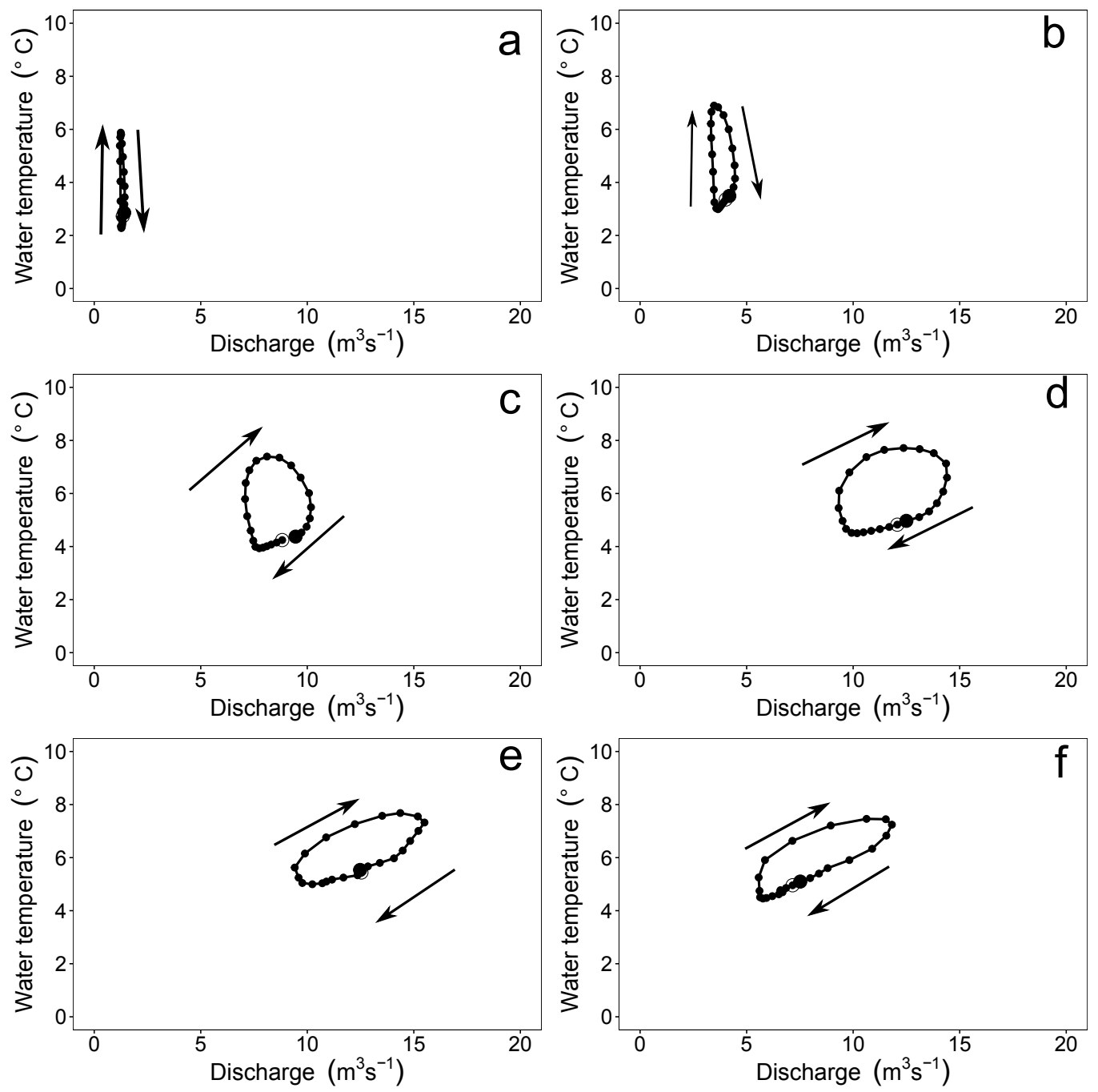

Figure 3.18: Diel cycles illustrating hysteresis of specific discharge (x axis) and water temperature (y axis), the average of each hour within the calendar months April (a) - September (f) 2004, for the Lonza. Open circle indicates the start of the loop, closed circle designates the loop end. 

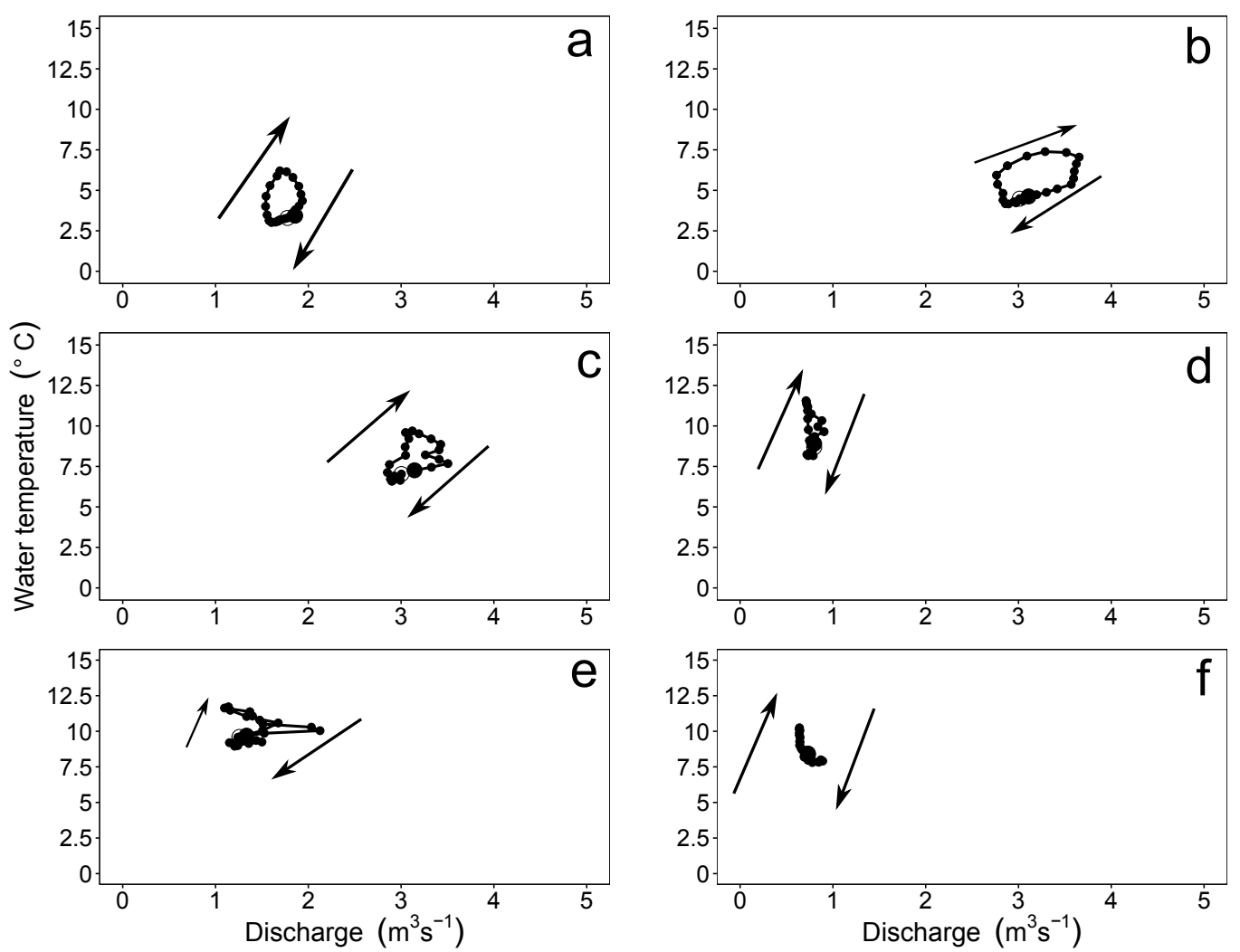

Figure 3.19: Diel cycles illustrating hysteresis of specific discharge (x axis) and water temperature (y axis), the average of each hour within the calendar months May (a) - September (f) 2004, for the Allenbach. Open circle indicates the start of the loop, closed circle designates the loop end. 

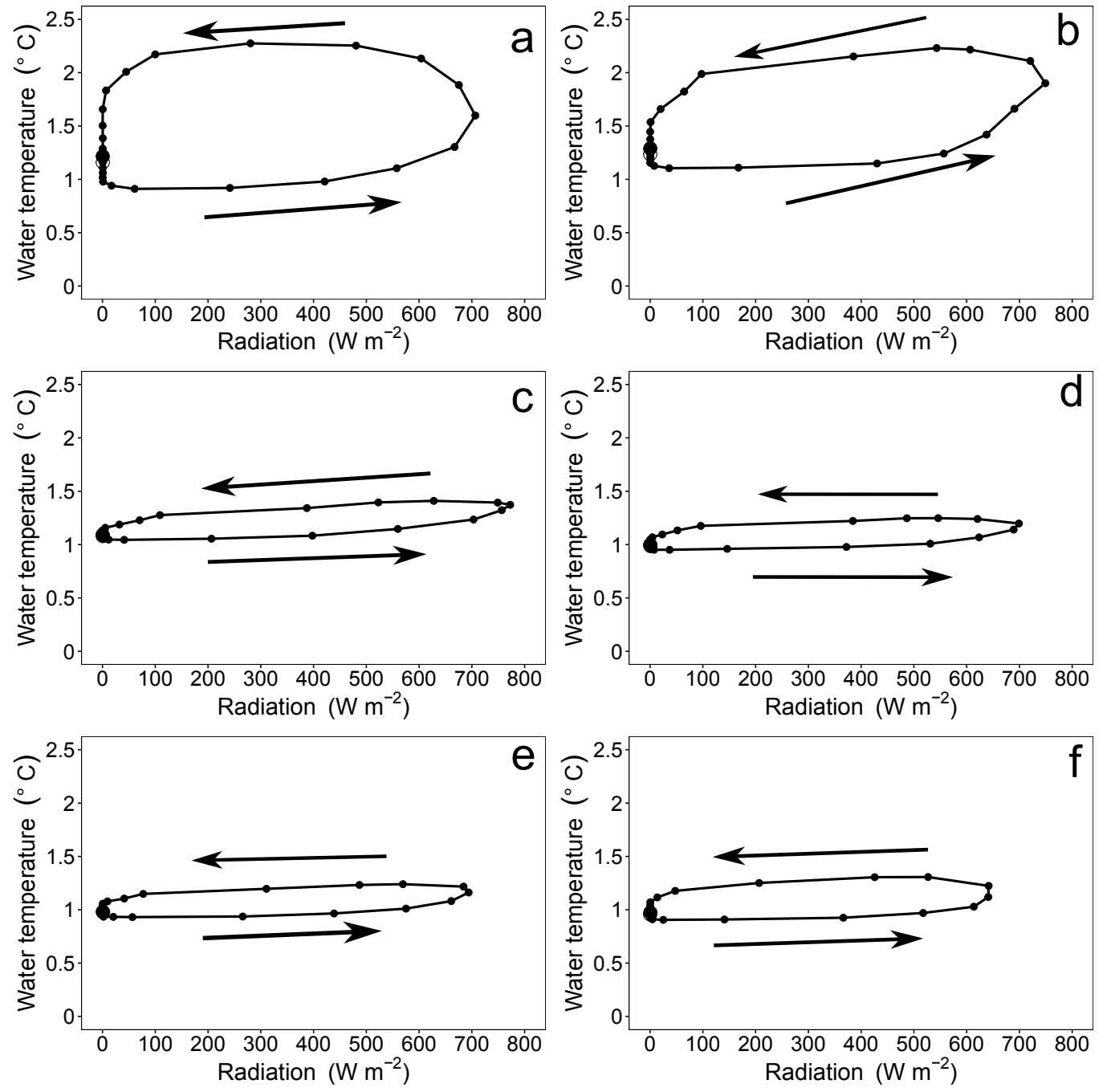

Figure 3.20: Diel cycles illustrating hysteresis of solar radiation, measured at Zermatt, (x axis) and water temperature of the Massa (y axis), the average of each hour within the calendar months April (a)-September (f) 2004. Open circle indicates the start of the loop, closed circle designates the loop end. 


\subsubsection{Year to year variations of stream temperature}

Table 3.17: Total winter precipitation $\left(P_{11-5}\right)$ measured at Zermatt, for the period 2003-2014.

\begin{tabular}{cc}
\hline Season & Precipitation $(\mathrm{mm})$ \\
\hline $2003-04$ & 163.8 \\
$2004-05$ & 259.3 \\
$2005-06$ & 246.8 \\
$2006-07$ & 386.7 \\
$2007-08$ & 317.9 \\
$2008-09$ & 422.4 \\
$2009-10$ & 356.7 \\
$2010-11$ & 164.4 \\
$2011-12$ & 396.9 \\
$2012-13$ & 444.4 \\
$2013-14$ & 469.7 \\
\hline
\end{tabular}

Total winter precipitation $\left(P_{11-5}\right)$, Table 3.17 , has a considerable effect over the discharge during the following summer (Collins, 2005). Whether fluctuations in $P_{11-5}$ alter the timing, and magnitude of maximum water temperature, in glacier-fed rivers, has been largely understudied. $P_{11-5}$ for the years 2003-04 and 2010-11 was significantly lower than other winters within the present study, only $163.8 \mathrm{~mm}$ and $164.4 \mathrm{~mm}$, respectively. Maximum $P_{11-5}$ was recorded during the winter of $2013-14(469.7 \mathrm{~mm})$ with the average total precipitation equalling $329.9 \mathrm{~mm}$.

Figure 3.21 illustrates the year to year variation in total radiation. It is clear that total levels of radiation do not mimic summer air temperatures particularly well, notable 2003 (very warm summer air temperature), had lower solar radiation receipts than 2009, for example. To better represent the effects total radiation may have on spring temperatures in the glacier-fed rivers, a subset of this data was taken, using the period prior to the summer 
Table 3.18: MWAT statistics for the Massa (M), Lonza (L) and Allenbach (A) for the period 2003-2014.

\begin{tabular}{ccccccc}
\hline Year & MWAT (M) & MWAT Date (M) & MWAT (L) & MWAT Date (L) & MWAT (A) & MWAT Date (A) \\
\hline 2003 & 1.7 & 16 Apr-22 Apr & 6.7 & 30 Jul-5 Aug & 12.5 & 6 Aug-12 Aug \\
2004 & 2.0 & 14 May-20 May & 6.6 & 3 Sep-9 Sep & 11.1 & 30 Jul-5 Aug \\
2005 & 2.0 & 23 Apr-29 Apr & 6.8 & 27 Aug-2 Sep & 11.1 & 16 Jul-21 Jul \\
2006 & 2.3 & 7 May-13 May & 6.8 & 16 Jul-21 Jul & 11.7 & 16 Jul-21 Jul \\
2007 & 2.2 & 2 Apr-8 Apr & 6.8 & 13 Aug-19 Aug & 10.5 & 16 Jul-21 Jul \\
2008 & 2.4 & 23 Apr-29 Apr & 7.0 & 30 Jul-5 Aug & 11.1 & 30 Jul-5 Aug \\
2009 & 2.2 & 30 Apr-6 May & 7.1 & 20 Aug-26 Aug & 11.1 & 20 Aug-26 Aug \\
2010 & 1.9 & 23 Apr-29 Apr & 7.5 & 9 Jul-15 Jul & 11.7 & 16 Jul-21 Jul \\
2011 & 1.7 & 2 Apr-8 Apr & 7.5 & 20 Aug-26 Aug & 12.2 & 20 Aug-26 Aug \\
2012 & 1.9 & 7 May-13 May & 7.4 & 20 Aug-26 Aug & 11.9 & 20 Aug-26 Aug \\
2013 & 1.7 & 9 Apr-15 Apr & 7.1 & 16 Jul-21 Jul & 11.4 & 22 Jul-29 Jul \\
2014 & 1.7 & 2 Apr-8 Apr & 7.1 & 16 Jul-21 Jul & 10.0 & 6 Aug-12 Aug \\
\hline
\end{tabular}


solstice, but after the spring maxima water temperature has subsided (Figure $3.22)$.

MWAT statistics were used to determine the relationship between meteorological variables and annual water temperatures, such statistics give the 7 day maximum average water temperature, together with the dates which the 7 day period occurred. Useful, not only to show changes in the magnitude of water temperature maxima, but also the timing of the peak (Table 3.18).

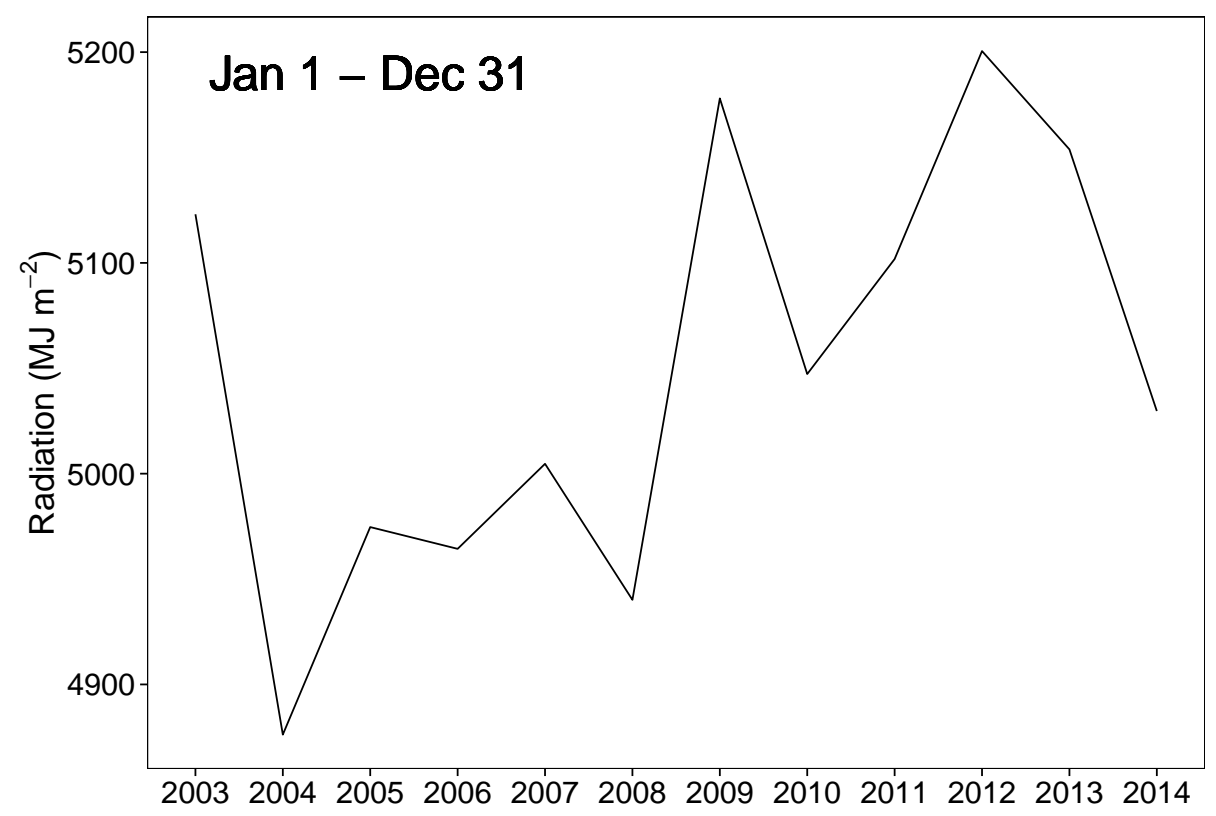

Figure 3.21: Year-to-year variations of total incoming shortwave radiation for the period 2003-2014. 


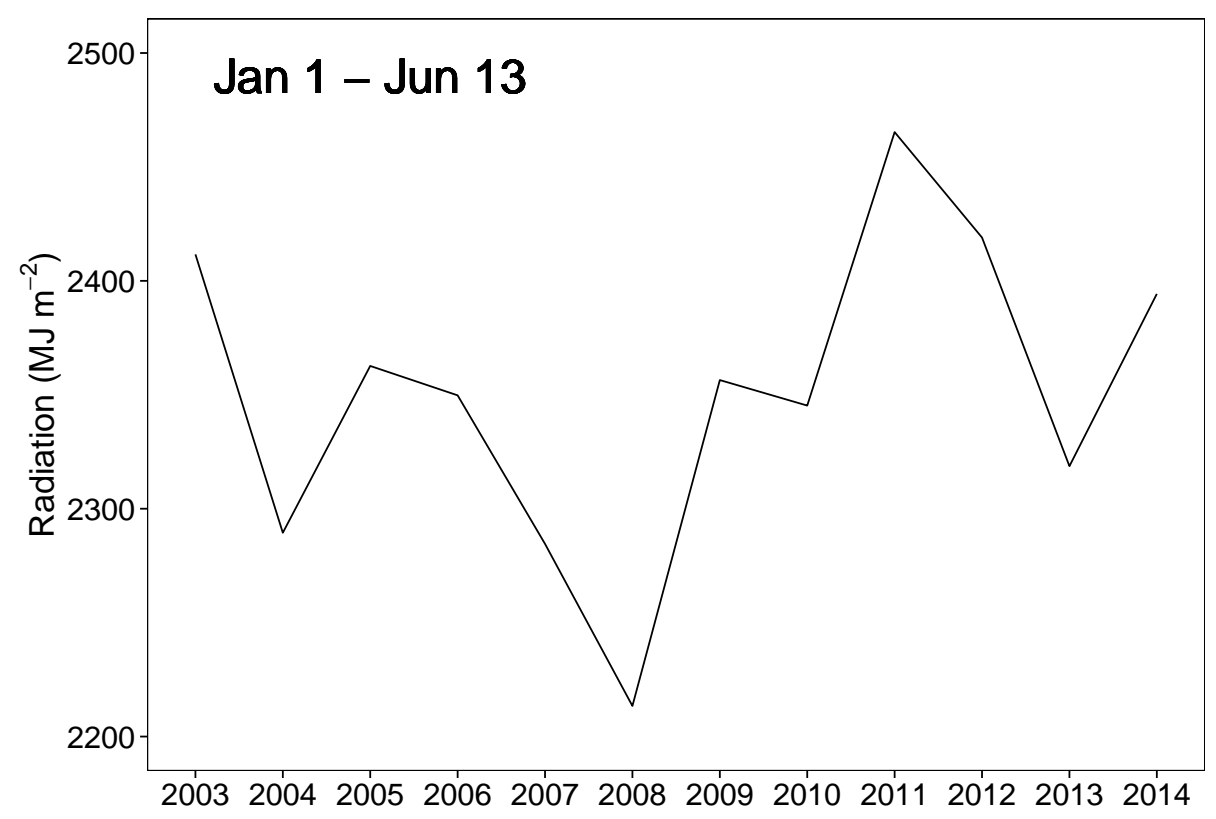

Figure 3.22: Year-to-year variations of total incoming shortwave radiation between Jan 1 and June 13, for the period 2003-2014.

\subsection{Discussion}

This study has assessed relationships between basin characteristics, which are influential in determining percentage glacierisation, radiation and discharge and the effects these relationships play on determining temperature of water downstream of large glaciers. Furthermore, some interesting results have been obtained and a substantial dataset has been collated from various sources as a result of this analysis. The following section outlines the essential determiners of the outlined processes and assesses how these results correspond with other studies.

Multiple linear regression (after Fellman et al., 2014) was a useful tool in assessing the influence of meteorological and basin characteristic factors on stream temperature. Results herein show that, for the four glacier-fed rivers used in this study, percentage glacierisation, often said to be the main predictor (Fellman et al., 2014; Moore, 2006), was not the major determiner in av- 
erage monthly stream temperatures. Instead, reach area (average width $\times$ length) is a better predictor. This provides explanation as to why temperatures of the Findelenbach, a much wider stream, tend to be warmer than rivers in other highly glacierised basins. Additionally, riverflows, despite having a negative influence on stream temperature, appear only to be a small determiner in seasonal temperature. The low influence of riverflow in the MLR adds weight to the suggestion that the relationship between rising discharge and falling summer temperatures is more complex than previously thought (i.e. not a direct relationship between rising riverflow, increasing heat capacity and lower temperatures).

\subsubsection{Variations of water temperature and hydro met- eorological variables}

This study has illustrated an interesting and previously undocumented phenomena with respect to patterns in summer water temperature of glacier-fed streams. Thermal regimes of streams emanating from glacier-fed rivers in the European Alps have a distinctive pattern, whereby maximum water temperature occurs in the Spring. Temperatures in the $65.9 \%$ glacierised Massa rise in-line with heightening levels of incoming shortwave radiation, between the months January and April. Discharge during the same period remains low and insignificant, thus with water at the glacier portal thought to be $\sim 1^{\circ} \mathrm{C}$ (Collins, 2009), incoming solar radiation can raise water temperatures easily. During May and June, increasing rates of melt significantly raise volumetric flow in the basin, with total weekly discharge rising dramatically from close to $0 \times 10^{6} \mathrm{~m}^{3}$ to greater than $40 \times 10^{6} \mathrm{~m}^{3}$, peaking usually in July or August. The summer solstice occurs on June 21 (June 20 on leap years) and maximum solar radiation occurs around this date. Between May and the summer solstice, levels of incoming solar radiation continue to rise. However, stream discharge also begins to rise significantly. Therefore, despite more heat being available to melt, the quantity of water within the reach is larger and this therefore offsets the greater energy availability. Consequently, stream tem- 
peratures are reduced and remain consistent throughout the summer period. These findings are in-line with other studies into summer temperatures in glacier-fed streams (Blaen et al., 2012; Cadbury et al., 2008; Fellman et al., 2014). Into October, volumetric flow returns to extremely low levels, and despite incoming solar radiation declining, less energy is needed to warm the lower volumes of water. Therefore, there is often a slight increase in water temperatures, before they begin to decline, in-line with falling levels of solar radiation. This pattern is most notable in the temperature regime of the Massa (65.9\% glacierised), where year-round temperature measurements were plentiful. The more highly glacierised Findelen and Gornera (73\% and 83.7\% respectively) appeared to follow the thermal regime of the Massa, during the period where data was available and could be compared.

Temperature graphs of the Lonza and Allenbach are remarkably similar in shape, despite the presence of glacier ice in the Lonza catchment (36.5\% glacierised) and despite the similarity of the Lonza hydrograph to that of discharge from the three highly glacierised catchments. There is, however, a reduction in the water temperature of the Lonza in comparison to the Allenbach, with maximum temperatures of the Lonza being on average lower than those recorded in the Allenbach. The reduction in water temperature indicates that discharge from the glacier still has some influence.

The timing of water temperature maximum is dependant upon the time of increasing discharge resulting from melting glacier ice. For example, MWAT statistics show that maximum temperature in the Massa occurs between 2-8 April and as late as 14-20 May. There appears to be no correlation between warm years and either cooler or warmer water temperatures. It is suggested, therefore, that peak water temperature is influenced both by the present years' radiation, but also by the previous winters precipitation. Should total snowfall from the previous winter be high, then the build up of the winter snow pack would be greater. This means a larger proportion of the basin would be snow covered as opposed to exposed ice, thus the albedo of the basin surface receiving radiation from the sun would be greater. If more radiation is reflected than absorbed, less meltwater will be produced and higher 
discharges will be delayed later into the year, as the winter snow pack recedes. The opposite would be true should the previous winter be witness to lower precipitation, in which case more ice will be exposed to melting early in the season; discharges will, therefore, be greater earlier in the season (Fleming, 2005).

In the build-up to the water temperature maxima, daily mean temperature values vary greatly. Deviations significantly decline after the spring maxima, before rising again at the end of the 'summer period', notably: June, July, August and September (Figure 3.10). This effect is seen to a much lesser extent in the Lonza, 36\% glacierised, (Figure 3.9) and is not visible in temperatures of the ice-free Allenbach, where variance is lower through the winter (Figure $3.8)$.

Analysis of the diurnal fluctuations in water temperature, discharge and incoming shortwave radiation across the entire season is relatively understudied. The relationships between, incoming solar radiation, specific discharge, and water temperature is complex. With respect to the highly glacierised catchments, runoff increases with a steep rising limb to a peak in the late afternoon, usually around 18:00, before falling gradually into the second day (see Figure 3.11). A portion of melt from day one will be delayed in the glacier system for a period of time, hence the more gentle falling limb on the hydrograph. Runoff on the second day will begin to rise shortly after sunrise. Some of the previous days discharge will still be passing through the glacial system, hence levels of runoff do not decline to minima of the previous day. The build up of discharge in such a way produces a distinctive incline in the hydrograph over multiple days (when shortwave radiation remains high). This pattern is mimicked in the 4 glacier-fed rivers, irrespective of percentage glacierisation. The ice-free Allenbach reflects this evolution in discharge, for the months April through June, when runoff from the basin is fed mostly by melting of the winter snowpack. Discharge in the subsequent months reflects short rainfall events (e.g. Figure 3.13e). 


\subsubsection{Relationships between air temperature, global ra- diation, discharge and water temperature}

To ascertain the relationship between warm air temperature and cooler temperatures, four years were chosen for analysis. The years $2003\left(19.9^{\circ} \mathrm{C}\right)$ and $2009\left(18.7^{\circ} \mathrm{C}\right)$ were selected as 'warm' years with $2004\left(17.8^{\circ} \mathrm{C}\right)$ and 2007 $\left(17.3^{\circ} \mathrm{C}\right.$ ) chosen for 'cool' years (using $\mathrm{T}_{2 m}$, May-September, air temperature records at Sion, Figure 3.2). Total incoming solar radiation was highest in $2009\left(5170 \mathrm{MJ} \mathrm{m}^{-2}\right)$, lower in 2003 - despite higher summer air temperature - $\left(5120 \mathrm{MJ} \mathrm{m}^{-2}\right)$. Shortwave radiation totals during 2004 and 2007 were measured at $4890 \mathrm{MJ} \mathrm{m}^{-2}$ and $5000 \mathrm{MJ} \mathrm{m}^{-2}$, respectively. Interconnections between summer air temperature, incoming shortwave radiation and water temperature in glacier-fed streams was complex (Figure 3.23). Despite significant warmer summer air temperature in 2003, water temperature of the Massa was substantially lower than those of 2007 (Figure 3.23a). Temperatures increased more rapidly to a greater spring maximum in $2007\left(2.15^{\circ} \mathrm{C}\right)$ whilst only heating to $\left(1.66^{\circ} \mathrm{C}\right)$ during 2003 . Temperatures better reflect the substantially higher discharge levels, annual average discharge in 2003 was $24.2 \%$ greater than that of 2007 (Figure 3.24). Comparatively, water temperature of the Massa during the warm year of 2009, was greater than that of the cooler 2004. Contrary to 2003/2007, average discharge levels measured in 2009 were also greater than those measured in 2004 by $8.4 \%$. This study suggests that there is no general trend between warmer summers (both in terms of those with high summer air temperatures of those with greater total shortwave radiation receipts), and cooler water temperatures in glacier fed rivers. This is despite a clear trend of greater discharges in years with high summer air temperature and high annual total radiation.

The results of the MWAT analysis showed there to be no apparent link between either: warmer summer air temperatures and spring solar radiation receipts and maximum weekly average water temperature. Although high spring shortwave radiation receipts, often reflected cooler water temperature maxima, especially when combined with years which followed drier winters 
(i.e. lower winter precipitation). For example, 2011 was witness to substantial total spring solar radiation $\left(>2400 \mathrm{MJ} \mathrm{m}^{-2}\right.$ ), and followed a relatively dry winter $\left(P_{11-5}=164.4 \mathrm{~mm}\right)$, with $\mathrm{MWAT}=1.7^{\circ} \mathrm{C}$. Comparatively, 2012 was witness to greater, albeit similar, levels of spring radiation, however levels of winter precipitation was also more great $(396.9 \mathrm{~mm})$. This resulted in MWAT temperature occurring much later into the year (May 7-13 compared to April 2-8). As a result maximum water temperature was higher in 2012, possibly due to the rising riverflow being delayed by the winter snow pack, allowing more time for the high levels of radiation to rise the temperature of the stream. This further highlights the complexity of the variables driving water temperature, showing that there is not a simple paradoxical relationship between high air temperatures or/and solar radiation levels and water temperature. 


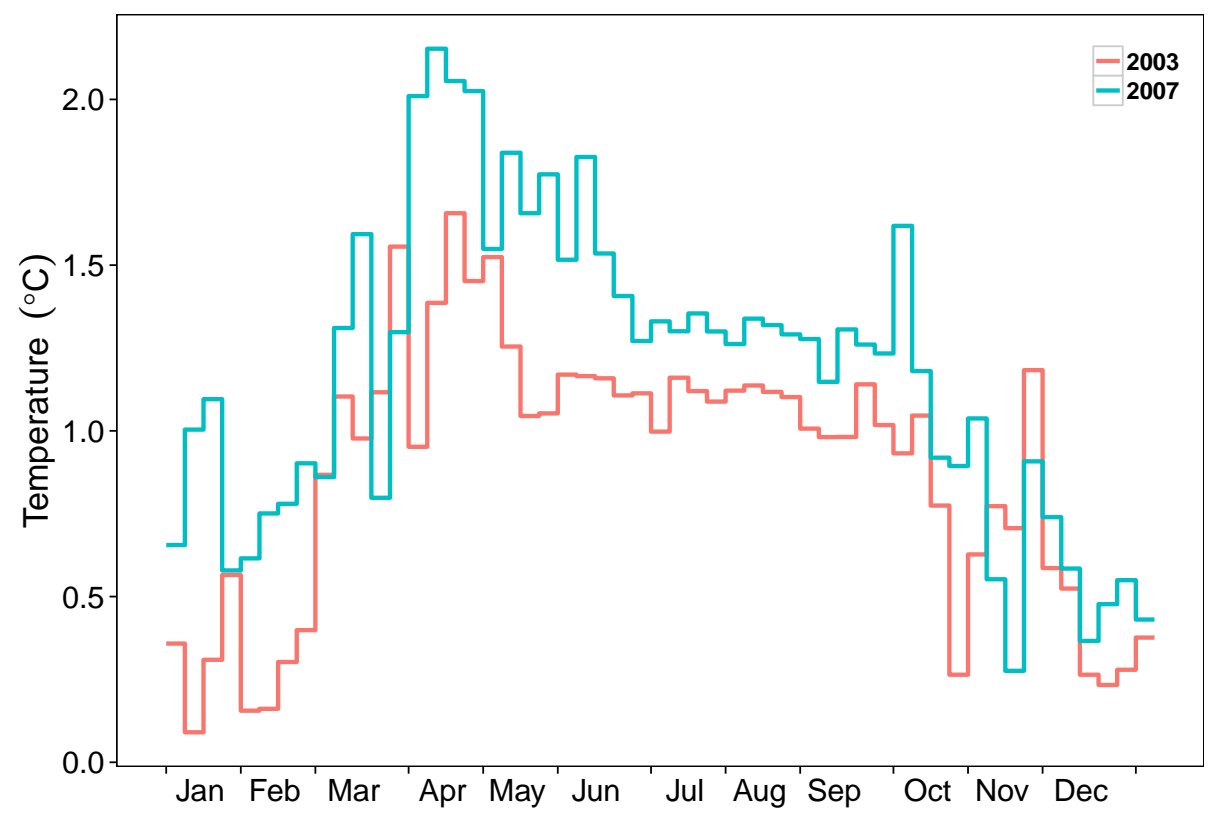

(a)

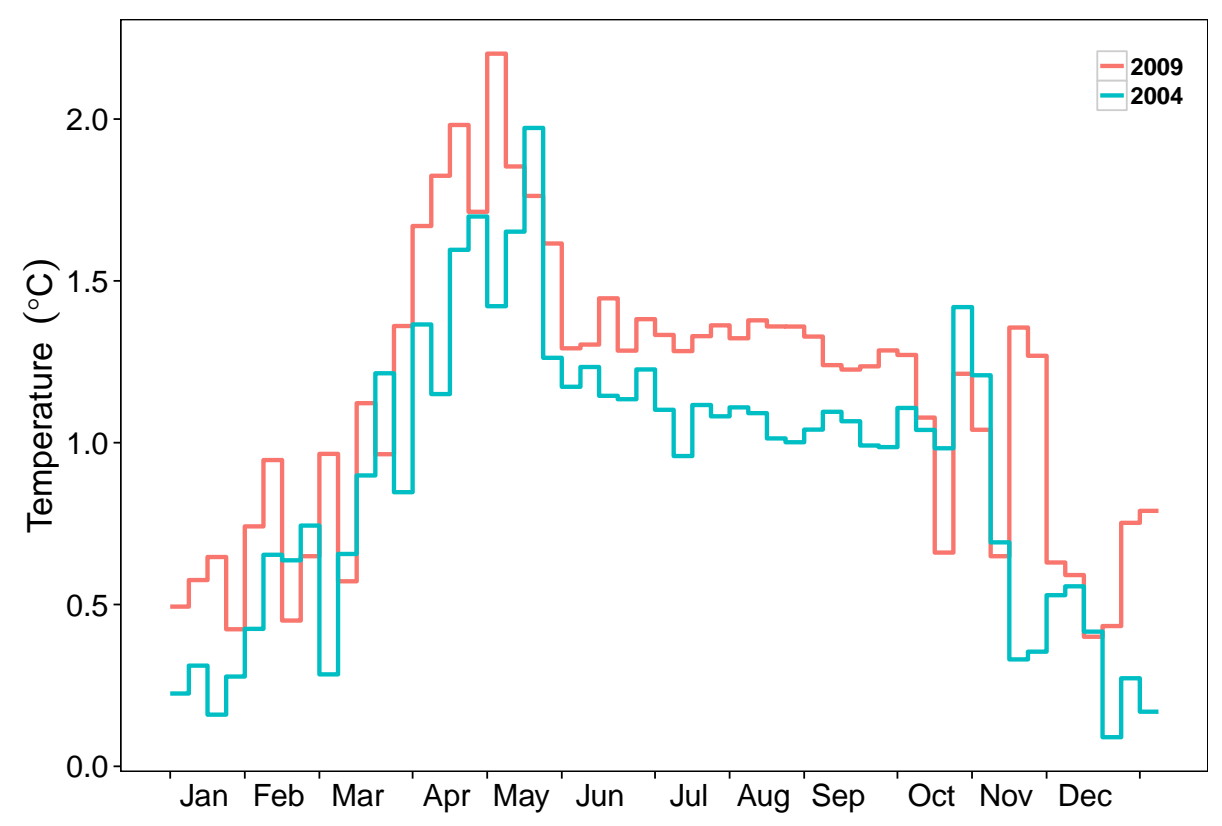

(b)

Figure 3.23: Comparisons of seasonal stream temperature patterns (7 day averages) in the Massa for the years (a) 2003 and 2007 and (b) 2004 and 2009. 


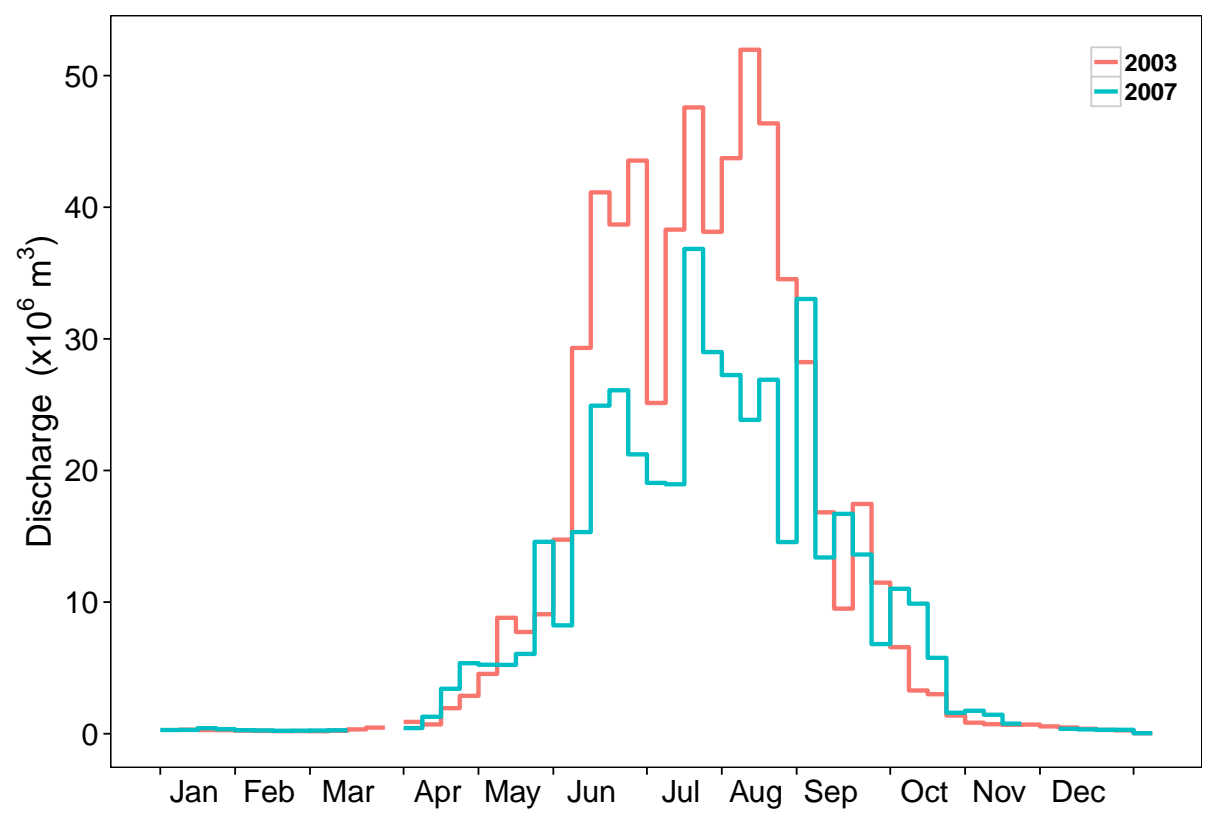

(a)

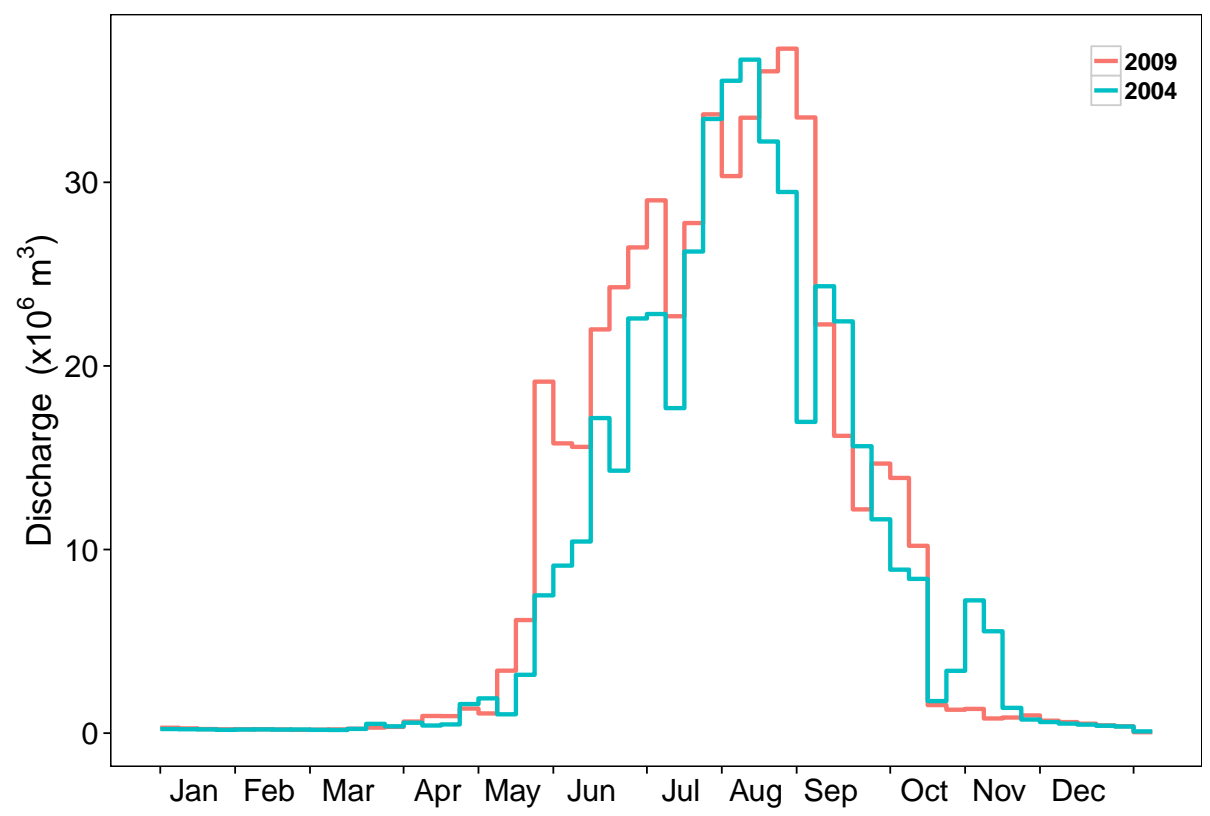

(b)

Figure 3.24: Comparisons of seasonal riverflow variations (7 day totals) of the Massa for the years (a) 2003 and 2007 and (b) 2004 and 2009. 


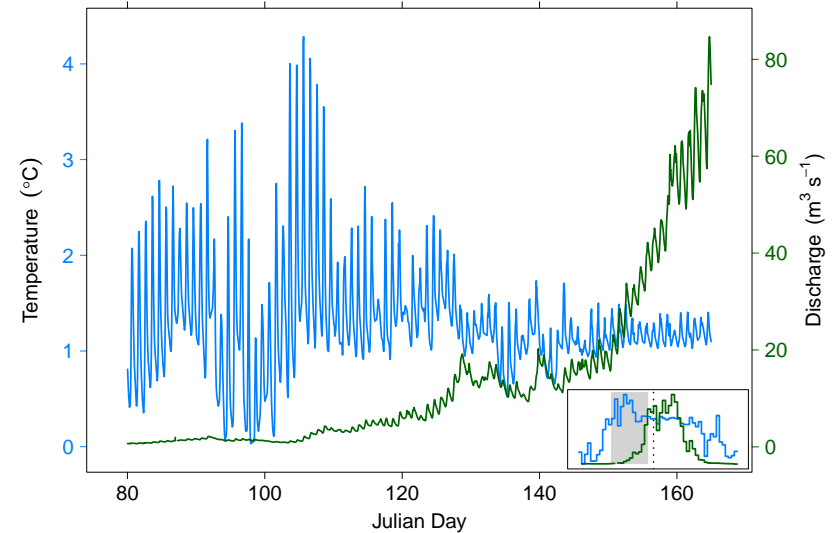

(a)

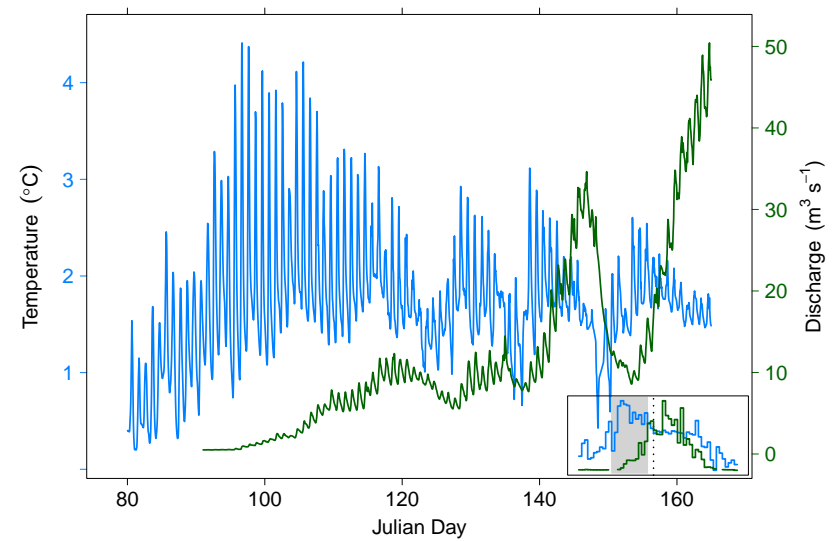

(c)

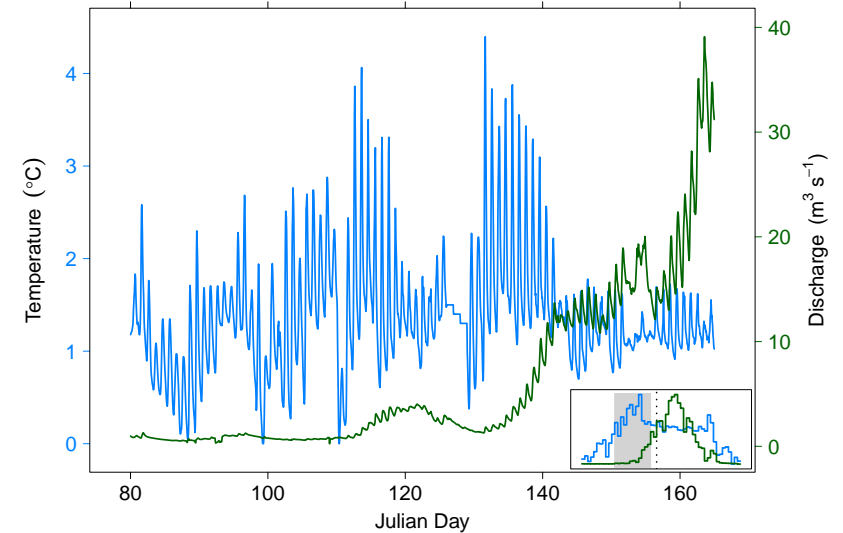

(b)

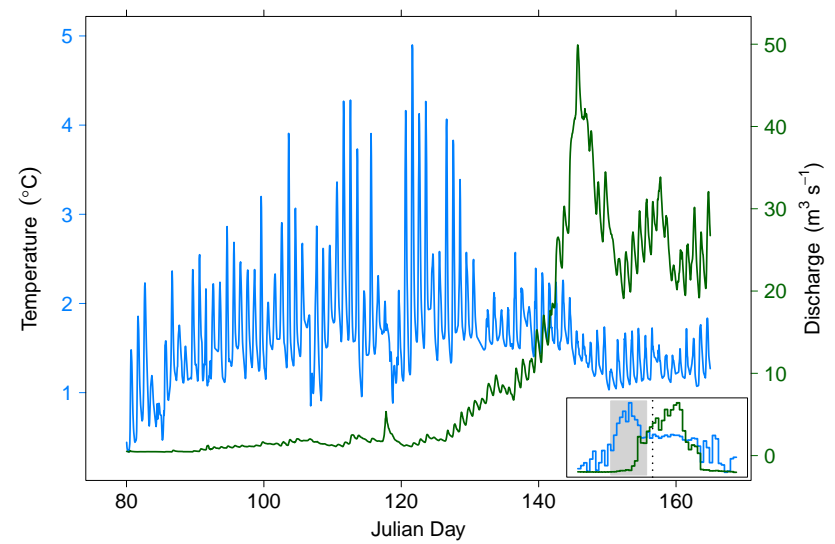

(d)

$\stackrel{\Xi}{\sim} \quad$ Figure 3.25: Diurnal variations of water temperature and discharge of the Massa between March 21 (Julian day 80) and June 13 (Julian day 164) for the years; (a) 2003, (b) 2004, (c) 2007, and (d) 2009. Inset: Seasonal patterns of 7 day average, water temperature and discharge, grey box outlining Julian days $80-164$. 


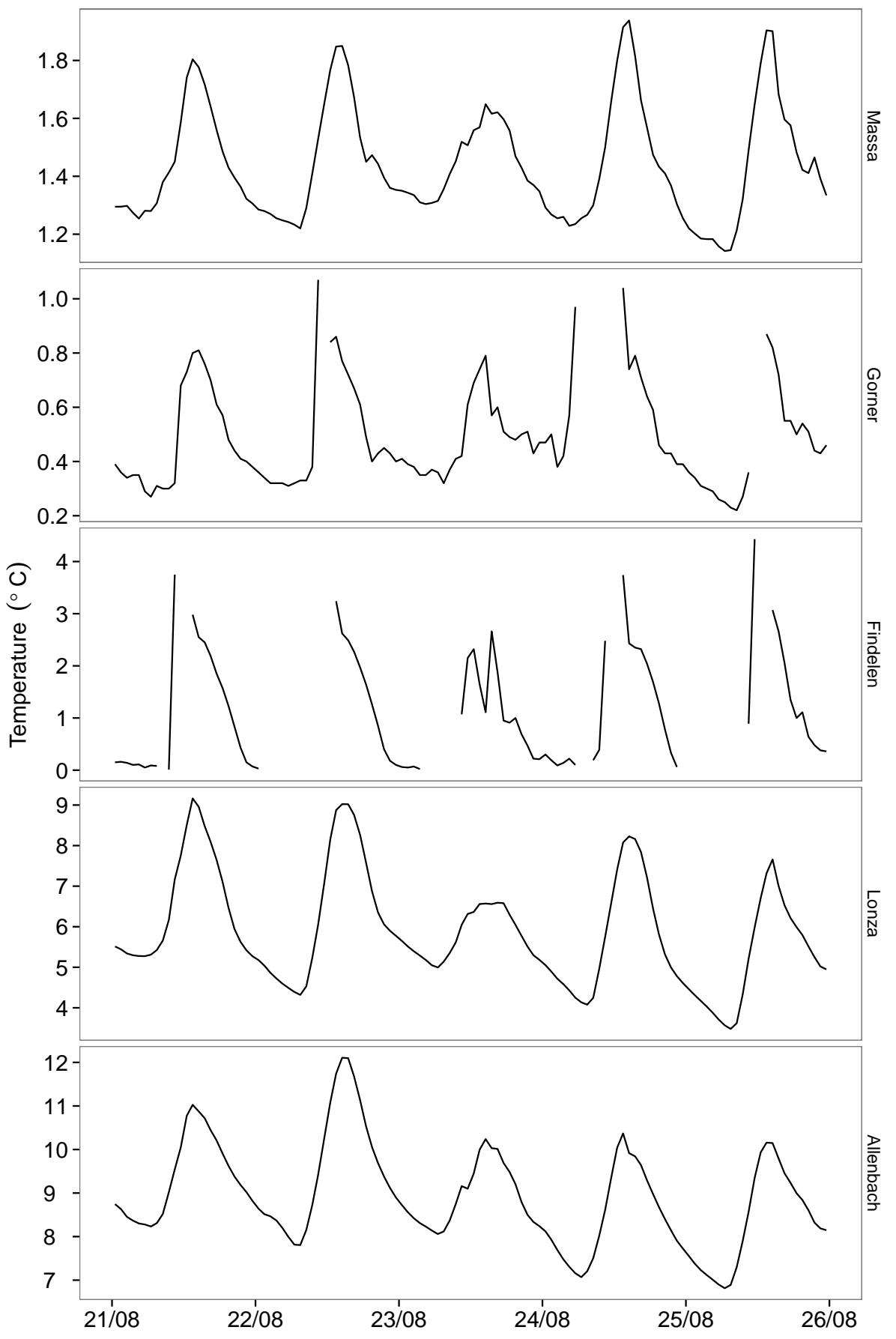

Figure 3.26: Diurnal patterns of water temperatures in the Massa, Gornera, Findelenbach,Lonza and Allenbach; for the period 21 - 25 August 2006. 


\section{Determination of factors influencing water temperature}

To what extent the seasonal relationships outlined in section 3.4.1 are reflected at the sub-daily timescale is a significant and understudied area for research in this field. Characteristic relationships between solar radiation, discharge and water temperature occur, and these interactions alter during different stages of the ablation period.

Analysis of the period 21 March through to 13 June for the years 2003, 2004, 2007 and 2009 illustrates the significant changes to both water temperature and discharge. Initially, temperatures are distinctly warm, with high variance in riverflows. Spring water temperatures quickly cool and discharge rapidly rises from insignificant levels in the winter, to substantial snow- and ice-melt driven highs (Figure 3.25).

The cursory analysis of meltwater temperatures of the Gornera show that temperatures vary little and remain low in agreement with other studies (Collins, 1986). Temperatures of the Gornera are lower with smaller diurnal range than those in the Massa. This is what would be expected to occur to stream temperatures with increasing basin glacier cover (Fellman et al., 2014). However in contrast, the Findelenbach has a distinctly greater diurnal range and maxima than those of both the Massa and Gornera (Figure 3.26). This suggests that percentage glacier cover is not solely a determiner, with respect to stream temperatures. Interestingly, both the Gornera and Findelenbach appear to be more sensitive to sudden rises in temperatures, e.g. during precipitation events. Differences in data collection tools and methodologies may be attributed to this apparent difference. 


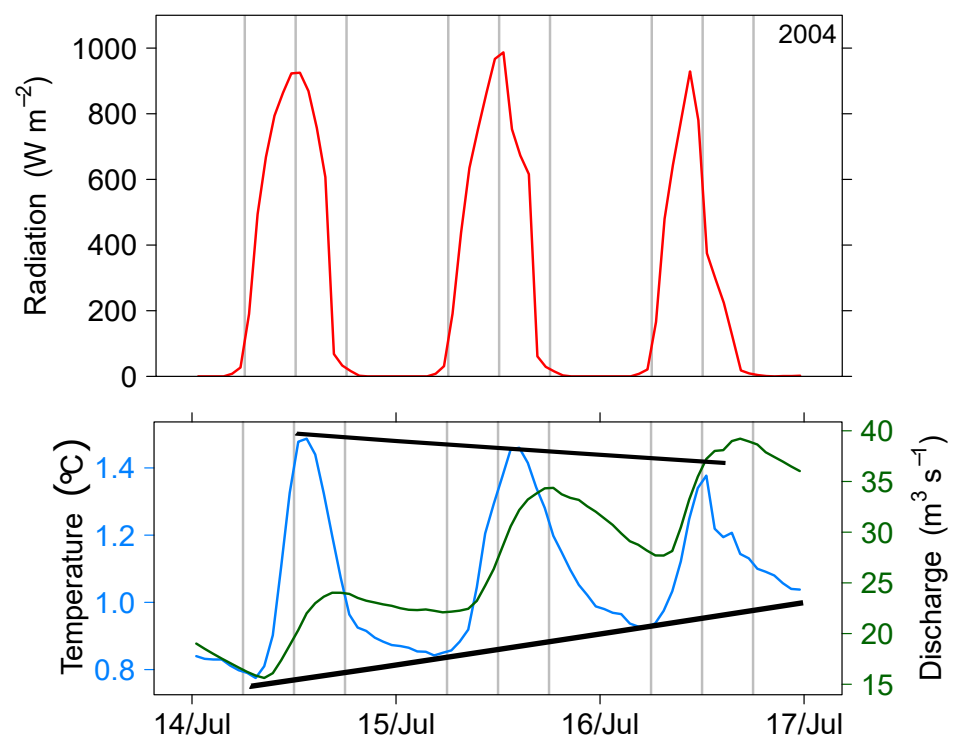

Figure 3.27: Diurnal variations of Radiation, measured at Zermatt, (red) water temperature (blue) and discharge (green) of the Massa for the period 14-16 July 2004. Black lines indicate fall/rise of maximum and minimum temperature.
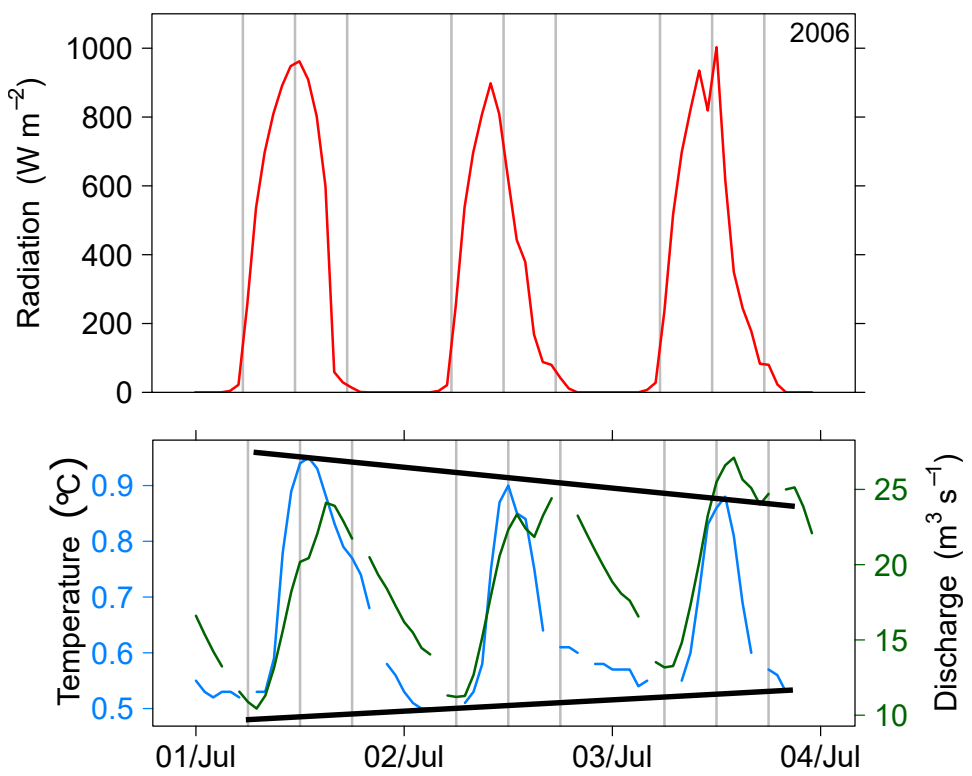

Figure 3.28: Diurnal variations of Radiation, measured at Zermatt, (red) water temperature (blue) and discharge (green) of the Gornera for the period 01-03 July 2006. Black lines indicate fall/rise of maximum and minimum temperature. 

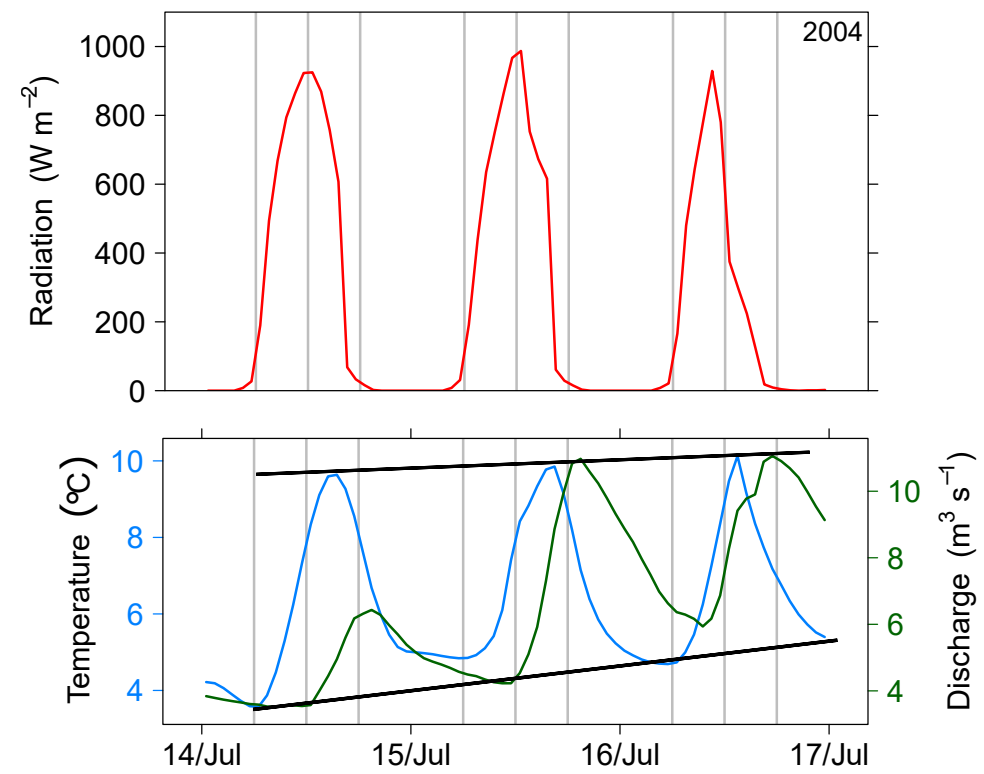

Figure 3.29: Diurnal variations of Radiation, measured at Zermatt, (red) water temperature (blue) and discharge (green) of the Lonza for the period 14-16 July 2004. Black lines indicate fall/rise of maximum and minimum temperature.
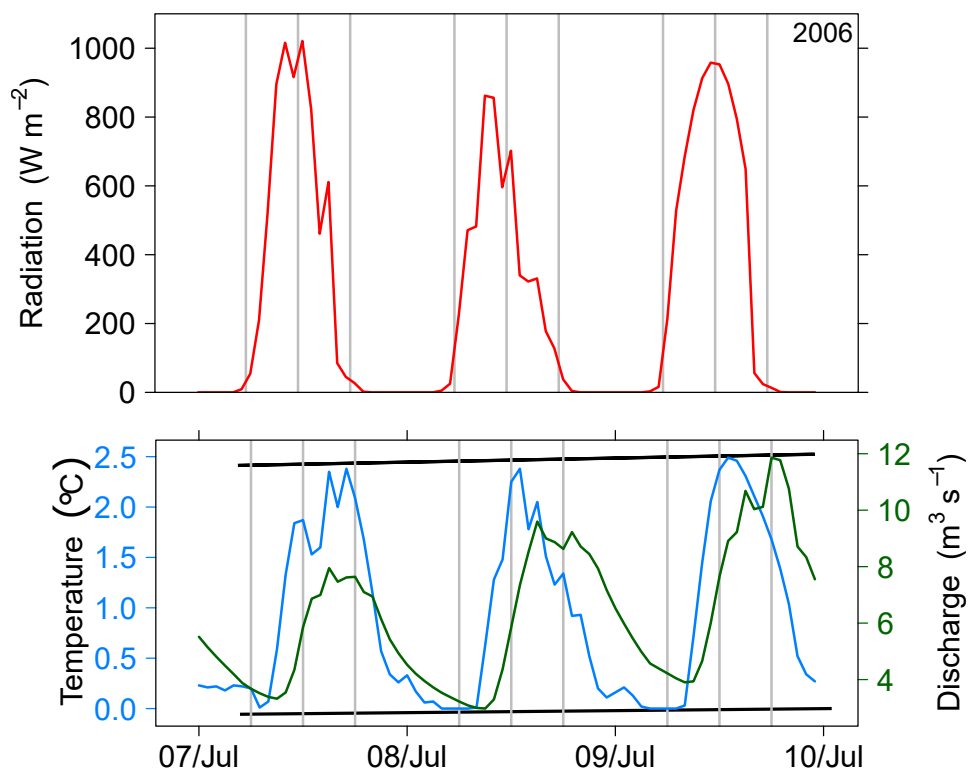

Figure 3.30: Diurnal variations of Radiation, measured at Zermatt, (red) water temperature (blue) and discharge (green) of the Findelenbach for the period 07-09 July 2006. Black lines indicate fall/rise of maximum and minimum temperature. 
A thought provoking and undocumented trait of the diurnal ranges in the water temperature of rivers which drain the two largest glacier-fed rivers, has been revealed in this study (Figures $3.27 \& 3.28$ ). Over a period of successive (three or more) clear sky days (thus high levels of solar radiation), discharge will increase day on day. This occurs as a result of meltwater produced on the first day being held in the glacier system and released over the subsequent days. As a result the typical rising discharge phase occurs i.e. before the first days discharge levels return to the levels attained at the beginning of the first day, the offset meltwater begin to pass through the glacier system. This keeps discharge levels relatively high before the second day melt begins to rise.

This study was able to illustrate how the diurnal temperature regime in a glacier-fed river responds to rising levels of discharge over a period of high incoming solar radiation (days with little cloud cover). Diurnal temperature regime shapes undergo a reduction in amplitude, day on day, throughout a period of days with rising riverflow. Temperatures respond to levels of riverflow with decreasing maximum values, but interestingly also are witness to an increase in minimum levels, leading to a decreasing diurnal range. This reduction in the amplitude of the water temperature range is a common trait of water temperature diurnal signal during a period of rising discharge ( $\mathrm{Gu}$ et al., 1998). Therefore, it is evident that water temperature of the Gornera and Massa are being influenced by levels of discharge. Gu et al., (1998) suggest that the impact of riverflows on river temperature is driven by the increase in river depth. Increasing discharge in the Lonza (Figure 3.29) and Findelenbach (Figure 3.30) did not appear to have the same impact on water temperature diurnal ranges. The diurnal regime of water temperature of the Lonza, and less so in the Findelenbach, reflected rising minima and rising maxima through a period of rising riverflows. This indicates discharge levels in both the Lonza and Findelenbach is less influential in driving water temperatures.

Notable information related to the characteristics of relationships between shortwave radiation, discharge and water temperature; throughout the hydrological season, was forthcoming when analysing the diurnal hysteresis cycles of the Massa and Findelenbach. The mean of each of the 24 hours was taken 
for the entire month. Water temperatures and specific discharges were investigated to gain understanding of sub daily interactions, at all stages of the seasonal thermal regime, found for streams draining large glaciers.

In the rivers draining highly glacierised catchments, interesting features of the deil cycle were found. In the highly glacierised Findelen and Massa catchments, hysteresis in the Findelenbach and Massa exhibit a peculiar feature (Figure 3.16). Throughout 2006, the shape of hysteresis in June (and May for the Massa) are 'tall and thin' reflecting the larger ranges in temperature, and low range of discharge. In July, as temperatures are reduced to their summer minima, and ranges in discharge are at their greatest, hysteresis demonstrates a 'short and fat' profile. From the months August through October, water temperature ranges are broader, resulting in a much taller hysteresis. Simultaneously discharge levels are reducing month on month, as well as the range of discharges, hence a much 'taller' and 'thinner' hysteresis pattern. This indicates that temperature ranges in the months May through to July are less than those of the months August to October.

Timing of the changing hysteresis profile alters, dependant on climatic and hydrological variables, during different seasons. The hysteresis loops for the same months in the year 2004 demonstrated a differing pattern. The hysteresis evolution from 'tall and slim' to 'wider and fatter' occurs, as did 2006 during July (Figure 3.15). The range of discharges is, however, much less than those of July 2006. This results in a hysteresis profile, which has toppled over without much widening. Discharge ranges in August remain great, and as a result temperatures vary only slightly. This leads to a continuation of the 'short and fat' profile. Only in September does the hysteresis loop begin to rise again, albeit much less in 2004 than in 2006. The changing hysteresis profiles are shown in Figure 3.31.

There appears to be no apparent correlation between higher ranges of discharges and lower ranges in water temperatures. The hysteresis profiles further illustrate the idea that only a small increase in discharge results in lower water temperatures, and even greater rises in specific runoff do not reduce 
temperatures further. This indicates a more complex relationship between water temperature and discharges in glacier-fed rivers.
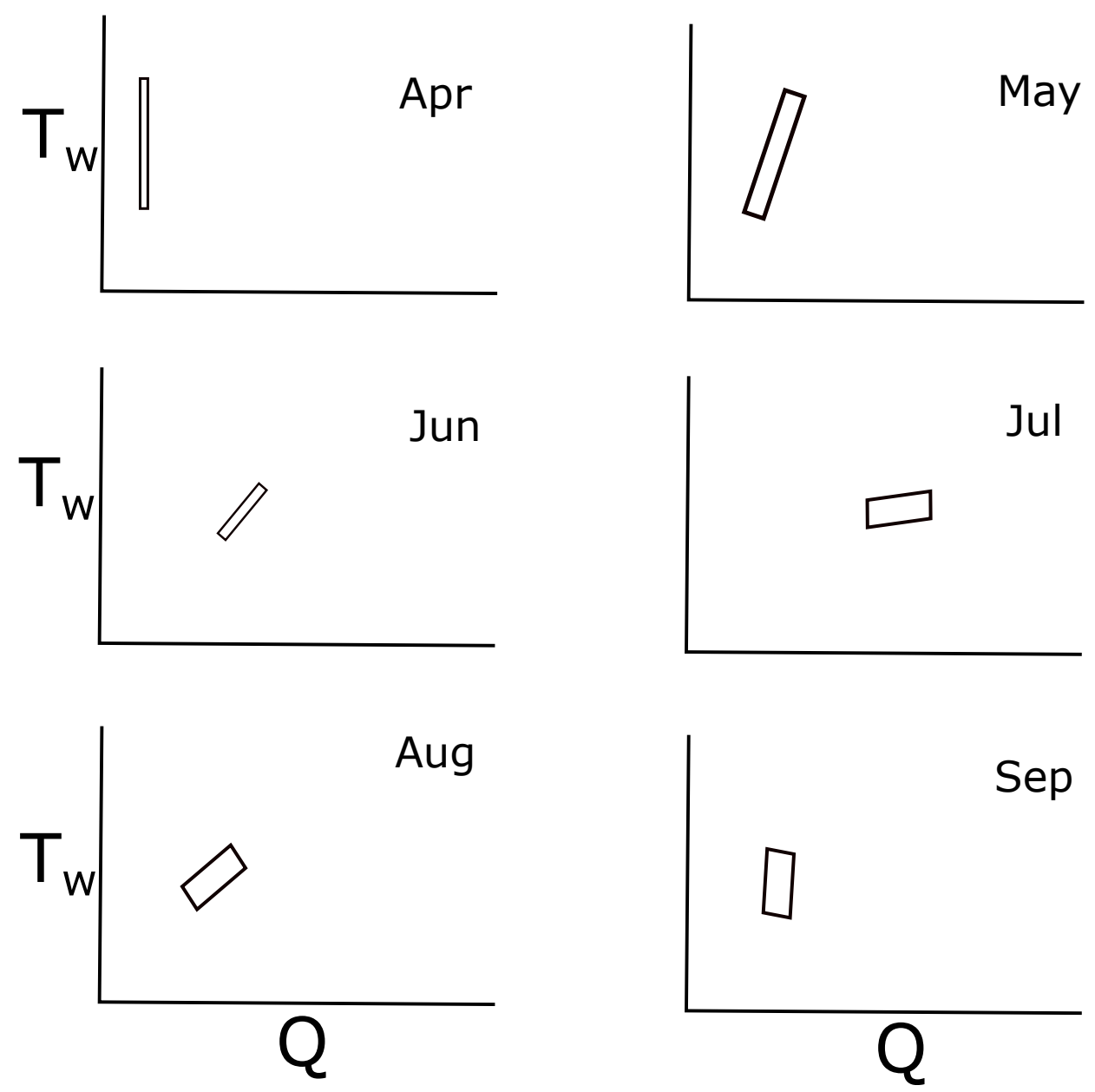

Figure 3.31: Demonstration of the change in hysteresis profiles during each month of the melt season (April-September).

\subsubsection{Basin characteristics impacts on patterns of stream temperature}

Percentage glacierisation is often cited as the key determiner of the extent glacier cover of a basin influences temperatures of streams, which issue from the basin (Collins, 2009; Fellman et al., 2014; Hood and Berner, 2009; Moore, 
2006). Despite this, the results outlined in this study suggest a more complex relationship, across a wider range of basin characteristics, having control on water temperature in glacier-fed streams.

Discharge of the Massa is significantly higher than that of any other basin within this study. However, percentage glacierisation was greater in both the Findelen and Gorner catchments.

Results of the multiple linear regression (MLR) analysis showed some interesting and undocumented information (to the authors knowledge), with respect to hydrometeorological and basin characteristics influence on stream temperatures.

With respect to the MLR for the interaction of hydrometeorological factors (shortwave radiation, discharge and precipitation) on stream temperatures of $65.9 \%$ glacier covered Massa; incoming solar radiation was the best determiner $\left(\beta_{s t d}=0.67: 1.07\right)$ of stream temperature. Shortwave radiation has a high positive influence on temperatures. Precipitation levels also positively increase stream temperature $\left(\beta_{\text {std }}=0.11: 0.29\right)$, with the low $\beta_{\text {std }}$ coefficients illustrating the lower influence of precipitation as a predictor. MLR results show that riverflow in the Massa negatively drives stream temperatures $\left(\beta_{\text {std }}=-0.04:-0.38\right)$. This in line with similar studies of Alaskan (Fellman et al., 2014) and Canadian (Moore, 2006) glacier-fed streams suggest the substantial increase in cold glacier water during summer months significantly reduces stream temperatures. However regression analysis for the highly glacierised Massa often demonstrated low adjusted $R^{2}$ values. This may be because with increasing summer radiation meltwaters from the glacier significantly reduce stream temperatures. Additionally, as previously outlined in this study, increases in riverflow initially lead to a drop in water temperatures. However, any further increase in riverflow does not further reduce temperature of the streams. This indicates that the thermal pattern in glacier-fed rivers is not a simple relation between quantity of runoff produced and its greater heating capacity, but a more complex relationship between discharge and river dynamics, together with cool glacier water inputs. 
Adjusted $R^{2}$ values for the MLR of the Lonza basin are on average greater than those of the Massa. This reflects the similar shape in temperature regime and meteorological inputs, as the inclusion of air temperature would likely increase this $R^{2}$ further. As a result of the better fit, standardised slope coefficients for both shortwave radiation and discharge are statistically significant in all years. One peculiar result from the MLR for temperatures in the Lonza is that riverflow positively influences stream temperatures and is the best determiner, in terms of the standardised coefficients. A standard deviation change in the riverflow drives water temperature up by between $0.42{ }^{\circ} \mathrm{C}$ and $0.64{ }^{\circ} \mathrm{C}$. Comparatively, $\beta_{\text {std }}$ coefficients for incoming solar radiation are of the range 0.25-0.61. Precipitation coefficients differ year on year and altered between positive and negative. The positive $\beta_{\text {std }}$ coefficients may occur as a result of the discharge of the Lonza having a greater proportion of groundwater tributaries which are warmer and have more influence in the downstream temperatures.

\subsection{Conclusion}

This chapter investigated the diurnal, seasonal and multi-annual relationship between incoming shortwave radiation, stream discharge and water temperature. Controlling factors within catchments influencing the thermal capacity of streams draining large glaciers in the Swiss Alps, are also explored.

This study highlights the lack of available water temperature records in the Swiss Alps. Outside of the period utilised in this work, there is little in the way of reliable long term, year round, data.

Seasonal patterns in water temperature have been thoroughly investigated within this study. Correlation analysis and monthly box plots were useful in describing temperature regimes on the seasonal scale. This analysis demonstrated a clear spring pulse in the Massa, which drains a highly glacierised catchment, which does not occur in the Lonza, which drains a catchment of around half the glacierisation. The temperature regime of the Lonza, des- 
pite temperatures evidently being cooled by glacier influence, follows that of the ice-free Allenbach. The reduction in summer temperatures of glacier fed rivers is in-line with studies of Alaskan and Canadian glacier-fed streams (Fellman et al., 2014). However, this study has demonstrated that, in the Swiss Alps percentage glacierisation cannot alone account for a decrease in stream temperatures. Findelenbach which drains a catchment of $73 \%$ glacier cover appears to warm more than both the Massa (65.9\%) and the Gornera $(83.7 \%)$. No empirical study has yet shown such a distinctive spring pulse, although temperature spring maxima have been shown in Alaskan glacier-fed rivers of high percentage glacierisation (Fellman et al., 2014).

Analysis of the seasonal ( 7 day average) temperature regime shows no correlation between warmer summer air temperature and cooler water temperatures; nor does it reveal a relationship between higher summer air temperatures and greater water temperatures in glacier-fed rivers. It is suggested herein, that maximum temperature timing and amount, must be influenced not only by the present year's air temperature and incoming shortwave radiation totals, but also by the previous year's winter precipitation. With the previous winter precipitation is higher the transient snowline will be lower in the basin and discharge will be delayed to later in the year. This timing of the rising discharge will impact the extent to which waters will warm in glacier-fed rivers.

Analysis of the diurnal patterns in water temperature of the Massa throughout the spring period, reveal interesting relationships between the temperature and riverflow. Temperatures appear to decline after only a small increase in stream discharge and any subsequent rise in discharge does not further influence temperature levels. It is suggested that this may be the result of changing river morphology, as discharge begins to rise, indicating a complex relationship between width, depth and velocity with rising riverflow, and water temperature. One reason for initial reduction in stream temperature could be because with rising discharge, temperatures are reduced as a result of the corresponding increasing velocities and thus reduced residence time and increased depth. Once the residence time offsets any stream temperature increase due to shortwave radiation, temperature profiles may mostly reflect 
the heat increase resulting from potential energy being converted to kinetic energy. This occurs as a result of the flowing stream losing altitude, and would mean that frictional heating would be the major source of heat in steep glacier-fed rivers. This is in agreement, therefore, with findings published with respect to the study of Alaskan streams (Chikita et al., 2010). Furthermore, there is evidence that discharge reaches a critical level, above which water temperature varies little with further increase in discharge, although below this critical discharge water temperature varies drastically for a change in discharge ( $\mathrm{Gu}$ et al., 1998). With respect to the water temperature of the Massa, the critical discharge was $\sim 10 \mathrm{~m}^{3} \mathrm{~s}^{-1}$.

An interesting phenomenon has been revealed in the Gornera and Massa rivers whereby diurnal ranges in temperature are reduced day on day through a period of sustained high radiation and rising riverflows. Falling peaks are accompanied by increasing minimum values, suggesting strong influence of discharge on water temperature ( $\mathrm{Gu}$ et al., 1998). Diurnal ranges in the Lonza and Findelenbach are not reduced through a period of increased discharge, which suggests that discharge is having less influence over the temperatures in the respective rivers, and this could account for the warmer waters in the Findelenbach and Lonza than in the Massa and Gornera. Furthermore, the diurnal hysteresis patterns show evolution throughout the melt season. Loop profiles begin 'tall and slim' in the early season, as low discharges reflect large range in stream temperature. This profile collapses around June/July to a 'short, fat' loop, where low ranges in stream temperature and present at times of higher discharges across a larger range. Loops begin to return to a 'taller, slimmer' profile as the melt season comes to a close; loops reflect falling riverflow and widening ranges in stream temperature.

Finally, climate change is likely to influence future stream temperatures (Hood and Berner, 2009; Mohseni et al., 1998; Moore, 2006; Webb et al., 2008). The study undertaken in this chapter has demonstrated that complex relationships between climatic and hydrological variables in glacier-fed rivers makes understanding any potential changes difficult. However, the collection and analysis of data in this chapter is an initial step in identifying potential im- 
pacts of climate change on glacier-fed river temperature. It is suggested that the manner of how river hydrodynamics changes with rising riverflow, will significantly impact temperatures. Therefore, rivers bounded by steep gorges will most likely remain consistent; whereas river temperature in a wide open plain would likely rise in a warming climate. Deeper empirical research, over a longer time period, is required to confirm the findings within this study. 


\section{Chapter 4}

\section{Stream surface albedo in highly glacierised Alpine catchments}

\subsection{Introduction}

GuRFACE albedo of rivers has the potential to be an important controlling variable on thermal inputs (Richards and Moore, 2011). The significance of stream albedo on heat budgets is attributed to incoming shortwave radiation being the primary heat input, increasingly so in high mountain environments. Therefore, Richards and Moore, (2011) suggested that the surface albedo of stream may impact negatively on the heat budget of glacier-fed rivers.

Suspended sediment concentration has been found to positively influence the albedo of clear-water streams, most significantly at the visible wavelengths (Han, 1997). The flushing of sediment from glacier systems, gives meltwater rivers a distinctive light milky colour during the ablation season. Additionally, whitecaps and surface roughness resulting from rapidly-flowing streams (Han, 1997; Richards and Moore, 2011) and oceans (Jin et al., 2004) is known to influence a water body's turbidity. Latitude and zenith angle of the sun (Cogley, 1979) further influences stream albedo. Given the importance of incoming 
shortwave radiation in a stream's heat budget (explained in Chapter 3), especially with respect to streams with little shading (Johnson, 2004; Richards and Moore, 2011; Webb and Zhang, 1999), stream albedo may be an important control on warming.

Deterministic water temperature models, which utilise the entire river's heat budget, often account for water surface albedo, in calculating the heat input to streams, multiplying incoming solar radiation by 1 - surface albedo to give net solar radiation. The values, either measured in the field or assumed, for stream surface albedo used in stream temperature modelling studies varies between 0.05 and 0.1 (e.g. Chikita et al., 2010; Garner et al., 2014; Leach and Moore, 2010; Magnusson et al., 2012). The majority of studies, notably those in Alaska, are on low gradient streams. Research has focused less, on the stream albedo of steep mountainous rivers, with rocky channels and high aeration during periods of high discharges (Richards and Moore, 2011). More research into the albedo of steep high mountain streams and the influence water surface albedo may have on water temperature is key.

The aim of this chapter is to describe and account for the effect suspended sediment concentrations, stream gradients and discharge may have on the albedo of glacier-fed streams. Results from this study will analyse the effect stream albedo has on the river's heat budget, and to suggest whether surface albedo is a key factor influencing meltwater temperatures.

\subsection{Method}

Stream surface albedo of the glacier-fed Findelenbach and Gornera which drain from the Findelengletscher and Gornergletscher, Kanton Vallais, Switzerland (Detailed descriptions of the study area are given in Chapter 1). 15 minute observations of stream surface albedo were collected during a brief field visit to the study site between September 6 and September 82015 to provide information detailing the interaction between suspended sediment driven surface albedo and meltwater temperature. 
Surface albedo measurements were recorded using a Kipp and Zonen CMA6 Albedometer (Figure 4.1). The albedometer consists of a pair of back-toback CMP6 pyranometers; (Figure 4.2). One sensor records the direct solar radiation, the second recording the reflected radiation from the stream surface. The pyranometers use the incoming shortwave radiation to generate an electrical current, utilising a blackened surface to absorb the incoming radiation. As this surface warms temperature is measured by either a thermopile or semiconductors. A voltage proportional to the blackened surface and the cooler white instrument housing is generated of the order of $10 \mu \mathrm{V}$ per $\mathrm{W} \mathrm{m}^{-2}$. Therefore, the output on a sunny day would be of the order of $\mathrm{mV}$ (Kipp\&Zonen, 2015). To protect the absorbing plate (blackened surface) from external parameters, e.g. wind, precipitation, and dust; a domed window is fitted over the top of the instrument's two sensors. Pyranometers are assigned unique sensitivity values, used to convert outputs in microvolts $(\mu \mathrm{V})$ to irradiance $\left(\mathrm{W} \mathrm{m}^{-2}\right)$. The $\mu \mathrm{V}$ output can be read by a logger, often converted by the logger program. However, during this present investigation it was necessary to manually take readings using a standard multimeter (Figure 4.3) and convert them into irradiance values during data analysis.

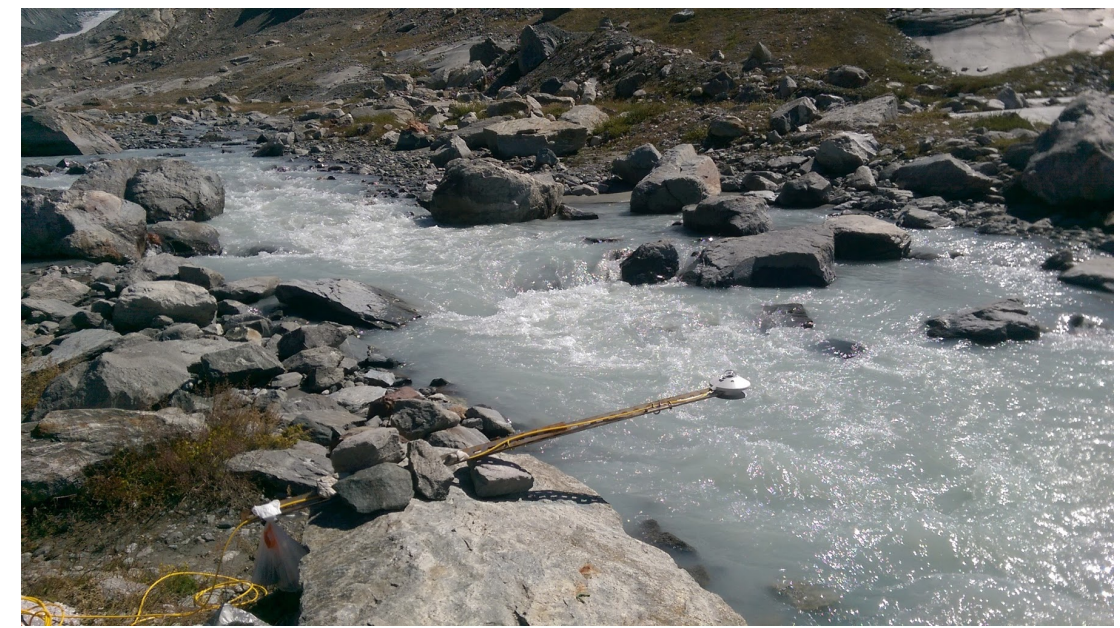

Figure 4.1: Kipp and Zonen CMA6 Albedometer in position $1.5 \mathrm{~m}$ above the surface of the Findelenbach study site, close to the Findelenbach gauging station $\left(46.00^{\circ}, 7.81^{\circ}\right)$.

Measurements of water temperature were also taken during this brief field 


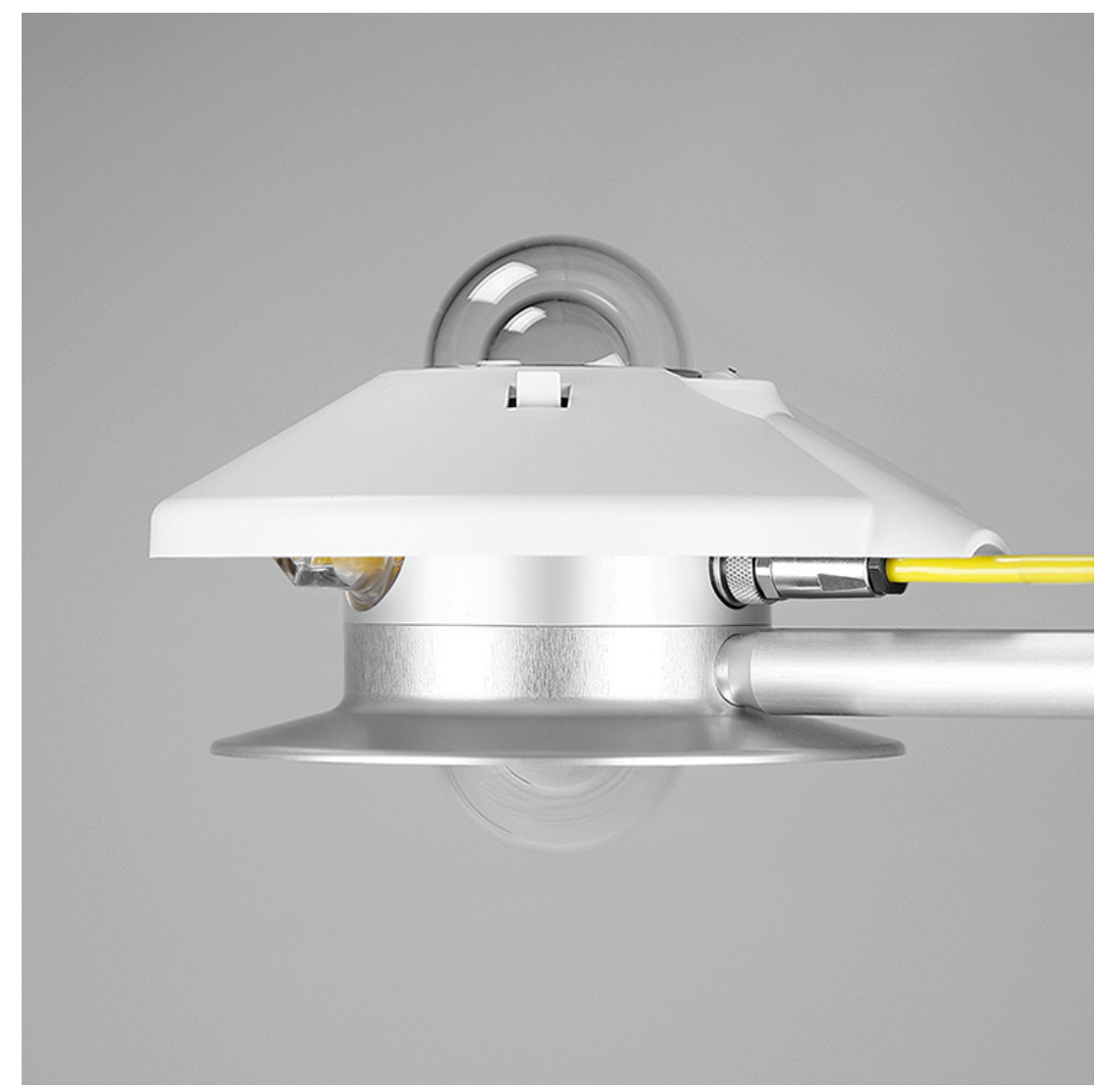

Figure 4.2: Kipp and Zonen Albedometer showing the upward, downward facing pair of CMP6 pyranometers (Source: Kipp\&Zonen, (2015)). 


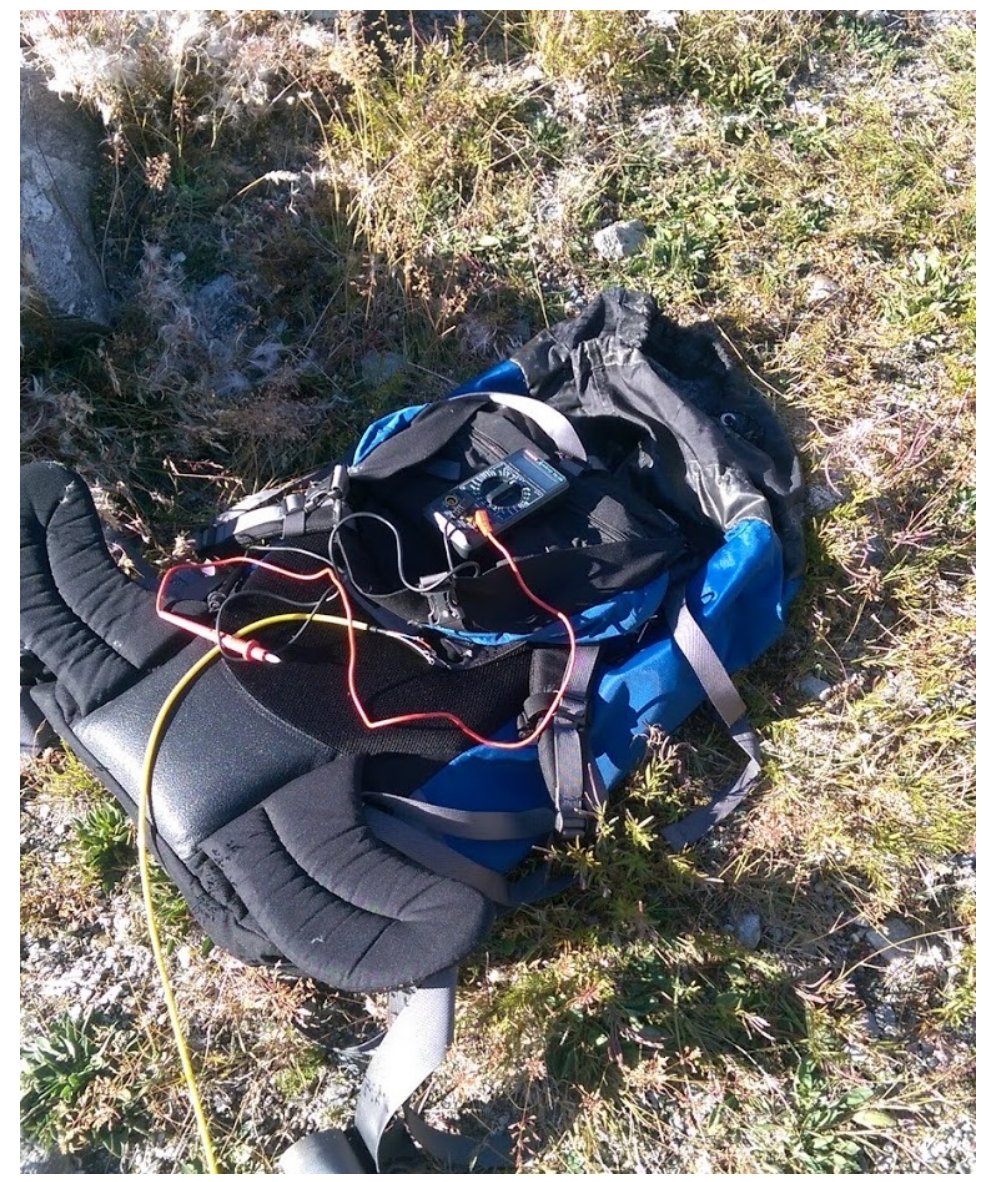

Figure 4.3: Kipp and Zonen CMA6 Albedometer wired to multimeter taking voltage readings. 
expedition. Temperature was recorded using TinyTag loggers immersed in the stream close to the albedometer position. The TinyTag logger was programmed to take measurements every 10 minutes. However, the brief period of time for readings to be taken during the present expedition (due to time and monetary constraints), resulted in only three days of temperature measurements to be collected.

\subsection{Results}

The following section is divided into two subsections outlining the results of albedometer measurements and water temperature readings taken during the field expedition.

\subsubsection{Findelenbach}

Temporal variations in incoming shortwave radiation during a three day period 6 September - 8 September, shown in Figure 4.4, ranged between $462.4 \mathrm{~W} \mathrm{~m}^{-2}$ and $892.7 \mathrm{~W} \mathrm{~m}^{-2}$. Both extremities occurred during September 7. Maximum radiation occurred after midday(CEST), at 13:15(CEST). Reflected radiation emanating from the stream surface, Figure 4.5, continues to rise post peak incoming radiation reaching $112.6 \mathrm{~W} \mathrm{~m}^{-2}$ at $14: 00(\mathrm{CEST})$, remaining constant until 15:15(CEST). This suggests albedo continues to rise to maxima at 15:45(CEST). Albedo values, shown in Figure 4.6, range between 0.06 and 0.18. Stream surface albedo rises in line with runoff.

Water temperature measurements (Figure 4.7 \& Figure 4.8 ) of the Findelenbach range from close to $0{ }^{\circ} \mathrm{C}$, to greater than $4{ }^{\circ} \mathrm{C}$ late in the ablation season. The water temperature measurements add weight to the suggestion that temperatures of Findelenbach are warmer than other pro-glacial streams. 


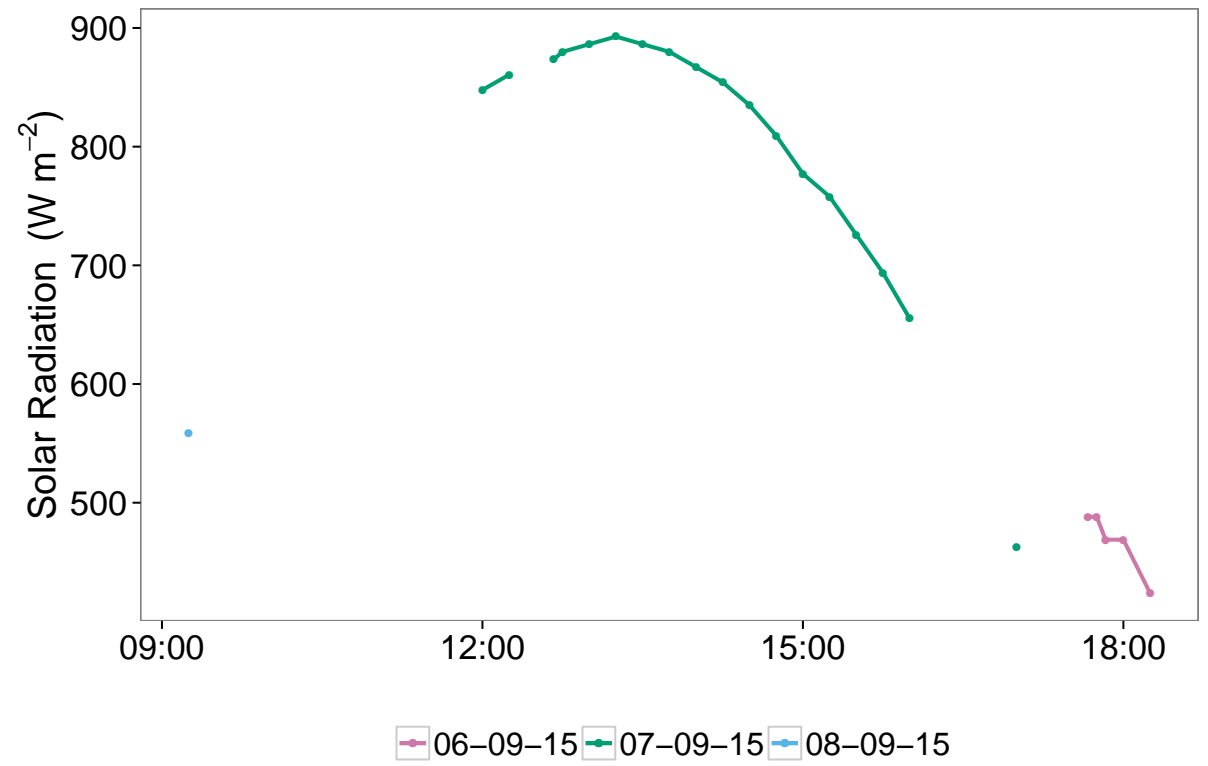

Figure 4.4: Incoming solar radiation measured over Findelenbach on the 6,7 and 8 September 2015.

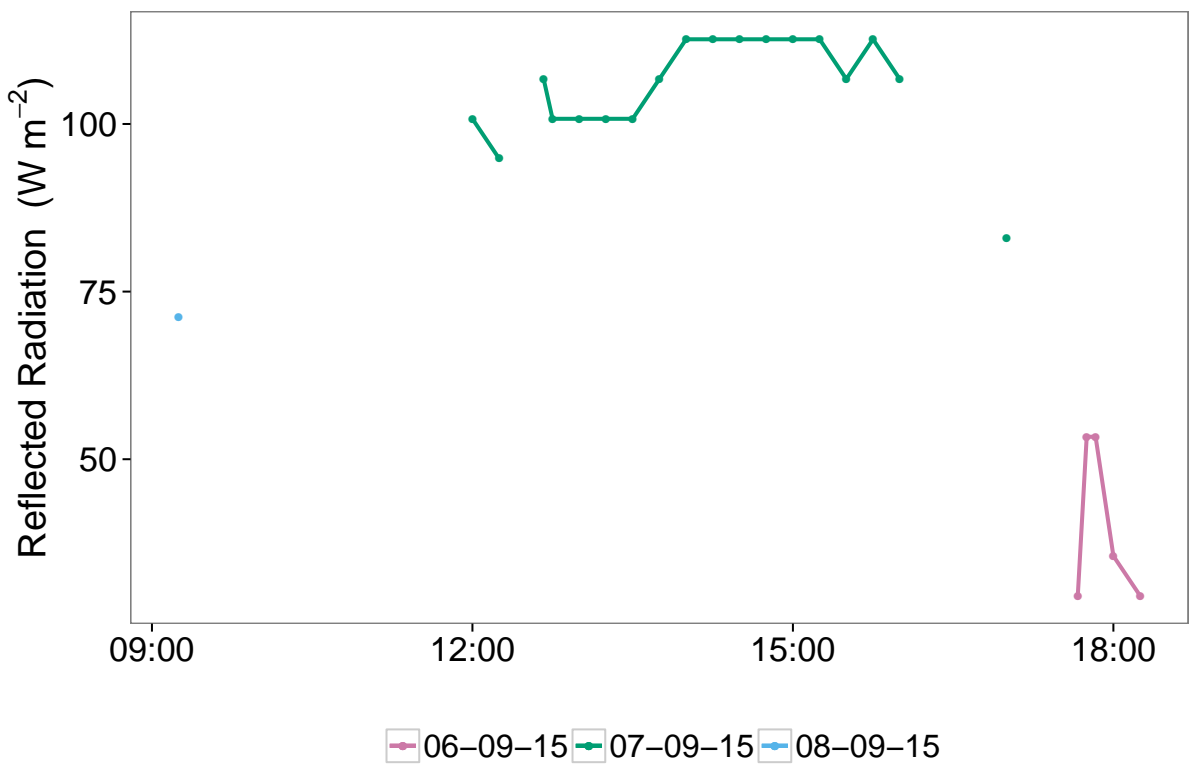

Figure 4.5: Reflected solar radiation measured over Findelenbach on the 6,7 and 8 September 2015. 


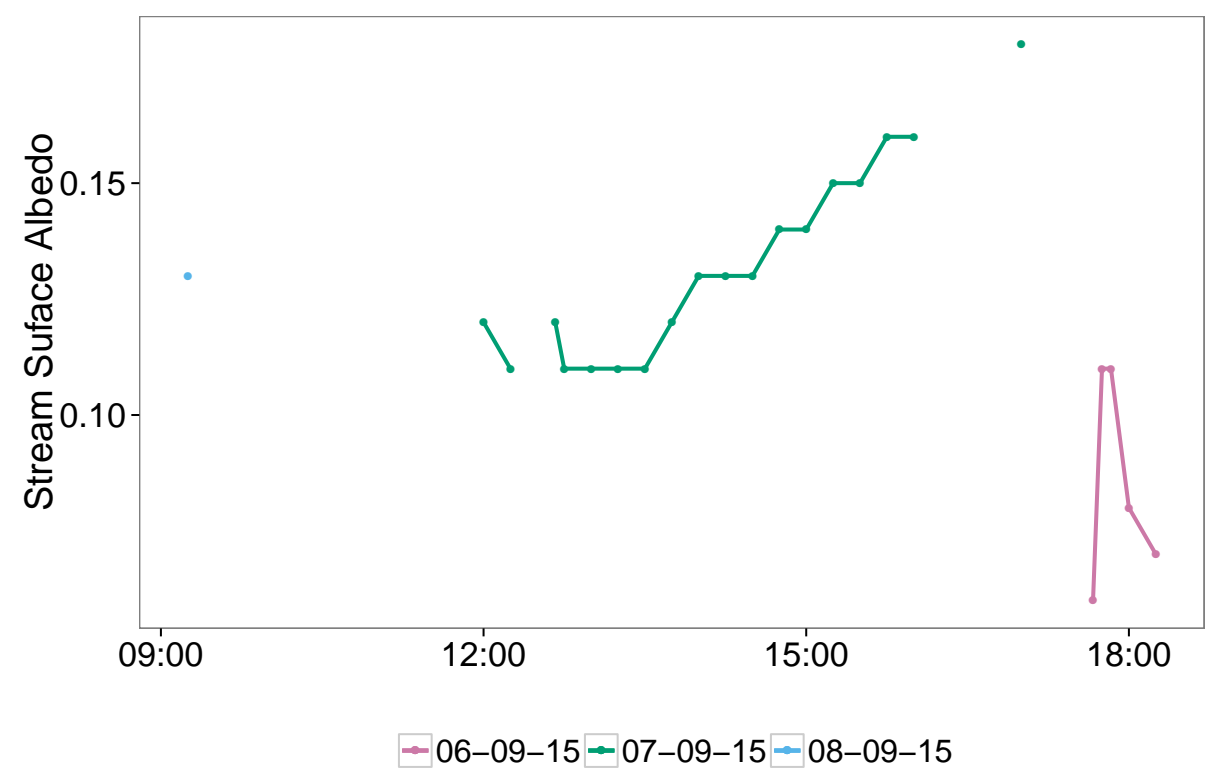

Figure 4.6: Stream surface albedo measured over Findelenbach on the 6,7 and 8 September 2015.

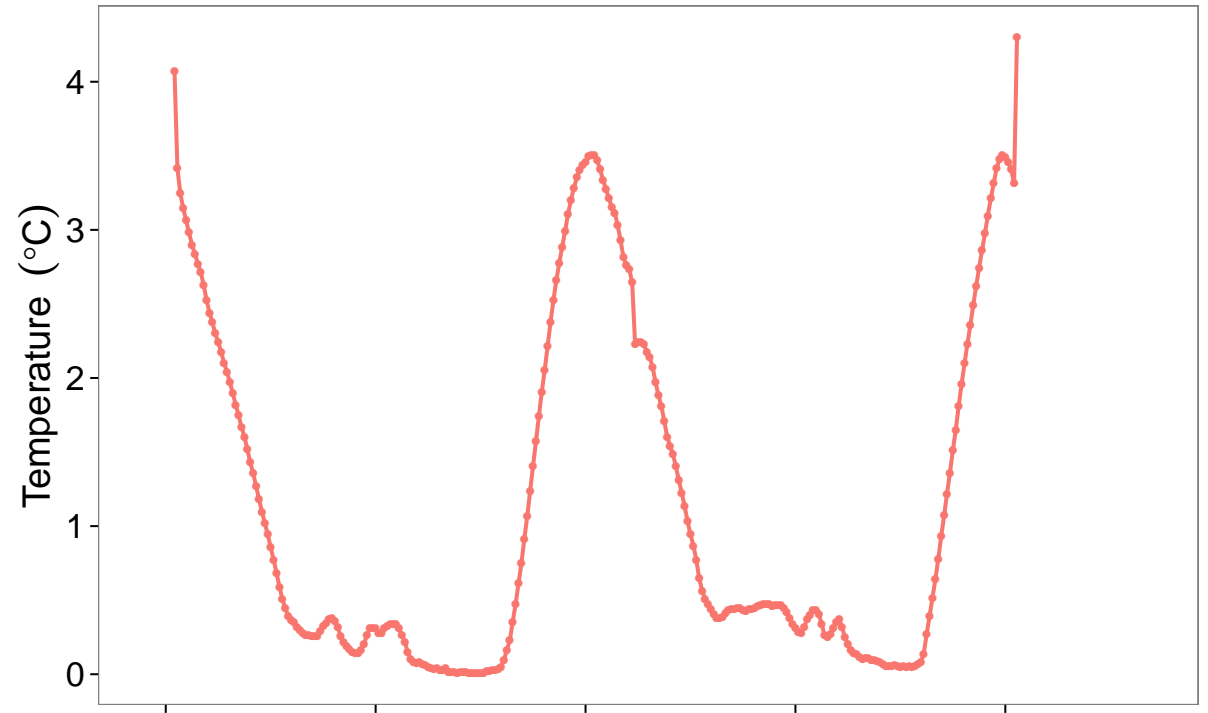

Sep 07 12:00 Sep 08 00:00 Sep 08 12:00 Sep 09 00:00 Sep 09 12:00

Figure 4.7: Water temperature of the Findelenbach recorded at 10-minute intervals using TinyTag data-loggers between 12:30(CEST) 07 September 2015 and 12:40(CEST) 9 September 2015. 


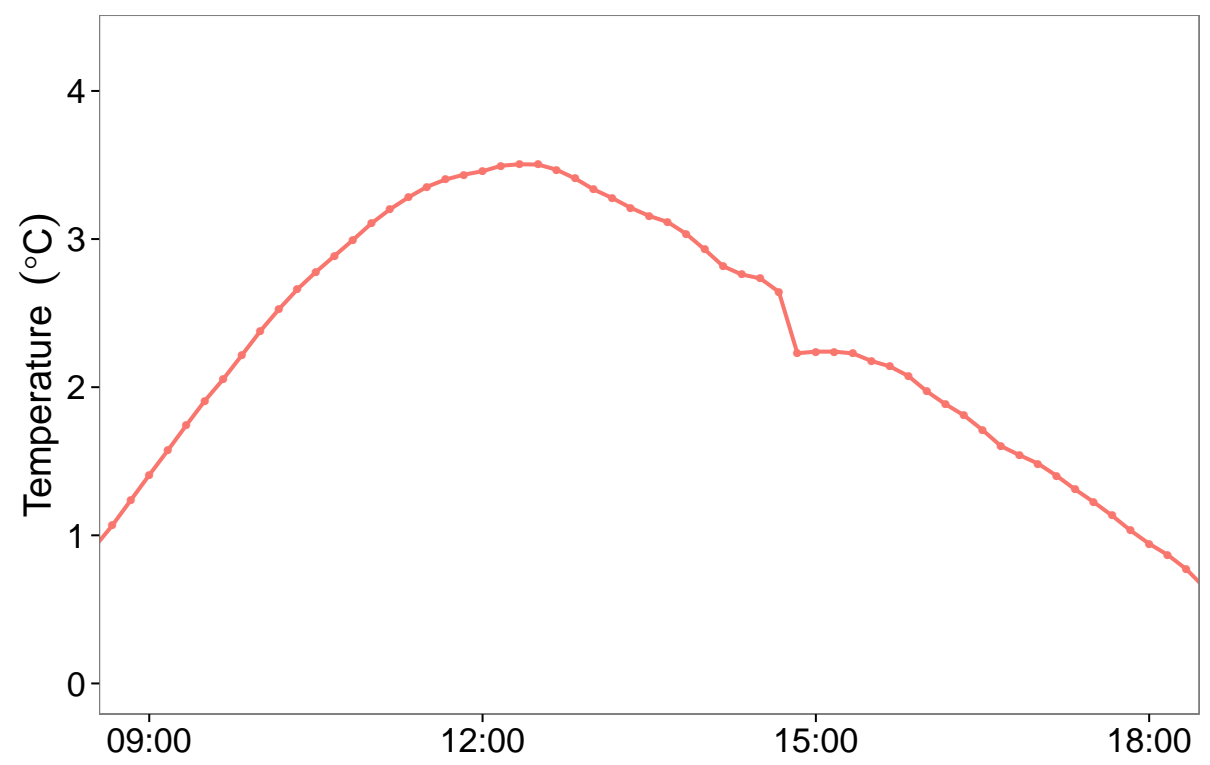

Figure 4.8: Water temperature of the Findelenbach recorded at 10-minute intervals using TinyTag data-loggers between 09:00(CEST) and 18:00(CEST) 8 September 2015. 


\subsubsection{Gornera}

To provide a comparison, short periods of measurements were recorded with the albedometer, over the Gornera which drains Gornergletscher. Distance between locations and aforementioned issues with the logger resulted in a very short measurement period. Results, however, are included in this chapter as they indicate a substantial difference in, incoming solar radiation and surface albedo, between two relatively close drainage basins. Incoming solar radiation over the Gornera is declining, from its peak at the beginning of the measurement period. Six recordings were taken between the hours of 15:00 and 16:30(CEST) at 15 minute intervals during 8 September 2015, measurements ranged between $854.2 \mathrm{~W} \mathrm{~m}^{-2}$ and $128.54 \mathrm{~W} \mathrm{~m}^{-2}$ (Figure 4.9). An important aspect of the incoming radiation over the Gornera is that between the times of 16:15 and 16:30 shortwave radiation dramatically declines from $635.8 \mathrm{~W} \mathrm{~m}^{-2}$ to $128.5 \mathrm{~W} \mathrm{~m}^{-2}$. The fall in shortwave radiation over this period is a result of the topography of the basin. Unlike the wide open valley in which Findelenbach flows, the Gornera is within a steep sided valley. As a result the sun falls behind the slopes in the late afternoon, leaving the majority of the stream under shade.

Reflected shortwave radiation, shown in Figure 4.10, ranges between 136.4 $\mathrm{W} \mathrm{m}^{-2}$ and $0 \mathrm{~W} \mathrm{~m}^{-2}$, appearing to mimic the falling incoming solar radiation, is dissimilar to the pattern at Findelenbach where reflected shortwave radiation remained high, despite falling incoming solar radiation. Outgoing shortwave radiation was recorded in negligible amounts, at the point of solar radiation falling dramatically 16:15(CEST). As a result, stream albedo (Figure 4.11) falls throughout the measurement period from 0.16 to 0 . Again the apparent pattern is different to that of the Findelenbach, where albedo continues to rise after 15:00(CEST). 


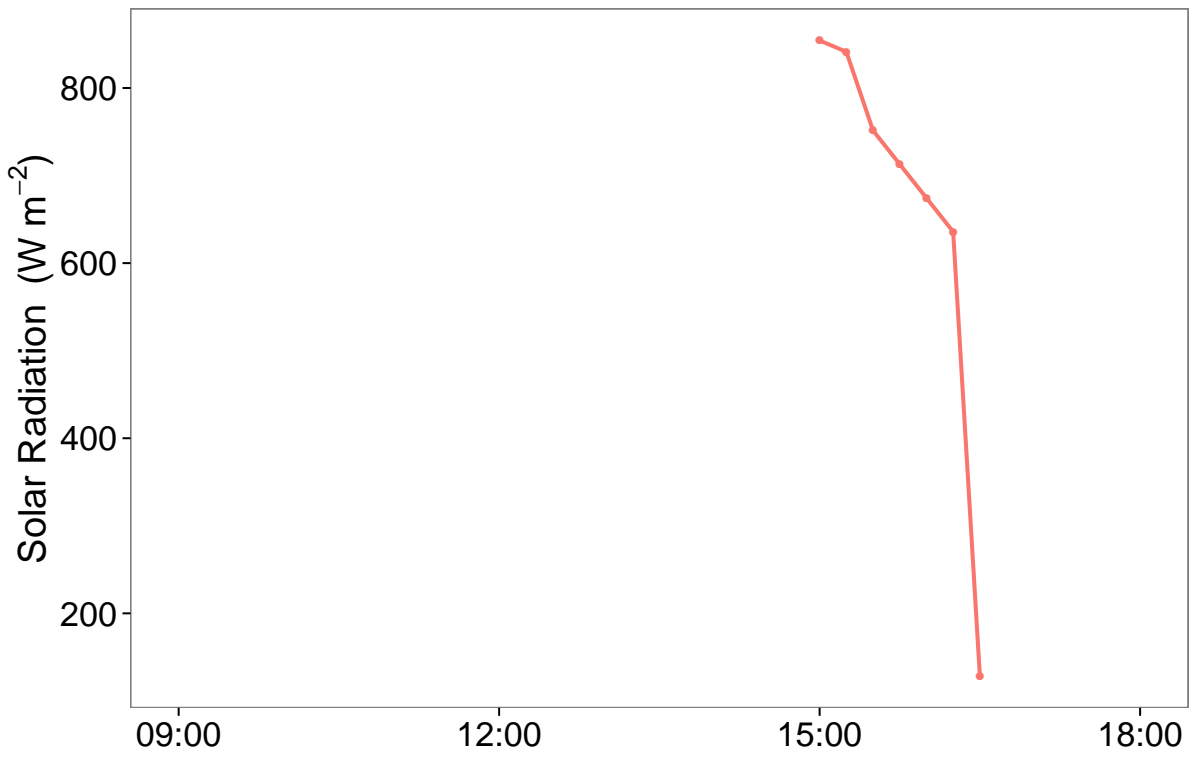

Figure 4.9: Incoming solar radiation measured over the Gornera between the times 15:00 and 16:30 during 08-09-2015.

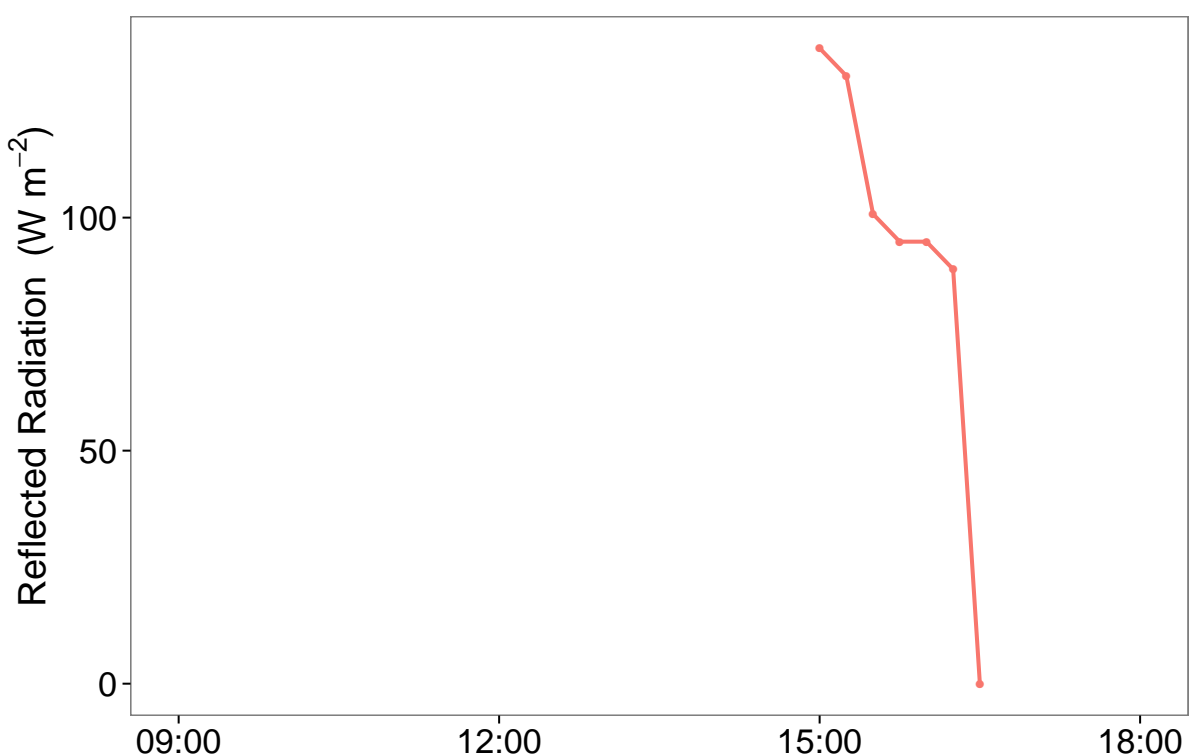

Figure 4.10: Reflected solar radiation measured over the Gornera between the times 15:00 and 16:30 during 08-09-2015. 


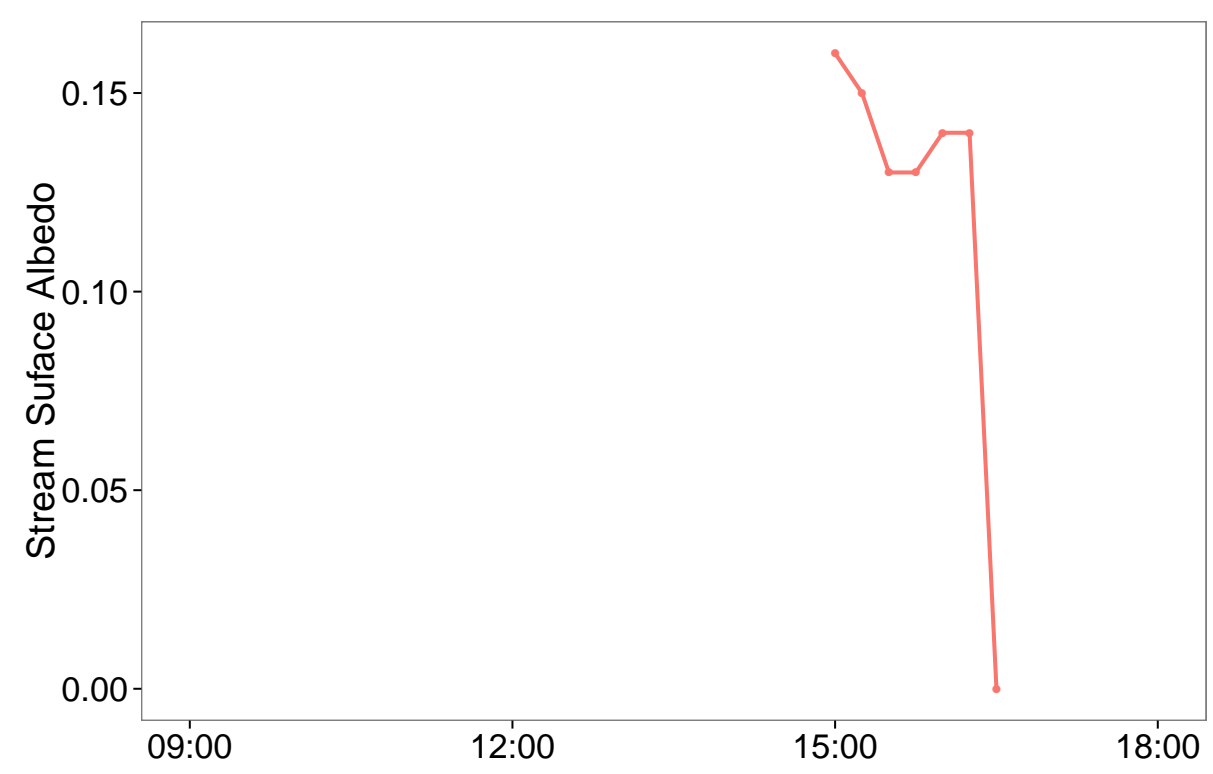

Figure 4.11: Stream surface albedo measured over the Gornera between the times 15:00 and 16:30 during 08-09-2015.

\subsection{Discussion}

It is difficult to draw conclusions from such a cursory analysis. The results, however, demonstrate that surface albedo of streams draining large glaciers varies substantially throughout a 24 hour period. Maximum surface albedo is greater than those used in previous studies assessing the water temperature of rivers. This indicates that values used in models throughout literature do not adequately account for reflected shortwave radiation.

This study has shown that basin properties, notably topography significantly alter albedo of streams in high mountain catchments. Increasing discharge which aerates the river water and channel features, which result in the production of whitecaps together with suspended sediment levels in glacier-fed rivers are probably the main determiners of stream albedo. It is therefore not appropriate to utilise a single value for stream albedo in heat budget calculations and water temperature models, both on the diurnal and seasonal scales, but also spatially. Conditions in the Gornera basin are drastically different 
pre 16:00(CEST) than they are post 16:30(CEST), because of the topographical shading which occurs; locally reducing the incoming shortwave radiation to zero. Heat budget models would therefore, need to account for this when modelling the shortwave radiation contribution to surface thermal exchanges.

\subsubsection{Comparison with albedo values used in previous studies}

Stream albedo ranged from between 0 and 0.16 for the Gornera and 0.06 and 0.18 for the Findelenbach. Albedo is greater in the Findelenbach during the overlapping hours. This is likely a result of the differing basin topographies, with longer sunshine hours in the Findelen basin than that of the Gornera. Additionally, flows in the Gornera are directed into a concrete hydroelectric water intake and the water, despite flowing at a faster rate, is relatively calm with fewer whitetops. Alternatively, water of the Findelenbach, which is flowing through a bouldery channel, is more aerated. This creates more whitetops which in turn results in a higher albedo, notably at periods of greater discharges, during late afternoon. Table 4.1, demonstrates how the range of albedo from the Gornera and Findelenbach compare to those values used in some of the heat budget, water temperature, and albedo investigation studies.

Results compare favourably with albedo values used in other modelling studies (e.g. Table 4.1). It is evident that values attributed to albedo in previous modelling studies, with respect to glacier-fed rivers, are lower than the measured values in this study. Albedo of the Findelenbach is greater despite having a more gradual slope. The results of this study are consistent with the findings of Richards and Moore, (2011), in that there is a positive relationship between stream surface albedo and discharge, in that higher reflection occurs the higher the flow. This is most likely because of the increased aeration and more turbid waters. The higher gradient of the streams draining the Place glacier (Richards and Moore, 2011) will result greater aeration and likely 
Table 4.1: Values for measured stream surface albedo with comparison of other studies.

\begin{tabular}{|c|c|c|c|c|}
\hline Study & River & River gradient & Albedo & $\begin{array}{c}\text { Discharge } \\
\left(\mathrm{m}^{3} \mathrm{~s}^{-1}\right)\end{array}$ \\
\hline & $\begin{array}{l}\text { Findelenbach, } \\
\text { Switzerland }\end{array}$ & 0.13 & 0.06 to 0.18 & \\
\hline & $\begin{array}{l}\text { Gornera, } \\
\text { Switzerland }\end{array}$ & 0.20 & 0.00 to 0.16 & \\
\hline $\begin{array}{l}\text { Richards and } \\
\text { Moore, } \\
(2011)\end{array}$ & $\begin{array}{l}\text { Place glacier, } \\
\text { Canada }\end{array}$ & 0.26 & 0.10 to 0.40 & 0.1 to 0.6 \\
\hline $\begin{array}{l}\text { Magnusson } \\
\text { et al., (2012) }\end{array}$ & $\begin{array}{l}\text { Star Creek, } \\
\text { Canada }\end{array}$ & 0.44 & 0.05 & 0.1 to 7.0 \\
\hline $\begin{array}{l}\text { Chikita et al., } \\
(2010)\end{array}$ & $\begin{array}{l}\text { Phelan } \\
\text { Creek, Alaska }\end{array}$ & 0.02 & 0.1 & 3.0 to 17.0 \\
\hline
\end{tabular}

accounts for the higher albedo measured when compared to surface albedo measurements of Findelenbach.

As noted by Richards and Moore, (2011), it was necessary to ensure that the albedometer was positioned sufficiently far out from the riverbank, to ensure that, at low flows, the albedometer was above the waters surface and not directly above exposed boulders. For the Findelenbach, this was easily achieved with the metal rod holding the instrument $1.5 \mathrm{~m}$ above and $1 \mathrm{~m}$ out from a supporting rock. It was more difficult to achieve this over the Gornera, where the rod was resting on a wall of the hydroelectric intake and $1 \mathrm{~m}$ above the stream. It was difficult to guarantee no interference from the concrete wall, which may have been within the view of the downward facing pyranometer during low flow.

\subsection{Conclusion}

The aim of this chapter was to gain an understanding as to whether stream albedo in a proglacial channel could be a significant determiner in summer 
cooling which occurs in glacier-fed streams(explained in Chapter 3).

This study is a considerable addition to the existing knowledge surrounding the albedo of glacier-fed rivers. The results within this chapter offer additional information about the diurnal ranges in albedo and suggests potential impacts this has on existing water temperature models.

From the stream surface albedo values measured in this study, combined with values from used in previous studies, it is assumed that changing stream albedo is not a key determiner in the heat balance of proglacial streams. Values of stream albedo are surprisingly low in the two glacier-fed rivers examined in this study, despite suspended sediment concentrations being high, with significant aeration and development of whitecaps during high discharges. However, more long term albedo measurements must be obtained to illustrate whether suspended sediment influences stream surface albedo. The present study took place at a time when the most substantial sediment concentrations had been exhausted, earlier in the melt seasons.

In spite of the lack of importance stream albedo may play in proglacial streams, it is clear that using a single value for surface albedo would bias any modelling of the heat budget and water temperature. This is in agreement with the findings of Richards and Moore, (2011), who demonstrated even larger albedo levels, of up to $40 \%$. Higher albedo measurements are likely a result of the steeper stream incline, which increases stream turbidity leading to foamier, more cloudy waters. This confirms the findings by Richards and Moore, (2011), who suggested that stream albedo for use in modelling should be parametrised from stream discharges. From the small amount of data obtained from this study it was not possible to suggest suitable parameters. It would be necessary, therefore, to collect continuous measurements over the entire ablation season for future study of the impact of stream albedo. This would also be useful for analysis to suggest whether the changing albedo may influence the summer reduction in Alpine stream water temperatures draining large glaciers, a phenomenon explored in Chapter 3. Despite the lack of measurements during the entire season, the data amassed here suggests the 
change in albedo must be insignificant. This is evident with such low readings in the September period when riverflow was still significant and waters highly turbid. 


\section{Part III}

\section{Modelling meltwater temperature}




\section{Chapter 5}

\section{Stream water temperature model}

\subsection{Introduction}

TREAM temperature is one of the most influential factors determining
the 'health' of a river system, in both a biological and chemical sense. Therefore, more understanding of changes brought on anthropogenically and naturally is important. Unfortunately it is difficult to gather long-term data of stream temperature in high altitude basins, due to the harsh environment (Benyahya et al., 2007). This is similarly true for the meteorological variables, e.g. air temperature, wind speed and relative humidity, which are often utilised as inputs in water temperature models. Therefore, a model which can simulate temperatures in Alpine streams, to a high degree of accuracy, using few input variables, will be useful both for estimating contemporary temperature in basins lacking measurements, and for predicting future change in stream temperature as the climate warms.

Models are conceptual representations of real world processes (Benedini and Tsakiris, 2013). Water temperature models can be divided into two categories (Caissie, 2006), deterministic and statistical. Deterministic models are 
physically-based representing full energy balances. Statistical models, conversely, relate water temperature to controlling variables, often air temperature, using regression techniques to predict stream temperatures.

Numerous variables, e.g. solar radiation, air temperature, channel orientation and shading, impact on the thermal regime of rivers. Incoming shortwave irradiance is the most important meteorological factor driving the heat budget of rivers (Johnson, 2004; MacDonald et al., 2014; Webb et al., 2008). However, studies have shown that in high mountain basins with steep river beds fluid friction, i.e. the internal dissipation of heat, can be as great, if not the greatest, component of the stream's heat budget (Chikita et al., 2010).

The first step when devising a model is to ascertain the aims to be achieved, as a result of the using model. This step includes identifying the areas to be studied, including the type of stream and its basin properties. Once this step has been realised, the next stage is to identify the main factors which are influencing the particular feature which is to be modelled, as models are a simplification of reality. Both of these steps should consider data availability, and monetary and time constraints of the study. Finally, assessment of whether the aims can be met using an existing model, or through modification of existing models or the creation of a wholly new model should be undertaken (James, 1993; Rees, 2014).

This chapter charts the background and development of a simplified stream temperature model, using the heat exchange equation set out by Edinger et al., (1968). In contrast to the many models which already exist (e.g. HeatSource, Air2water and SNTEMP), the model created here allows for prediction of stream temperature in locations where few meteorological variables are measured. The chapter is set out as follows. Section 5.2 describes the methods including description of the overall scope of the model (§5.2.1). Catchment profiles of basins used in the model creation and application (§5.2.2) are also discussed, followed by a discussion of the experimental design (§5.2.3). Section 5.3 describes the creation of the model, explaining how the heat budget has been simplified. (§5.3.1). This is followed by descriptions of both the wa- 
ter temperature model (§5.3.4) and the river dynamics model, which relates riverflow to average stream width. (§5.3.5).

\subsection{Method}

This section details the method behind model creation, assesses the scope of the model, and describes the study catchments used in calibration and validation of the model, together with the experimental design employed.

\subsubsection{Scope of model}

The Alpine Stream Water Temperature Model (ASTM) had to be suitable to meet the aforementioned aims. The modeller must have full understanding of physical processes which drive the variable which is to be modelled. Similarly the limitations of the model and data must be set out in the early stages of modelling.

The overriding aim was to create a simple, low-cost model which requires as few input variables as possible. Ideally, net radiation above stream surface was hypothesised to be the only necessary input with sensible heat and latent heat fluxes cancelling out one another (Leach and Moore, 2010). Secondary to this, the model needed to be capable of being adapted to a wide variety of Alpine basins with differing topography and stream dynamics. Unlike many other models (e.g. those listed in Chapter 2), ASTM was required to be capable of modelling temperatures during the summer months when Alpine glacier-fed river discharges are at their greatest.

\subsubsection{Study Area}

ASTM was calibrated and applied to Findelenbach in the Swiss Alps (Figure 5.1). The Findelenbach $\left(46.01^{\circ} \mathrm{N}, 7.81^{\circ} \mathrm{E}\right)$ a small stream in the Findelen 


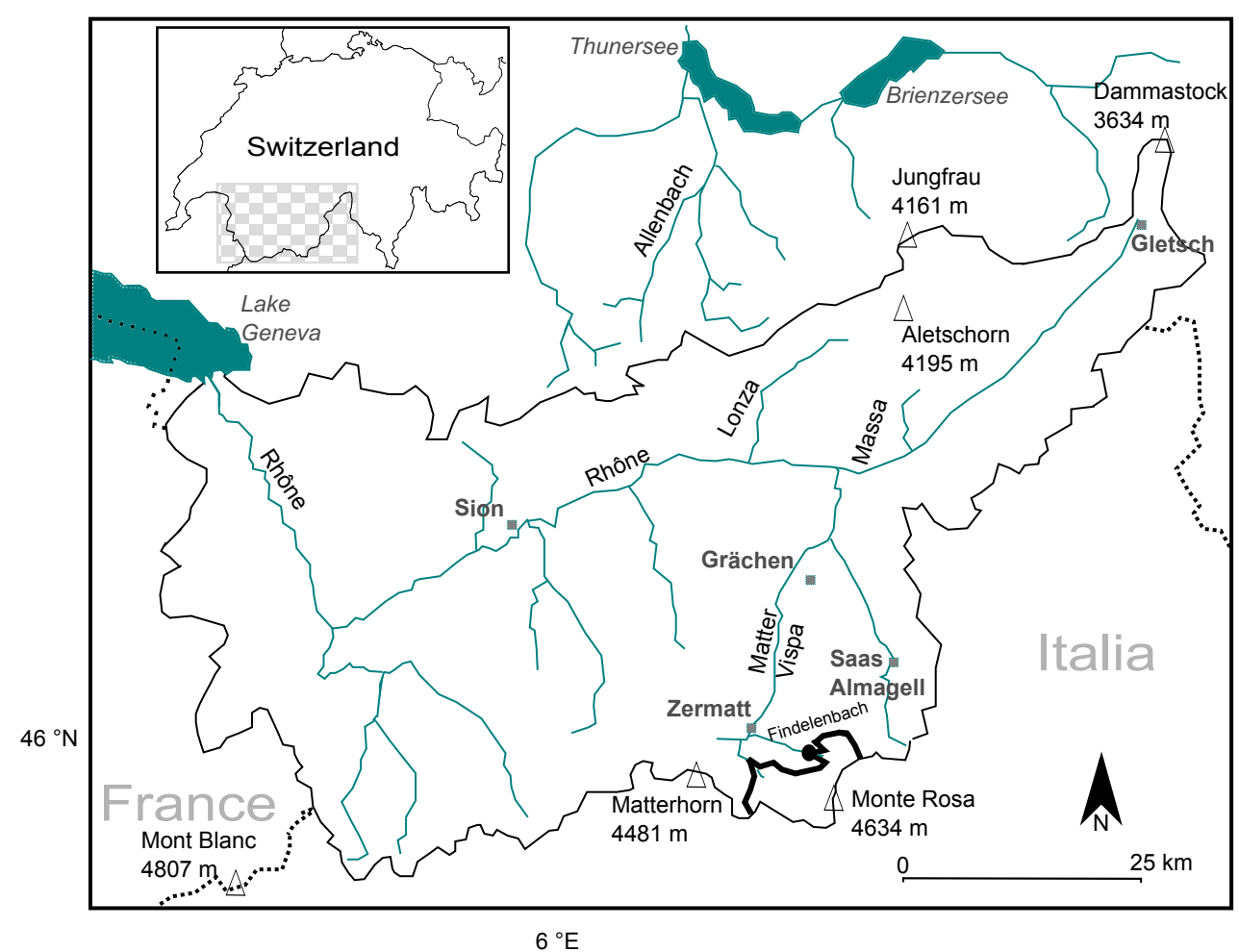

Figure 5.1: Map of Findelen study catchment in the upper Rhône basin, Kanton Wallis, Switzerland.

basin $\left(24.9 \mathrm{~km}^{2}\right)$ is $73 \%$ glacierised. The study reach is located between the glacier terminus (2639 $\mathrm{m}$ a.s.l) and the position of the gauge at $2488 \mathrm{~m}$ a.s.l. Findelenbach is gauged $1 \mathrm{~km}$ from the glacier terminus, thus reducing the effect of any groundwater sources which might offset the thermal regime of the stream.

Full details of the river and catchment area are given in Chapter 1.

\subsubsection{Model design}

An important aspect of development of a modelling technique is identifying the availability of the data needed to calibrate and validate the model. Two factors leading to the lack data availability in the Findelen study catchment 
include: the generally sparse collection of meteorological data at high elevation in the Swiss Alps. Resolution of the available data is important with respect to model creation. Models are only as useful as the data used in the input. Poor input data will inevitably lead to poor simulations; model outputs can only be as reliable as the initial model inputs (Ji, 2008).

Water temperature was recorded at both the gauging station and glacier portal. Measurements have been collected every year since 2003 at the gauge and infrequently at the Findelenbach's portal. Measured temperature readings are taken using Hach Minisonde 4a probes. However, limitations as to when the field trips took place, coinciding with the issue of battery powered probes led to gaps in the data at certain times, during most years. Incoming shortwave radiation was recorded by MétéoSuisse at the Findelen gauging station. Discharge measurements were made available for the catchments by Grande Dixence S.A., a hydroelectric power company which monitors meltwaters as they enter the hydroelectric intakes. Finally in-stream water temperature readings have been collected over many years through field trips to the catchments, as part of the Alpine Glacier Project led by Prof. David N. Collins (University of Salford).

\section{Field experiment}

A simple experiment was conducted using a fixed bowl of water placed on the ground, close to the bank of the River Gornera, a glacier-fed river located close to the Findelenbach and the town of Zermatt, (46 0'40.99"N, $7^{\circ} 44^{\prime} 22.32^{\prime \prime} \mathrm{E}$ ). The aim was to determine the effects of solar radiation on small streams at high altitude. The experiment was undertaken on 11 July 2014. The location was $4.5 \mathrm{~km}$ downstream of the glacier and as a result the water temperature was substantially warmer than would be the case at the river gauge.

Air temperature was measured at $13: 56$ as $20.1{ }^{\circ} \mathrm{C}$, and the results of the experiment are shown in Figure 5.2.

As illustrated in Figure 5.2, temperature of the water in the bowl increased 

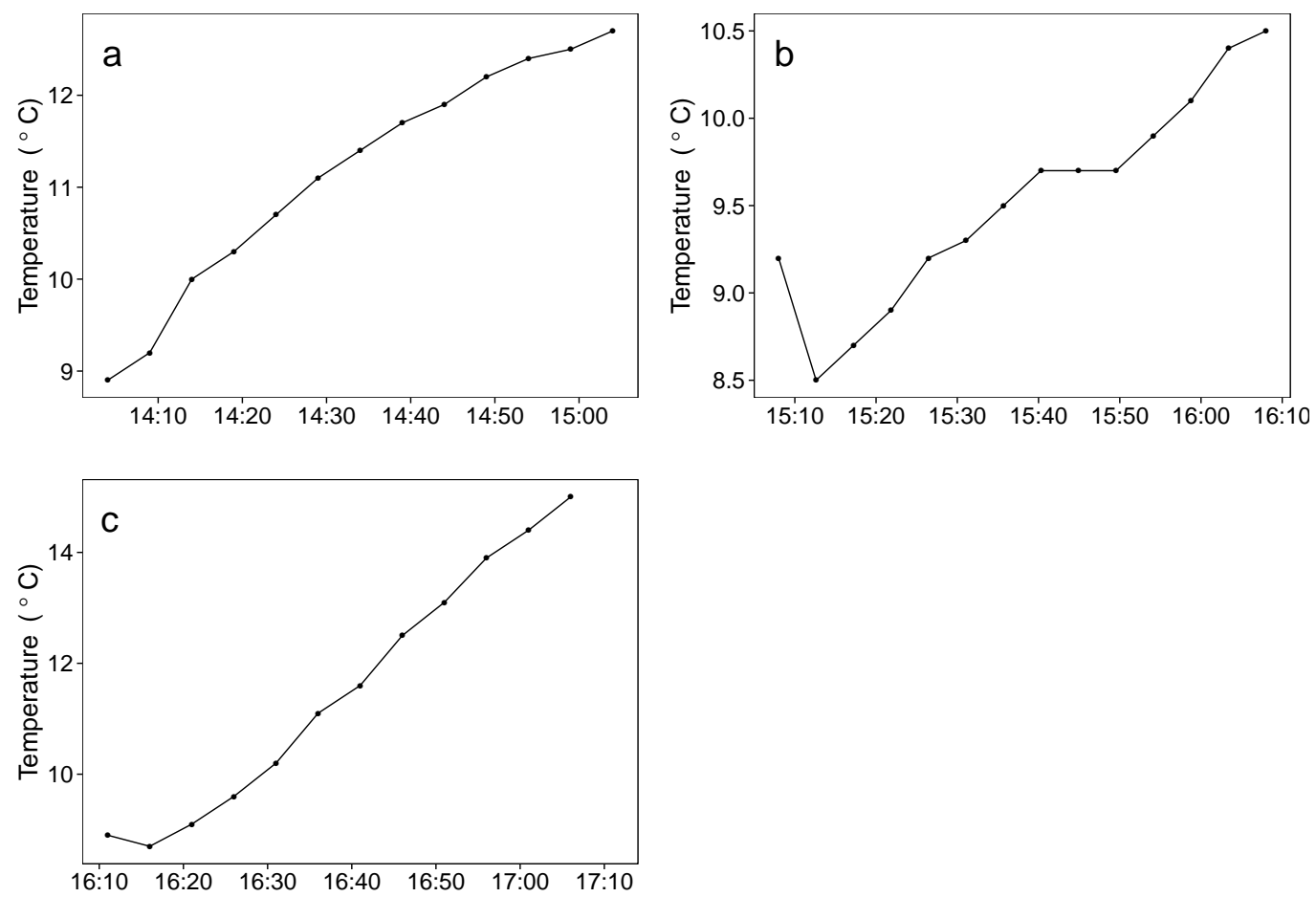

Figure 5.2: Results of field experiment: (a) heating of still water under cloud cover, (b) heating of still water under cloud cover with black sheet covering bowl and (c) warming of still water uncovered under clear sky conditions, increased direction solar radiation and sides of bowl insulated. Each for separate 1 hour periods with readings taken every 5 minutes on 11 July 2014 
linearly and at a greater rate when exposed to direct solar radiation. Whilst under overcast conditions, water in the bowl increased in temperature in a similar fashion, but was clearly subdued in that it increased from $8.9^{\circ} \mathrm{C}$ to $12.7^{\circ} \mathrm{C}$ in a 1 hour period (Figure $5.2 \mathrm{a}$ ). This increase is lower than when receiving direct solar radiation, $8.9^{\circ} \mathrm{C}-15.0^{\circ} \mathrm{C}$, (Figure 5.2c). Similarly, water temperature when measured under cover of black plastic sheeting (to block incoming solar radiation) for the same length of time only increased from $9.2^{\circ} \mathrm{C}$ to $10.5^{\circ} \mathrm{C}$, indicating the importance of radiation in raising the water temperature (Figure 5.2b). This experiment is in agreement with Johnson, (2004), who found that temperature maxima is evidently influenced by shading and as a result it is indicative that solar radiation is the most important variable driving water temperature.

\subsection{Alpine Stream Water Temperature Model}

When creating a model it is vital to understand the physical characteristics which are driving the real world processes. Often, models are not required to be developed from scratch, as the processes and physics which influence the variable to be modelled are relatively well understood. Therefore, equations and assumptions used in existing models can often be adapted for a desired use.

The Lagrangian approach to modelling calculates variables as a function of distance, and was first applied to river temperature modelling by Theurer et al., (1985). The Lagrangian method divided the stream into sections, recording the temperature of a parcel of water as it passed downstream through each river segment (Arismendi et al., 2012; 2014). For the purpose of the ASTM the model calculates the change in stream temperature for the time-period that the parcel of water resided in each section of stream. As the parcel of water moved into the following segment a new heat exchange was computed and the parcel of water would be heated or cooled accordingly. 


\subsubsection{River heat budget components and assumptions}

Certain assumptions were made with relation to the ASTM. The major assumption was that net radiation is the major component of heat budget of an Alpine stream. Thus the heat flux above the stream was simply:

$$
\Phi=K_{s} \downarrow+K_{l} \downarrow-K_{l} \uparrow
$$

$\Phi$ is the heat input $\left(\mathrm{W} \mathrm{m}^{-2}\right)$ which, for this model only accounts for net incoming solar radiation $\left(K_{s} \downarrow\right)$, incomming long wave radiation from the atmosphere $\left(K_{l} \downarrow\right)$ and emitted long wave radiation $(K \uparrow)$.

\subsubsection{Model concept}

With the scope of the model set out initially in $\$ 5.2 .1$, the next stage of the process was to conceptually design the model (Figure 5.3) so as to meet the desired aims - to create a simple, low-cost model requiring few input variables.

Incoming solar radiation must first be combined with any other important temperature-driving variables which can be modelled within the scope of this present study, before being fed into the Alpine Stream Temperature Model. A flow routing model has been developed to parametrise: average stream width, flow velocity and thus the residence time of a parcel of water in the stream segment. This may be computed for the entire reach, useful for short reaches with no tributaries, or divided into segments, where the temperature is calculated before being fed into the next segment; which is useful for longer streams where the heat inputs may have changed substantially between the glacier portal and gauge. The output of the flow routing model, which calculates stream width as a function of riverflow, is then fed into the water temperature model and the simulated stream temperature is printed to memory. 


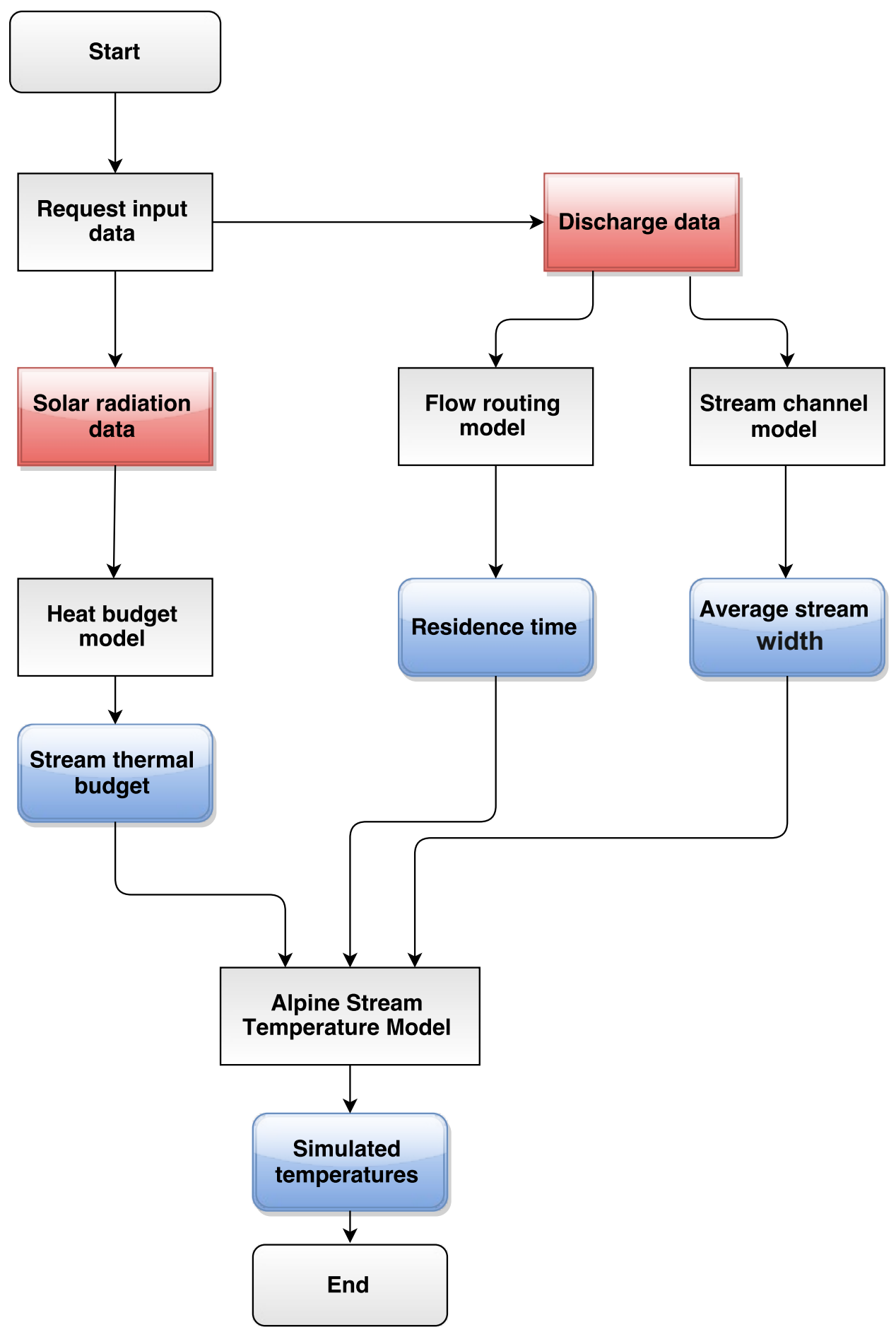

Figure 5.3: Schematic of the Alpine Stream Temperature Model program, illustrating processes (grey boxes), input data (red boxes) and stored output data (blue boxes). 


\subsubsection{Model programming}

As all data manipulation, analysis and visualisation was undertaken using the $\mathrm{R}$ programming language ( $\mathrm{R}$ Core Team, 2013) it was appropriate to utilise the same coding language in the creation of the Alpine Stream Temperature Model. The $\mathrm{R}$ statistical language has many benefits as a tool for both stochastic and numerical modelling, in part thanks to its numerical computation capabilities. Another deciding factor in the selection of a programming language include the array of available 'packages' which have been contributed to the $\mathrm{R}$ community and officially distributed through the Comprehensive $\mathrm{R}$ Archive Network (CRAN). These packages contain code and functions and, once installed, can be loaded into $\mathrm{R}$ sessions as required. Some of the packages which have been developed and are of use when running deterministic water temperature models include:

1. DeSolve (Soetaert et al., 2010). A package for solving differential equations, such as the heat exchange equation (Equation 5.2).

2. Plyr (Wickham, 2011). A package containing tools for splitting large data and applying functions to each individual part - useful when reading multiple files into a model.

3. Ggplot2 (Wickham, 2009) and Lattice (Sarkar, 2008). Graphics packages for creating publication quality plots, useful for model outputs.

4. HydroGOF (Zambrano-Bigiarini, 2014). Package for generating goodness of fit statistics for two time-series data, usually observed data and simulated model results.

Some negative features of $\mathrm{R}$ include: odd syntax which is difficult to learn and has a steep learning curve, memory intensive computing - $\mathrm{R}$ can often use up much of the available computer memory, and it is slower than many other languages - even other non-compiled, high level programming languages. Code was also developed, with respect to the water temperature model, in the Python programming language. However, for continuity purposes all data 
manipulation and modelling was conducted using $\mathrm{R}$.

\subsubsection{Water temperature model}

There are two deterministic approaches to modelling stream temperature, one method represents the temperature as a function of time and space, revealing change to the temperature of a parcel of fluid as it passes through a fixed point in space and time. Thus, water temperature $\left(T_{w}\right)$ is simulated as a function of time $(t)$ (Equation 5.2) (Caissie et al., 2007; Chikita et al., 2010). The second method simulates temperature of a parcel of fluid at each moment as it flows downstream. Properties (i.e. temperature) of the parcel are revealed at each point as the parcel moves, essentially the reference point moves with the aliquot of fluid. In the second framework, water temperature is calculated $\left(T_{w}\right)$ as a function of distance downstream $(x)$ (Equation 5.3) (Fellman et al., 2014; Garner et al., 2014; Leach and Moore, 2011; MacDonald et al., 2014; Magnusson et al., 2012).

To simulate stream water temperature in the present study, the model created was based on the Lagrangian energy conservation equation used in the literature (Equation 5.3), where $T_{w}$ is water temperature $\left({ }^{\circ} \mathrm{C}\right), x$ is distance $(\mathrm{m})$, $\rho$ equals the specific heat capacity of water, $4.21 \times 10^{3} \mathrm{~J} \mathrm{~kg}^{-1} \mathrm{~K}^{-1}$ (at $0{ }^{\circ} \mathrm{C}$ ), $Q$ is equal to riverflow, measured in $\mathrm{m}^{3} \mathrm{~s}^{-1}, C$ is density of water expressed in $\mathrm{kg} \mathrm{m}^{-3}$.

$$
\begin{gathered}
\frac{\delta T_{w}}{\delta t}=\frac{\Phi}{\rho C \overline{\bar{d}}} \\
\frac{\delta T_{w}}{\delta x}=\frac{W \Phi}{\rho C Q}
\end{gathered}
$$

The total heat input $(\Phi)$ for the purpose of this study is simply the net radiative heat fluxes (Eq. 5.4), with the lack of meteorological data in high mountain regions prevented more in depth heat budget assessment. 


$$
\Phi=K_{s} \downarrow+K_{l} \downarrow-K_{l} \uparrow
$$

\subsubsection{River dynamics models}

The Alpine Stream Temperature Model requires input of average stream widths. These are calculated using a separate flow routing model, which is utilised within the temperature model program (Figure 5.3). Using simple power function relationships set out in Leopold and Maddock Jr, (1953), whereby:

$$
\begin{aligned}
& w=a Q^{b} \\
& d=c Q^{f} \\
& v=k Q^{m}
\end{aligned}
$$

$Q$ represents discharge, $w$ is the width, $d$ gives the depth, and $v$ is the velocity of the stream, it is possible to infer the hydraulic geometry of streams. The above equations demonstrate velocity, depth and width all being a function of discharge as a result of:

$$
Q=\text { area } \times \text { velocity }
$$

thus:

$$
Q=\left(c Q^{f} \times a Q^{b}\right) \times k Q^{m}
$$

The sum of the exponents must, therefore, be one and the product of the coefficients must also be equal to one (Gleason and Smith, 2014; Leopold and 
Code Listing 5.1: Water temperature model excerpt (Full R script available in the appendix)

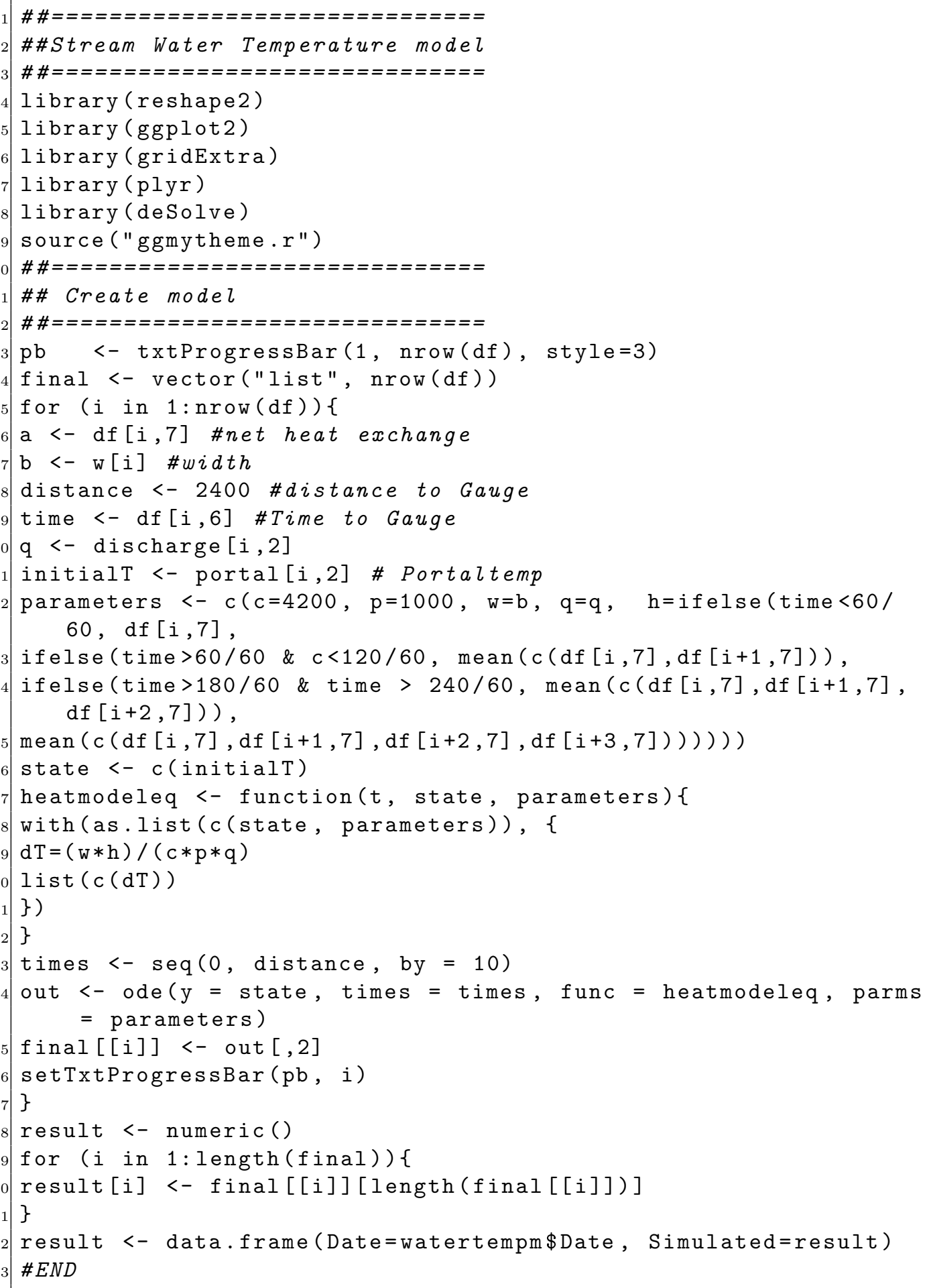


Maddock Jr, 1953; Park, 1977).

Values of the exponents $b, f$ and $m$ and the coefficients $a, c$ and $k$ would usually be empirically determined, with the use of multiple measurements of width depth and velocity at a river cross section (Gleason and Smith, 2014).

As a result, discharge data must be used as a model input. Equation 5.6 gives the average depth. This can either be programmed to be the entire study reach, or pre-defined sections of a study stream. Equation 5.7, gives the velocity of the stream or reach sections. This along with the reach length, is used to calculate the time a parcel of water will reside in the stream section.

\subsection{Model application and performance}

\subsubsection{Model calibration}

All models must go through the stages of calibration and validation. During calibration, the model parameters are evaluated and tuned through "parameter optimisation', where they are adjusted to ensure realistic outputs from the model. This calibration is usually performed over a number of time periods by comparing model outputs to measured data (Figure 5.4). This approach may be referred to as inverse modelling (Soetaert and Petzoldt, 2010), whereby simulation outputs are fitted to measured data. The first stage of calibration involved running a sensitivity analysis which assessed the importance of each parameter, which included parameters used in both the flow routing model and the temperature model.

\section{Sensitivity analysis: Parameter optimisation}

A sensitivity analysis is the investigation into the uncertainty of model outputs and how these may be attributed to model input variables. 


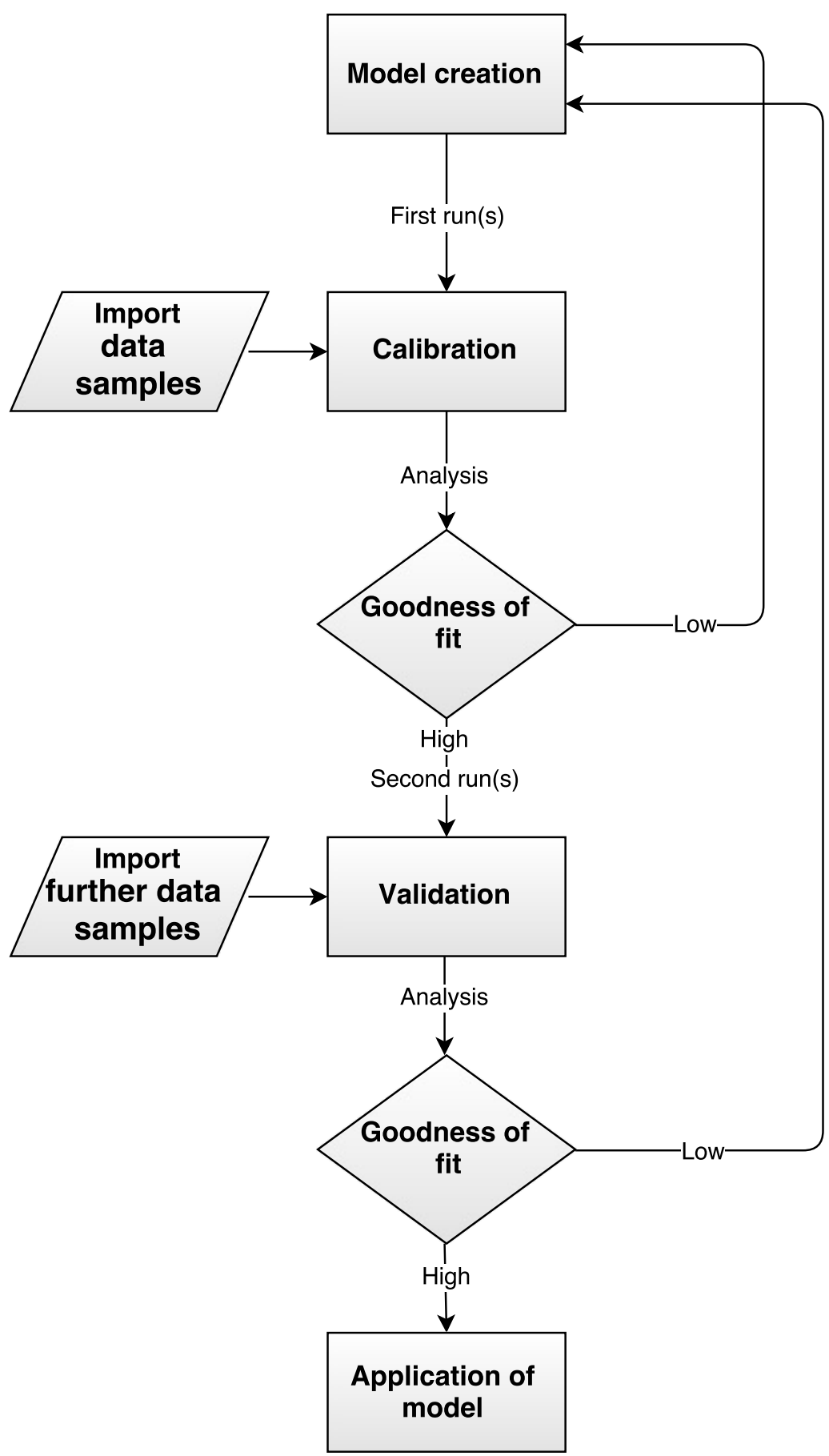

Figure 5.4: Schematic of model creation, calibration and validation routines. 
Sensitivity analysis was performed to assess the influence of parameters $a$, $b, c, f, k$ and $m$ (Equations 5.5-5.7) used in the flow routing model on the output of the water temperature model. To assess the relationship between width $(\mathrm{W})$ and riverflow $(\mathrm{Q})$, the stream temperature model was used under a selection of different parameters in the flow routing model. The model was applied over a period of three days (14 - 16 July 2006). Heat gain due to potential energy could be calculated from the elevation loss $(\mathrm{m})$ from the glacier portal to the gauge. Upstream conditions were measured with a Hach Minisonde logger positioned close to the glacier portal. A second Minisonde logger was positioned at the downstream position (close to the Findelenbach hydroelectric intake). Each iteration of the model was run with new parameter values, and for each model simulation statistics for $r, R^{2}, R M S E$ and NSE were generated using the HydroGOF package (Zambrano-Bigiarini, 2014) in the $\mathrm{R}$ programming environment ( $\mathrm{R}$ Core Team, 2013). Using the goodness of fit statistics, the best fit model was used to suggest the best parameters for the flow routing model (Moriasi et al., 2007).

Two possible width/discharge relationships were hypothesised. First, stream width which would change significantly with changing riverflow (Figure 5.5). Initial values of $a=0.9$ and $b=1.5$ were selected. With each iteration, the value of the coefficient, $a$, was kept constant and the value of $b$, the exponent, was raised by 0.1. Each iteration, resulted in reducing coefficients of determination and correlation coefficients $R^{2}=0.91-0.74$ and $r=0.95-0.86$. Root Mean Square Errors (RMSE) and Nash-Sutcliffe Efficiency (NSE), on the other hand, improve up to $b=2.0(R M S E=0.35$ and $N S E=0.74)$. Further increase in $b$ resulted in worsening RMSE and NSE coefficients (e.g. $b=2.2$ : $R M S E=0.63$ and $N S E=0.17)$. Secondly, the model was run with changing coefficients, which would result in little change of stream width per change in discharge (Figure 5.6). For this scenario, initial values of $a$ and $b$ were 40 and 0.0006 respectively. The low exponent ensures width changes little with riverflow and remains around the value of the coefficient. The coefficient was increased by 5 for each iteration. $R^{2}$ and $r$ coefficients reduced after each iteration. RMSE and NSE coefficients, improve up to $a=60$ ( $R M S E=0.31$, 
$N S E=0.8)$, with any further increases resulting in reducing goodness of fit. Visual inspection of Figure 5.5e and Figure 5.6d, despite similar goodness of fit coefficients, suggest that width increasing significantly with discharge gives a better visual goodness of fit to observed data. For example, this is most noticeable on 14 July 2006. 
$\mathrm{R} 2=0.91 \mathrm{r}=0.95 \mathrm{RMSE}=0.6 \mathrm{NSE}=0.27$

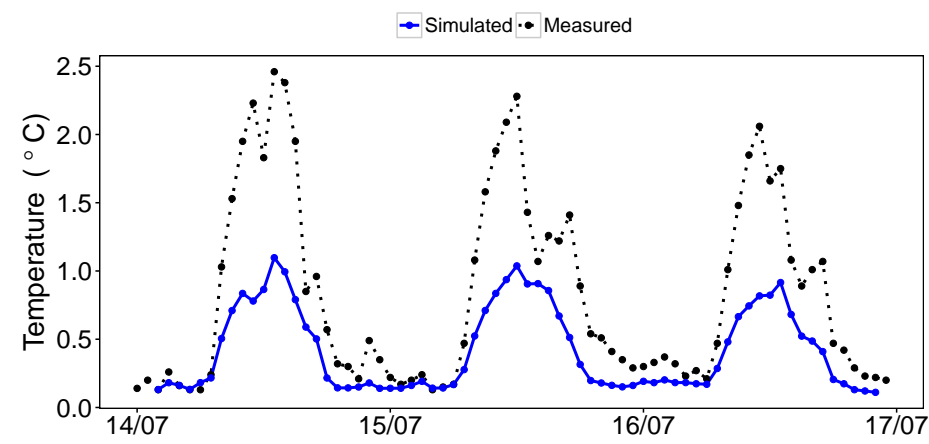

(a)

$R 2=0.87 \mathrm{r}=0.93 \mathrm{RMSE}=0.48 \mathrm{NSE}=0.52$

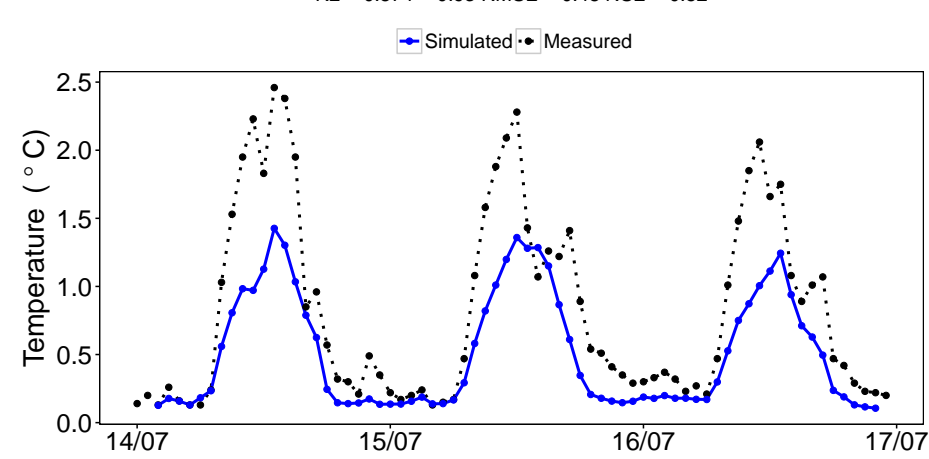

(c)

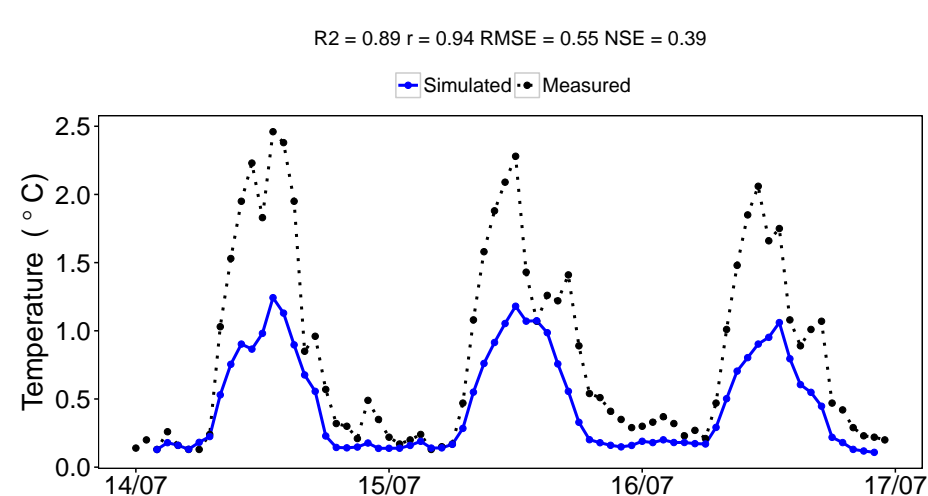

(b)

$\mathrm{R} 2=0.84 \mathrm{r}=0.92 \mathrm{RMSE}=0.42 \mathrm{NSE}=0.64$

$\rightarrow$ Simulated $\bullet$ Measured

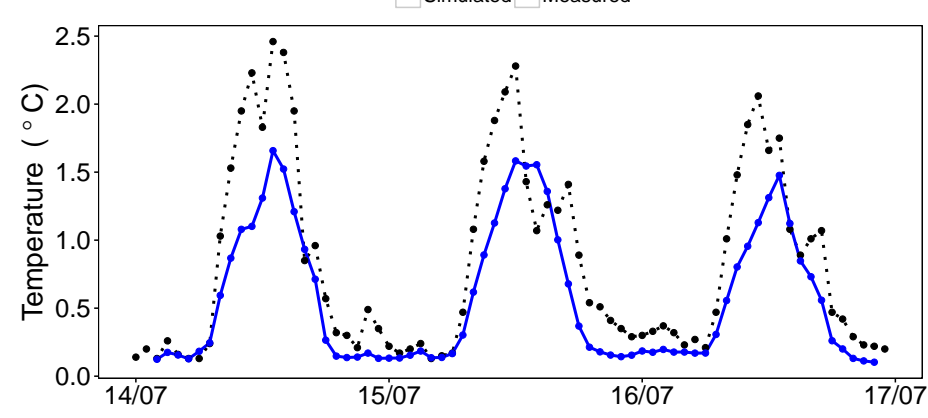

(d)

Figure 5.5: Sensitivity analysis result: altering coefficient $a$ and exponent $b$ to define a width which changes significantly with riverflow. $a=0.9$ and $b=1.5$, Figure (a), to 2.2, Figure (h), increasing by 0.1 each iteration. 
$\mathrm{R} 2=0.82 \mathrm{r}=0.9 \mathrm{RMSE}=0.36 \mathrm{NSE}=0.73$

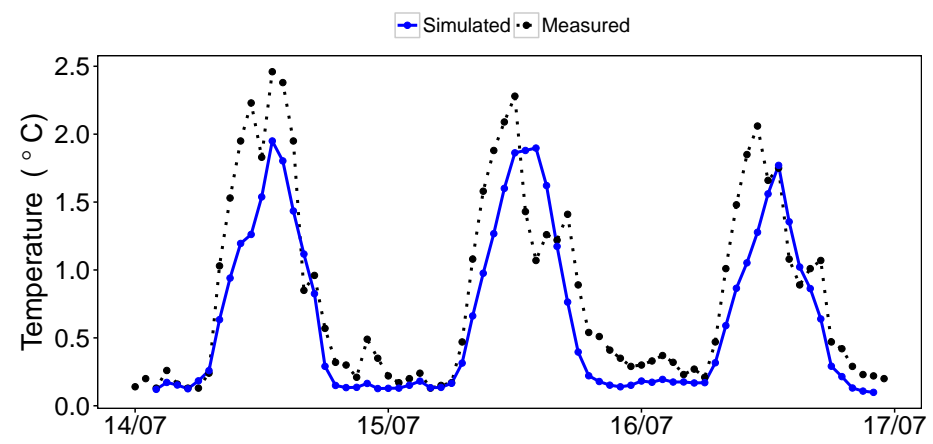

(e)

$\mathrm{R} 2=0.76 \mathrm{r}=0.87 \mathrm{RMSE}=0.44 \mathrm{NSE}=0.6$

$\rightarrow$ Simulated $\bullet$ Measured

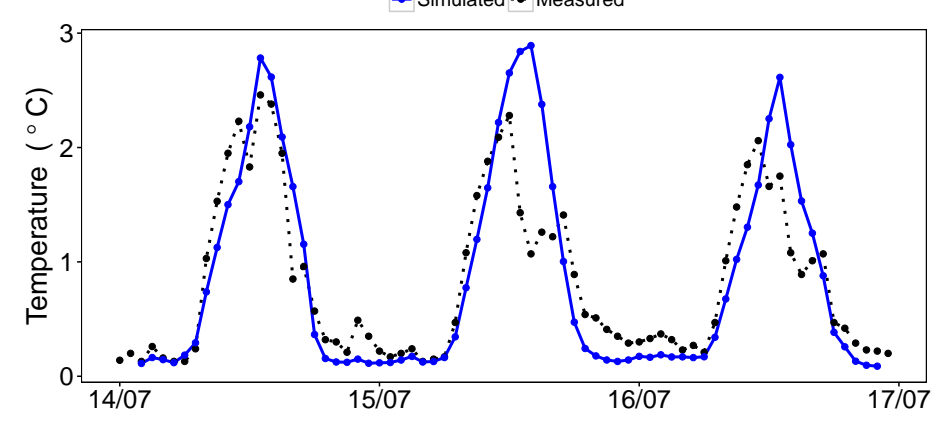

(g)

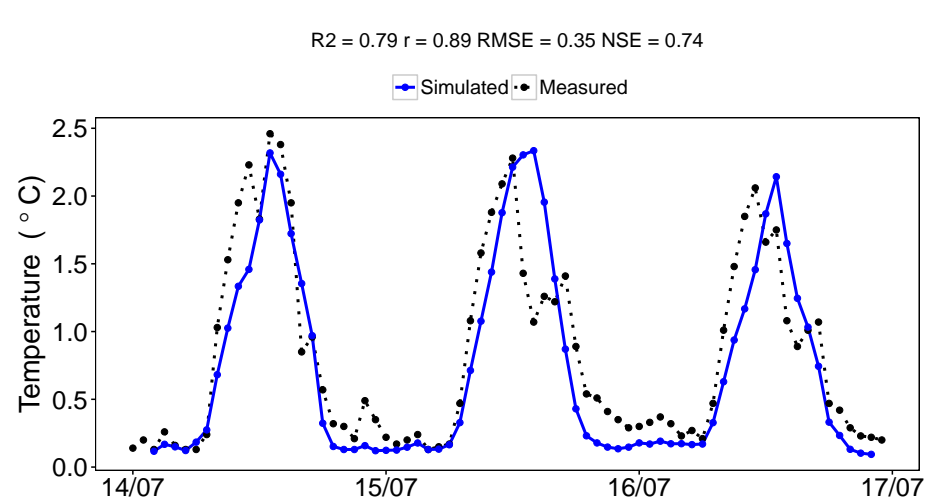

(f)

$\mathrm{R} 2=0.74 \mathrm{r}=0.86 \mathrm{RMSE}=0.63 \mathrm{NSE}=0.1$

$\rightarrow$ Simulated $\bullet$ Measured

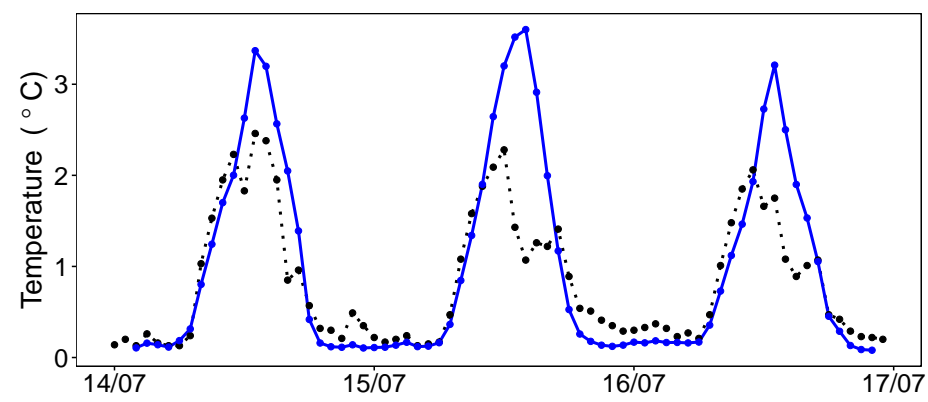

(h)

Figure 5.5: Sensitivity analysis result: altering coefficient $a$ and exponent $b$ to define a width which changes significantly with riverflow. $a=0.9$ and $b=1.5$, Figure (a), to 2.2, Figure (h), increasing by 0.1 each iteration. 
$\mathrm{R} 2=0.86 \mathrm{r}=0.93 \mathrm{RMSE}=0.43 \mathrm{NSE}=0.62$

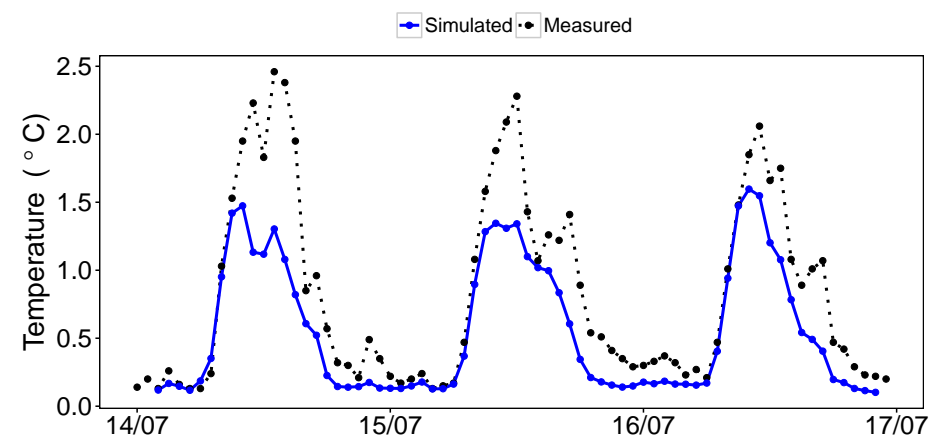

(a)

$\mathrm{R} 2=0.85 \mathrm{r}=0.92 \mathrm{RMSE}=0.36 \mathrm{NSE}=0.74$

$\rightarrow$ Simulated $\bullet$ Measured

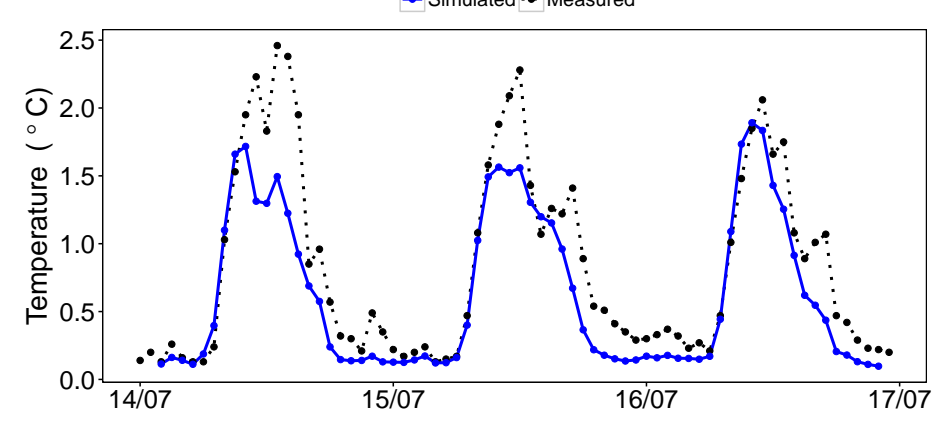

(c)

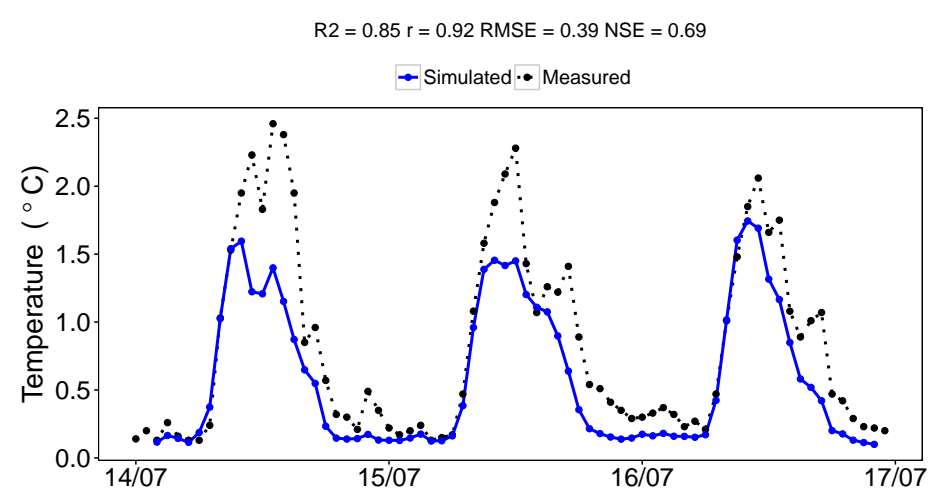

(b)

$R 2=0.85 r=0.92 \mathrm{RMSE}=0.33 \mathrm{NSE}=0.78$

- Simulated $\bullet$ Measured

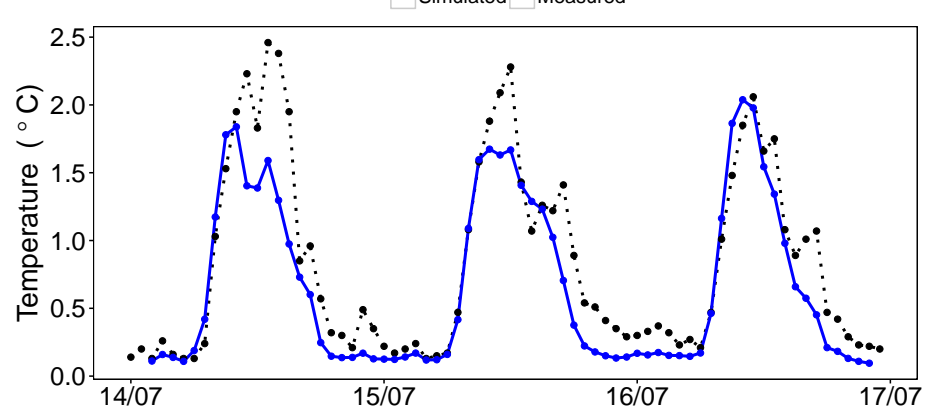

(d)

Figure 5.6: Sensitivity analysis result: altering coefficient $a$ and exponent $b$ to define a width which changes little with riverflow. $a=40$, Figure (a), to 75, Figure (h), increasing by 5 each iteration. and $b=0.0006$. (Continued 
$\mathrm{R} 2=0.84 \mathrm{r}=0.92 \mathrm{RMSE}=0.31 \mathrm{NSE}=0.8$

- Simulated $\cdot \bullet$ Measured

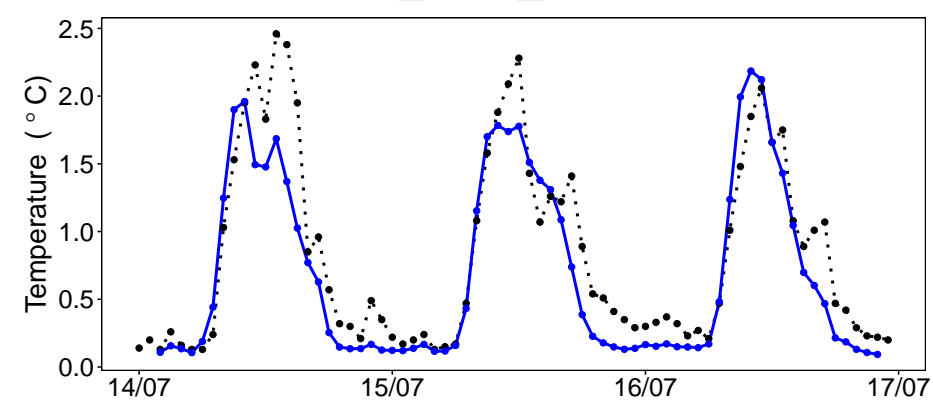

(e)

$\mathrm{R} 2=0.84 \mathrm{r}=0.92 \mathrm{RMSE}=0.32 \mathrm{NSE}=0.8$

- Simulated • Measured

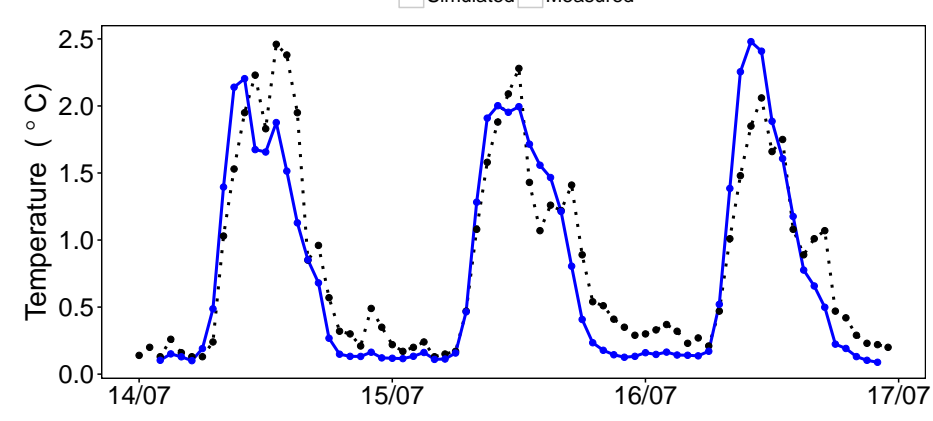

(g)

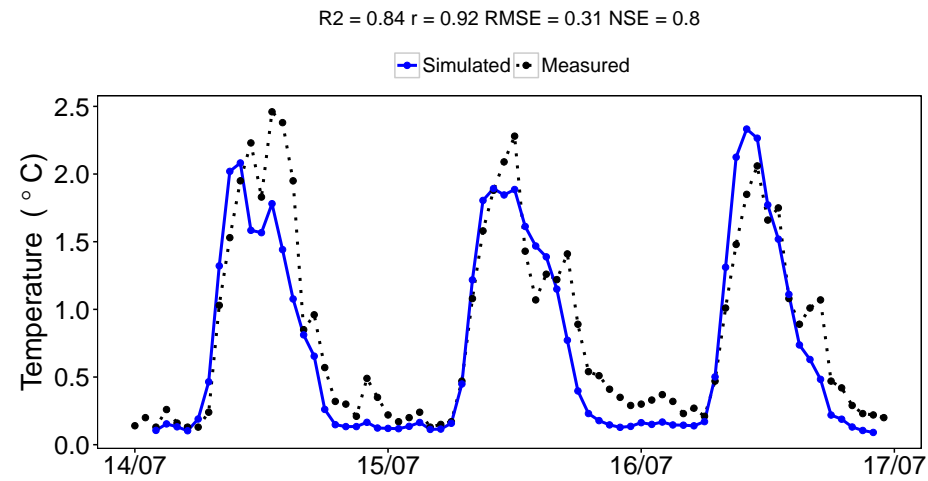

(f)

$R 2=0.84 r=0.92 \mathrm{RMSE}=0.33 \mathrm{NSE}=0.77$

$\rightarrow$ Simulated $\bullet$ Measured

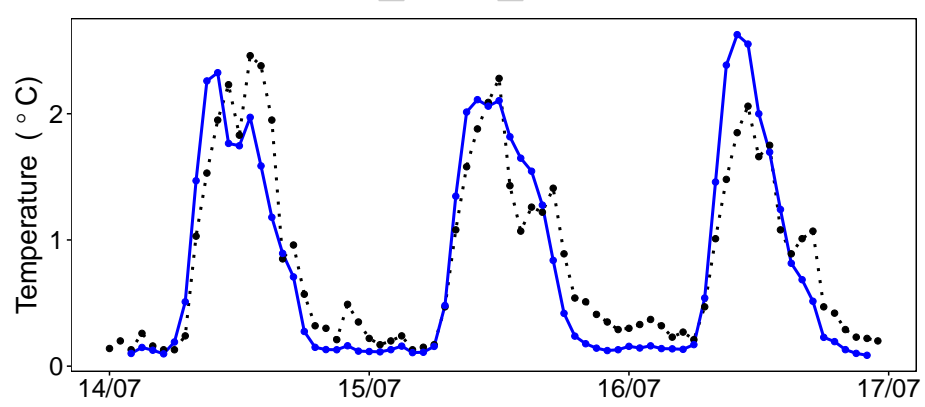

(h)

Figure 5.6: Sensitivity analysis result: altering coefficient $a$ and exponent $b$ to define a width which changes little with riverflow. $a=40$, Figure (a), to 75, Figure (h), increasing by 5 each iteration. and $b=0.0006$. (Concluded.) 


\subsubsection{Model validation}

Models which have been calibrated are still not sufficient in predicting real life processes. Further validation of models must be undertaken to improve their credibility (Ji, 2008).

Water temperature in the Findelenbach was recorded at the gauge between the period 28 June and 8 September 2006. With upstream water temperatures unknown throughout the entire period, the average temperature for each hour during the period when portal temperatures are known, is used across the entire study period. Despite being less accurate, ranges in portal temperature are low, and this therefore attempts to account for the small range across a 24 hour period. The period (28 June-8 September 2006) was used to further validate the model using the aforementioned parametrisation of stream width to riverflow. Two simulations were used. One simulation using parameters to simulate stream width increasing significantly with riverflow. The second simulation modelling with stream width parameterised to increase by only small amounts with changing riverflow. Parameters were set from the sensitivty analysis outlined in the previous section. Hence the parameters which resulted in the best Nash-Sutcliffe Coefficient were selected for each width scenario. Figure 5.7 shows modelled temperature when the width input changes drastically with levels of discharge. Parameters used were $a=0.9$ and $b=2.0$. Nash-Sutcliffe Coefficient was best, however, when discharge resulted in a small change in stream width. Figure 5.8 illustrates such scenario. Parameters used in the second simulation were $a=40$ and $b=0.001$.

Results demonstrate that changing width slightly with riverflow, results in much improved simulated temperatures $(N S E=0.05, R M S E=0.84)$ than when modelled with width increasing substantially with riverflow $(N S E=$ $-0.03, R M S E=0.87)$. Low Nash-Sutcliffe Coefficients are given due to the model accuracy falling at times of low discharge. This would be expected for a model using only net radiation as the input parameter; at low discharges it could be expected that radiation is reduced due to cloud cover and the 
percentage of influence of radiation driving temperatures is reduced (Moore, 2006). 

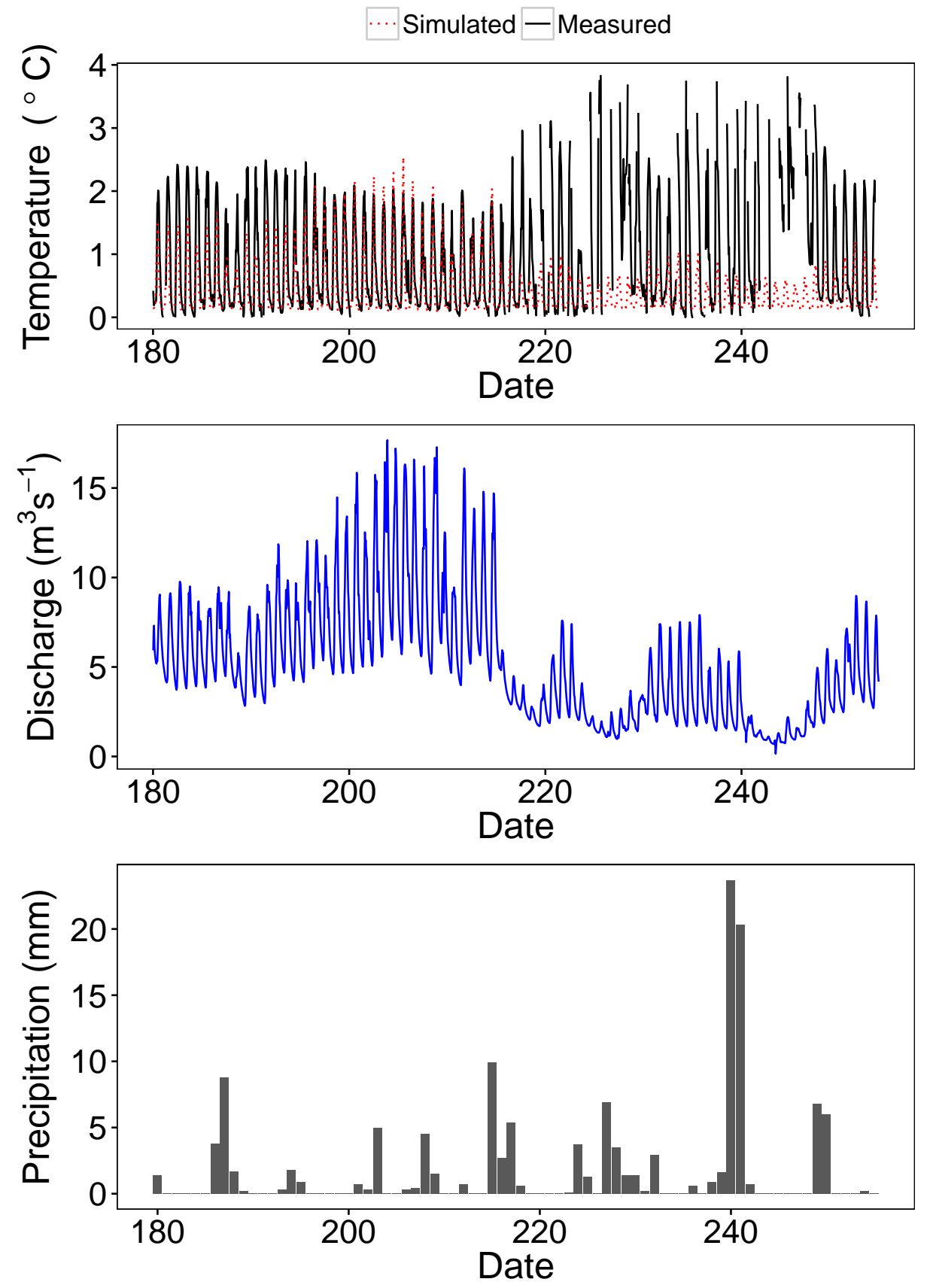

Figure 5.7: Simulated water temperature (modelled with width changing substantially with discharge) during the period Julian day 180 (June 28) to Julian day 253 (September 8) 2006 (top plot), here shown together with: Hourly riverflow levels of the Findelenbach (middle plot) and daily precipitation totals at Zermatt (lower plot). 

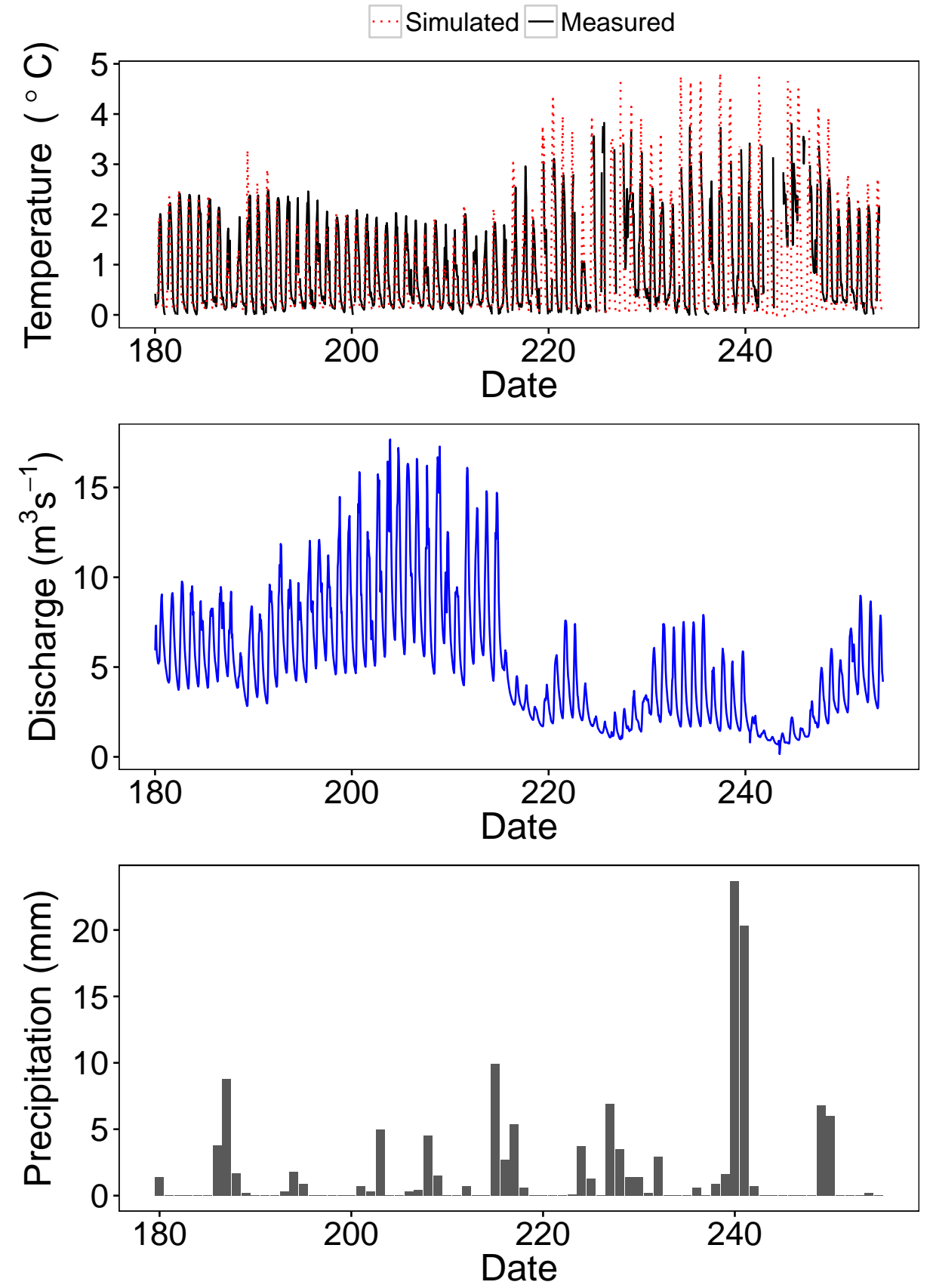

Figure 5.8: Simulated water temperature (modelled with width changing little with discharge) during the period Julian day 180 (June 28) to Julian day 253 (September 8) 2006 (top plot), here shown together with: Hourly riverflow levels of the Findelenbach (middle plot) and daily precipitation totals at Zermatt (lower plot). 
Nash-Sutcliffe efficiency coefficients improve when assessing the period 28 June to 01 August 2006, when discharges are at typical summer levels (NSE = $0.33, R M S E=0.58$ in low variable width model). Total daily precipitation is also shown in Figure 5.7 and Figure 5.8. This is to demonstrate how during the period of low riverflow, precipitation levels increased. For example, between day 220 (August 7 2006) and the end of the study period. Warmer waters in this period will reflect lower discharge levels, and warming is due to warmer precipitation mixing with the glacier meltwater.

24-hour averages of simulated stream temperature consistently underestimate daily averages of recorded values (Figure 5.9, $N S E=-0.33, R M S E=0.49$ ). The underestimation is likely due to upstream boundary conditions being different from those used in the model. Upstream conditions are usually important in deterministic models (Garner et al., 2014). Additionally, night time temperature in the stream when modelled utilising only net radiation, and heat gain from the conversion of potential to kinetic energy, is likely to be underestimated as warming/cooling would occur during these hours. Therefore, driven by forces not accounted for in this present model e.g. heatloss due to convection. 


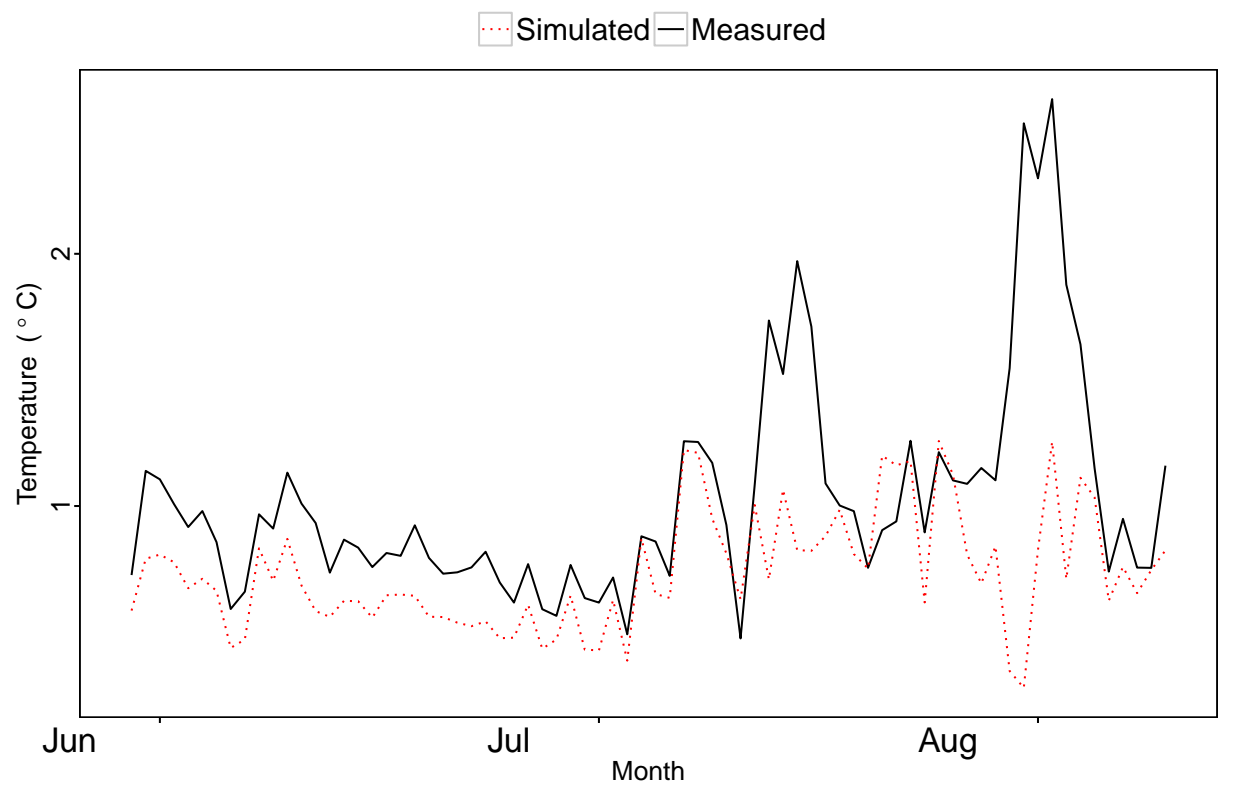

Figure 5.9: 24 hour average of simulated water temperature and average daily measured water temperature of the Findelenbach for the period Julian day 180 (June 28) to Julian day 253 (September 8) 2006.

\subsection{Model Application}

The Alpine Stream Water Temperature Model was applied to the Findelenbach for the period September 20 (Julian day 263) to October 6 (Julian day 279), 2009. During this period water temperature measurements were taken at both the gauging location, close to Findelen hydroelectric intake, and close to the portal of Findelengletscher. Simulated stream temperature using the water temperature model together with the flow routing model, were compared to observed temperatures in the Findelenbach. Modelled stream temperature downstream of the glacier portal were generally good during day-time hours (Figure 5.10). Goodness of fit statistics for the period were: $R M S E=0.68$, $N S E=0.68, R^{2}=0.77$. Thermal changes during night-time hours is frequently overestimated. However, this was expected as the model was only accounting for heat loss/gain as result of net radiation. 

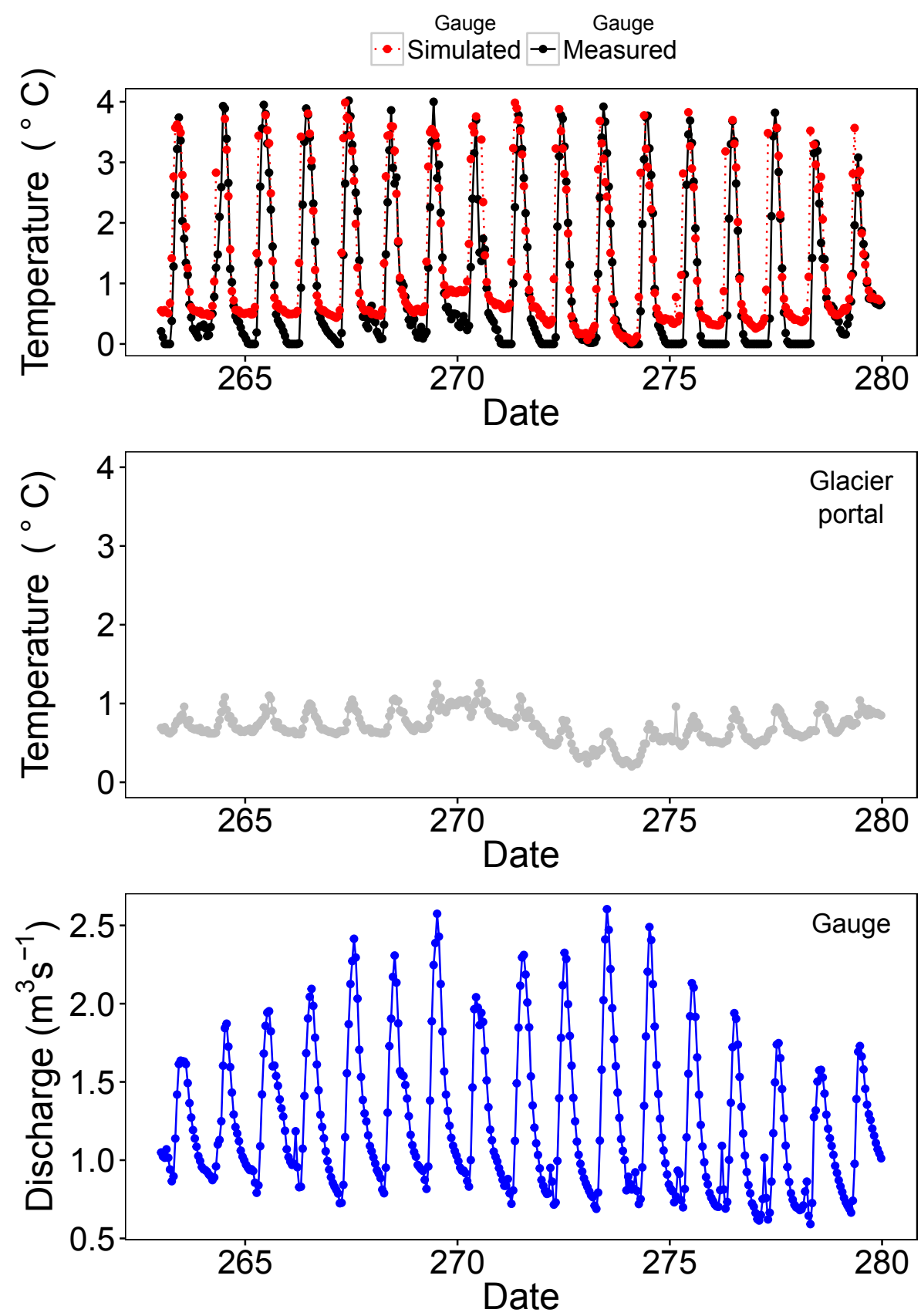

Figure 5.10: Simulated water temperature during the period Julian day 264 (September 21) to Julian day 280 (October 7) 2009 (top plot), shown together with: Observed up-stream temperature, at the glacier portal (middle plot), and Hourly riverflow levels of the Findelenbach (lower plot). 

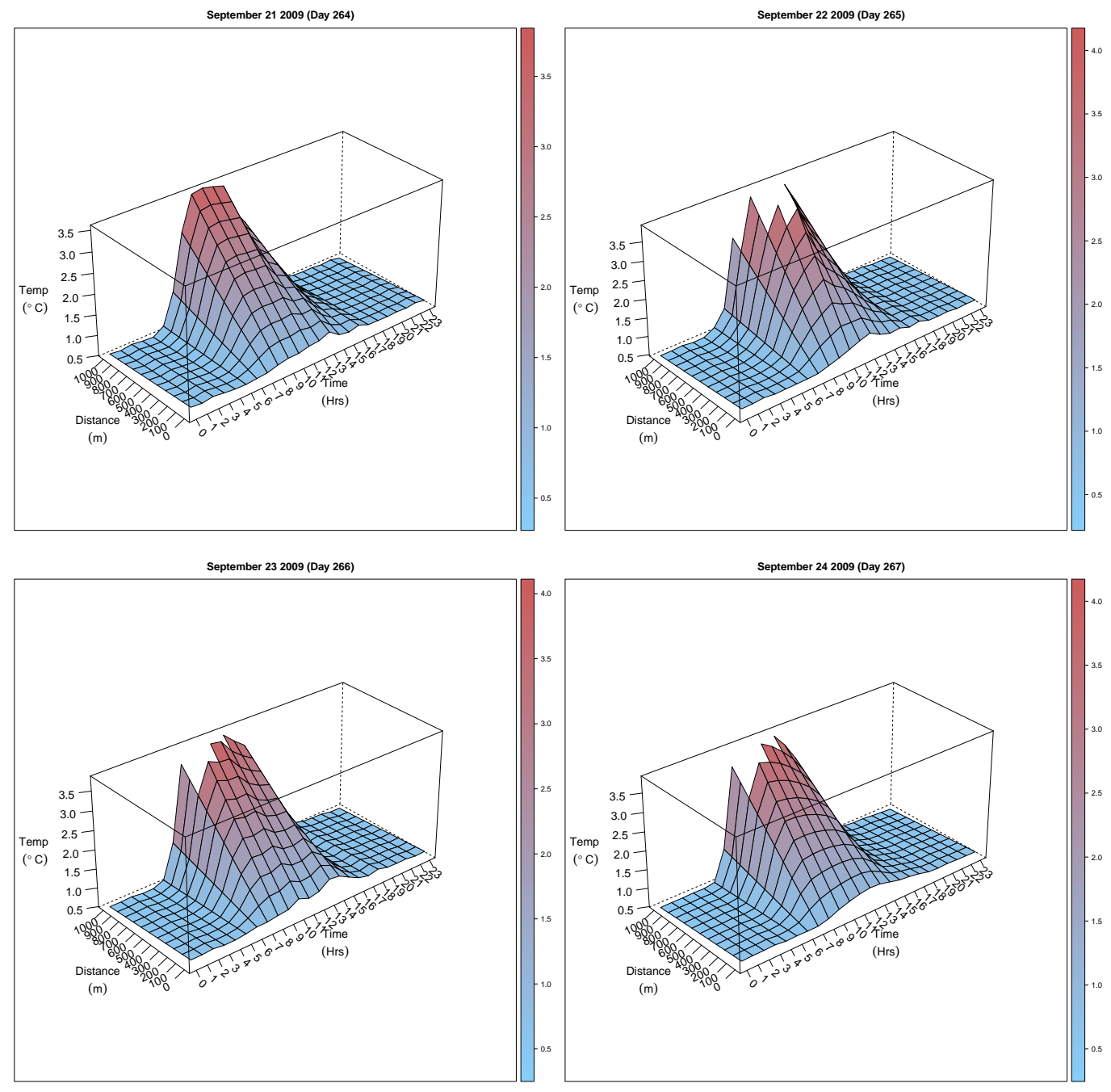

Figure 5.11: Representation of the warming aliquots of water (black line on Time axis) as they pass downstream from the glacier portal for the period September 21 to September 24, 2009. 
Figure 5.11 shows simulated longitudinal water temperature change, every $10 \mathrm{~m}$ downstream from glacier portal. Such a simple model is unable to simulate longitudinal increase in temperature. As an aliquot of water moves downstream in the present model the input variables are constant in each 'box'. Therefore, this model is incapable of determining the result of climatic change upon the longitudinal warming in glacier-fed rivers. To quantify the longitudinal heating along a stream reach it would be necessary to conduct an assessment of heat input over every $10 \mathrm{~m}$ 'box' along the stream. Similar studies have conducted measurements and models of heat budgets along a stream reach (Garner et al., 2014; Leach and Moore, 2011). Similar methods could be adopted in a glacier-fed river catchment, to quantify longitudinal heating.

During simulation of September 21 2009, water temperature warmed between $1.1{ }^{\circ} \mathrm{C}$ and $3.6^{\circ} \mathrm{C}$ during the time of greatest heating (09:00), with clear cloud cover after 11:00, resulting in reduced ability for warming. This is slightly lower than temperature measured at the downstream gauging position $\left(3.7^{\circ} \mathrm{C}\right)$. This small difference of $0.1^{\circ} \mathrm{C}$ could be due to some of the constituents of the heat budget which are not accounted for in the ASTM.

Figure 5.11 also demonstrates the inefficiency in the temperature model during night-time hours. For example, between the hours of 20:00 (September 22 ) and 04:00 (September 23) 2009, there is only a very slight decrease in longitudinal temperature change. Decreasing temperature ranged from around $0.6^{\circ} \mathrm{C}$ at the glacier portal to around $0.5^{\circ} \mathrm{C}$. This decrease is being driven by emitted longwave radiation dominating the heat budget in the model input during night hours. Recorded temperatures at the downstream gauging position, in fact cooled from $0.3^{\circ} \mathrm{C}$ to $0.1^{\circ} \mathrm{C}$ demonstrating that the heat budget used within this model does not fully account for night-time cooling.

Comparison of the first, second and third days (September 21-23 2009) show rising levels of riverflow in the catchment (Figure 5.10). However, assessment of temperature gradients in the stream indicate that temperatures do not decrease with rising riverflow in the Findelen catchment. Simulated tem- 
peratures (Figure 5.11) rise from $1.1^{\circ} \mathrm{C}$ to $3.7^{\circ} \mathrm{C}$ during period of maximum warming on September 222009 , and $0.8^{\circ} \mathrm{C}$ to $3.7^{\circ} \mathrm{C}$ on September 23, despite discharge increasing. There was a similar difference between measured temperatures in the Findelenbach across the two days, $3.9^{\circ} \mathrm{C}$ and $4.0^{\circ} \mathrm{C}$ respectively.

\subsubsection{Model application on other glacier-fed rivers}

Application of the ASTM to a different study site revealed interesting results. When applied to the Findelenbach's contiguous river catchment the Gornera, model results had a poorer fit. Figure 5.12 shows simulated water temperature, with observed water temperature measured at the Gornera gauging station. Table 5.1 gives the goodness of fit statistics for the model application.

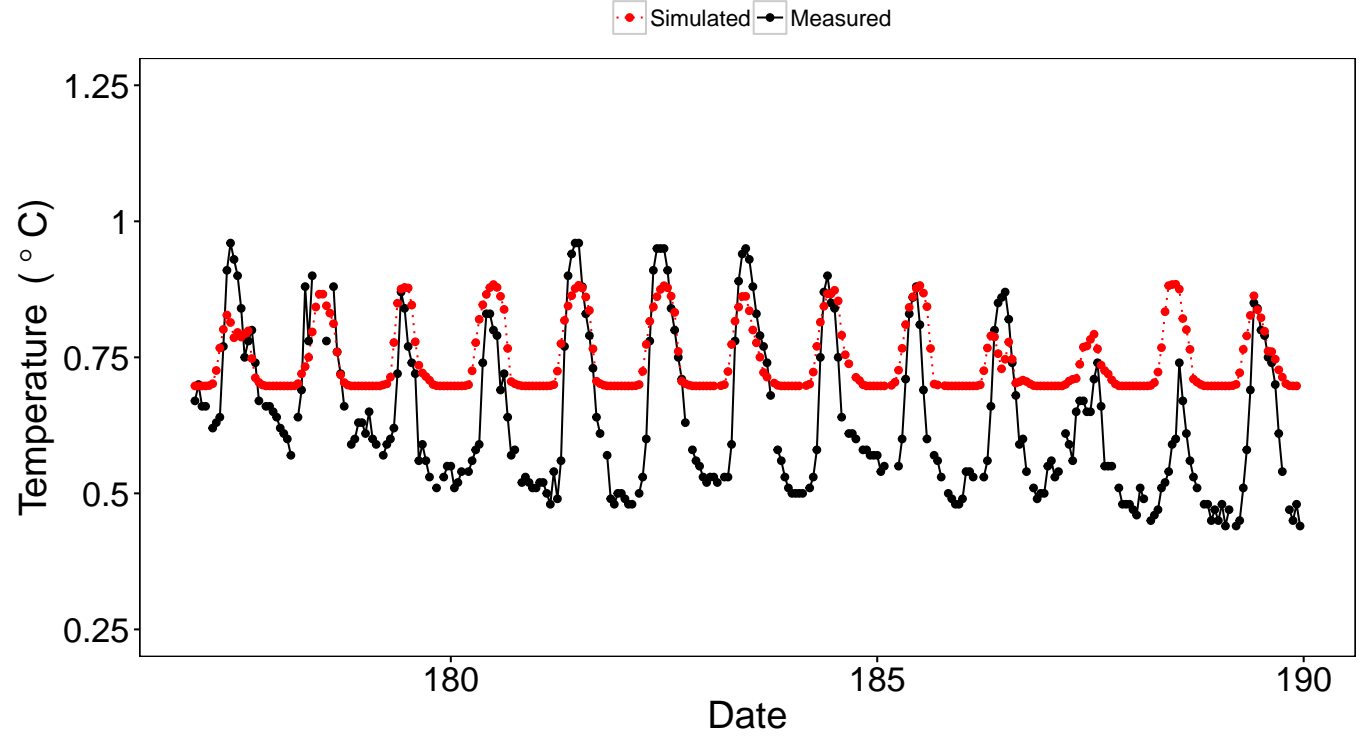

Figure 5.12: Simulated water temperature and observed hourly water temperature of the Gornera at the Gorner gauging station, for the period Julian day 179 (June 27) to Julian day 190 (July 8) 2006.

Simulated water temperature at the Gorner gauging station does not fit ob- 
Table 5.1: Goodness of fit statistics for simulated to observed water temperature of the Gornera (27 June - 8 July 2006).

\begin{tabular}{ccrcc}
\hline $\mathrm{r}$ & $R^{2}$ & $\mathrm{MAE}$ & $\mathrm{RMSE}$ & $\mathrm{NSE}$ \\
\hline 0.76 & 0.59 & 0.13 & 0.15 & -0.12
\end{tabular}

served measurements well, demonstrated by low (-0.12) Nash-Sutcliffe Efficiency coefficient.

There are many reasons as to why the model does not perform well in this instance. One major drawback of this simulation is the lack of upstream water temperature data. Without upstream conditions being available the model is unable to account for the variance in upstream temperature which occurs even at the glacier portal, as demonstrated at the Findelenbach. To replace this lack of data, a set input temperature of $0.6^{\circ} \mathrm{C}$ was used as the assumed upstream boundary condition. This is an imperfect solution as, in the Findelenbach at least, temperatures ranged from just above $0^{\circ} \mathrm{C}$ to around $1{ }^{\circ} \mathrm{C}$.

A second issue with the simulation when applied to the Gornera, which also hindered use of the model on the Findelenbach, is the lack of available width data. Utilising measurements from Google Earth it became clear that during visibly high flows, the Gornera has an average width of around $16 \mathrm{~m}$ (average of every $10 \mathrm{~m}$ moving longitudinally down stream). It also became evident that at lower flows average stream width was much reduced. As with the Findelenbach study, width was parametrised from discharge using relationships set out by Leopold and Maddock Jr, (1953) — width being a power function of discharge. Optimisation of this power function resulted in the width being equal to:

$$
w=0.6 Q^{1.00009}
$$

Once this power function was selected and applied to the model the results 
(Figure 5.12) demonstrated that net radiation was not sufficient in warming the stream to its daily maxima. Despite this, and as was the case in the Findelenbach, night-time temperatures were, as expected, over estimated. Night time heat fluxes are negative, with atmospheric longwave radiation being the only net contributor (Ouellet et al., 2014).

The underestimation of daily temperature maxima suggests the possibility that net radiation is not the overriding heat input into the stream. Assuming the width used in the model is correct then this theory holds true. One reason for this could be that the heat budget of this reach is similar to those studied by Chikita et al., (2010). Chikita et al., (2010) show that frictional heating is the major contributor to the heat budget of a glacier-fed river in Alaska. In the present study, although not the major contributor, frictional heating could hold a significant influence over the water temperature.

Another important aspect which should be considered is the topographic shading in mountainous regions. The Findelenbach is unshaded for the majority of the day, whereas the Gornera is in a deep valley which the sun falls behind fairly early, in the afternoon around 16:00-17:00. Shading of rivers has been found to be an important factor influencing a rivers heat budget, sometimes even reducing longitudinal stream heating (Garner et al., 2014; Johnson, 2004). Shading significantly reduces solar radiation inputs, leading to increasing percentage contribution from latent and sensible heat fluxes and net longwave radiation (Johnson, 2004). The Alpine Stream Water Temperature Model does not account for topographic shading influences on the net radiation, and including this may improve the correlation between simulated and observed water temperatures. In spite of this, Johnson, (2004) suggest that shading, by either vegetation or topography, does not influence minimum (night time temperatures). Observed maximum temperatures are also warmer than the model predicted, which suggests that the shading factor does not account for the difference between modelled and observed temperatures in the day.

To address these limitations it is suggested that a full heat budget assessment 
of the Gornera is carried out over a short time period. This would reveal the major contributors to the heat budget and allow for better predictions using the model. Along with this, real data could replace the parameterised width within the temperature model, and a clearer picture would emerge of what controls the higher than predicted stream temperature maxima. The results of the Gornera may also indicate some useful information regarding why summer temperatures are reduced in some glacier-fed river such as the Massa and Gornera. Unlike the Findelenbach, high discharges (and how channel morphology reacts) of the Gornera may reduce the impact of solar radiation. Through the remaining of the summer, water temperature may be reflecting another components of the heat budget such as heat gain due to potential energy, or friction with the stream bed. A heat budget assessment of the Gornera would show whether this is true or not. The reduced influence of net radiation in the heat budget may answer questions which arose in Chapter 5. For example, why rising discharge has a reducing effect on water temperature, but after a critical level further rising discharge has little or no impact on stream temperature (Gu et al., 1998). Finally any future study should try to take observations of water temperature at the Gornergletscher portal. When applied to the Findelenbach, model performance was much improved when upstream conditions were known. Therefore, upstream water temperature of the Gornera should result in better model outputs.

\subsection{Conclusion}

It must be stressed that no model, regardless of the number of input variables or the resolution of such data, is fully accurate or precise. There will always be a degree of uncertainty in the output. Thus, using a model with fewer input datasets must increase this inaccuracy. Also, every river system and basin is unique; therefore models of this kind should always be accompanied by sufficient data samples to enable users to tweak the model for each individual stream system (Ji, 2008). 
In spite of this, the present study has demonstrated that it is possible to model stream temperature downstream of a glacier with few input variables at least for wide shallow rivers, with a large surface area, like the Findelenbach. This has potential implications for researchers of glacier-fed rivers who wish to assess the impacts of catchment features and climate change, on the downstream temperature of glacier-fed waters, in locations where it can be difficult and costly to collect the input data usually required. Therefore, the ASTM meets its aim of being parsimonious.

This chapter has outlined the importance of how increasing riverflow is reflected in the width, depth and velocity of the river, when discharge is used in the model inputs. Ideally, width measurements would be recorded at points along a stream reach, between the glacier and gauge position. However, this chapter has illustrated the possibility of reverse modelling, to gain understanding of how width changes with discharge when the heat budget of the stream is known. The complete heat budget in the current study was not known and hence a series of parameter optimisations were used to achieve the best goodness of fit.

Future research aims to utilise an aerial drone survey to measure stream width in the Findelen basin, at times of different riverflows, throughout the entire season. This data should confirm the values of widths used in the present study.

Where lack of data is an issue in high mountain rivers, the ASTM, presented within this chapter, could be utilised. However, it is suggested that where possible this model should be combined with either modelled or measured net radiation, discharge and water temperature at multiple locations within the reach (e.g. every $10 \mathrm{~m}$ ). This would allow interested parties to determine how water temperature alters longitudinally, as it flows downstream. Such information would be useful to ecologists who may want to understand how upstream glacier-fed waters influence downstream fisheries in mountain catchments.

It is suggested that studies should utilise the model outlined within this chapter to assess how day-time temperatures will be impacted on during a 
period of climatic change. This would enable researchers to better understand the effect that rising riverflows and increasing distance (from glacier to gauge) due to glacier recession as air temperatures rise, will have on water temperatures. 


\section{Chapter 6}

\section{Modelling water temperature in a changing climate}

\subsection{Introduction}

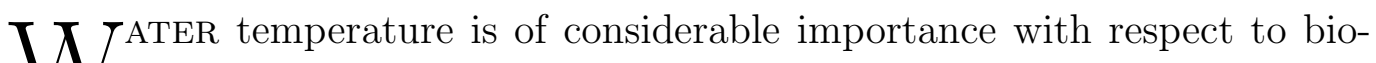

ل logical conditions and chemical processes within streams (Brown and Hannah, 2008; Segura et al., 2015); how stream temperatures respond in a changing climate is a concern of increasing importance (Arismendi et al., 2012; IPCC, 2013; Webb et al., 2008). Moore et al., (2009, p.55) have suggested that "Glacier retreat is likely to produce a range of other changes, including higher stream temperatures ...". Despite this claim there have been no studies to estimate the change in stream temperature, of a glacier-fed river, as the glacier retreats. Such changes will concern river managers and ecologists when considering the effect alterations in stream temperatures have on downstream fisheries (notably cold water fish i.e. brown trout and salmon) (Brown et al., 2005; Isaak et al., 2010; Mohseni et al., 1998; Segura et al., 2015).

Modelling water temperature, in glacier-fed Alpine rivers, is a difficult undertaking due to the lack of available meteorological data needed to accurately predict water temperature. Thus water temperature modelling studies 
in glacier-fed rivers are often approached using statistical as opposed to deterministic mathematical models (Bustillo et al., 2014). Using a statistical modelling technique is advantageous in that it is possible to model the temperature of streams with somewhat reliable outcomes using air temperature alone. When assessing the affect of anthropogenic climate change on water temperature over a long time scale, air temperature becomes the most useful input variable, due to it being the most reliable factor modelled by general circulation models (GCMs) (Bustillo et al., 2014). There have been some recent advances in modelling future changes in stream temperature, although not for glacier-fed rivers, based on linear and non-linear statistical models incorporating interconnections with air temperature. However, such models have shown that air temperature is a poor variable for accurate prediction of water temperature in rivers (Arismendi et al., 2014). Similar models have demonstrated the ability to approximate historic stream temperatures (Segura et al., 2015).

Further difficulties with modelling stream temperatures in a changing climate arise with respect to how changes in stream discharge are reflected in alterations in the depth, width and velocity of streams. The relationship between these variables is complex (Leopold and Maddock Jr, 1953), and yet they are considerably important variables with regard to determining stream temperatures. Chapter 5 provides analysis of such complex relationships.

In a period of warming, glaciers will retreat. Initially this will lead to a deglaciation discharge dividend (Collins, 2006), resulting in an initial rise in runoff from the basin. Therefore, any increase energy inputs, which will accompany the increased stream length, will be offset by increasing discharge. Once the deglaciation discharge dividend has expired, glaciers will continue to retreat further increasing reach length. Discharge levels will decline, and no longer offset warming occurring as a result of greater residence times. Thus, temperatures of glacial stream will be warmer. Figure 6.1 shows how a glacier-fed river's water temperature will respond to deglaciation. Prolonged deglaciation will result in greater discharge, initially, and increasing stream length as the glacier retreats. Increasing stream length results in greater residence times 


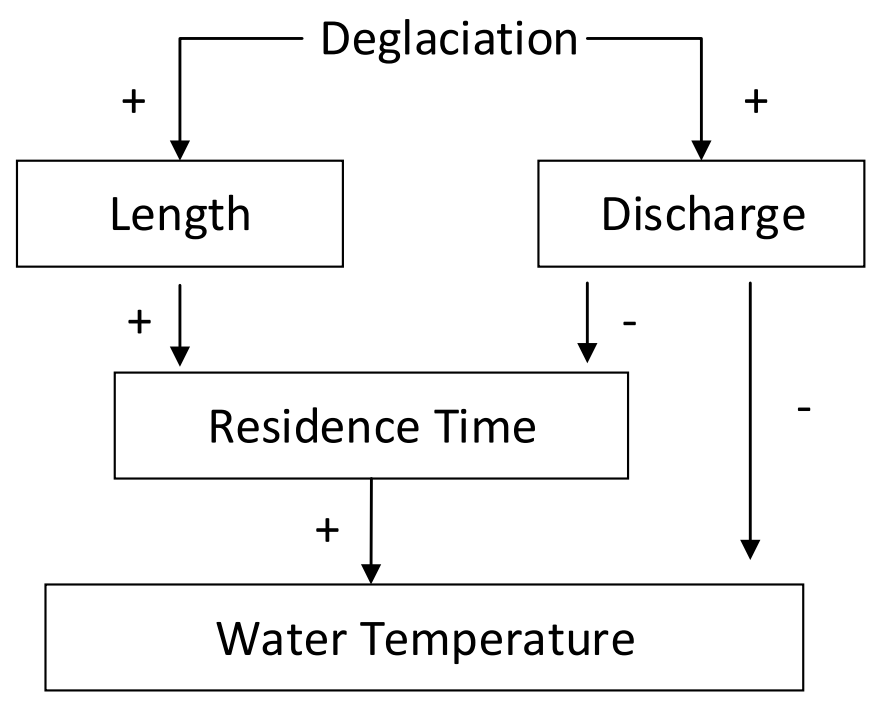

Figure 6.1: Schematic diagram showing the response of stream water temperature of a glacier-fed river to deglaciation (D. N. Collins, Personal Communication, May 2016).

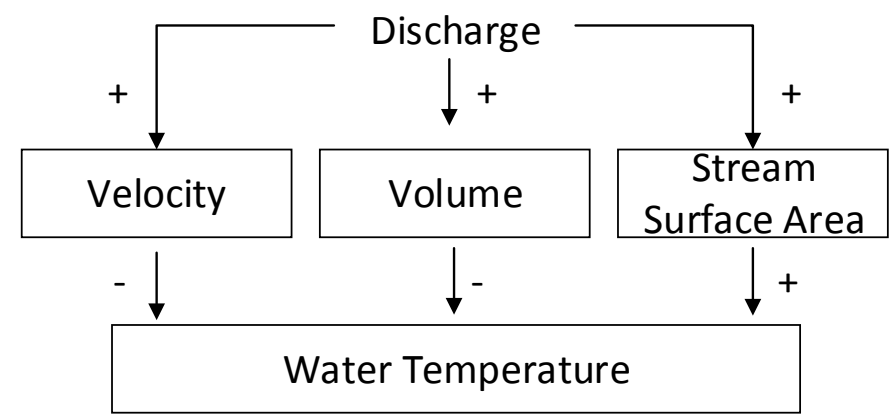

Figure 6.2: Schematic diagram showing the response of stream water temperature of a glacier-fed river to increasing discharge augmented by deglaciation (D. N. Collins, Personal Communication, May 2016). 
of water within the reach, thus heating time is greater. This will result in warmer stream temperatures. However, the initial increase in discharge will result in lower water temperatures (Figure 6.2). Rising riverflows will lead to greater velocities which will reduce the residence time and therefore the time over which heating can occur, and this will reduce water temperatures. Discharge rising will also lead to a greater volume of water in the reach. This will increase the heat capacity of the water within the channel and reduce the water temperature. Stream surface area will increase with rising discharge and, as a result, the area over which heating can occur will be greater and this will positively influence water temperatures. Despite this, rising discharge will ultimately lead to lower water temperature in glacier-fed rivers.

The aim of this chapter is to introduce differing scenarios to the Alpine Stream Temperature Model (ASTM). Specifically with the objective to analyse how changing length of reach - simulating a retreating glacier, together with associated increasing discharges will impact the temperature of glacier meltwater streams. It is hypothesised that a receding glacier would result in warmer water temperature in the draining river, but increasing discharge, augmented by the deglaciation discharge dividend, would decrease stream temperatures.

\subsection{Method}

This study will use the Alpine Stream Temperature Model, created in Chapter 5 , and test the model on current conditions with observed data. The model will then be re-run several times under different hydrological scenarios which simulate glacier recession.

There are some limitation to this method. Solar radiation is the only heat input to the model, this means only day-time simulated temperatures can be analysed from the output. Furthermore, the model is only applied to one river system, which due to the location the model performs to a high degree of accuracy. The model has been found to perform less well when applied to other river systems, even those close to the current study site. The reason 
for the reduced model fidelity when applied to other study rivers is likely the differing proportions of heat budget constituents driving stream temperature. Finally this approach does not account for changes in the heat budget of the river system as the climate warms. The assumption is that solar radiation is the overriding constituent of the heat budget at present and in the future.

Temperature data collected through field visits, measured shortwave radiation together with riverflow and calculated net radiation were used for model inputs. As the ASTM is more accurate when upstream temperature conditions are provided, data was selected for a period in which both upstream and downstream conditions were measured. The climate change scenarios for this experiment were: (a) an increase in riverflow by $10 \%$ and $20 \%$ and (b) an increase in stream length by $1000 \mathrm{~m}$ and $2000 \mathrm{~m}$, both of which are reasonable assumptions for a period of glacial recession. For the purpose of this study, climate models show that incoming shortwave radiation will remain similar to present day conditions under a changing climate. The influence of increasing air temperatures and the possible related change in river heat budget (i.e. should the influence of latent and sensible heat fluxes increase) is probably small and beyond the scope of this study.

\subsubsection{Study Area}

Data was collected at the Findelen glacier portal (upstream conditions) and $1000 \mathrm{~m}$ downstream of the glacier portal close to the Findelenbach hydroelectric power intake. The reach is typified by wide meandering braided channels which fan out from the glacier portal, before merging close to the Findelenbach hydroelectric intake (Figure 6.3). Chapter 1 provides detailed description of the Findelen basin. 


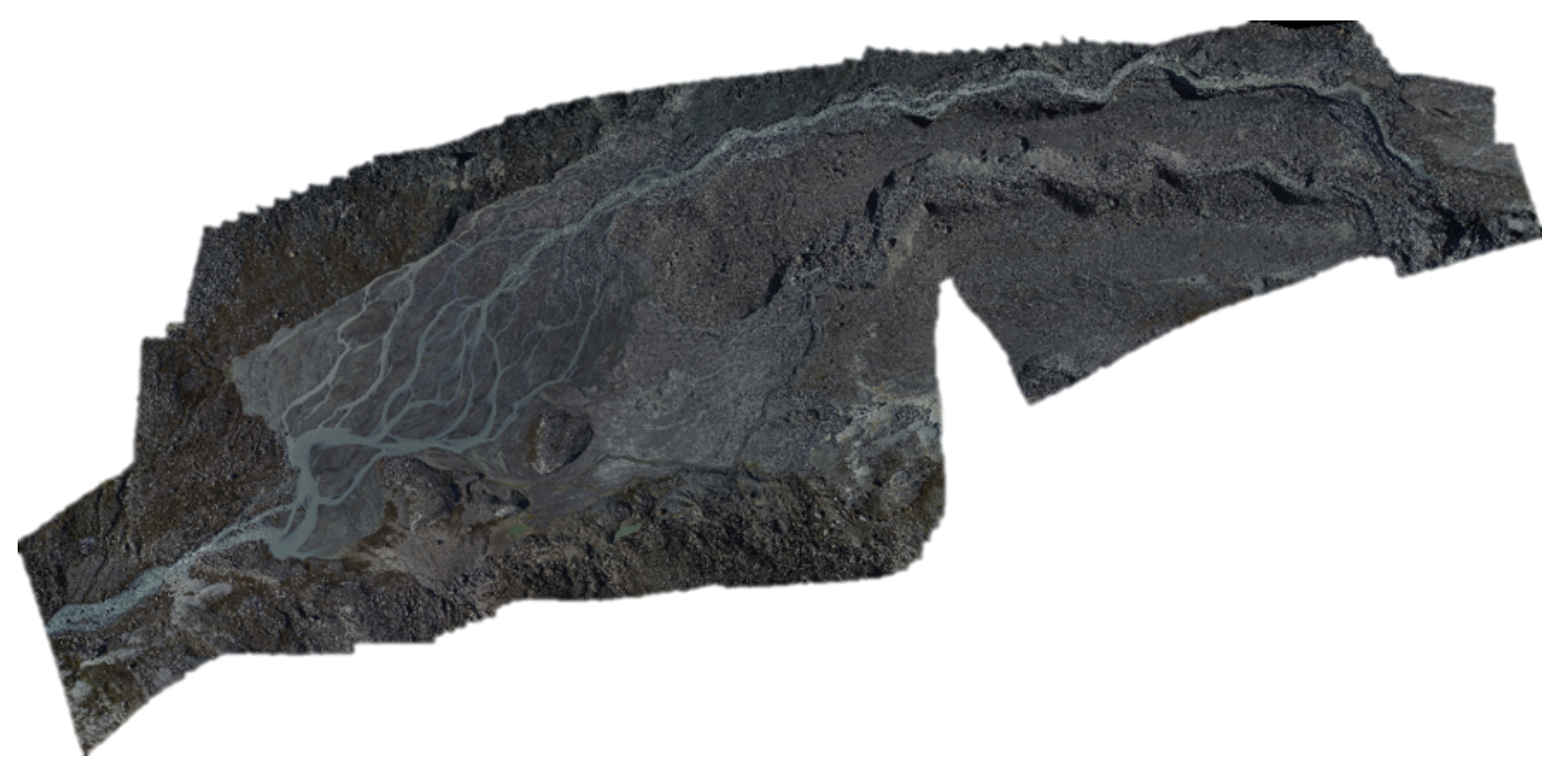

Figure 6.3: Aerial view of Findelenbach, captured with Dji Drone flown at $30 \mathrm{~m}$ a.g.l. Orthophoto mosaic from 348 individual images. Glacier portal to gauging station is from right to left. Courtesy of Dr Neil Entwistle, University of Salford. 


\subsubsection{Data Collection}

Riverflow data was provided by the Grande Dixence (S.A.) which monitor the discharge of the Findelenbach as it flows into hydroelectric intakes. Water temperature data was recorded during field visits where Hach Minisonde 4 data loggers are positioned in stream. One logger was positioned close to the glacier portal, with the second close to the hydroelectric intake. Measurements of incoming shortwave radiation were provided by the Swiss Meteorological department.

Knowledge of glacier retreat is vital, with respect to modelling future water temperatures of glacier-fed rivers. Figure 6.4 illustrates how the Findelengletscher has retreated and advanced between 1881 and 2015 (GlaciologicalReports, 2016). There has been significant retreat, with only a few short periods in which the glacier advanced (briefly in the late 1800s and early 1900s, together with a sustained period between 1979 and 1984). Between 1979 and 1980 Findelengletcher advanced $84 \mathrm{~m}$ with the largest retreat occurring between 1957 and 1958, where the glacier retreated $478 \mathrm{~m}$. Cumulative length change was positive up to 1927. Since 1927 Findelengletscher has retreated $2.43 \mathrm{~km}$. This data was used, therefore, to suggest reasonable increases in heating distance as the glacier retreats.

Observed water temperature, discharge and shortwave radiation measurements for the period 14 to 17 July 2006 were selected for the first study period. This 'reference period' was selected as incoming solar radiation was substantial (albeit influenced somewhat by cloud cover), riverflow of the Findelenbach was relatively high, and upstream water temperature conditions were available. This ensured that the results were representative of a period of high flows and substantial radiation, common to the melt season. A second 'reference period', 28 September through to 1 October 2009, was used to demonstrate potential change under different hydrometeorological conditions. Riverflows and levels of solar radiation were lower in this period. This data will help demonstrate the impact of a changing climate during periods of low flow, when the summer melt period is drawing to a close. Availability of upstream 


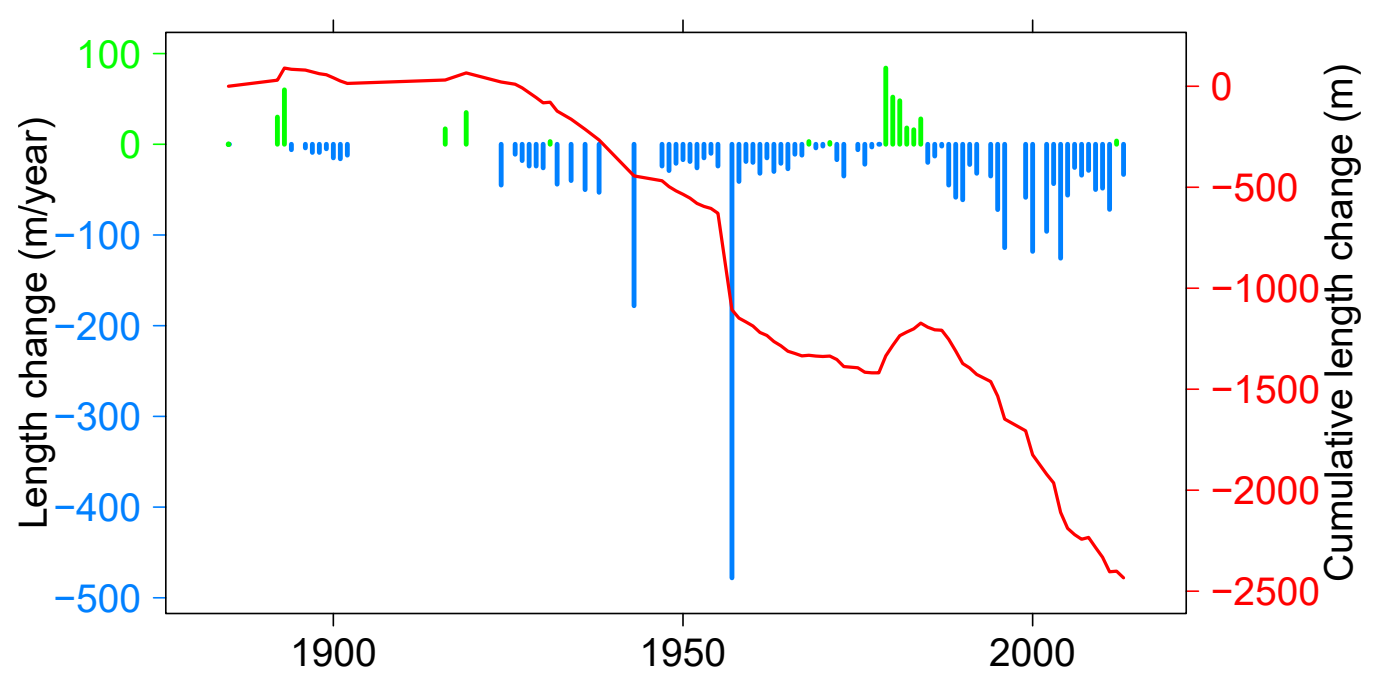

Figure 6.4: Findelengletscher positive (green bars) and negative (blue bars) length change together with cumulative length change (red line) for the period 1881-2015. Data: Glaciological-Reports, (2016).

water temperatures was important for model fit. However, it is assumed that water temperatures at the glacier portal will remain similar to those of the present day, as climate warms. Summary statistics for model input data are given in Table 6.1.

Table 6.1: Summary statistics of input data used for the modelling scenarios using Reference Period A (14 - 17 July 2006) and Reference Period B (28 September - 1 October 2009).

\begin{tabular}{lrrrrrr}
\hline & \multicolumn{3}{c}{ Reference Period A } & \multicolumn{3}{c}{ Reference Period B } \\
\cline { 2 - 7 } & Max & Mean & Min & Max & Mean & Min \\
\hline Radiation & 1035.0 & 290.1 & - & 706.0 & 183.7 & - \\
Discharge & 14.5 & 8.1 & 4.6 & 2.6 & 1.3 & 0.7 \\
Water & 2.5 & 0.8 & 0.1 & 3.9 & 1.0 & 0.0 \\
Temperature & & & & & & \\
\hline
\end{tabular}




\subsubsection{Stream temperature model}

Water temperatures, for both reference periods, were simulated using the Lagrangian Alpine Stream Temperature Model. This models the change in temperature of aliquots of water, as they pass downstream though $10 \mathrm{~m}$ boxed segments bounded by nodes. The simplified water temperature model releases a parcel of water on the hour, each hour of the day, with the hourly averages of discharge, radiation and downstream water temperature assumed to be constant, in both space and time, throughout the hour. Therefore, the model does not account for changes in riverflow or radiation sub-hourly.

Stream temperature in each segment of the ASTM was computed using the heat conservation equation (Equation 6.1). Where $W$ is the average stream width, herein used as a proxy for the width, depth, and velocity based on riverflow. $\Phi$ is the heat inputs, net- shortwave radiation and longwave radiation. $x$ is the distance downstream. $\rho$ equals the specific heat capacity of water, $4.21 \times 10^{3} \mathrm{~J} \mathrm{~kg}^{-1} \mathrm{~K}^{-1}$ (at $0{ }^{\circ} \mathrm{C}$ ), $Q$ is equal to riverflow, measured in $\mathrm{m}^{3} \mathrm{~s}^{-1}, C$ is density of water expressed in $\mathrm{kg} \mathrm{m}^{-3}$. Detailed description of the modelling techniques used in this study are given in $\S \S 5.3 .4$.

$$
\frac{\delta T_{w}}{\delta x}=\frac{W \Phi}{\rho C Q}
$$

\subsection{Results}

One future 'climate' scenario was used in the following study. These include: shortwave radiation remaining at current levels, as within the time-frame of deglaciation levels of shortwave radiation are unlikely to deviate much from present day levels (Budyko, 1968). Under this climatic scenario, three length changes are assumed. First, the stream length to remain the same as present day, second the length to increase by $1000 \mathrm{~m}$ and third, length to increase by $2000 \mathrm{~m}$. For each length change scenario, three riverflow scenarios were applied. First, discharge to remain at present day levels, second, discharge 
to rise by $10 \%$ and third, discharge to rise by $20 \%$. Results of simulated temperature for the Findelenbach, under the above scenarios, are outlined in the following section.

\subsubsection{Reference Period A (14 - 17 July 2006)}

For the purpose of this study, changes to daily maxima of water temperature were used to demonstrate any changes in stream temperature under the scenarios: solar radiation levels remaining constant, glacier recession and increased discharge (Table 6.3). This is because the temperature model used herein overestimates minimum temperatures (night) and as a result average temperatures are also overestimated. Goodness of fit statistics for simulated and observed water temperatures in the reference period are provided in Table 6.2 .

Table 6.2: Goodness of fit statistics for simulated to observed water temperature during Reference Period A (14 - 17 July 2006).

\begin{tabular}{ccccc}
\hline $\mathrm{r}$ & $R^{2}$ & $\mathrm{MAE}$ & $\mathrm{RMSE}$ & $\mathrm{NSE}$ \\
\hline 0.94 & 0.88 & 0.21 & 0.30 & 0.76
\end{tabular}

Alterations in riverflow had little impact on the temperature of water downstream of a glacier under present climatic conditions and the current reach length (Figure 6.5). A 10\% increase in riverflow resulted in a reduction in maximum water temperature of $0.14{ }^{\circ} \mathrm{C}$ on July 14 2006. On average, increasing discharge by $10 \%$ (keeping reach length and solar radiation constant) resulted in an decrease of $0.13^{\circ} \mathrm{C}$ at the downstream boundary. Increasing riverflow further (20\% increase) had a more noticeable impact on downstream water temperature. On average increasing water temperature by $0.25^{\circ} \mathrm{C}$, more than double the increase which was a result of a $10 \%$ rise in riverflow. However, changing stream length impacted water temperatures of the Findelenbach significantly. A $1000 \mathrm{~m}$ glacier recession resulted in water temperature warming from $2.01^{\circ} \mathrm{C}$ to $3.58^{\circ} \mathrm{C}$, on July 142006 , an increase of $78 \%$ (Figure 6.6). Fur- 
ther recession of the glacier $(2000 \mathrm{~m})$ resulted in water temperatures at the downstream gauge rising to $4.92^{\circ} \mathrm{C}$ ( $144 \%$ increase), when current discharge and shortwave radiation levels are held constant (Figure 6.7).

Despite higher water temperatures evidently being the overriding result from increasing stream length, it is clear that higher discharge levels reduced this warming, to some degree (comparison of Figure 6.5, 6.6, and 6.7). When solar radiation levels are kept at present day values, increasing reach length from $1000 \mathrm{~m}$ to $2000 \mathrm{~m}$ (i.e. glacier receding $1000 \mathrm{~m}$ ) increased daily maximum water temperature on average by $1.51^{\circ} \mathrm{C}$. If this reduction in glacier length (and thus increase in stream length) corresponds with a $10 \%$ rise in riverflow then daily maximum water temperatures will rise, on average, by $1.24^{\circ} \mathrm{C}$. Thus, under the scenario of glacier receding $1000 \mathrm{~m}$, an $10 \%$ increase in riverflow will result in a $0.27^{\circ} \mathrm{C}$ reduction in stream temperature maxima. Should the glacier retreat $2000 \mathrm{~m}$ (worst case scenario), water temperature maxima would rise on average by $2.81^{\circ} \mathrm{C}$. Under a scenario whereby a $2000 \mathrm{~m}$ glacier retreat, is accompanied by an $10 \%$ increase is stream discharge, average daily maximum temperatures increase by $2.61^{\circ} \mathrm{C}$. Under the worst case scenario, of glacier recession equating to $2000 \mathrm{~m}$ and riverflow increasing by $20 \%$, daily maxima would increase, on average, by $2.27^{\circ} \mathrm{C}$. 
Table 6.3: Simulated daily water temperature maxima of the Findelenbach $\left({ }^{\circ} \mathrm{C}\right)$, under current levels of shortwave radiation, during Reference Period A (14 - 17 July 2006).

\begin{tabular}{|c|c|c|c|c|c|}
\hline \multicolumn{2}{|c|}{ Scenario } & 14 July & 15 July & 16 July & 17 July \\
\hline \multirow{3}{*}{ Length $=1000 \mathrm{~m}$} & $\begin{array}{l}\text { Current } \\
\text { discharge }\end{array}$ & 2.01 & 1.99 & 1.99 & 1.84 \\
\hline & $\begin{array}{l}\text { Discharge } \\
+10 \%\end{array}$ & 1.87 & 1.85 & 1.85 & 1.72 \\
\hline & $\begin{array}{l}\text { Discharge } \\
+20 \%\end{array}$ & 1.75 & 1.74 & 1.74 & 1.61 \\
\hline \multirow{3}{*}{ Length $=2000 \mathrm{~m}$} & $\begin{array}{l}\text { Current } \\
\text { discharge }\end{array}$ & 3.58 & 3.54 & 3.53 & 3.23 \\
\hline & $\begin{array}{l}\text { Discharge } \\
+10 \%\end{array}$ & 3.29 & 3.26 & 3.25 & 2.97 \\
\hline & $\begin{array}{l}\text { Discharge } \\
+20 \%\end{array}$ & 3.05 & 3.02 & 3.02 & 2.76 \\
\hline \multirow{3}{*}{ Length $=3000 \mathrm{~m}$} & $\begin{array}{l}\text { Current } \\
\text { discharge }\end{array}$ & 4.92 & 4.94 & 4.94 & 4.30 \\
\hline & $\begin{array}{l}\text { Discharge } \\
+10 \%\end{array}$ & 4.71 & 4.66 & 4.66 & 4.23 \\
\hline & $\begin{array}{l}\text { Discharge } \\
+20 \%\end{array}$ & 4.36 & 4.31 & 4.31 & 3.92 \\
\hline
\end{tabular}




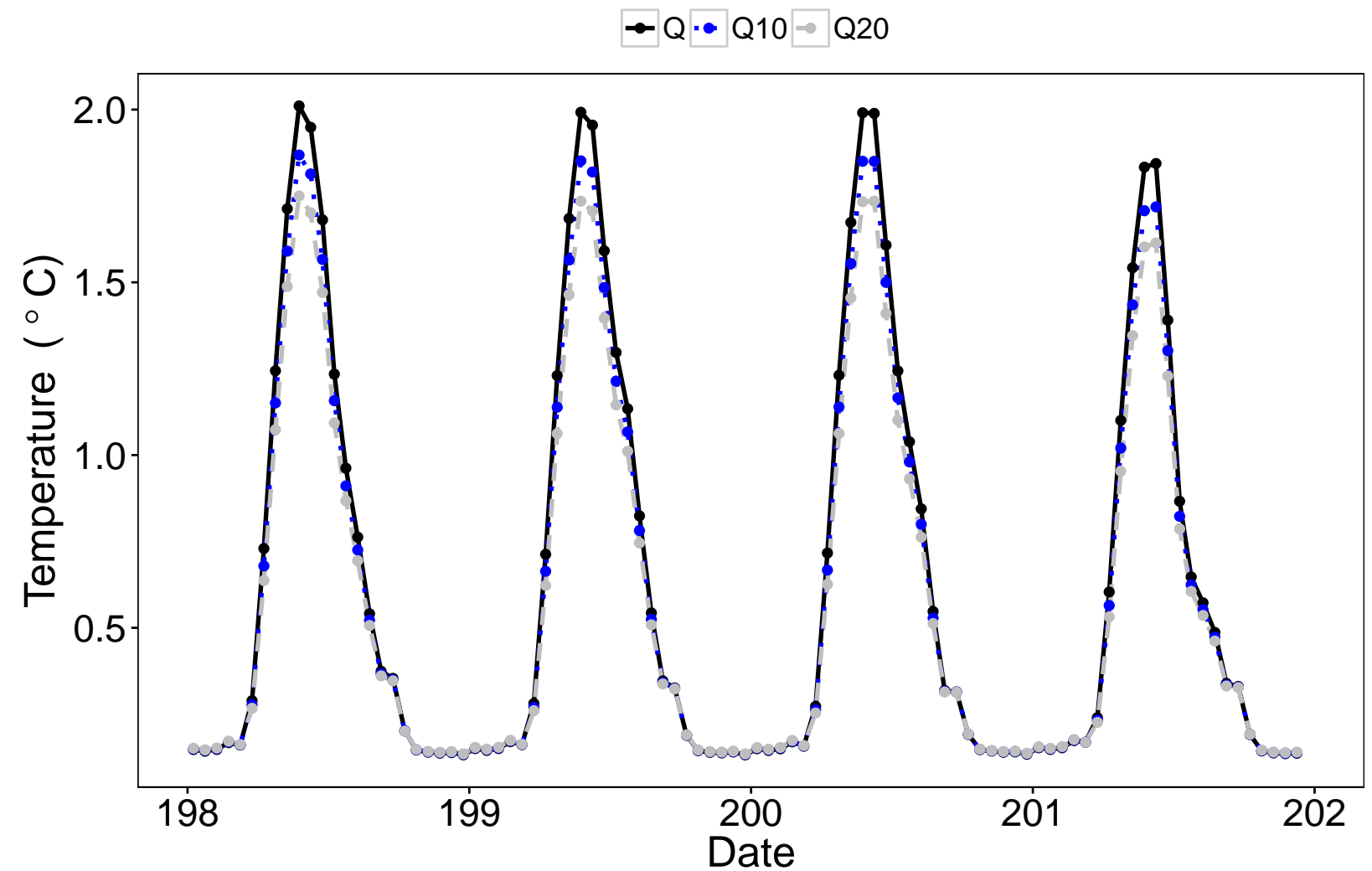

Figure 6.5: Daily water temperature simulations, under current levels of shortwave radiation, with reach length $1000 \mathrm{~m}$ and varying levels of riverflow $(+10 \&+20 \%)$, during Reference Period A (14 - 17 July 2006). 


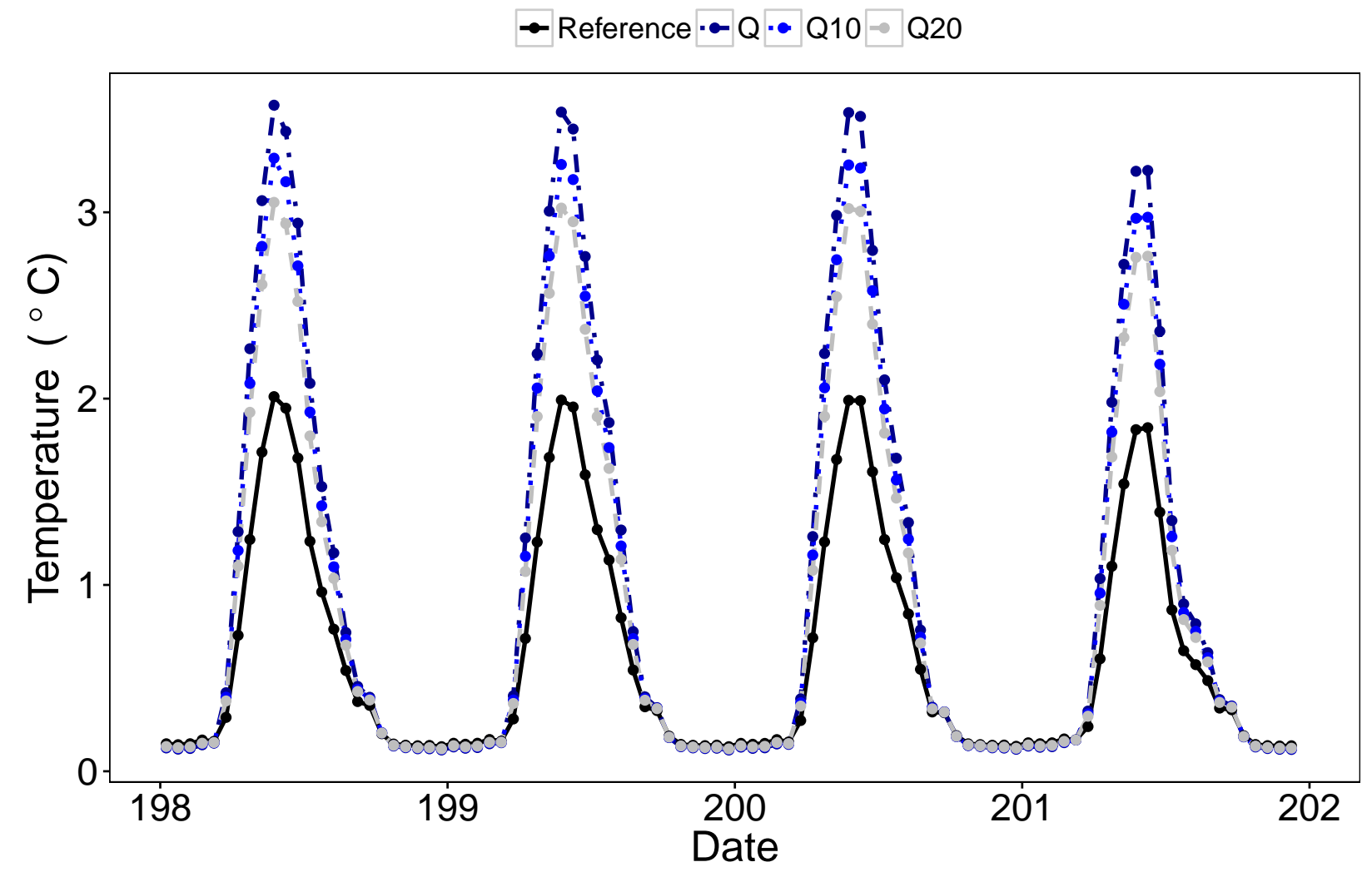

Figure 6.6: Daily water temperature simulations, under current levels of shortwave radiation, with reach length $2000 \mathrm{~m}$ and varying levels of riverflow $(+10 \&+20 \%)$, during Reference Period A (14 - 17 July 2006). 


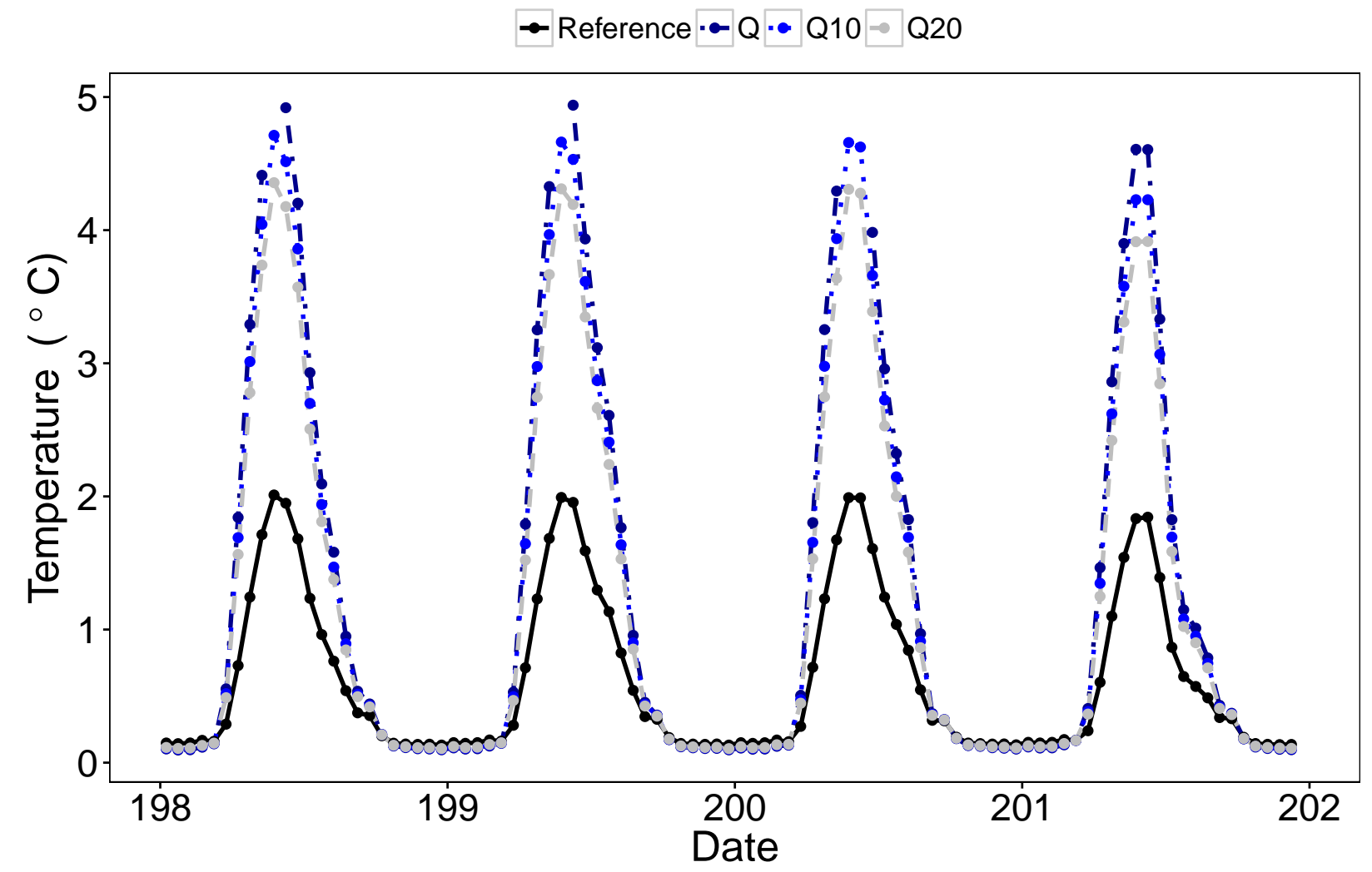

Figure 6.7: Daily water temperature simulations, under current levels of shortwave radiation, with reach length $3000 \mathrm{~m}$ and varying levels of riverflow $(+10 \&+20 \%)$, during Reference Period A (14 - 17 July 2006). 


\subsubsection{Reference Period B (28 September - 1 October 2009)}

A second reference period (28 September 2009 - 1 October 2009) was selected to provide a comparison with the first reference period. The second study period was used to demonstrate potential changes in the stream temperature of glacier-fed rivers under different hydrometeorological conditions. As highlighted in Chapter 3, during this period, water temperatures are warmer, riverflows are reduced, and solar radiation receipts are lower. The water temperature model was applied, and goodness of fit statistics are provided in Table 6.4. The model output fit observed temperatures well (e.g. Nash-Sutcliffe Efficiency $=0.83$ ) and was, therefore, used as the reference temperature within the scenario models in this section.

Table 6.4: Goodness of fit statistics for simulated to observed water temperature during Reference Period Reference Period B (28 September - 1 October 2009).

\begin{tabular}{ccrcc}
\hline $\mathrm{r}$ & $R^{2}$ & MAE & RMSE & NSE \\
\hline 0.94 & 0.89 & 0.48 & 0.61 & 0.83 \\
\hline
\end{tabular}

Diurnal ranges of the Findelenbach's water temperature is greater during Reference Period B, than Reference Period A. Daily temperature maxima during Reference Period B are approximately double that of Reference Period A. Under present day levels of solar radiation, increasing discharge first by $10 \%$, then $20 \%$, had very little impact on stream temperature (Table 6.5). On average, throughout the four day study period, a response of $0.36{ }^{\circ} \mathrm{C}$ was observed when riverflows were increased by $10 \%$. This increased to $0.66{ }^{\circ} \mathrm{C}$ with respect to levels of riverflow rising by $20 \%$ (Figure 6.8 ). It becomes obvious that increased stream length, an occurrence with retreating glaciers, caused stream temperatures to rise significantly (Figure 6.8). Under a scenario of glacier retreat equating to $1000 \mathrm{~m}$ — with riverflow and solar radiation remaining at present day levels - waters in the Findelenbach warmed from $4.46^{\circ} \mathrm{C}$, to $8.42^{\circ} \mathrm{C}$ an $89 \%$ increase. Under a scenario of $2000 \mathrm{~m}$ glacier retreat, 
Table 6.5: Simulated daily water temperature maxima of the Findelenbach $\left({ }^{\circ} \mathrm{C}\right)$, under current levels of shortwave radiation, during Reference Period B (28 September - 1 October 2009).

\begin{tabular}{|c|c|c|c|c|c|}
\hline \multicolumn{2}{|c|}{ Scenario } & 28 Sept & 29 Sept & 30 Sept & 1 Oct \\
\hline \multirow{3}{*}{ Length $=1000 \mathrm{~m}$} & $\begin{array}{l}\text { Current } \\
\text { discharge }\end{array}$ & 4.41 & 4.71 & 4.11 & 4.60 \\
\hline & $\begin{array}{l}\text { Discharge } \\
+10 \%\end{array}$ & 4.07 & 4.33 & 3.77 & 4.22 \\
\hline & $\begin{array}{l}\text { Discharge } \\
+20 \%\end{array}$ & 3.79 & 4.01 & 3.49 & 3.90 \\
\hline \multirow{3}{*}{ Length $=2000 \mathrm{~m}$} & $\begin{array}{l}\text { Current } \\
\text { discharge }\end{array}$ & 8.11 & 8.94 & 7.82 & 8.79 \\
\hline & $\begin{array}{l}\text { Discharge } \\
+10 \%\end{array}$ & 7.44 & 8.17 & 7.14 & 8.03 \\
\hline & $\begin{array}{l}\text { Discharge } \\
+20 \%\end{array}$ & 6.88 & 7.53 & 6.58 & 7.39 \\
\hline \multirow{3}{*}{ Length $=3000 \mathrm{~m}$} & $\begin{array}{l}\text { Current } \\
\text { discharge }\end{array}$ & 11.81 & 13.16 & 11.53 & 12.98 \\
\hline & $\begin{array}{l}\text { Discharge } \\
+10 \%\end{array}$ & 10.80 & 12.01 & 10.51 & 11.84 \\
\hline & $\begin{array}{l}\text { Discharge } \\
+20 \%\end{array}$ & 9.96 & 11.05 & 9.67 & 10.89 \\
\hline
\end{tabular}




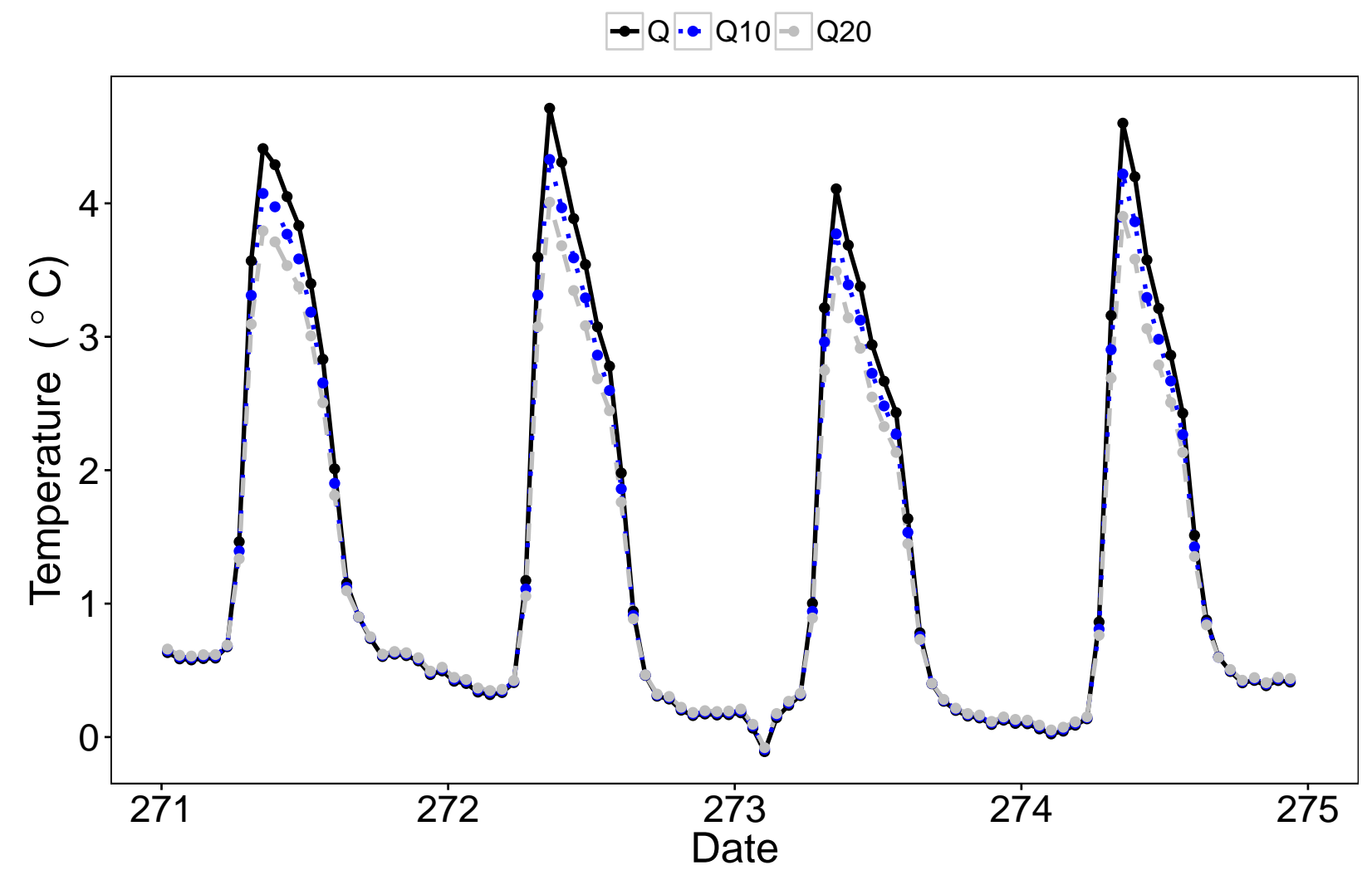

Figure 6.8: Daily water temperature simulations, under current levels of shortwave radiation, with reach length $1000 \mathrm{~m}$, each with varying levels of riverflow $(+10 \&+20 \%)$, during Reference Period B (28 September -1 October 2009). 


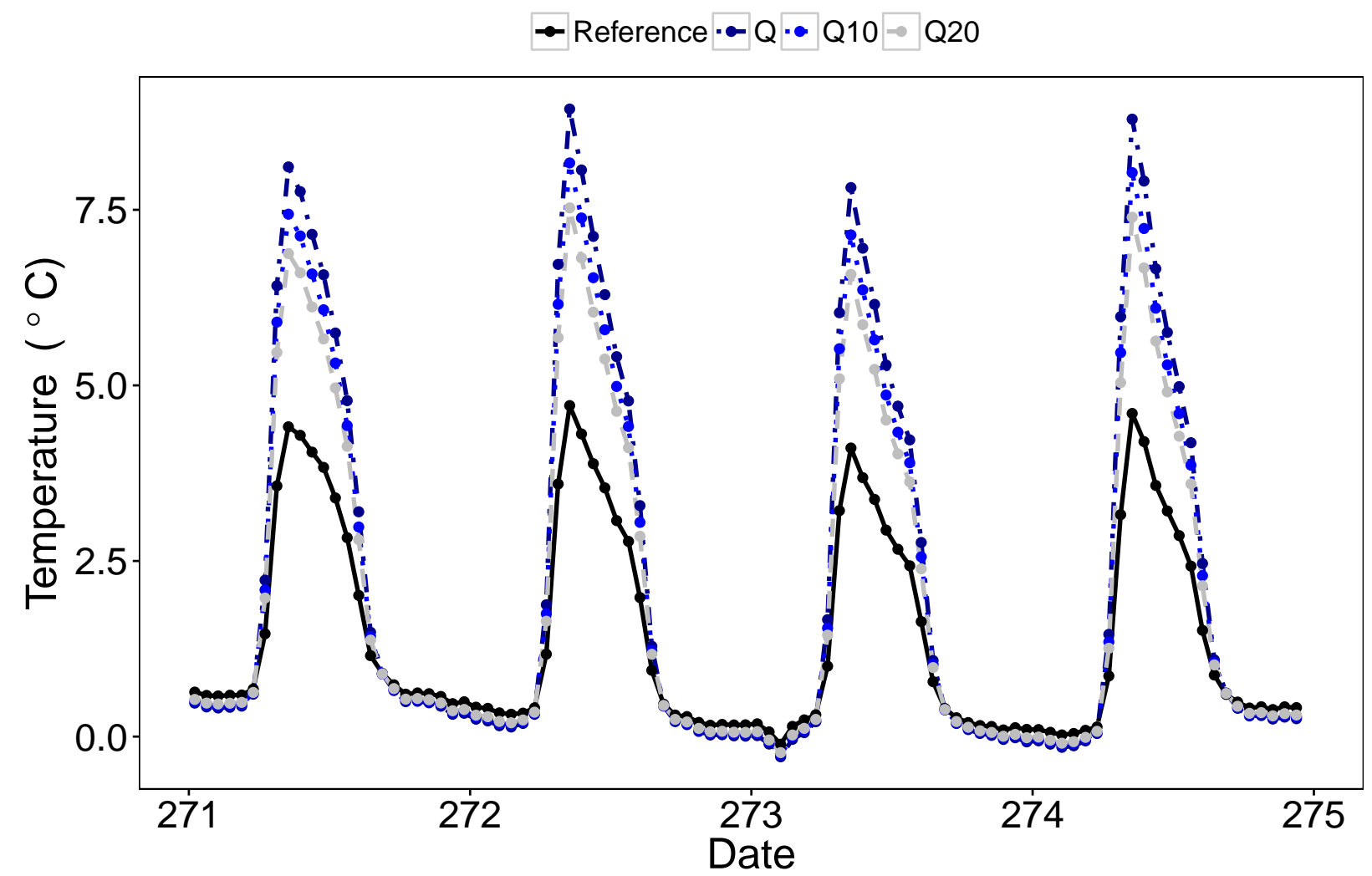

Figure 6.9: Daily water temperature simulations, under current levels of shortwave radiation, with reach length $2000 \mathrm{~m}$, each with varying levels of riverflow $(+10 \&+20 \%)$, during Reference Period B (28 September -1 October 2009). 


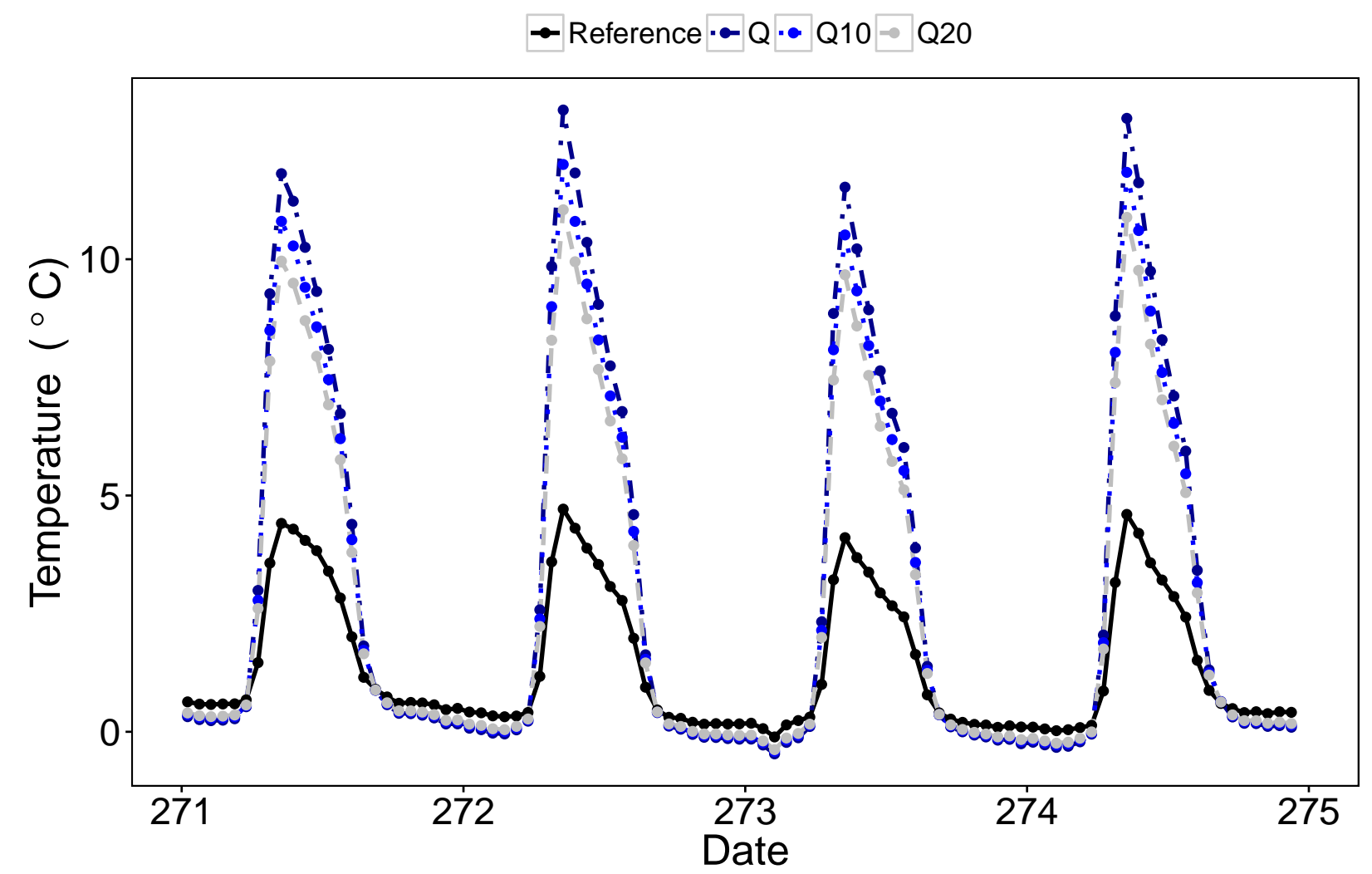

Figure 6.10: Daily water temperature simulations, under current levels of shortwave radiation, with reach length $3000 \mathrm{~m}$, each with varying levels of riverflow $(+10 \&+20 \%)$, during Reference Period B (28 September -1 October 2009). 
Findelenbach's average stream temperature maxima increased to $12.37^{\circ} \mathrm{C}$, an increase of $178 \%$.

Similar to Study Period A, the results of Study Period B indicate that length is the overriding scenario which water temperature in glacier-fed rivers will respond. Increasing riverflow will subdue this increase to some degree. With present day meteorological conditions, an increase in stream length of $1000 \mathrm{~m}$ will increase stream temperature by $3.96{ }^{\circ} \mathrm{C}$. This increase is offset with the expected rise in riverflow, as more meltwaters are generated. Under the scenario of $10 \%$ rise in riverflows, the rise in average maxima temperature falls to $3.24{ }^{\circ} \mathrm{C}$ (a difference of $0.72{ }^{\circ} \mathrm{C}$ ). This difference increases to $1.32^{\circ} \mathrm{C}$ under a $20 \%$ increase in discharge scenario. Should the glacier retreat, $2000 \mathrm{~m}$, stream temperature would rise to $12.37^{\circ} \mathrm{C}$. However, when this scenario is combined with a $20 \%$ rise in meltwaters, this warming is reduced by $1.98^{\circ} \mathrm{C}$ to $10.39^{\circ} \mathrm{C}$.

\subsection{Discussion}

The results of this scenario modelling study are the first to quantify the impact of climate change on the water temperature of Alpine glacier-fed rivers. This research has assessed the impact on stream temperature resulting from the following scenarios: increase in river length resulting from retreating glaciers, and rising riverflow augmented by the deglaciation discharge dividend. Discharge will rise as a result of the deglaciation discharge dividend, leading to initial enhanced ice-melt as glaciers retreat (Collins, 2006). This section outlines how likely a combination of these scenarios will influence the heating capacity of glacier-fed rivers and assess implications the resulting warming may have in a warmer world.

\subsubsection{Future water temperature of a glacier-fed river}

Simulated results clearly indicate the response of glacier-fed stream temperatures to climatic change. The results of this study are novel in that they 
quantify the impact of climate change on the temperature of a glacier-fed river. With respect to the Findelenbach the results highlight significant warming is likely to occur; mainly as a consequence of the increasing stream reach, as the glacier tongue retreats. Residence time of waters in the reach will increase, despite greater velocities, and the surface area of the reach will be greater, so there will be more energy being available for heating (Fellman et al., 2014). During a period of high riverflow, and under present day levels of solar radiation, daily maximum water temperature will rise on average by $1.51^{\circ} \mathrm{C}-$ when simulating a glacier reduction of $1000 \mathrm{~m}$. During a period of low discharge, where water temperatures are generally warmer, this increase rises to $3.96^{\circ} \mathrm{C}$. Rivers are more susceptible to changes in temperature at low flows (Hood and Berner, 2009). Not only is the volume of water within the channel reduced at low discharges, the flow rate is also lowered. Together, these result in greater response to change, especially with respect to increasing length. This is in spite of radiation levels being lower than in the summer.

With regard to river temperature at a given point downstream of a glacier, the scenario simulations highlight slight cooling. For example, at $1000 \mathrm{~m}$ downstream of the glacier portal. If riverflows were up by $10 \%$ this would reflect an average decrease in daily maximum temperature by $0.13^{\circ} \mathrm{C}$ during periods of high flow. In a period of lower riverflows, replicating those experienced in the late melt season, the decrease in average water temperature maxima is more pronounced at $0.33^{\circ} \mathrm{C}$. This, further, demonstrates how water temperature of rivers at low flow respond more to change than that of those with greater discharges.

\subsubsection{Channel shape influences}

River morphology appears to be a fairly significant factor which influences water temperature in high mountain glacier-fed streams. It has been suggested that the water temperature of Alpine glacier-fed rivers is driven significantly, by stream surface area (Chapter 3). Generally, width and length dictate the area for which heating is available over the channel, as well as the time during 
which heating can occur (Blaen et al., 2012; Cadbury et al., 2008; Hannah et al., 2004). The results of the scenario models used in this chapter are in agreement with this statement.

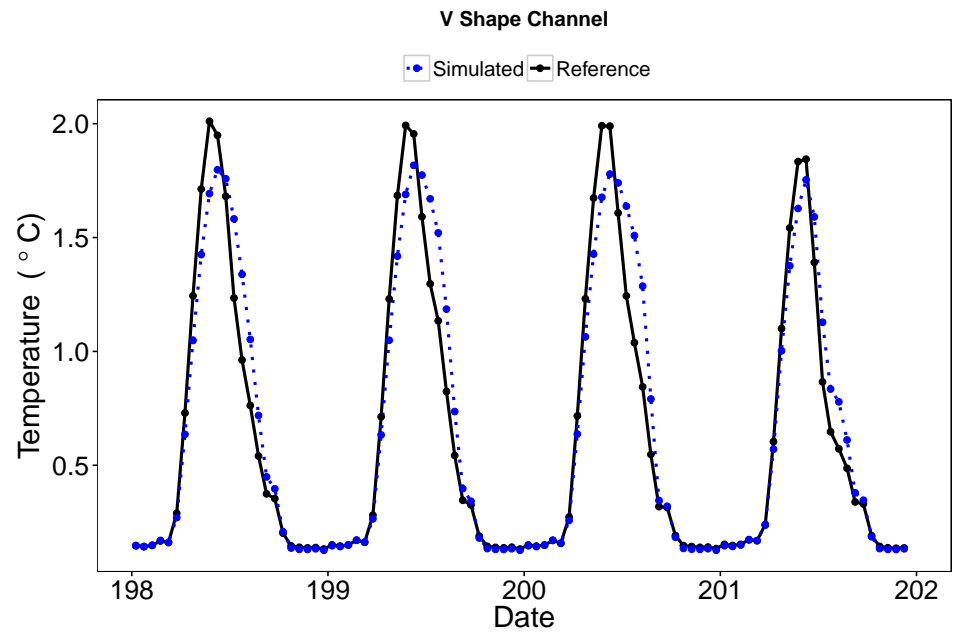

(a)

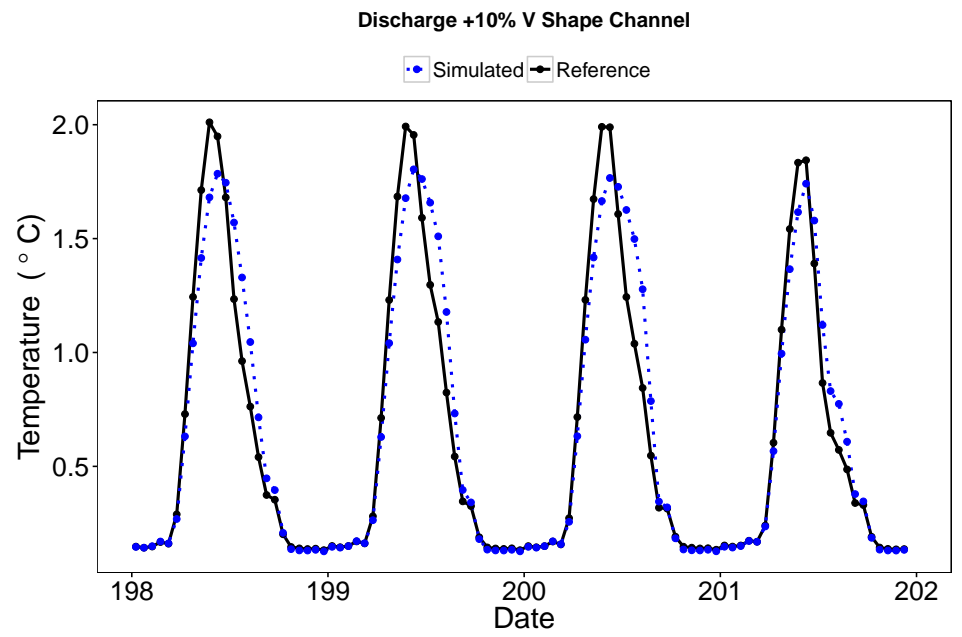

(b)

Figure 6.11: Daily water temperature simulations (blue line), under current levels of shortwave radiation, with riverflows at: (a) current levels, and (b) current levels $+10 \%$, with channel morphology resulting in width increasing significantly with discharge. Both compared to reference simulation (black line) under current hydro-climatic conditions for Reference Period A (14- 17 July 2006).

Figure 6.11 shows simulations of water temperature for a river with a channel 
shape where width rises significantly with rising discharge. This is compared to the simulated Findelenbach temperature, a channel in which width remains fairly constant with changing riverflow (Figure 6.11a). The model was then re-run under the scenario of a $10 \%$ increase in riverflow as augmented by the deglaciation discharge dividend (Figure 6.11b).

When channel morphology within the water temperature model is modified to represent a ' $V$ ' shape, average daily maximum water temperature for the study period fall from $1.96{ }^{\circ} \mathrm{C}$ to $1.79^{\circ} \mathrm{C}$. However, should riverflows increase by $10 \%$, a figure which is potentially representative of future riverflows as a glacier retreats, average daily maximum water temperature falls to $1.77^{\circ} \mathrm{C}$. This is significantly less than the $0.13^{\circ} \mathrm{C}$ decline in stream temperature maximum which is reflected in channels where width remains constant with riverflow, when discharge is increased by $10 \%$. It is suggested therefore, that rivers which flow in channels which reflect a 'V shape', as opposed to a 'U shape' will respond differently in the future. The difference in the decline in temperature is likely a result of the increasing width allowing more surface area to receive solar radiation, whilst velocity and/or depth not changing substantially with rising riverflows, offsetting the fact that, to some degree, there is more water to be warmed within the channel. This does not account for the increasing distance downstream, between glacier portal and gauging location. However, as discussed in Chapter 5, rivers in such channels are believed to be less influenced by solar radiation, due to channel orientation, topographic shading and significantly lower residence times and steep gradients. This appears to be in agreement with the findings of Chikita et al., (2010), in that longitudinal temperature increase, in such channels, is influenced more by frictional heat and the conversion of potential to kinetic energy. The model used within this study does not account for future changes to such heat budgets and thus cannot accurately quantify the warming in such streams into the future, as glacier's recede. It does demonstrate however, the influence that basic channel morphology has on river stream temperature with changing riverflows. 


\subsubsection{Credibility of results}

This study is sufficient in describing future trends to the Findelenbach, However, on a wider scale, especially globally, more research would be required, as this study has not examined a multitude of streams across many different environments. The results herein are, however, likely to be sound in respect of river length being the most influential determiner of future water temperatures. Therefore, the conclusion that glacier-fed rivers will eventually be significantly warmer in a changing climate is a valid one. Although, the magnitude of such temperature change will need to be studied over a greater number of rivers to confirm that the findings in the present study hold true. Scenario models should be conducted on rivers whose shape differs from that of the Findelenbach, and also ones which are located in different regions of the planet. Finally, this study does not account for any changes to the streams heat budget through a changing climate, and assumes that radiation will remain the overwhelming driver of stream temperatures, in some high mountain glacier-fed rivers in the European Alps.

These results can be said to be reasonably plausible, thanks to the fact that physical explanations of the results can be offered. On the whole, the results are consistent with our understanding of the water temperature of glacierfed rivers and confirm the general statement that increasing length between glacier and gauge will result in warmer glacier-fed streams in the future (Moore et al., 2009). This study was the first to estimate by how much glacier-fed rivers will warm in a changing climate.

As the results within this chapter are focused on a single Alpine glacier-fed river they should be considered only indicative of the behaviour of water temperature response to climatic change. The results herein are specific to the Findelenbach and should, therefore, not be used for decision making for any other Alpine or non-Alpine river and use of the model will, as outlined in Chapter 5, potentially yield different results. However, the ASTM can be adapted for use on other river systems with relative ease. Ecologists may use the outcomes attained in this study to help understand and mitigate for water 
temperature rises, downstream of glaciers where lotic environments may be impacted and therefore protect these environments and prepare for necessary changes.

The model used in this chapter is most reliable for streams which drain basins similar to that of the Findelenbach. Rivers in basins with little impact from topographic shading, and those which flow in a wide channel, of which the width does not alter drastically with riverflow, are likely to be good study sites to replicate the use of this model.

\subsection{Conclusion}

This chapter has outlined the application of the stream temperature model explained, in detail, in Chapter 5. Simulated water temperatures from the scenario models highlight the importance of change in reach length in driving the water temperature of glacier-fed rivers with regards to a changing climate. It is expected that the European Alps will experience warmer air temperature into the future (Beniston et al., 2007; Fischer et al., 2012). As a result, glaciers in the region will continue to retreat and riverflows will initially increase as a consequence of the enhanced melting of glacier ice (Collins, 2006). How water temperature in streams which drain glaciers in the European Alps react to these changes has not received much study, hence the results offered in this chapter are novel. The simulations enable better understanding of future water temperature response to climate change, in high mountain environments.

The scenario simulation results suggest the increasing length between glacier portal and gauging position, as the glacier retreats, will overwhelmingly drive future day-time water temperature maxima higher. For example, a warming of $1.51^{\circ} \mathrm{C}$ would occur if the glacier was to retreat $1000 \mathrm{~m}$, at a period of relatively high discharge, with solar radiation and riverflow held constant.

Initially, riverflow levels will rise as a result of retreating glaciers. The results in this chapter demonstrate that a likely rise of $10 \%$ riverflow will reduce water 
temperature, initially, by on average $0.13^{\circ} \mathrm{C}$. This small initial decline will be significantly offset by the increased distance downstream as the glacier begins to retreat. The Findelenbach's water temperature will rise by $1.51^{\circ} \mathrm{C}$, when the glacier retreats $1000 \mathrm{~m}$. Under the scenario of $1000 \mathrm{~m}$ glacier reduction, and $10 \%$ increase in discharge during the main summer melt season; water temperature maxima will only increase by $1.24^{\circ} \mathrm{C}$. 


\section{Part IV}

\section{Summary}




\section{Chapter 7}

\section{Conclusion}

\subsection{Introduction}

This thesis has presented the context and background to thermal regimes in rivers, and its modelling, together with how stream temperature may be impacted in a changing climate (Chapter 1 \& 2), Chapter 3 provided an in depth analysis into the thermal patterns of both glacier-fed and non-glacierfed rivers in the European Alps. Chapter 4 outlined an analysis of stream albedo, which was conducted following a brief fieldtrip to the study sites in 2015. This assessed the potential impact albedo may have on the warming of high mountain glacier-fed rivers. Building on the findings of this study, the development of a new parsimonious model was undertaken; from model design in Chapter 5, through to the application of the simplified model using scenarios to represent what would happen in a changing climate (Chapter 6). This Chapter will summarise the main findings of this research project, incorporating how the key aims and objectives of this study were met (§7.2). §7.3, indicates the limitations of this research and recommends possible improvements. Proposed directions for future research are put forward (§7.4), §7.5 provides a summary of the significance of this $\mathrm{PhD}$ research. Finally, $\S 7.6$ is a brief closing commentary of this thesis; a final analysis of the importance 
of the study.

\subsection{Summary of main findings}

The research offered in this thesis was novel in the following ways:

Firstly, the study has outlined the unique seasonal temperature regime which occurs in rivers which drain highly glacierised catchments. To the author's knowledge, no studies have identified the spring pulse in seasonal water temperature patterns which occurs only in the rivers which drain highly glacierised catchments. Additionally, this research has improved knowledge into what causes cooling in glacier-fed river summer temperatures, previously suggested by Fellman et al., (2014) and Hood and Berner, (2009). This work has also demonstrated different links between basin controls and river thermal regimes than those attained in these previous studies. Suggestions have been made as to why such a strong spring maxima pulse occurs in the Massa and Gornera rivers;

Secondly, stream albedo has previously been hypothesised to hold significant control over water temperatures of glacier-fed rivers, because of the increased slope and rocky channels. This leads to greater aeration and white tops, together with larger sediment loads, which are a feature of such rivers and cause significant cloudiness in the stream. This study has started initial measurements of stream albedo using a CMA 6 Kipp and Zonen albedometer, above both the Findelenbach and Gornera. Although only a cursory analysis could be completed within the timeframe of the $\mathrm{PhD}$ research, it is apparent that surface albedo is not a major control on thermal capacity within streams;

Thirdly, a simple temperature model was devised and created based on the assumption that net radiation was the major influencing factor driving the water temperature in high altitude streams. The model was, as prescribed, simple with fewer input parameters necessary, whilst at the same time retaining its usefulness; 
Finally, the Alpine Stream Temperature Model produced as a result of this thesis was used to quantify the effect of certain climate change scenarios on a stream reach, in the Swiss Alps, would have on the streams water temperature. This new approach is the first to quantify the effects of climate change on temperature dynamics of high mountain streams, which drain large glaciers.

\subsubsection{Meeting the aims and objectives}

The aim of this research, outlined in Chapter 1, was to develop greater understanding of the water temperature regimes of Alpine meltwater streams. Another aim was to develop a simplified water temperature model, said to be parsimonious in both resources and necessary predictor variables. The overriding principal aim included utilising the stream temperature model to quantify the potential effect climate change will have on the temperature of the upper-reaches of rivers which drain Alpine glaciers. The specific objectives were to:

1. Examine how percentage glacierisation and basin properties affect the seasonal and diurnal patterns of stream temperature for rivers draining Alpine basins.

2. Create a simplified stream water temperature model with few parameters; a parsimonious model.

3. Use the deterministic water temperature model to quantify how water temperature will be affected under different climate scenarios.

The work in Chapters: 3, 5, and 6, clearly demonstrate how the aims and objectives of the research proposal were met.

The results provided in Chapter 3 examine the water temperature patterns on a seasonal basis, developing on recent work conducted for Alaskan glacier-fed rivers (Fellman et al., 2014; Hood and Berner, 2009). However, this study is the first in its kind to be approached from the European Alps perspective. The work demonstrates some interesting and contradictory findings to those 
from other studies, demonstrating percentage glacierisation to be a convenient proxy, but not the key determiner of seasonal water temperature patterns and maxima. Furthermore, the research proffered in Chapter 3 provides novel insights to the response of meltwater temperature throughout the melt season, at the sub daily level, highlighting patterns which have not previously been documented.

Chapter 5 charts the creation, calibration and application of a stream water temperature model demonstrating the possibility, thanks to the nature of the river system and the high altitudes involved, of modelling stream temperature using few input variables. This therefore, shows the model to be as prescribed, parsimonious. The approach used in this research design is clearly novel in that no other studies have attempted to utilise a water temperature model based on net radiation, instead opting for air temperatures, when simplicity is required (Arismendi et al., 2014). The model retains its usefulness, despite the removal of some energy budget constituents, but is best at predicting daily temperatures and hence daily maxima. Mean averages are overestimated due to the nature of the model, with night time changes to stream temperature being poorly reflected. This is attributed to the fact that energy fluxes during night time hours are predominantly negative, with atmospheric longwave radiation being the only positive contributor (Ouellet et al., 2014).

Chapter 6 contains innovative material quantifying the effect of climate change on the water temperature of Alpine glacier-fed rivers. Utilising the model created in Chapter 5, this chapter was able to offer insights into how daily maximum water temperatures are likely to react under different hydro-climatic scenarios. The physical explanations given for the simulated results indicate that the outcomes of this research were plausible and hence could be used with respect to river managers and ecologist downstream of the glacier-fed river studied. Although, only utilised on a single glacier-fed Alpine river, the model was capable of simulating good results and could be modified for utilisation on other similar catchments. Little effort would be needed to adapt the model for use in other climate change river studies. 


\subsection{Drawbacks and possible improvements}

This PhD research offers sound findings and meets the study aims and objectives. However, there are some limitations to both the research and methodology. Such issues are examined in the following subsections, together with suggestions of how these could be avoided in any similar studies of this nature.

Some key areas are highlighted as potential drawbacks to the present study and are set out in the following subsections.

\subsubsection{Understanding of water temperature patterns in the European Alps}

This study has shown that the link between water temperature ranges and percentage glacierisation is not a simple one, disproving links made recently in literature, instead this research has illustrated that reach area is a better determiner of meltwater temperatures. However, a key issue with the results presented in this thesis is that the statistical significance of the results is hindered, due to of the lack of study sites. In light of this, it is suggested that the method used in Chapter 3 is replicated over many more study sites; specifically those similar in nature to the Findelen study site. This would indicate whether the findings herein are true for a wider region.

Secondly, this study has outlined water temperature patterns of rivers draining Alpine basins; highlighting novel patterns both at the seasonal and diurnal temporal resolution, together with explanations of the physical drivers. It would be beneficial, however, to gather further water temperature data within the basin. This should include not only regular measurements of water temperature at the glacier portal, but also measurements of meltwater higher up in the glacier system. This would enable a greater understanding of what causes the shrinking diurnal range in water temperature over multiple days of substantial radiation. Scarcity of water temperature measurements at the glacier terminus, especially at the Grosser Aletschgletscher (Massa) 
and Gorner (Gornera) glaciers is a drawback of this study. Setting up a year round, or summer melt season, logging system would be costly and time consuming; therefore substantial funding would be required to achieve this aim. However, the emergence of inexpensive and small logging equipment should ease some of these constraints into the future.

Finally, regression based models have the potential for sampling bias (Moore, 2006). This study addresses some of the concerns raised by similar multiple linear regression studies. For example, application across basins under different climatic conditions and catchments of less than $100 \mathrm{~km}^{2}$. However, it is crucial that further studies should be conducted to improve the insight into reach- and catchment- scale water temperature relationships.

\subsubsection{Data availability and model inputs}

Data availability was a key drawback to this study. In part, this was down to the harsh mountainous environment in which the study was conducted. However, the lack of funding and time constraints also contributed to data availability. Therefore, some fundamental suggestions for improvement can be made. Riverflow data is continuously monitored in the majority of glacierfed streams in Switzerland, water temperature measurements, however, are not. Setting up continuous observations of water temperature and meteorological factors, a temporary weather station for a longer study period would significantly improve the method applied in this thesis. This would enable a complete heat budget assessment of glacier-fed rivers and highlight, with more reliability in the true physical interactions which occur.

The key aim of the water temperature model applied here was for it to be developed at low cost whilst retaining its reliability. As mentioned throughout this work no model, regardless of the number of input variables, is $100 \%$ accurate of real world physics. Any model, therefore, which attempts to use fewer variables must lose some precision and accuracy. Despite this, the study shows that it is possible to model glacier-fed river temperatures using net ra- 
diation as the only input variable. The model is only applicable to certain streams, however, and should not be used on rivers with more complex relationships involving a rivers heat budget. Although stream albedo is thought to have minimal impact on water temperatures, future models should look to incorporate an albedo variable which is parametrised from riverflow and a constant, as used in this study. It must be noted that this does not account for how albedo changes on a diurnal basis with rising and falling discharges. Also the model used in this research did not account for topographic shading; something not particularly necessary in respect of the Findelenbach. However, models applied to other rivers such as the Gornera would most certainly need to account for shade factors.

\subsubsection{Application of the meltwater temperature model}

One improvement of the Alpine Water Temperature Model would be to collect and utilise, measurements of velocity, depth and width together with volumetric flow. At present the model parametrises width, depth and velocity using a method of reverse modelling from observed water temperatures. Using actual measurements would enable the model to be used on rivers with different wetted profiles and may enable more rivers to be represented and give better understanding to how water temperature of river with different profiles will respond differently to climatic change. Results from this research demonstrate the importance of how a river responds to increasing riverflows as an important factor in determining temporal patterns in glacier-fed stream's water temperature. Thus modelling a range of rivers will yield interesting findings which may differ from those outlined in the present scenario modelling study.

\subsection{Future research directions}

Some interesting research ideas have been forthcoming over the course of this study, both as a result of the findings presented herein, but also from the 
limitations and drawbacks which have hindered this study. Some suggestions for future work include the following:

1. Further research into the response of river's width, depth and velocity to varying riverflows in the Swiss Alps;

2. Utilising UAV technology to make accurate measurements of the above variables, throughout the melt season;

3. Utilising more space/power efficient temperature loggers throughout an entire ablation season at the Findelenbach and Gonera, and confirm the findings of the multiple linear regression results of the present study;

4. Research into the complete heat budget of the Findelenbach and Gornera - Utilising a full weather station for a substantial study period;

5. Investigation into the influence of topographic shading and channel orientation on river water temperature, in mountain environments;

6. The set up of a series of temperature loggers at different locations within the basin, especially at the portal of tributary glaciers within the Gorner basin. Analysis of the longitudinal temperature change as waters pass through the glaciated portion of the basin;

7. Longer term investigation into the albedo of glacier rivers, in the Swiss Alps;

8. Utilising the above albedo observations to calculate methods of parametrising stream albedo with respect to levels of discharge, utilising such parametrisations in river temperature models;

9. Reprogramming the model used within the present study so that it can be implemented with more precision, across a wider range of rivers, with more measured input variables;

10. Adapting the stream temperature model to the above findings, and subsequently applying the model to other streams, i.e. the Massa and 
Gornera; simulating potential future water temperature in a similar scenario based modelling study.

\subsection{Impact of study}

The work presented in this $\mathrm{PhD}$ study is the first to quantify glacier-fed river's response to a warming climate. Preliminary results were presented at the American Geophysical Union conference (December 2014) where it was well received. More recently, work associated this thesis was presented during the 2015 American Geophysical Union conference again piquing interest in the study of potential water temperature response to climate change for high mountain rivers.

The results outlined in this thesis will be of interest to river managers and ecologists who may be concerned about the downstream effect of warmer upstream temperatures and how this may impact fisheries downstream of glacier-fed rivers. However, as previously mentioned the results of this study - despite being useful - should only be used as reference, and only for the river system in question. Other rivers may respond to climate change to a greater or lesser degree, and models should be applied to individual basins before any management or mitigation is considered.

This research has also demonstrated the possibility of modelling water temperature using net radiation alone, omitting many of the other heat budget constituents, when applying the model to high altitude glacier-fed rivers. In spite of the model's simplicity, the results attained appear to be plausible. However, this only holds true for daytime temperatures. Such models do not account for night time cooling gradients and thus minima and mean average temperatures are over estimated. This work is of use to similar studies, provided catchment factors and climatic conditions are similar to those in this study. The Alpine Stream Temperature Model can be conducted using fewer input data and at relatively low cost in terms of both time and money. 
The results within this thesis, have significant implications for current understanding. After Fellman et al., (2014) and Hood and Berner, (2009), it has become generally accepted that percentage glacierisation is the key factor influencing water temperature in glacier-fed rivers. This study has demonstrated that this is not always true. The likely reason for previous findings is that generally percentage glacierisation is highly correlated with reach length and river surface area. Therefore, often percentage glacierisation will appear to be the main catchment determiner.

Interesting patterns in seasonal water temperature regimes have been thoroughly examined. The present study being the first to demonstrate the complexities in what causes cooler waters during the main summer ablation season. Notably, that only a very small increase in river discharge significantly reduces stream temperature, and further rises in riverflow have no further influence on the temperature. This study is the first to hypothesise that water temperature in rivers which drain large glaciers, in steep catchments, are influenced little by incoming radiation. However, this study was not able to confirm the findings of Chikita et al., (2010), in whether the major contributor to the rivers heat budget was frictional heating.

In addition to the above, this research has highlighted a undocumented diurnal pattern in river water temperature; with rising minima and falling maxima across multiple days of high radiation and rising riverflows. It is suggested that this reflects the increasing efficiency in the glaciers drainage network, thus leading to higher water temperatures at the glacier portal.

\subsection{Summary}

To summarise, this study has developed our understanding of the key determiners of cooler summer water temperatures experienced in glacier-fed rivers. Some interesting findings have arisen; notably ones which challenge much of the current knowledge into how basin characteristics influence water temperatures in mountain rivers. From the assumption that net radiation is the key 
constituent of the energy balance driving stream water temperature, a simple parsimonious model has been developed. The study utilises this model to contribute new knowledge as to how water temperature in Alpine glacier-fed streams will respond in a changing climate; the first to quantify the impact of climatic change, with the application of a simple scenario based modelling approach. 


\section{References}

Aktuelle Situation Gewässer (2014). German. URL: http: //www . hydrodaten . admin.ch/de/index.html?lang=de (Retrieved 30/07/2012).

Arismendi, I., Johnson, S. L., Dunham, J. B., Haggerty, R. and HockmanWert, D. (2012). The paradox of cooling streams in a warming world: regional climate trends do not parallel variable local trends in stream temperature in the Pacific continental United States. Geophysical Research Letters, 39 (10).

Arismendi, I., Safeeq, M., Dunham, J. B. and Johnson, S. L. (2014). Can air temperature be used to project influences of climate change on stream temperature? Environmental Research Letters, 9 (8), 084015.

Barnett, T. P., Adam, J. C. and Lettenmaier, D. P. (2005). Pottential impacts of a warming climate on water availablity in snow dominated regions. Nature, 438, 303-309. DOI: 10.1038/nature04141.

Bartholow, J. (2002). Stream Segment Temperature Model (SSTEMP) Version 2.0. Tech. rep. US Geological Survey.

Benedini, M. and Tsakiris, G. (2013). Water quality modelling for rivers and streams. Vol. 70. Springer Science \& Business Media.

Beniston, M., Stephenson, D. B., Christensen, O. B., Ferro, C. A. T., Frei, C., Goyette, S., Halsnaes, K., Holt, T., Jylhä, K., Koffi, B., Palutikof, J., Schöll, R., Semmler, T. and Woth, K. (2007). Future extreme events in European climate: an exploration of regional climate model projections, Climatic change. 81 (1), 71-95.

Benyahya, L., Caissie, D., St-Hilaire, A., Ouarda, T. B. M. J. and Bobee, B. (2007). A Review of Statistical Water Temperature Models. Canadian Water Resources Journal, 32 (3), 179-192.

Birgand, F. Evaluation of QUAL2E.

Blaen, J. P., Hannah, D. M., Brown, L. E. and Milner, A. M (2012). Water temperature dynamics in High Arctic river basins. Hydrological Processes, DOI: $10.1002 /$ hyp. 9431. 
Box, G. E. P. (1979). Robustness in the strategy of scientific model building. Robustness in statistics 1, 201-236.

Boyd, M. and Kasper, B. (2003). Analystical Methods for Dynamic Open Channel Heat and Mass Transfer: Methodology for heat source model version 7.0. Tech. rep.

Braithwaite, R.J. and Zhang, Y. (2000). Sensitivity of mass balance of five Swiss glaciers to temperature changes assessed by tuning a degree day model. Journal of Glaciology, 46 (152), 7-14.

Braun, L. N., Weber, M. and Schulz, M. (2000). Consequences of climate change for runoff from Alpine regions. Annals of Glaciology, 31, 19-25.

Brittain, J. E. and Milner, A. M. (2001). Ecology of glacier-fed rivers: current status and concepts. Freshwater Biology, 46, 1571-1578.

Brown, L. C. and Barnwell, T. O. (1987). The enhanced stream water quality models QUAL2E and QUAL2E-UNCAS: documentation and user manual. US Environmental Protection Agency. Office of Research and Development. Environmental Research Laboratory.

Brown, L. E. and Hannah, D. M. (2007). Alpine Stream Temperature Response to Storm Events. Journal of Hydrometeorology, 8, 952-967.

Brown, L. E. and Hannah, D. M. (2008). Spatial heterogeneity of water temperature across an alpine river basin, Hydrological Processes. 22 (7), 954967.

Brown, L. E., Hannah, D. M. and Milner, A. M. (2004). "Alpine stream temperature variability and potential implications for benthic communities." In: Hydrology: science and practice for the 21st century, Volume II. Proceedings of the British Hydrological Society International Conference. Imperial College, London, British Hydrological Society, 28-38.

Brown, L. E., Hannah, D. M. and Milner, A. M. (2005). Spatial and temporal water column and streambed temperature dynamics within an alpine catchment: implications for benthic communities. Hydrological Processes, 19 (8), 1585-1610.

Brown, L. E., Hannah, D. M. and Milner, A. M. (2006a). Hydroclimatological influences on water column and streambed thermal dynamics in an alpine river system. Journal of Hydrology, 325 (1), 1-20.

Brown, L. E., Hannah, D. M. and Milner, A. M. (2006b). Thermal Variability and Stream Flow Permanency in an Alpine River System. River Research and Applications, 22, 493-501.

Budyko, M. I. (1968). The effect of solar radiation variations on the climate of the Earth. Tellus 21 (5), 611-619.

Bustillo, V., Moatar, F., Ducharne, A., Thiéry, D. and Poirel, A. (2014). A multimodel comparison for assessing water temperatures under changing 
climate conditions via the equilibrium temperature concept: case study of the Middle Loire River, France. Hydrological Processes, 28 (3), 1507-1524.

Cadbury, S. L., Hannah, D. M., Milner, A. M., Pearson, C. P. and Brown, L. E. (2008). Stream Temperature Dynamics Within a New Zealand Glacierised River Basin. River Research and Applications, 24, 68-89.

Caissie, D. (2006). Review Article The thermal regime of rivers: a review. Freshwater Biology, 51, 1389-1406.

Caissie, D., El-Jabi, N. and Satish, M. G. (2001). Modelling of maximum daily water temperatures in a small stream using air temperatures. Journal of Hydrology, 251 (1), 14-28.

Caissie, D., Satish, M. G. and El-Jabi, N. (2005). Predicting river water temperatures using the equilibrium temperature concept with application on Miramichi River catchments (New Brunswick, Canada). Hydrological Processes, 19 (11), 2137-2159.

Caissie, D., Satish, M. G. and El-Jabi, N. (2007). Predicting water temperatures using a deterministic model: Application on Miramichi River catchments (New Brunswick, Canada). Journal of Hydrology, 336, 303-315.

Chikita, K. A., Kaminaga, R., Kudo, I., T., Wada. and Kim, Y. (2010). Parameters Determining Water Temperature of a Proglacial Stream: the Phelan Creek and the Gulkana Glacier, Alaska. River Research and Applications, 26, 995-1004.

Cho, H-Y. and Lee, K-H. (2011). Development of an air-water temperature relationship model to predict climate-induced future water temperature in estuaries. Journal of Environmental Engineering, 138 (5), 570-577.

Cogley, G. (1979). The albedo of water as a function of latitude. Monthly Weather Review, 107 (6), 775-781.

Collins, D. N. (1986). Characteristics of meltwaters draining from the portal of an alpine glacier during the emptying of a marginal ice-dammed lake. Alpine glacier project. Tech. rep. Working paper series, 4, University of Manchester, Department of Geography, 2813. Lake Drainage Mechanisms for the lce-Dammed Obercr Russellsee 14.

Collins, D. N. (1987). Climatic Fluctuations and runoff from glacierised Alpine basins. IAHS Publications, 168, 77-119.

Collins, D. N. (1989). "Hydrometeorological conditions, mass balance and runoff from Alpine glaciers," in: ed. by J. Oerlemans. Chap. Glacier Fluctuations and Climatic Change. 235-260.

Collins, D. N (1998). Outburst and rainfall-induced peak runoff events in highly glacierized Alpine basins, Hydrological processes. 12 (15), 23692381. 
Collins, D. N. (2005). Changes in quantity and variability of runoff from Alpine Basins with climatic fluctuation and glacier decline. IAHS Publications. $318,75-85$.

Collins, D. N. (2006). Climatic variation and runoff in mountain basins with differing proportions of glacier cover. Nordic Hydrology, 37 (4-5), 315-326.

Collins, D. N. (2008). Climatic warming, glacier recession and runoff from Alpine basins after the little ice age maximum. Annals of Glaciology. 48, 119-124.

Collins, D. N. (2009). Seasonal variations of water temperature and discharge in rivers draining ice-free and partially-glacierized Alpine basins. 17th International Northern Research Basins Symposium and Workshop, 67-74.

Collins, D. N. and Taylor, P. (1990). Variability of Runoff from partiallyglacierised Alpine basins. Water Resources Research, 193, 365-372.

Crisp, D. T and Howson, G.l (1982). Effect of air temperature upon mean water temperature in streams in the north Pennines and English Lake District. Freshwater Biology, 12 (4), 359-367.

Davies, B. J. and Glasser, N. F. (2012). Accelerating shrinkage of Patagonian glaciers from the Little Ice Age $(\sim$ AD 1870$)$ to the present day, Journal of Glaciology. 58 (212), 1063-1084.

Deas, M. L and Lowney, C. L. (2000). "Water Temperature Modeling Review: Central Valley". In: California Water Modeling Forum.

Dickson, N. E., Carrivick, J. L. and Brown, L. E. (2012). Flow regulation alters alpine river thermal regimes. Journal of Hydrology.

Edinger, J. E., Duttweiler, D. W. and Geyer, J. C. (1968). The response of water temperatures to meteorological conditions, Water Resources Research. 4 (5), 1137-1143.

Evans, E. C., McGregor, R. and Petts, G. E. (1998). River energy budgets with special reference to river bed processes. Hydrological Processes, 12, 575-595.

Fellman, J. B., Nagorski, S., Payare, S., Vermilyea, A. W., Scott, D. and Hood, E. (2014). Stream temperature response to variable glacier coverage in coastal watersheds of Southeast Alaska. Hydrological Processes. 28, 20622073. DOI: 10.1002/hyp. 9742.

Fischer, A. M., Weigel, A. P., Buser, C. M., Knutti, R., Künsch, H. R., Liniger, M. A., Schär, C. and Appenzeller, C. (2012). Climate change projections for Switzerland based on a Bayesian multi-model approach. International Journal of Climatology, 32 (15), 2348-2371.

Fleming, S. W. (2005). Comparative analysis of glacial and nival streamflow regimes with implications for lotic habitat quantity and fish species rich- 
ness, River Research and Applications. 21 (4), 363-379. ISSN: 1535-1467. DOI: 10.1002/rra.810. URL: http://dx.doi.org/10.1002/rra.810.

Fröhlich, C. and Lean, J. (1998). The Sun's Total Irradiance: Cycles, Trends and Related Climate Change Uncertainties since 1976. Geophysical Research Letters, 25 (23), 4377-4380.

Garner, G., Malcolm, I. A., Sadler, J. P. and Hannah, D. M. (2014). What causes cooling water temperature gradients in a forested stream reach? Hydrology and Earth System Sciences, 18 (12), 5361-5376. DOI: 10.5194/ hess-18-5361-2014. URL: http://www .hydrol-earth-syst-sci.net/ $18 / 5361 / 2014 /$.

Glaciological-Reports (2016). "The Swiss Glaciers" Yearbooks of the Cryospheric Commission of the Swiss Academy of Sciences (SCNAT) published since 1964 by the Labratory of Hydraulics, Hydrology and Glaciology (VAW) of ETH Zürich. No. 1-132, ETH Zurich. URL: http : / / glaciology .ethz.ch/swiss-glaciers/.

Gleason, C. J. and Smith, L. C. (2014). Toward global mapping of river discharge using satellite images and at-many-stations hydraulic geometry. Proceedings of the National Academy of Sciences, 111 (13), 4788-4791.

$\mathrm{Gu}, \mathrm{R}$. R. and Li, Y. (2002). River Temperature sensitivity to hydraulic and meteorological parameters. Journal of Environmental Management, 66, 43-56.

Gu, R., Montgomery, S. and Austin, T. A. (1998). Quantifying the effects of streams discharge on summer river temperature. Hydrological Sciences Journal, 43 (6), 885-904.

Han, L. (1997). Spectral reflectance with varying suspended sediment concentrations in clear and algae-laden waters. Photogrammetric Engineering and Remote Sensing, 63 (6), 701-705.

Hannah, D. M., Malcolm, I. A., Soulsby, C. and Youngson, A. F. (2004). Heat Exchanges and Temperature Within A Salmon Spawning Stream in the Cairngorms, Scotland: Seasonal and Sub-Seasonal Dyanamics. River Research and Applications, 20, 635-652.

Hari, R. E., Livingstone, D. M., Siber, R., Burkhardt-Holm, P. and Guttinger, H. (2006). Consequences of climatic change for water temperature and brown trout populations in Alpine rivers and streams. Global Change Biology, 12, 10-26.

Harrison, S., Rowan, A. V., Glasser, N. F., Knight, J., Plummer, M. A. and Mills, S. C. (2014). Little Ice Age glaciers in Britain: Glacier-climate modelling in the Cairngorm mountains, The Holocene. 24 (2), 135-140.

Herb, W. R. and Stefan, H. G. (2011). Modified equilibrium temperature models for cold-water streams. Water Resources Research, 47 (6). 
Hewitt, G. M. (1996). Some genetic consequences of ice ages, and their role in divergence and speciation. Biological Journal of the Linnean Society, 58 (3), 247-276.

Hock, R., Jansson, R. and Braun, L. N. (2005). "Modelling the Response of Mountain Glacier Discharge to Climate Warming," in: ed. by U.M. Humber, H.K.M. Bugman and M.A Reasoner. Dordrecht: Springer. Chap. Global Change and Mountain Regions (A State of Knowledge Overview). 243-252.

Hood, E. and Berner, L. (2009). Effects of changing glacial coverage on the physical and biogeochemical properties of coastal streams in southeastern Alaska, Journal of Geophysical Research: Biogeosciences (2005-2012). 114 (G3).

Hurrell, J. W. (1995). Decadal trends in the North Atlantic Oscillation: regional temperatures and precipitation. Science, 269 (5224), 676-679.

Huss, M., Bauder, A., Werder, M., Funk, M. and Hock, R. (2007). Glacierdammed lake outburst events of Gornersee, Switzerland, Journal of Glaciology. 53 (181), 189-200.

Huss, M., Funk, M. and Ohmura, A. (2009). Strong Alpine glacier melt in the 1940s due to enhanced solar radiation. Geophysical Research Letters, 36, L23501. DOI: 10.1029/2009GL040789.

IPCC (2013). Climate Change 2013: The Physical Science Basis. Contribution of Working Group 1 to the Fifth Assessment Report of the Intergovernmental Panel on Climate Chnage. Ed. by T. F. Stoker, G. K. Quin, M. Plattner, S. K. Tignor, J Allen, A Boschung, Y. Nauels, V. Xia and P. M. Midgley. Cambridge, United Kingdom: Cambridge University Press.

Isaak, D.l J., Luce, C. H., Rieman, B. E., Nagel, D.E., Peterson, E. E., Horan, D. L., Parkes, S. and Chandler, G. L. (2010). Effects of climate change and wildfire on stream temperatures and salmonid thermal habitat in a mountain river network. ECOLOGICAL APPLICATIONS, 20 (5), 13501371.

Iziomon, M. G., Mayer, H. and Matzarakis, A. (2000). Empirical models for estimating net radiative flux: A case study for three mid-latitude sites with orographic variability. Astrophysics and Space Science, 273 (1-4), 313-330.

James, A. (1993). An introduction to water quality modelling. Ed. 2. John Wiley and Sons Ltd.

Jansson, P., Hock, R. and Schneider, T. (2003). The Concept of Glacier Storage: A Review. Journal of Hydrology, 282, 116-129.

Ji, Z-G (2008). Hydrodynamics and water quality: modeling rivers, lakes, and estuaries. John Wiley \& Sons.

Jin, Z., Charlock, T. P., Smith, W. L. and Rutledge, K. (2004). A parameterization of ocean surface albedo. Geophysical Research Letters, 31 (22). 
Johnson, M. F., Wilby, R. L. and Toone, J. A. (2014). Inferring air-water temperature relationships from river and catchment properties. Hydrological Processes, 28, 2912-2928.

Johnson, S. L. (2004). Factors influencing stream temperatures in small streams: substrates effects and shading experiment. Canadian Journal of Fisheries and Aquatic Sciences, 61 (6), 913-923.

Karl, T. R. and Trenberth, K. E. (2003). .Modern Global Climate Change. Science, 302, 1719-1723. DOI: 10.1126/science.1090228.

Kaushal, S. S., Likens, G. E., Jaworski, N. A., Pace, M. L., Sides, A. M., Seekell, D., Belt, K. T., Secor, D. H. and Wingate, R. L. (2010). Rising stream and river temperatures in the United States. Frontiers in Ecology and the Environment, 8 (9), 461-466.

Kelleher, C., Wagener, T., Gooseff, M., McGlynn, B., McGuire, K. and Marshall, L. (2012). Investigating controls on the thermal sensitivity of Pennsylvania streams. Hydrological Processes, 26 (5), 771-785. ISSN: 1099-1085. DOI: 10.1002/hyp.8186. URL: http://dx.doi.org/10.1002/hyp.8186.

Kipp\&Zonen (2015). The Working Principle of a Thermopile Pyranometer. URL: http://www . kippzonen. com/News/572/The-Working-Principleof-a-Thermopile-Pyranometer\#.VrHpEtWLRhE.

Kobayashi, D., Ishii, Y. and Kodama, Y. (1999). Stream temperature, specific conductance and runoff process in mountain watersheds. Hydrological Processes, 13, 865-876.

Kurylyk, B. L., Moore, R. D. and MacQuarrie, Kerry T. B. (2015). Scientific briefing: quantifying streambed heat advection associated with groundwater-surface water interactions. Hydrological Processes, $\mathrm{n} / \mathrm{a}-\mathrm{n} / \mathrm{a}$. ISSN: 1099-1085. DOI: 10 . 1002 /hyp . 10709. URL: http://dx . doi . org/10 . 1002/hyp. 10709.

Leach, J. A. and Moore, R. D. (2010). Above-stream microclimate and stream surface energy exchanges in a wildfire-disturbed riparian zone. Hydrological Processes, 24 (17), 2369-2381.

Leach, J. A. and Moore, R. D. (2011). Stream temperature dynamics in two hydrogeomorphically distinct reaches. Hydrological Processes, 25 (5), 679690.

Leach, J. A. and Moore, R. D. (2014). Winter stream temperature in the rain-on-snow zone of the Pacific northwest: influences of hillslope runoff and transient snow cover. Hydrology and Earth System Sciences, 18 (2), 819-838.

Lean, J., Beer, J. and Bradley, R. (1995). Reconstruction of solar irradiance since 1610: Implications for climate change, Geophysical Research Letters. 22 (23), 3195-3198. 
Leopold, L. B. and Maddock Jr, T. (1953). The hydraulic geometry of stream channels and some physiographic implications. Tech. rep.

MacDonald, R. J., Boon, S. and Byrne, J. M. (2014). A process-based stream temperature modelling approach for mountain regions. Journal of Hydrology, 511, 920-931.

Magnusson, J., Jones, T. and Kirchner, J. W. (2012). Temperature dynamics of a proglacial stream: Identifying dominant energy balance components and inferring spatially integrated hydraulic geometry. Water Resources Research, 48, W06510. DOI: 10.1029/2011WR011378.

Mann, M. E. (2002). Little ice age. Encyclopedia of global environmental change, 1, 504-509.

Matthews, J. A. and Briffa, K. R. (2005). The 'Little Ice Age': Re-evaluation of an evolving concept. Geografiska Annaler: Series A, Physical Geography, 87 (1), 17-36.

Meier, W., Bonjour, C., Wuest, A. and Reichert, P. (2003). Modeling the Effect of Water Diversion on the Temperature of Mountain Streams. Journal of Environmental Engineering, 129 (8), 755-764.

Mellina, E., Moore, R. D., Hinch, S. G., Macdonald, J. S. and Pearson, G. (2002). Stream temperature responses to clearcut logging in British Columbia: the moderating influences of groundwater and headwater lakes. Canadian Journal of Fisheries and Aquatic Sciences, 59 (12), 1886-1900.

Milner, A. M., Brittain, J. E., Brown, L. E. and Hannah, D. M. (2010). Water Sources and Habitat of Alpine Streams. In: Alpine Waters. Springer, 175191.

Milner, A. M. and Petts, G. E. (1994). Glacial rivers: physical habitat and ecology. Freshwater Biology, 32 (2), 295-307.

Mohseni, O., Erickson, T. R. and Stefan, H. G. (1999). Sensitivity of stream temperatures in the United States to air temperatures projected under a global warming scenario. Water Resources Research, 35 (12), 3723-3733.

Mohseni, O. and Stefan, H. G. (1999). Stream temperature, air temperature relationship a physical interpretation. Journal of Hydrology, 218, 128-141.

Mohseni, O., Stefan, H. G. and Eaton, J. G. (2003). Global warming and potential changes in fish habitat in US streams. Climatic change, 59 (3), 389-409.

Mohseni, O., Stefan, H. G. and Erickson, T. R. (1998). A nonlinear regression model for weekly stream temperatures. Water Resources Research, 34 (10), 2685-2692.

Moore, R. D. (2006). Stream temperature patterns in British Columbia, Canada, based on routine spot measurements, Canadian Water Resources Journal. 31 (1), 41-56. 
Moore, R. D., Fleming, S. W., Menounos, B., Wheate, R., Fountain, A., Stahl, K., Holm, K. and Jakob, M. (2009). Glacier change in western North America: influences on hydrology, geomorphic hazards and water quality, $H y$ drological Processes. 23 (1), 42-61.

Moriasi, D. N, Arnold, J. G., Van Liew, M. W., Bingner, R. L., Harmel, R. D. and Veith, T. L (2007). Model evaluation guidelines for systematic quantification of accuracy in watershed simulations. Transactions of the $A S A B E, 50$ (3), 885-900.

Ouellet, V., Secretan, Y., St-Hilaire, A. and Morin, J. (2014). Water temperature modelling in a controlled environment: comparative study of heat budget equations, Hydrological Processes. 28 (2), 279-292.

Park, C. C. (1977). World-wide variations in hydraulic geometry exponents of stream channels: an analysis and some observations. Journal of Hydrology, 33 (1), 133-146.

Piccolroaz, S., Toffolon, M. and Majone, B. (2013). A simple lumped model to convert air temperature into surface water temperature in lakes. Hydrology and Earth System Sciences, 17 (8), 3323-3338.

R Core Team (2013). R: A Language and Environment for Statistical Computing. ISBN 3-900051-07-0. R Foundation for Statistical Computing. Vienna, Austria. URL: http://www.R-project.org/.

Rees, H. G. (2014). Potential Impacts of Climatic Warming on Glacier-Fed River Flows in the Himalaya. PhD. University of Salford.

Richards, J. and Moore, R. D. (2011). Discharge dependence of stream albedo in a steep proglacial channel. Hydrological Processes, 25 (26), 4154-4158.

Rott, E., Cantonati, M., Füreder, L. and Pfister, P. (2006). Benthic algae in high altitude streams of the Alps-a neglected component of the aquatic biota. Hydrobiologia, 562 (1), 195-216.

Sarkar, D. (2008). Lattice: Multivariate Data Visualization with R. ISBN 9780-387-75968-5. New York: Springer. URL: http://lmdvr.r-forge.rproject.org.

Segura, C., Caldwell, P., Sun, G., McNulty, S. and Zhang, Y. (2015). A model to predict stream water temperature across the conterminous USA. Hydrological Processes, 29 (9), 2178-2195.

Smith, B. P. G., Hannah, D. M., Gurnell, A. M. and Petts, G. E. (2001). A hydrogeomorphological context for ecological research on alpine glacial rivers. Freshwater Biology, 46 (12), 1579-1596.

Soetaert, K. and Petzoldt, T. (2010). Inverse modelling, sensitivity and monte carlo analysis in R using package FME. Journal of Statistical Software 33 (3), 1-28. 
Soetaert, K., Petzoldt, T. and Woodrow Setzer, R. (2010). Solving Differential Equations in R: Package deSolve, Journal of Statistical Software. 33 (9), 1-25. ISSN: 1548-7660. URL: http://www.jstatsoft.org/v33/i09.

Stefan, H. G. and Preud'Homme, E. B. (1993). STREAM TEMPERATURE ESTIMATION FROM AIR TEMPERATURE. JAWRA Journal of the American Water Resources Association, 29 (1), 27-45.

Theurer, F. D., Voos, K. A. and Miller, W. J. (1985). Instream water temperature model, 16. Western Energy et al.

Toffolon, M., Piccolroaz, S., Majone, B., Soja, A-M, Peeters, F., Schmid, M. and Wüest, A. (2014). Prediction of surface temperature in lakes with different morphology using air temperature. Limnol. Oceanogr. 59 (6), 2185-2202.

Trimmel, H., Gangneux, C. and Kalny G.and Weihs, P. (2015). Application of the model 'Heat Source'to assess the influence of meteorological components on stream temperature and simulation accuracy under heat wave conditions. Meteorologische Zeitschrift,

Uehlinger, U., Malard, F. and Ward, J. V. (2003). Thermal patterns in the surface waters of a glacial river corridor (Val Roseg, Switzerland). Freshwater Biology, 48 (2), 284-300.

Uhlmann, B., Jordan, F. and Beniston, M. (2013). Modelling runoff in a Swiss glacierized catchment-part I: methodology and application in the Findelen basin under a long-lasting stable climate. International Journal of Climatology, 33 (5), 1293-1300.

Vega, M., Pardo, R., Barrado, E. and Debán, L. (1998). Assessment of seasonal and polluting effects on the quality of river water by exploratory data analysis. Water research, 32 (12), 3581-3592.

Ward, J. V. (1994). Ecology of alpine streams. Freshwater biology, 32 (2), $277-294$.

Webb, B. W., Clack, P. D. and Walling, D. E. (2003). Water-air temperature relationships in a Devon river system and the role of flow. Hydrological Processes, 17 (15), 3069-3084.

Webb, B. W., Hannah, D. M., Moore, R. D., Brown, L. E. and Nobilis, F. (2008). Recent advances in stream and river temperature research. Hydrological Processes, 22 (7), 902-918.

Webb, B. W. and Nobilis, F. (1995). Long term water temperature trends in Austrian rivers. Hydrological Sciences Journal, 40 (1), 83-96.

Webb, B. W. and Nobilis, F. (2007). Long-term changes in river temperature and the influence of climatic and hydrological factors. Hydrological Sciences Journal, 52 (1), 74-85. 
Webb, B. W. and Zhang, Y. (1999). Water temperatures and heat budgets in Dorset chalk water courses. Hydrological Processes, 13 (3), 309-321.

Wickham, H. (2009). ggplot2: elegant graphics for data analysis, Springer New York. ISBN: 978-0-387-98140-6. URL: http://had.co.nz/ggplot2/book.

Wickham, H. (2011). The Split-Apply-Combine Strategy for Data Analysis, Journal of Statistical Software. 40 (1), 1-29. URL: http://www . jstatsoft . org/v40/i01/.

Wild, M., Ohmura, A., Gilgen, H. and Rosenfeld, D. (2004). On the consistency of trends in radiation and temperature records and implications for the global hydrological cycle. Geophysical Research Letters, 31 (11).

Woltemade, C. J. and Hawkins, T. W. (2016). Stream Temperature Impacts Because of Changes in Air Temperature, Land Cover and Stream Discharge: Navarro River Watershed, California, USA. River Research and Applications, n/a-n/a. ISSN: 1535-1467. DOI: 10 . 1002/rra. 3043. URL: http://dx.doi.org/10.1002/rra.3043.

Yang, D., Marsh, P. and Ge, S. (2014). Heat flux calculations for Mackenzie and Yukon Rivers. Polar Science, 8 (3), 232-241.

Yearsley, J. R. (2009). A semi-Lagrangian water temperature model for advectiondominated river systems, Water Resources Research, 45 (12).

Zambrano-Bigiarini, Mauricio (2014). hydroGOF: Goodness-of-fit functions for comparison of simulated and observed hydrological time series. $\mathrm{R}$ package version 0.3-8. URL: http: //CRAN . R-project.org/package=hydroGOF. 


\section{Appendix A}

\section{Alpine Stream Temperature Model}

The Alpine Stream Water Temperature Model is a simple model which uses the Lagrangian heat exchange equation (Eq. A.1) to compute the water temperature of a parcel of water as it moves downstream.

$$
\frac{\delta T_{w}}{\delta x}=\frac{W \Phi}{\rho C Q}
$$

For this study, the model utilised only the net radiative heat budget constituents (Eq. A.2), where $K$ is the net longwave radiation $\left(\mathrm{W} \mathrm{m}^{-2}\right)$, and $\mathrm{R}$ is the net shortwave radiation $\left(\mathrm{W} \mathrm{m}^{-2}\right)$. However, the model can be adapted to accept more constituents of the heat budget with relative ease.

$$
\Phi=R+K
$$

The model is printed below, and compromises an $\mathrm{R}$ script file. The code can be sourced in an $\mathrm{R}$ environment, although care should be taken to alter the names of input/output files.

Lines $5-9$ of the $\mathrm{R}$ script load the relevant $\mathrm{R}$ packages which will be utilised. Lines 13-30 read in the input data. These data files should be tab delimited 
text files consisting of hourly resolution timeseries data, column 1 containing dates and times, column 2 containing data values. These files are read into the $\mathrm{R}$ environment and merged to create a large data frame containing all of the input variables.

Lines 31-43 require the setting of parameters which relate width, depth and velocity to discharge (Leopold and Maddock Jr, 1953). This information is then appended to the input dataframe. Lines 46 and 48 calculated the heat gain and heat loss as a result of longwave radiation, estimated using the Stefan-Boltzmann law (Eq. A.3).

$$
K=\varepsilon_{w} \sigma\left(\varepsilon_{a}\left(T_{a}+273\right)^{4}-\left(T_{w}+273\right)^{4}\right)
$$

Line 52 sources the water temperature model $\mathrm{R}$ script (see Chapter 5). This uses the deSolve R package (Soetaert et al., 2010), to compute the temperature change of a parcel of water as it flows downstream. The reach is divided into a series of segments bounded by nodes. Each segment is $10 \mathrm{~m}$ long and the reach length must be set before this file is sourced. For simplicity a parcel of water is released from the glacier-terminus $(0 \mathrm{~m})$ every hour, and the temperature of the parcel of water is calculated as it passes each node (every $10 \mathrm{~m}$ ). The temperature of the parcel of water at the end of reach is taken as the temperature at the gauging location, extracted from the model output and input into a new timeseries. For the purposes of this study,the parcel of water would have taken less than 1 hour to reach the gauging location, thus the measured radiation value for any given hour was assumed to remain constant for the hour. Moreover, for simplicity, the radiation was said to be consistent longitudinally downstream. Discharge and stream width are also assumed constant over the length of the reach, thus for longer reaches this model would not be appropriate and significant alterations would need to be made to the script.

The resulting output timeseries is plotted in graphical output (lines 59-121), and goodness of fit measures are calculated and printed (lines 136-148). 
Alpine Stream Temperature Model R Script.

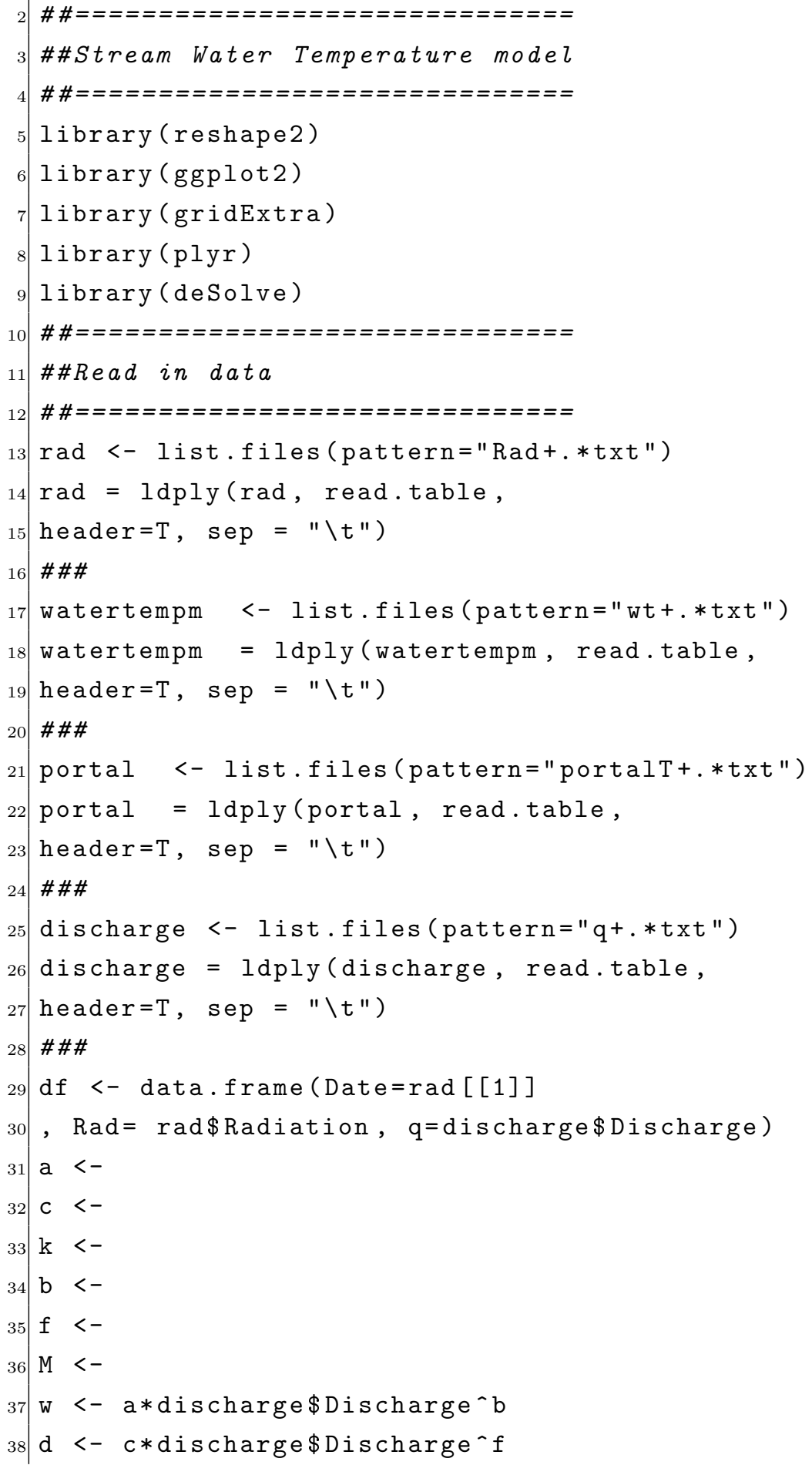




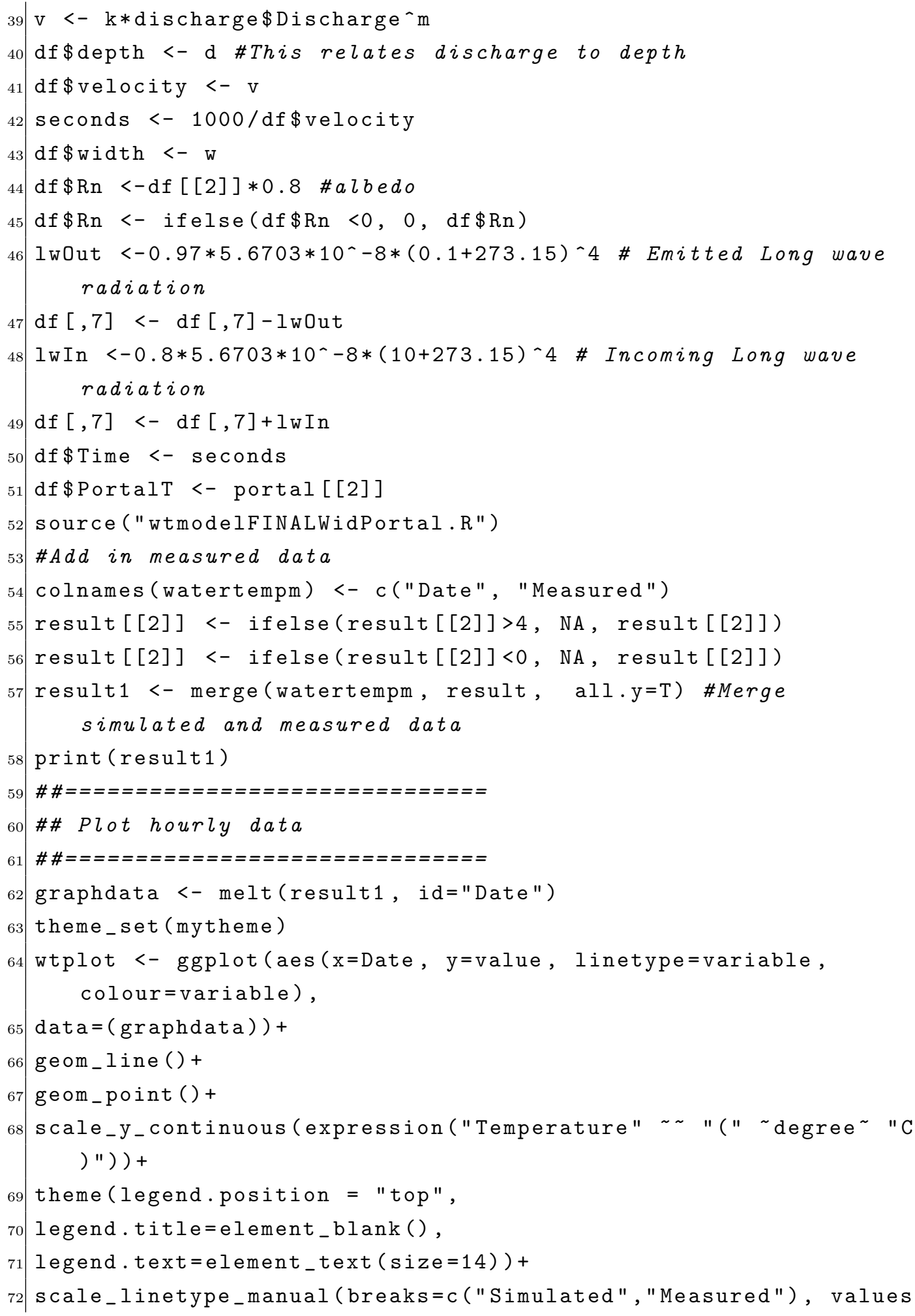




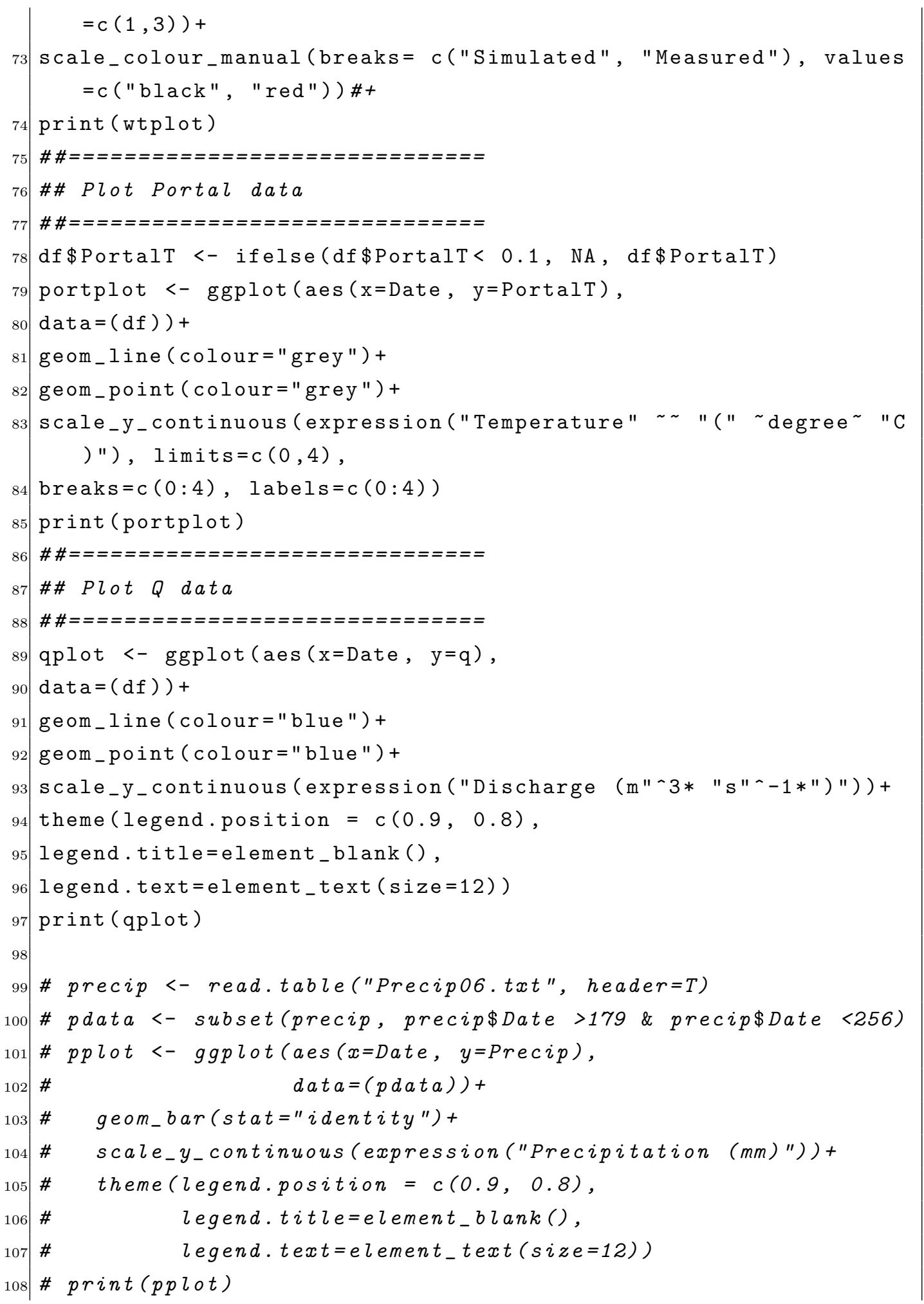




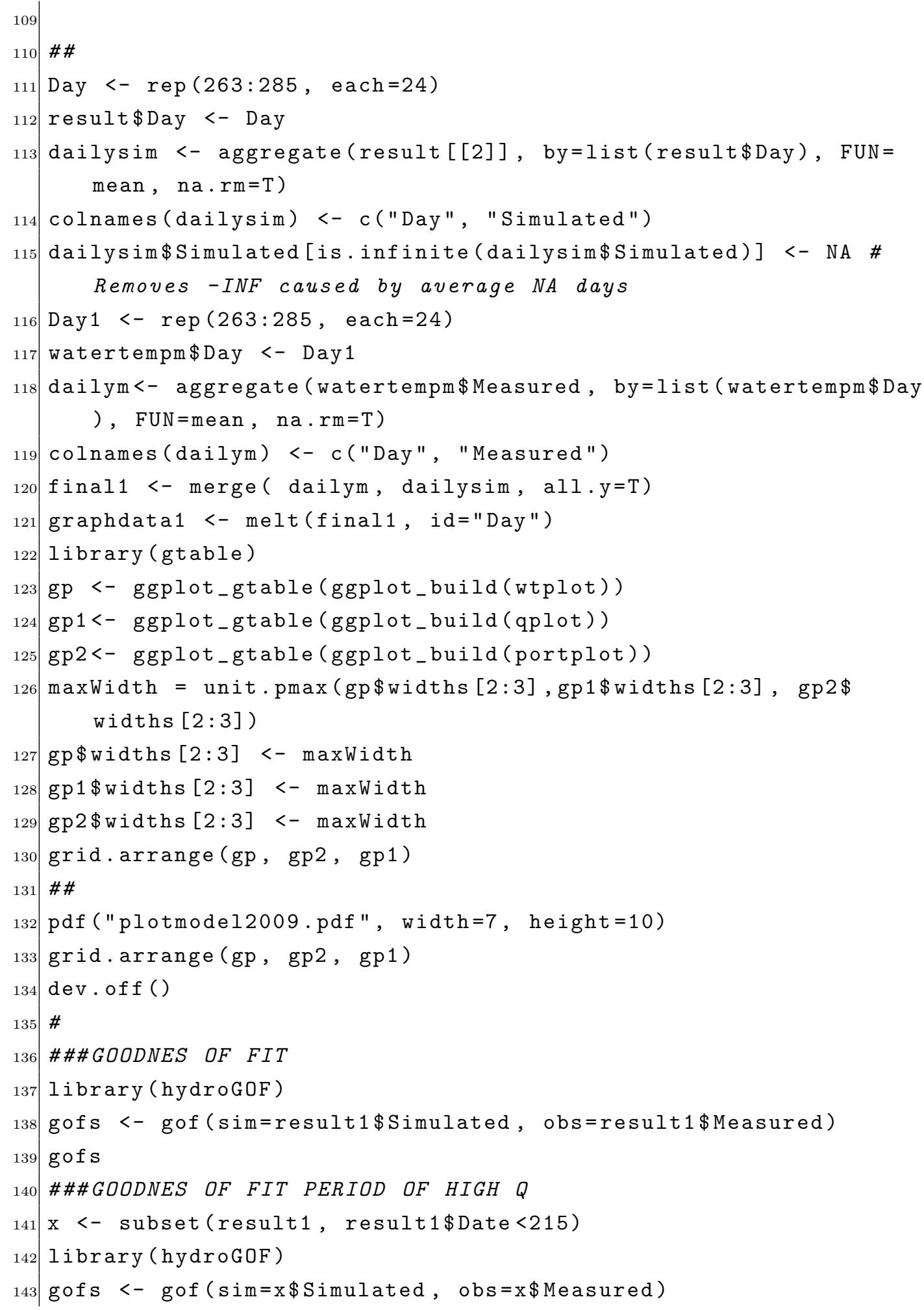




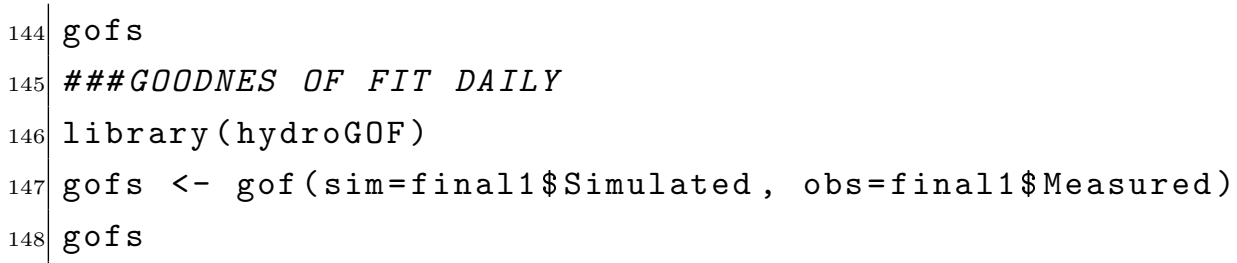




\section{Appendix B}

\section{Conference presentations associated with this study}

The conference presentations and posters that were presented as a result of this study are included below:

1. Meltwater temperature in rivers draining from Alpine glaciers. American Geophysical Union Fall Conference 2014, 15-19 Dec 2014, San Francisco

Robert J. Williamson, \& David N. Collins

Both air temperature and incoming solar radiation influence the seasonal pattern of snow- and ice-melt in glacierised Alpine basins, so that glacier-fed rivers have distinctive regimes with more than $90 \%$ of flow occurring in the months April through October. Snow melt increases discharge slowly in April and May, before the transient snow line starts to rise, exposing glacier ice to melt and leading to flow maxima in late July/early August. Meltwater temperature is inversely related to discharge as well as being positively influenced by energy and heat availability. Close to glacier termini, water temperatures reach maxima in spring, before decreasing as the volume of water being heated increases 
with rising discharge. Records of meltwater temperature and discharge for rivers draining basins with between 17 and $80 \%$ glacierisation in Kantons Bern and Wallis, Switzerland, have been examined, together with measurements of radiation and $2 \mathrm{~m}$ air temperatures at stations close to or in the catchment areas, at hourly resolution, within the period 2003-2013. The aims were to characterise seasonal and diurnal patterns of variation of meltwater temperature and to assess impacts of energy availability, discharge, distance downstream to measurement site, and percentage cover of basin with snow and ice on temperature. On a diurnal basis, water temperature increases before discharge rises, reducing as runoff reaches daily peak. Diurnal temperature ranges are greatest during times of relatively low flows in spring. On a seasonal scale, water temperature peaks in spring before the main discharge period. Temperatures remain in relatively limited ranges, and are suppressed during high flows in the main ablation season. Summer reduction in temperature is larger the more highly glacierised the basin and the closer to the glacier terminus. A simple radiation-forced model has been used to assess relationships between discharge, water surface area, flow velocity and length of time of water exposure to energy input. 


\section{Meltwater Temperature Variations in Rivers Draining Declin- ing Alpine Glaciers}

American Geophysical Union Fall Conference 2015, 14-18 Dec 2015, San Francisco

David N. Collins, Robert J. Williamson, 8 Neil S. Entwistle

Marked patterns of seasonal and diurnal variations of discharge and temperature characterise meltwater rivers draining from large Alpine glaciers. Meltwater temperature warms with distance downstream, influenced both by energy availability and the volume of meltwater flowing. The amount of meltwater produced depends also on energy availability but also on the area of ice substrate over which melt occurs. As climate warms, meltwater production by ablation in summer will first increase with increasing energy for melting, before decreasing as the area of ice available for melt decreases, off-setting continuing increase in energy availability. Future meltwater temperature changes will depend on the inter-relationship between increasing energy availability and enhancing volume of meltwater produced. Relationships between rates of ice melt, reduction in ice area, and meltwater production will influence melt water temperature changes as climate warms. Meltwater temperature is inversely related to discharge whilst positively related to heat availability. Records of water temperature and discharge of meltwaters in rivers draining from three valley glaciers in Kanton Wallis, Switzerland have been examined. Hourly data for the Massa, Grosser Aletschgletscher, for the period 2003-2014, the Gornera, Gornergletscher , 2007-2014, and Findelenbach, Findelengletscher, 2007-2014 obtained at distances of a few kilometres from the glacier portals have been analysed, for summer months, during which more than $90 \%$ of discharge occurs. Distinctive seasonal temperature regimes have highest annual water temperatures during low flows in May., but then as discharge increased with first increasing radiation, increasing ice area as the transient snow line moved up glacier, and higher air temperatures, water temperatures decreased. 
On a diurnal basis, meltwater temperatures increased with rising radiation ahead of rising discharge (discharge being delayed by flow through time within the glacier between ice surface and portal) before reducing through daily peak flows. These relationships are assessed with a simple radiation-forced model integrating changing ice areas, lengthening distances of water exposure to radiation from the glacier portal, and flow through velocities dependent on discharge. 